UNIVERSIDADE DE SÃO PAULO

ESCOLA DE ENFERMAGEM DE RIBEIRÃO PRETO

JESSICA ADRIELLE TEIXEIRA SANTOS

GRAVIDADE DA DEPENDÊNCIA DE COCAÍNA (FUMADA E INALADA) EM INDIVÍDUOS EM TRATAMENTO AMBULATORIAL

RIBEIRÃO PRETO

2017 
JESSICA ADRIELLE TEIXEIRA SANTOS

\section{GRAVIDADE DA DEPENDÊNCIA DE COCAÍNA (FUMADA E INALADA) EM INDIVÍDUOS EM TRATAMENTO AMBULATORIAL}

Tese apresentada à Escola de Enfermagem de Ribeirão Preto da Universidade de São Paulo, para obtenção do título de Doutor em Ciências, Área concentração: Enfermagem Psiquiátrica.

Linha de Pesquisa: Uso e Abuso de Álcool e Drogas

Orientadora: Profa. Dra. Sandra Cristina Pillon

\section{RIBEIRÃO PRETO}


Autorizo a reprodução total ou parcial deste trabalho, por qualquer meio convencional ou eletrônico, para fins de estudo e pesquisa, desde que citada a fonte.

Santos, Jessica Adrielle Teixeira.

Gravidade da dependência de cocaína (fumada e inalada) em indivíduos em tratamento ambulatorial, Ribeirão Preto, 2017.

167p.:il; $30 \mathrm{~cm}$

Tese apresentada à Escola de Enfermagem de Ribeirão Preto/USP. Área de concentração: Enfermagem Psiquiátrica.

Orientadora: Profa. Dra. Sandra Cristina Pillon

1. Cocaína Crack. 2. Transtornos Relacionados ao Uso de Cocaína. 3. Condições Sociais. 4. Centros de Tratamento de Abuso de Substâncias. 
SANTOS, Jessica Adrielle Teixeira

Gravidade da dependência de cocaína (fumada e inalada) em indivíduos em tratamento ambulatorial

Tese apresentada à Escola de Enfermagem de Ribeirão Preto da Universidade de São Paulo, para obtenção do título de Doutor em Ciências. Área concentração: Enfermagem Psiquiátrica.

Linha de Pesquisa: Uso e Abuso de Álcool e Drogas

Aprovado em:

\section{Banca Examinadora}

Prof. Dr.

Instituição:

Prof. Dr.

Instituição:

Prof. Dr.

Instituição:

Prof. Dr.

Instituição:

Prof. Dr.

Instituição: 


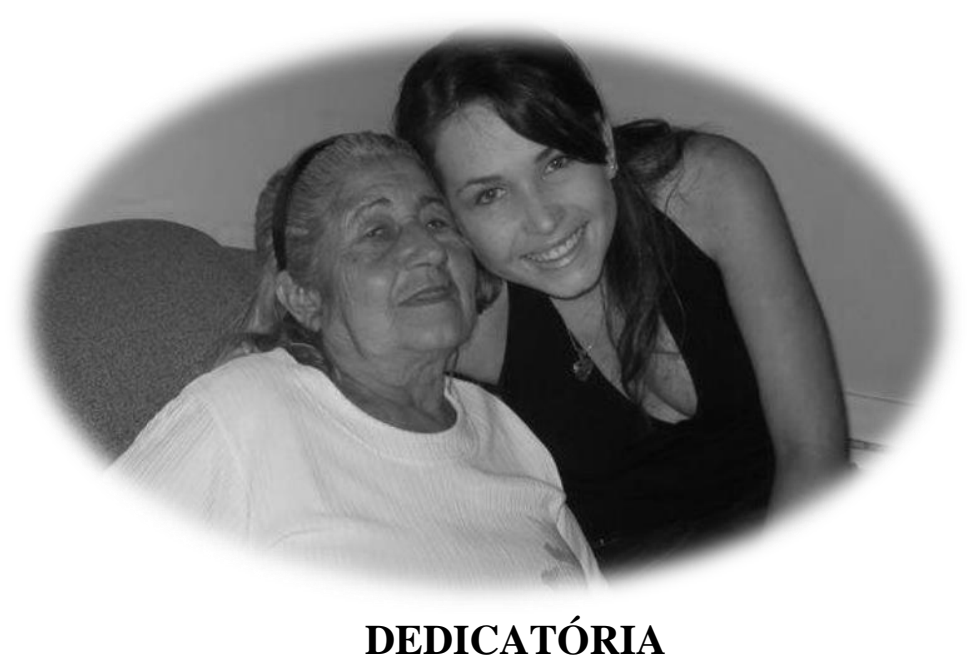

À minha querida avó, Dona Cida (in memoriam),

Como forma de agradecimento pela sua importante coautoria na produção desta grande conquista. Suas palavras não foram registradas nesta obra acadêmica, pois seria injusto com tal nobre sabedoria, mas seus ensinamentos estão escritos nos capítulos iniciais do livro da vida da autora desta pesquisa. Cada parte de mim inserida neste estudo tem, nas entrelinhas, a doce melodia da sua voz me dizendo: "Vai dar tudo certo, minha princesa".

- Eu consegui, minha avó querida!

\section{À minha família,}

Obrigada pelo apoio e paciência. Sei que essas belas palavras nunca substituirão aquela cadeira vazia e as constantes despedidas, mas todos esses sacrifícios resultaram nesta almejada conquista.

\section{À minha nova família,} meu marido, Matheus, e a nossa filha, Sofia.

Matheus obrigada pelo seu companheirismo, amizade, paciência, compreensão, apoio e amor, que proporcionaram momentos de serenidade e reflexão que tanto auxiliaram a produção deste estudo. Também sou eternamente grata por ter me concedido o meu maior presente, o nossa filha, e por toda a felicidade que ela nos reserva.

Obrigada por ter feito do meu sonho o nosso sonho! 


\section{AGRADECIMENTOS ESPECIAIS}

À professora Dra. Sandra Cristina Pillon, por ter me incentivado a buscar esse Doutorado, pela confiança, e, acima de tudo, por todas orientações que transcenderam a elaboração desta Tese. Gostaria de agradecer por ter compartilhado seu grande conhecimento, principalmente, por sua amizade, coisas que pretendo levar para toda a vida.

Aos participantes deste estudo, atendidos no CAPS-ad, pela importante contribuição nesta pesquisa, compartilhando as suas histórias de vida, muitas vezes marcadas por momentos ruins, que não queriam relembrar.

Aos profissionais que trabalham no CAPS -ad, pelo acolhimento na dinâmica assistencial do serviço e o auxílio prático e teórico durante a coleta de dados. Agradecimentos especiais à enfermeira Natalia, pelo treinamento dos instrumentos utilizados no presente estudo, além das contribuições diárias na coleta de dados, e, sobretudo, por sua amizade. 


\section{AGRADECIMENTOS}

Aos professores do Programa de Pós-Graduação em Enfermagem Psiquiátrica,

por compartilharem seus saberes e conhecimento, imprescindíveis para o meu amadurecimento como pesquisadora. Agradecimentos especiais à Profa. Edilaine, pelas sugestões que tornaram factíveis a realização deste estudo.

\section{À Coordenação de Aperfeiçoamento de Pessoal de Nível Superior (CAPES),} pelo incentivo e apoio financeiro à pesquisa por meio da bolsa concedida, por ter ampliado as minhas oportunidades de aprimoramento em meus conhecimentos ao realizar o Programa Doutorado-Sanduíche no Canadá.

Ao estatístico Jonas, por sua disponibilidade e paciência na assessoria estatística, fundamentais na análise dos dados.

\section{Aos pesquisadores do Center for Addiction and Mental Health,}

Em especial Dr. Bernard Le Foll e Dr. Benedikt Fischer que se disponibilizaram a discutir a proposta deste estudo e contribuíram para o amadurecimento teórico do mesmo.

A todos os meus amigos, que sempre me incentivaram e torceram pela minha vitória.

\section{À Secretária do Programa de Pós-Graduação em Enfermagem Psiquiátrica,} Adriana, pela valiosa colaboração durante esses cinco anos, simpatia, gentileza e, acima de tudo, amizade.

A todas as pessoas que, direta ou indiretamente, contribuíram para a execução desta Tese de Doutorado. 


\section{RESUMO}

SANTOS, J. A. T. Gravidade da dependência de cocaína (fumada e inalada) em indivíduos atendidos em tratamento ambulatorial. 167 p. Tese (Doutorado). Escola de Enfermagem de Ribeirão preto, Universidade de São Paulo, Ribeirão Preto, 2017.

O estudo teve por objetivo avaliar os fatores sociais e de saúde associados à da gravidade da dependência de cocaína (fumada e inalada) entre usuários em tratamento ambulatorial. Tratase de um estudo transversal de abordagem quantitativa, realizado com 160 indivíduos em tratamento para a dependência química no CAPS-ad de Ribeirão Preto, SP. Os participantes foram selecionados mediante critérios de elegibilidade e avaliação do estado mental por meio da Brief Psychiatric Rating Scale (BPRS-A). Para a coleta de dados um questionário foi elaborado contendo: Informações sociodemográficas, Addiction Severity Index (ASI-6); Short Alcohol Dependence Data (SADD); Alcohol Use Disorders Identification Test-Consumption (AUDIT-C); Severity of Dependence Scale (SDS) e Cocaine Craving Questionnaire - Brief (CCQ-B). Na análise estatística foram utilizados os testes: qui-quadrado, regressão logística, teste Mann Whitney e correlação de Spearman. A amostra foi composta por $78(48,8 \%)$ de cocaína inalada e $82(51,2 \%)$ de crack. Em relação aos aspectos sociais e de saúde, os usuários de crack foram mais velhos $(p=0,028)$, com menos anos de estudo $(p=$ $0,042)$,desempregados $(p=0,05)$, maioria em situação de rua $(p<0,001)$, com antecedentes de tratamentos $(p=0,019)$, baixa renda mensal $(p<0.001)$, renda incompatível com despesas $(p=0,002)$, mais envolvidos em roubo $(p=0,009)$, sofreram agressão (por pessoa conhecida e desconhecida $(p=0,005$ e $p=0,014)$, presenciaram agressão/homicídio $(p=0,030)$, dormiram em albergues $(\mathrm{p}=0,011)$, apresentam problemas para dormir $(p=0,007)$, sintomas de alucinações $(p>0,001)$, agressividade $(p=0,031)$. Os usuários de cocaína inalada se diferenciaram apenas por apresentarem maior contato com amigo íntimo $(p=0,007)$. Em relação ao uso de drogas, os usuários de crack apresentaram maior tempo de uso na vida de tabaco $(p=0,032)$ e maconha $(p=0,047)$, maior frequência de uso do crack $(p=0,009)$. Nos resultados da análise multivariada, os indivíduos adultos (OR 3,1 95\%CI 1,50;6,7) e em situação de rua (OR 4,5 95\%CI 1,49;13,61) apresentaram chances aumentadas de utilizar crack. Quanto à avaliação final da ASI, constatou-se que os usuários de crack apresentaram elevados níveis de problemas nas áreas Emprego $(p=0,005)$ e Psiquiátrica $(p=0,003)$. Os níveis de problemas relacionados ao álcool, drogas e fissura (AUDIT, SDS, CCQ-B) não se diferenciaram entre os usuários de cocaína, resultando em severos níveis de gravidade independente a via de uso, com exceção da SADD. Das correlações entre as áreas da ASI e o dos instrumentos, destaca-se que a área Álcool foi correlacionada positivamente com os todos os instrumentos, a área Droga e os resultados do AUDIT, SDS e CCQ-B, a área Família com o CCQ-B, a área Psiquiátrica com SDS e CCQ-B, a área Problemas Sociais com a SDS e a CCQ-B. A área Médica foi correlacionada negativamente com a SDS. O uso de cocaína apresenta variações em relação aos níveis de gravidade da dependência da droga e problemas nas áreas emprego e sustento, uso de álcool e de drogas, situação legal social e saúde mental.

Descritores: Cocaína Crack; Transtornos relacionados ao uso de cocaína; condições sociais; Centros de Tratamento de Abuso de Substâncias. 


\begin{abstract}
SANTOS, J. A. T. The Severity of cocaine dependence (smoked and snuffed) in subjects undergoing outpatient treatment. 167 p. Doctoral Dissertation. University of São Paulo at Ribeirão Preto College of Nursing, Ribeirão Preto, 2017.

The aim of this study was to evaluate the social and health factors associated with the severity of cocaine dependence (smoked and snuffed) among users on outpatient treatment. This is a cross-sectional quantitative study conducted with 160 individuals undergoing treatment for chemical dependence in the CAPS-ad in Ribeirão Preto, Sao Paulo. Participants were selected through eligibility criteria and mental status assessment using the Brief Psychiatric Rating Scale (BPRS-A). The data collection instruments were: Addiction Severity Index (ASI-6); Short Alcohol Dependence Data (SADD); Alcohol Use Disorders Identification TestConsumption (AUDIT-C); Severity of Dependency Scale (SDS) and Cocaine Craving Questionnaire - Brief (CCQ-B). In the statistical analysis, the following tests were used: chisquare, logistic regression, Mann Whitney test and Spearman correlation. The sample consisted of $78(48.8 \%)$ snorted cocaine and $82(51.2 \%)$ of crack. In relation to social and health aspects, crack users were older $(\mathrm{p}=0.028)$, with less years of study $(\mathrm{p}=0.042)$, unemployed $(\mathrm{p}=0.05)$, homeless $(p<0,001)$, history of previous treatments $(\mathrm{p}=0.019)$, low monthly income $(\mathrm{p}<0.001)$, income incompatible with expenses $(\mathrm{p}=0.002)$, more involved in robbery $(\mathrm{p}=0.009)$, suffered aggression (per person known and unknown $(\mathrm{p}=0.005$ and $\mathrm{p}$ $=0.014)$, witnessed aggression / homicide $(\mathrm{p}=0.030)$, slept in shelters $(\mathrm{p}=0.011)$, trouble sleeping $(p=0.007)$, hallucinations $(p>0.001)$ and aggressiveness $(p=0.031)$. The snuffed cocaine users differed only because they had greater contact with close friends $(p=0.007)$. Regarding the drug use, crack users had a longer time of use in the life of tobacco $(p=0.032)$ and marijuana $(p=0.047)$, a higher frequency of crack use $(p=0.009)$. In the results of the multivariate analysis, the adult individuals (OR $3.195 \%$ CI 1.50, 6.7) and homeless (OR 4.5 $95 \%$ CI $1.49,13.61)$ presented increased odds of use crack. Regarding the final evaluation of ASI, It was found that crack users presented high levels of problems in the areas of Employment $(p=0.005)$ and Psychiatric $(p=0.003)$. The levels of alcohol, drug and fissure problems (AUDIT, SDS, CCQ-B) did not differ among cocaine users, resulting in increased levels of severity independent of the route of use, with the exception of SADD. From the correlations between the ASI and the instruments, the Alcohol use positively correlated with all the instruments, the Drug area and the results of the AUDIT, SDS and CCQ-B, the Family area with CCQ- B, the Psychiatric area with SDS and CCQ-B, the Social Problems area with SDS and CCQ-B. The Medical area was negatively correlated with SDS. The use of cocaine showed various severity levels of drug dependence and problems in the areas of employment and livelihood, alcohol and drug use, social legal status, and mental health.
\end{abstract}

Descriptors: Crack Cocaine; Cocaine-Related Disorders; Social Conditions; Substance Abuse Treatment Centers. 


\title{
RESUMEN
}

\author{
SANTOS, J. A. T. La gravedad de la dependencia de la cocaína (fumada e inhalada) en \\ sujetos tratados en tratamiento ambulatorio. $167 \mathrm{~h}$. Tesis (Doctorado). Escuela de \\ Enfermería de Ribeirão Preto, Universidad de São Paulo, Ribeirão Preto, 2017.
}

La finalidad del presente estudio fue evaluar los factores sociales y de salud asociados con la severidad de la adicción a la cocaína (fumada e inhalada) entre usuarios en tratamiento ambulatorio. Se trata de un estudio de tipo transversal, con enfoque cuantitativo, desarrollado con 160 individuos sometidos a tratamiento para la adicción a las drogas en CAPS-ad Ribeirão Preto SP. Los participantes fueron seleccionados sobre la base de criterios de elegibilidad y la evaluación del estado mental mediante la Brief Psychiatric Rating Scale (BPRS-A). Para la recolección de datos se elaboró un cuestionario que contiene información sociodemográfica; Addiction Severity Index (ASI-6); Short Alcohol Dependence Data (SADD); Alcohol Use Disorders Identification Test- Consumption (AUDIT-C); Severity of Dependency Scale (SDS) and Cocaine Craving Questionnaire - Brief (CCQ-B). Se utilizaron las pruebas estadísticas: Chi-cuadrado, la regresión logística, prueba de Mann-Whitney y la correlación de Spearman. La muestra fue de 78 (48,8\%) de cocaína inhalada y $82(51,2 \%)$ de cocaína (fumada). En cuanto a los aspectos sociales y de salud, los consumidores de "crack" eran de mayor edad $(\mathrm{p}=0,028)$, con menos años de educación $(\mathrm{p}=0,042)$, desempleados $(\mathrm{p}=$ $0,05)$, la mayoría viven en la calle $(\mathrm{p}<0.001)$, con historia de tratamiento anterior $(\mathrm{p}=$ $0,019)$, de bajos ingresos mensuales $(\mathrm{p}<0,001)$, el ingreso incompatible con los gastos $(\mathrm{p}=$ $0,002)$, más involucrados en el robo $(\mathrm{p}=0,009)$, fueron víctimas de abuso (por persona conocida y desconocida $(\mathrm{p}=0,005$ y $\mathrm{p}=0,014)$, habían presenciado agresión / homicidio $(\mathrm{p}=$ $0,030)$, dormían en albergues $(\mathrm{p}=0,011)$, con problemas para dormir $(\mathrm{p}=0,007)$, alucinaciones $(\mathrm{p}<0,001)$ y agresividad $(\mathrm{p}=0,031)$. Los consumidores de cocaína inhalada diferían sólo porque tienen más contacto con un amigo cercano $(\mathrm{p}=0,007)$. En relación con el uso de drogas, los usuarios de la cocaína fumada tenían uso prolongado de tabaco $(\mathrm{p}=0,032)$ y de la marihuana $(p=0,047)$, mayor frecuencia de uso de cocaína fumada $(p=0,009)$. Los resultados del análisis multivariado mostraron que sujetos adultos $(\mathrm{OR}=3,195 \% \mathrm{CI}$ : 1,50; 6,7) y sin hogar (OR=4,5 95\%CI: 1,49;13,61) tenían mayores posibilidades de consumir la cocaína fumaba. En cuanto a la evaluación final de la ASI, se encontró que los consumidores de cocaína fumada mostraron altos niveles de problemas en las áreas de empleo $(p=0,005)$ y de psiquiatría $(\mathrm{p}=0,003)$. Los niveles de los problemas relacionados con alcohol, drogas y crack (AUDIT, SDS, CCQ-B) no difirieron entre los consumidores de cocaína, lo que resulta en grados de gravedad independiente de uso, con la excepción de SADD. Las correlaciones entre las áreas de ASI y los instrumentos, enfatiza que la zona de alcohol se correlacionó positivamente con todos los instrumentos, el área de drogas y los resultados de la auditoría, SDS y CCK-B, el área de la familia con CCQ área de Psiquiatría B con SDS y CCQ-B, el área de problemas sociales SDS y CCQ-B. El área médica se correlacionó negativamente con la SDS. El uso de la cocaína presenta variaciones en los niveles de gravedad de la adicción a las drogas y los problemas en el empleo y las zonas de vida, el uso de alcohol y drogas, situación jurídica y social de la salud mental.

Descriptores: Cocaína Crack; Trastornos Relacionados con Cocaína; Condiciones Sociales; Centros de Tratamiento de Abuso de Sustancias 


\section{Lista de Figuras}

Figura 1. Fatores de risco e de proteção associados ao uso de substâncias psicoativas.....

Figura 2. Comparação entre os critérios diagnósticos CID-10 e DSM-5 em relação à mensuração do nível de dependência do consumo de substâncias psicoativas.

Figura 3. Fluxograma das etapas de recrutamento dos participantes do estudo

\section{Lista de Quadros}

Quadro 1. Farmacocinética da cocaína conforme as vias de uso..................................... 26

Quadro 2. Neurotransmissores versus efeitos resultantes da abstinência........................ 28

Quadro 3. Fases da evolução da fissura................................................................. 29

Quadro 4. Critérios diagnósticos da dependência de substâncias psicoativas................. 31

Comparação entre os critérios diagnósticos CID-10 (OMS) e DSM-5

Quadro 5. (APA) para classificação do uso problemático de substâncias psicoativas

Quadro 6. Composição do instrumento de coleta de dados

Quadro 7. Classificação e pontuação do CCQ-B - versão brasileira adaptada para o crack.

\section{Lista de Gráfico}

Gráfico 1. Progressão do envolvimento com substâncias psicoativas, segundo usuários de cocaína (independentemente da via de uso) $(\mathrm{N}=160)$. Ribeirão Preto, 2015 


\section{Lista de Tabelas}

Tabela 1. Informações sociodemográficas e uso de cocaína (fumada e inalada) $(\mathrm{N}=$ 160). Ribeirão Preto, 2015.

Tabela 2. Informações relacionadas à educação, emprego e finanças, segundo os usuários de cocaína (fumada e inalada) $(\mathrm{N}=160)$. Ribeirão Preto, 2015

Tabela 3. Informações sobre envolvimento em situações de violência, segundo os usuários de cocaína (fumada e inalada) $(\mathrm{N}=160)$. Ribeirão Preto, 2015

Tabela 4. Informações sobre vínculo familiar e relacionamentos sociais, segundo os usuários de cocaína (fumada e inalada) $(\mathrm{N}=160)$. Ribeirão Preto, 2015.

Tabela 5. Informações sobre situação de moradia nos últimos seis meses, segundo os usuários de cocaína (fumada e inalada) $(\mathrm{N}=160)$. Ribeirão Preto, 2015.

Tabela 6. Informações sobre condição física e atenção à saúde clínica, segundo os usuários de cocaína (fumada e inalada) $(\mathrm{N}=160)$. Ribeirão Preto, 2015.

Tabela 7. Informações sobre sintomas psiquiátricos e atenção à saúde mental (exceto para problemas relacionados ao uso de substâncias), segundo os usuários de cocaína (fumada e inalada) $(\mathrm{N}=160)$. Ribeirão Preto, 2015

Tabela 8. Informações sobre a idade de início do uso de álcool e outras drogas, segundo usuários de cocaína (fumada e inalada) $(\mathrm{N}=160)$. Ribeirão Preto, 2015.

Tabela 9. Informações sobre o uso de álcool e outras substâncias psicoativas na vida, segundo os usuários de cocaína (fumada e inalada) $(\mathrm{N}=160)$. Ribeirão Preto, 2015 .

Tabela 10. Informações sobre anos de uso crônico (3-4 vezes na semana) de álcool e outras drogas, segundo os usuários de cocaína (fumada e inalada) $(\mathrm{N}=160)$. Ribeirão Preto, 2015.

Tabela 11. Informações sobre a média de dias usando álcool e outras substâncias psicoativas nos últimos 30 dias, segundo os usuários de cocaína (fumada e inalada) $(\mathrm{N}=160)$. Ribeirão Preto, 2015

Tabela 12. Informações sobre frequência de uso, sintomas de abstinência, fissura e dinheiro gasto em droga, segundo os usuários de cocaína (fumada e inalada) (N = 160). Ribeirão Preto, 2015.

Tabela 13. Tabela de frequências, Odds Ratio Bruto e Ajustado para a variável de desfecho uso de crack segundo algumas variáveis explicativas $(\mathrm{N}=160)$. Ribeirão Preto, 2015.

Tabela 14. Classificação dos níveis de gravidade do uso e dependência de álcool (AUDIT, SADD), drogas (SDS) e fissura (CCQ-B), segundo os usuários de cocaína (fumada e inalada) $(\mathrm{N}=160)$. Ribeirão Preto, 2015.

Tabela 15. Comparação das médias dos escores finais das áreas da ASI, segundo os usuários de cocaína (fumada e inalada) $(\mathrm{N}=160)$. Ribeirão Preto, 2015.........

Tabela 16. Coeficiente de correlação entre as escalas (AUDIT, SADD, SDS, CCQ-B) e as áreas da ASI $(\mathrm{N}=160)$. Ribeirão Preto, 2015 


\section{Lista de Abreviaturas}

CAPS-ad Centro de Atenção Psicossocial - álcool e drogas CAPS-ad

ACTH Hormônio adrenocorticotrófico

APA

American Psychiatric Association

ASI

Addiction Severity Index

ATV

Área Tegumentar Ventral

AUDIT-C Alcohol Use Disorders Identification Test-Comsuption

BPRS-A Brief Psychiatric Rating Scale-A

CAPS-ad Centro de Atenção Psicossocial - álcool e drogas CAPS-ad

CAPSI-ad Centro de Atenção Psicossocial para Crianças e Adolescentes - álcool e drogas

CCQ-B Cocaine Craving Questionnaire - Brief

CID Classificação Internacional de Doenças

CONEP Conselho Nacional de Ética em Pesquisa

CRF Corticotrofina

DA Dopamina

DSM Diagnostic and Statistical Manual of Mental Disorders

DST Doença Sexualmente Transmissível

EUA Estados Unidos da América

IC Intervalo de Confiança

INSS Instituto Nacional de Seguridade Social

IRA Infecção Renal Aguda

JIFE Junta Internacional de Fiscalização de Entorpecentes

OBID Observatório Brasileiro de Informações sobre Drogas

OMS Organização Mundial de Saúde

OMS Organização Mundial de Saúde

ONU Organização das Nações Unidas

OR Odds ratio

PR Prevenção de recaida

RAPS Rede Assistencial em Saúde Mental

RP Razão de prevalência

SADD Short Alcohol Dependence Data

SDS Severity of Dependence Scale

SENAD Secretaria Nacional de Políticas sobre Drogas

SIS Sistemas de Informações em Saúde

SNC Sistema Nervoso Central

SPA Substância psicoativa

SPSS Statistical Program of Social Science

SUS Sistema Único de Saúde

TCLE Termo de Consentimento Livre e Esclarecido

UBS Unidades Básicas de saúde 


\section{SUMÁRIO}

1. INTRODUÇÃ

2. REVISÃO DA LITERATURA........................................................... 18

2.1 Aspectos Históricos da Cocaína.............................................................. 19

2.2 Contextualização Epidemiológica do Consumo de Cocaína.................... 22

2.3 Aspectos Neuroquímicos da Cocaína e Vias de Uso ............................ 24

2.4 Síndrome de Dependência da Cocaína e Mensuração da Gravidade...... 30

2.5 Fatores Associados com a Dependência de Cocaína.............................. 35

3. JUSTIFICATIVA.......................................................................... 49

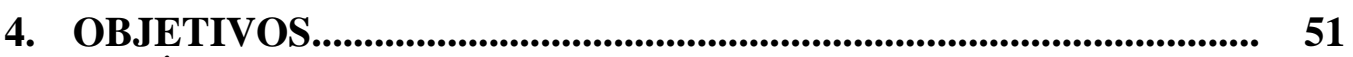

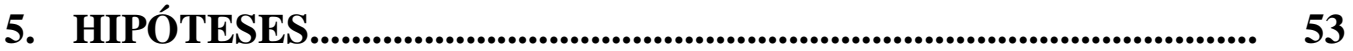

6. MATERIAL E MÉTODOS........................................................................ 55

6.1 Delineamento Metodológico do Estudo................................................ 56

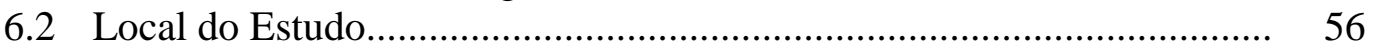

6.3 Participantes do Estudo................................................................ 5

6.3.1 Recrutamento da Amostra............................................................... 58

6.4 Procedimentos de Coleta de Dados...................................................... 59

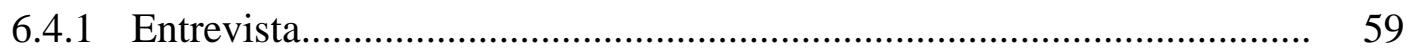

6.5 Instrumentos de Coleta de Dados....................................................... 60

6.5.1 Informações Sociodemográficas..................................................... 61

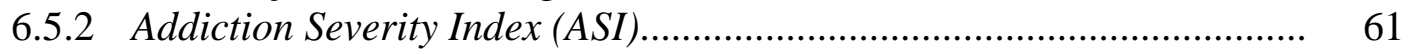

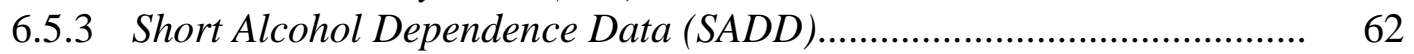

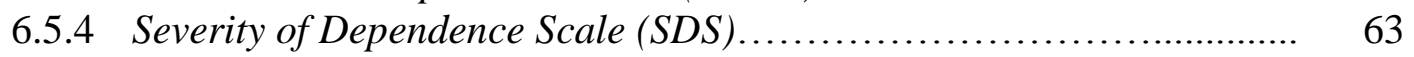

6.5.5 Cocaine Craving Questionnaire - B $(C C Q-B) \ldots \ldots \ldots \ldots \ldots \ldots \ldots \ldots . \ldots \ldots$

6.5.6 Alcohol Use Disorders Identification Test-C (AUDIT-C)............. 65

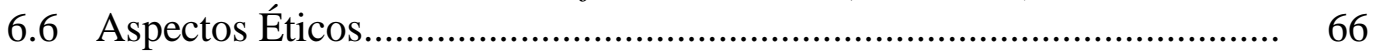

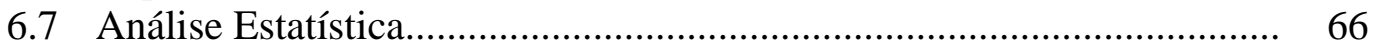

7. RESULTADOS................................................................................... 68

7.1 Características sociodemográficas e uso de cocaína (inalada e fumada). 69

7.2 Fatores Associados ao Uso de Cocaína e Outras Drogas (ASI)............. 79

7.3 Modelo final regressão logística........................................................ 79

7.4 Aspectos relacionados à gravidade da dependência da cocaína.............. 86

8. DISCUSSÃO ............................................................................................ 89

8.1 Fatores Associados à Dependência da Cocaína (fumada e inalada) ....... 90

8.2 Fatores Associados ao Uso de Cocaína (fumada e inalada) e Outras

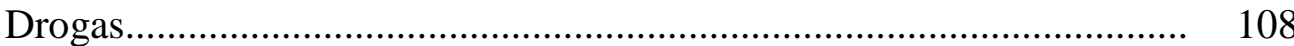

9. LIMITES E RECOMENDAÇÕES................................................. 120

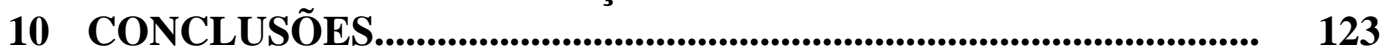

REFERẼNCIAS........................................................................... 127

APENDICE-A Termo de Consentimento Livre e Esclarecido (TCLE).......................... 141

ANEXO- A Brief Psychiatric Rating Scale-A (BPRS-A)................................ 145

ANEXO- B Instrumentos de Coleta de Dados.......................................................... 148

ANEXO- C Carta de Autorização do Local de Estudo............................................. 164

ANEXO- D Autorização da Secretaria de Saúde....................................................... 165

ANEXO- E Parecer do Comitê de Ética e Pesquisa..................................................... 166 
In tro d u ção $\mid \mathbf{1 4}$

1. Introdução 


\section{INTRODUÇÃO}

Os danos resultantes do aumento do consumo e a circulação dos derivados da cocaína representam uma das principais preocupações na sociedade atual, como evidenciado por diversos estudos (UCHÔA, 1996; GOOTENBERG, 1999; KESSLER; PECHANSKY, 2008; DUAILIBI; RIBEIRO; LARANJEIRA, 2008; DEGENHARDT et al., 2008; HSER et al., 2006; OPAS, 2009; RIBEIRO; LARANJEIRA, 2012; RIBEIRO; LARANJEIRA, 2013; ABDALA et al., 2014; UNODC, 2016). A magnitude dos agravos reflete a pluralidade de fatores individuais, ambientais e socioculturais, que, juntos, constituem os fatores causais (GALEA; VLAHOV, 2002; FERRI et al., 2004; SHORTER et al., 2015) e resultantes do uso nocivo (RIBEIRO, 2004; KILUK et al., 2013; NARVEZ et al., 2015; KESSLER et al., 2012). A compreensão desse dinâmico fenômeno requer uma análise mais ampla do movimento da sociedade e das funções sociais, do papel que a droga exerce nesse contexto e de todos os elementos relacionados ao contato do homem com a substância (CIBA, 1992; SANTOS; OLIVEIRA, 2013b).

A cocaína é uma substância estimulante de alto poder no desenvolvimento da dependência (REBOUSSIN; ANTHONY 2006). O efeito gerado pelo uso dessa droga inclui excitação do sistema dopaminérgico (aumento da energia, diminuição da fadiga e agilidade mental) (ABOU-DONIA, 1992; RIBEIRO; SANCHEZ; NAPPO, 2010), porém os efeitos adversos, além dos danos clínicos resultantes da alteração simpatominérgica (PALIWALA; HYMANA; SINHA, 2008; RIEZZO et al., 2012), afetam indiretamente o bem-estar e as diversas áreas da vida do usuário (KILUK et al., 2013, NARVAEZ et al., 2015; RIBEIRO, LARANJEIRA, 2010).

O cloridrato de cocaína, extraído das folhas de coca (Erythroxylum coca), é uma das substâncias psicoativas de maior versatilidade de uso, que se adequa aos recursos disponíveis e às necessidades dos usuários (KARCH, 1999; NAPPO et al., 2001; RIBEIRO, LARANJEIRA, 2010; UNODC, 2016). No Brasil, a maior prevalência de uso da cocaína é basicamente pela via inalada. Desse modo, estima-se que 5,1 milhões de usuários utilizam a droga por essa via de uso. Em segundo lugar, está o uso fumado, com 1,8 milhão de usuários. Por fim, a via de uso injetável já não é tão comum (NEGRETE, 1992; BUCHER, 1992; BASTOS et al., 2011; ABDALA et al., 2014). O país foi classificado como o segundo maior mercado de cocaína do mundo, em virtude de sua localização geográfica que integra a rota de tráfico internacional (OPAS, 2009; UNODC, 2016). 
As peculiaridades neuroquímicas da cocaína e a gravidade da dependência resultante também estão relacionadas aos determinantes sociais (CIBA, 1992; GALEA, VLAHOV, 2002; NARVAEZ et al., 2015; SHORTER et al., 2015; UNODC, 2016). Embora as diferentes vias de uso estimulem o mesmo circuito dopaminérgico no Sistema Nervoso Central (SNC) (VOLKOW; KOOB; MCLELLAN, 2016; SULZER, 2011), as vias inalada e fumada possuem características peculiares em relação à reação provocada no organismo e, por conseguinte, nos comportamentos e nas ações decorrentes do uso. Por toda essa complexidade, os usuários devem ser avaliados em suas singularidades (LOWENSTEIN et al., 1987; DUNN; LARANJEIRA, 1999; GUINDALINI et al., 2006; SHORTER et al., 2015). Estudos avaliaram essas diferenças nas últimas décadas, sobretudo no contexto internacional (LOWENSTEIN et al., 1987; VAUGHN et al., 2010, KILUK et al., 2013, MARTINS et al., 2014; PALAMAR; DAVIES; OMPAD, 2015), bem como os níveis de severidade da dependência (REBOUSSIN; ANTHONY, 2006; KILUK et al., 2013; SHORTER et al., 2015; VOLKOW; KOOB; MCLELLAN, 2016). No entanto, evidências apontam que tais diferenças ainda têm sido pouco exploradas em termos de níveis de gravidade e o seu entorno, o que faz com que o tratamento de tais usuários continue sendo um desafio para os profissionais nos diversos serviços de saúde (KESSLER et al., 2012; KILUK et al., 2013). Em estudos com usuários de crack foram observados elevados índices de abandono do tratamento e de recaída, bem como o desenvolvimento e agravamento da dependência e de consequências físicas e sociais de forma mais severa (CHEN; ANTHONY, 2004; REBOUSSIN; ANTHONY, 2006; RIBEIRO; LARANJEIRA 2010; KILUK et al., 2013).

Essas lacunas na literatura indicam a necessidade de compreender e valorizar os aspectos individuais e os determinantes sociais que modulam as repercussões da gravidade da dependência considerando as diversas áreas que constituem o cotidiano do usuário. Sabe-se que o uso da cocaína, independentemente de sua via de administração, acarreta sérios prejuízos que se estendem do âmbito individual ao sociofamiliar (NUTT et al., 2007; VAUGHN et al., 2010; KESSLER et al., 2012; KILUK et al., 2013; MARTINS et al., 2014; PALAMAR; DAVIES; OMPAD, 2015; NARVAEZ et al., 2015). No entanto, poucos estudos compararam a magnitude dos prejuízos ocasionados pelas duas formas de uso em indivíduos sob tratamento, principalmente no contexto nacional.

Acrescenta-se também que o contexto de análise do presente estudo representa um marco em relação à atenção ao dependente de drogas, uma vez que corrobora as orientações internacionais sobre o tratamento da dependência química, que urge por ampliação de informações de forma sistematizada, em especial a anamnese e a interação com o contexto 
individual (BRASIL, 2002; BRASIL, 2004; UNODC, 2016; OMS, 1993; NIDA, 2009; APA, 2014).

Acima de tudo, torna-se necessário reconhecer que tanto a dependência de drogas como os demais transtornos psiquiátricos não são oriundos de um fator causal unilateral, mas de um processo de doença que engloba elementos intrínsecos do sujeito, bem como fatores externos que interagem diretamente em uma relação dialética entre indivíduo, droga e contexto social (CIBA, 1992). Vale dizer que, no Brasil, a assistência aos usuários de drogas tem se materializado no Centro de Atenção Psicossocial - álcool e drogas (CAPS-ad) (BRASIL, 2004). Nesse sentido, o cuidado de enfermagem a essa clientela tem sido posto em relevo, uma vez que busca um cuidado integral e humanizado (CAMPBELL et al., 1998; BRASIL, 2002; SPRICIGO et al., 2004).

O CAPS-ad é um serviço de saúde especializado no tratamento da dependência de drogas que integra a Rede de Atenção Psicossocial (RAPS) e, geralmente, localiza-se próximo às áreas mais vulneráveis nos municípios (BRASIL, 2004; STOTTS et al., 2007; HORTA et al., 2011; SANTOS; OLIVEIRA, 2013a; BOTTI; MACHADO; TAMEIRÃO, 2014). Esse dispositivo possibilita um olhar instrumentalizado do sujeito em seu ambiente de convívio, promove a valorização da autonomia, o empoderamento individual e um agir efetivo, dinâmico e comunitário, sem reclusão em instituições asilares. Esse conhecimento é de crucial importância para o desenvolvimento de estratégias terapêuticas mais efetivas, que resultem em melhores prognósticos quanto à reabilitação e reinserção social do indivíduo (CAMPBELL et al., 1998; RANGE, 2001; RIBEIRO; LARANJEIRA 2010), visto que favorece tratamento adequado às suas necessidades do contexto social do cuidado (HORTA et al., 2011; SANTOS CRUZ et al., 2013, BOTTI; MACHADO; TAMEIRÃO, 2014; NARVAEZ et al., 2015; GALASSI et al., 2016).

Nesse serviço, os profissionais de saúde, em especial os enfermeiros, que estão na linha do cuidado, têm, entre suas funções, estabelecer o tratamento mediante um cuidado integral ao indivíduo, desenvolvendo ações assistenciais, por meio de estratégias de prevenção, promoção da saúde e reabilitação psicossocial. De forma a operacionalizar a sistematização da assistência em enfermagem voltada ao cuidado em saúde mental e implementar ações terapêuticas que garantam o sucesso da reinserção social do usuário (SANTOS; OLIVEIRA, 2013), torna-se fundamental promover uma escuta ativa instrumentalizada na assistência aos sujeitos que estão vivenciando tais situações (ROSENBERG; FEDER, 2014) e compreender a dinâmica dos complexos sistemas sociais que ocorrem simultaneamente ao uso problemático da substância. 


\section{REVISÃO DA LITERATURA}

A seguir, uma revisão da literatura é apresentada sobre as temáticas que contribuíram para as bases teóricas adotadas no desenvolvimento do presente estudo.

\subsection{Aspectos históricos da cocaína}

A cocaína refere-se a um alcaloide branco, inodoro e cristalino, tal como conhecemos atualmente. Essa substância foi sintetizada pela primeira vez em 1860, em um laboratório alemão (GOOTENBERG, 1999). Entretanto, estudos sugerem que seu uso tenha ocorrido há pelo menos 8000 anos, pelos povos nativos da América do Sul (DILLEHAY et al., 2010), em sua forma in natura, ou seja, o arbusto Erythroxylum coca (por meio das folhas de coca). Essa planta apresenta na composição de suas folhas diversos alcaloides químicos - um deles, e o mais conhecido, a cocaína (ABOU-DONIA, 1992). Em tempos mais remotos, as folhas de coca eram tipicamente utilizadas sobretudo sob a forma de chá e/ou mastigadas, hábitos comuns entre os povos andinos, com o propósito de minimizar a fome, auxiliar no processo digestivo, promover analgesia e mitigar os efeitos da falta de oxigênio, muito comum em regiões de altitudes elevadas (UCHÔA, 1996; DILLEHAY et al., 2010).

A princípio, a cocaína foi considerada um fármaco milagroso, muito apreciado por suas propriedades estimulantes e potencialidades em tratar enfermidades graves (BUCHER, 1992; ESCOHOTADO, 1996; UCHÔA, 1996; GOOTENBERG, 1999; KARCH, 1999). A sua popularidade foi crescente no meio médico com contribuições de Sigmund Freud (GOOTENBERG, 1999), na literatura especializada (BUCHER, 1992) e na área comercial (KARCH, 1999). Historicamente, há registros marcantes do consumo de forma mais popular em duas bebidas que alcançaram grande notabilidade: o Vinho de Coca Mariani, uma infusão alcoólica de folhas de coca, e a bebida gaseificada Coca-Cola®, que até meados de 1903 mantinha cloridrato de cocaína em sua composição (KARCH, 1999). Atualmente, a cocaína foi substituída por cafeína na Coca-Cola®, ainda que folhas de coca "descocainizadas" permaneçam sendo utilizadas em sua composição (KARCH, 1999; SEIBEL, 2010).

Apesar das diversas motivações, os efeitos negativos gerados pelo uso da cocaína acabaram descobertos, assim como seu potencial para o desenvolvimento da dependência, descrito inicialmente por Freud (GOOTENBERG, 1999). Apesar de ter havido uma redução 
significativa do consumo a partir do início do século passado, a cocaína manteve seu status legal até a década de 1960, quando finalmente o seu uso foi proibido (KARCH, 1999).

Historicamente, alguns fatores sociais e políticos contribuíram fortemente para a minimização e, por conseguinte, coibição do consumo de cocaína, por exemplo, o fortalecimento proibicionista dos Estados Unidos da América (EUA), o advento de novas drogas estimulantes, crises econômicas e a implantação, na Europa, de medidas socioeducativas e de saúde pública, visando à prevenção e ao tratamento de usuários (ESCOHOTADO, 1996).

Entretanto, a cocaína apenas retornou ao mercado na década de 1970, como uso recreativo pela via intranasal (inalada), iniciando restrita a classes socioeconômicas mais altas, como uma "droga das elites" (GOOTENBERG, 1999). Por outro lado, seu consumo pela via pulmonar (fumada) era praticamente desconhecido na América do Sul (NEGRETE, 1992), embora neste período já estivesse em ascensão nas comunidades marginalizadas nos EUA (SIEGEL, 1984).

A cocaína utilizada por via pulmonar, ou seja, fumada, refere-se ao "crack". Trata-se de uma nova forma de uso da substância que tem se tornado muito disponível em nosso meio social. É uma forma potente da cocaína, que resulta em rápido e notável efeito estimulante quando fumada, o que parece ser um dos fatores responsáveis por seu alto poder de desenvolvimento da dependência. Essa forma de consumo foi obtida em um processo caseiro, conhecido como "freebasing", em que se mistura o cloridrato de cocaína com água, bicarbonato de sódio e hidróxido de amônia em meio aquoso altamente aquecido. Tal mistura origina um produto não solúvel em água, conhecido pelo nome de crack, devido ao efeito sonoro produzido pela ruptura dos cristais do cloridrato de cocaína quando queimado (UCHÔA, 1996; SEIBEL, 2010).

No Brasil, os primeiros registros da presença de crack datam do final da década de 1980 (RAUPP; ADORNO, 2011). Levantamentos epidemiológicos realizados antes de 1989 com amostras de meninos em situação de rua não identificaram essa forma de consumo. Todavia, em estudos posteriores, desenvolvidos em 1993 e 1997, a prevalência de uso de crack destacou-se em evidente crescimento na população em geral, com elevados índices (36\% e 46\%, respectivamente) (NOTO et al., 1998).

Durante a década de 1990 no Brasil, com o advento do HIV/Aids, observou-se uma transição nas vias de uso entre os usuários de cocaína, com aumento significativo do número de usuários de crack (DUNN; LARANJEIRA, 1999). Entre outros fatores contribuintes para 
essa migração, destacam-se o preço expressivamente menor quando comparado ao da cocaína pó, os efeitos potencialmente mais intensos e rápidos, cerca de 10 a 15 segundo após o uso, a facilidade de acesso e a tolerância ao uso, requerendo doses cada vez maiores e mais potentes (WASHTON, 1989; RIBEIRO; LARANJEIRA, 2012).

Atualmente, o uso de crack tem sido observado em pessoas de diversas classes sociais, etnias, gênero e idades, apesar de evidências apontarem maior prevalência de uso na vida dessa droga em jovens e em pessoas de classes sociais de menor poder aquisitivo (NAPPO et al., 2001; RIBEIRO, DUABILIB, LARANJEIRA, 2008; REIS, 2014). Os dependentes de crack de maior e menor poder aquisitivo não apresentam diferenças em relação à intensidade e à frequência de uso da droga (FREIRE et al., 2012). Além disso, nota-se atualmente um incremento do número de usuários de crack com idade igual ou superior a 30 anos (UNODC, 2016).

Quando comparados a usuários de cocaína inalada, são notórias a maior visibilidade e a preocupação mais acentuada da sociedade em relação aos usuários de crack, devido ao um padrão de consumo mais grave, maior envolvimento em atividades ilegais, maior frequência de comportamentos sexuais de risco, maiores chances de morar ou ter morado na rua, além de associação com graves problemas sociais (NOTO et al., 1998; NAPPO et al., 2001; DUAILIBI; RIBEIRO; LARANJEIRA, 2008). Há reconhecimento por parte das influências sociais a respeito do perfil desses usuários, muitas vezes alinhado a uma abordagem estigmatizante, repressiva e criminalizante do usuário de crack (RODRIGUES et al., 2015). Entre outros aspectos, o papel social desempenhado pelos usuários de crack constitui uma das muitas barreiras que dificultam a atuação dos profissionais das áreas sociais e de saúde e sua inserção nos serviços assistenciais.

Como descrito por Santos e Oliveira (2013), a partir do momento em que os danos resultantes do uso de drogas passaram a refletir prejudicialmente na sociedade, na saúde mental, física e social do usuário (KILUK et al, 2013; NARVAEZ et al., 2015), tais agravos foram configurando-se em problemas sociais e de saúde pública. Dessa maneira, embora o uso de cocaína e seus derivados resulte em sequelas físicas específicas, a compreensão satisfatória desse agravo requer uma investigação que transcenda as características do padrão de consumo e contemple, sobretudo, os sistemas dinâmicos que perfazem o cotidiano de vida dos sujeitos. 


\subsection{Contextualização epidemiológica do consumo de cocaína}

De acordo com dados do Relatório Mundial Sobre Drogas (UNODC, 2016), a prevalência do uso de drogas ilícitas aumentou de 4,9\% em 2006 para 5,2\% em 2014, resultando em uma estimativa de 247 milhões de pessoas (entre 15 e 64 anos), das quais aproximadamente 29 milhões desenvolveram algum tipo de prejuízo relacionado ao uso (dependência ou complicações clínicas e /ou sociais relacionadas). O relatório ressaltou ainda que, em relação à assistência à saúde, apenas uma em cada seis pessoas recebeu tratamento adequado para o problema (ABDALLA et al., 2014; UNODC, 2016). Sobre o uso específico da cocaína, estimou-se, em 2014, um total de aproximadamente 18 milhões de usuários na população mundial, o que resultará em uma demanda considerável para os serviços de saúde (UNODC, 2016).

Embora o uso de maconha agregue o maior número de usuários, o de cocaína vem aumentando na América do Sul desde o ano de 2010, sobretudo após a implementação de medidas mais rígidas de controle do tráfico nas fronteiras dos países da América do Norte. Apesar das flutuações regionais, na região das Américas manteve-se uma prevalência estável do uso de cocaína entre 1998-2014, com pequeno incremento de $0,3 \%$ e $0,4 \%$ da população com idade entre 15-64 anos (UNODC, 2016). Atualmente, estima-se que no continente americano vivam aproximadamente 8,6 milhões de consumidores de cocaína (fumada e inalada) (PAHO, 2009), sendo 3,2 milhões no Brasil (ABDALLA et al., 2014).

No contexto nacional, convém salientar, que desde a década de 1990 as transições da via de uso da cocaína têm sido um fenômeno notório (SEIGEL, 1982; NAPPO et al., 2001; GUINDALINI, et al., 2006; RIBEIRO, LARANJEIRA, 2010; BASTOS; BERTONI, 2013; REIS, 2014), em que os usuários de cocaína inalada migraram para o crack. Tal fenômeno não era esperado por grandes cientistas e gestores, uma vez que havia expectativa de aumento crescente do consumo de ópio (DUNN; LARANJEIRA, 1999; GOOTENBERG, 1999; BUCHER, 1992). Esses dados são preocupantes, pois, apesar da recente introdução dessa modalidade de uso no país, o Brasil detém cerca de $20 \%$ da circulação de mundial de crack (INPAD, 2013; UNODC, 2016; OPAS, 2009), sendo o segundo maior mercado do mundo, perdendo posição apenas para países da América do Norte (BASTOS; BERTONI, 2013; REIS, 2014). 
De acordo com o II Levantamento Nacional sobre Álcool e Drogas, observou-se, quanto ao uso de cocaína e crack no Brasil, prevalência de uso na vida de cocaína inalada de $3,9 \%$ e 1,5\% de crack. Em relação ao uso no ano anterior à pesquisa, houve prevalência de 1,7\% para o de cocaína e de 0,8\% de crack. (ABDALLA et al., 2014). Nesse levantamento, a taxa de prevalência de indivíduos que se tornaram dependentes após um único uso foi de 0,6\%, aumentando para 41,4\% entre os que a consumiram nos últimos 12 meses (ABDALLA et al., 2014).

Quanto ao perfil desses usuários, aqueles que optaram pelo uso inalado, na maioria das vezes, faziam praticamente o uso exclusivo (78\%) dessa substância, embora apresentassem altos índices de uso concomitante de maconha (cerca de $70 \%$ usaram no último ano). Esse subgrupo caracterizou-se por indivíduos mais jovens, com melhores níveis de escolaridade em relação aos usuários de crack (9-12 anos de estudo) e início tardio de uso, geralmente antes dos 18 anos (45\%) (ABDALLA et al., 2014). Em relação aos usuários de crack, observou-se predominância de homens $(78,68 \%)$, não brancos $(79,68 \%)$, solteiros $(60,64 \%)$, com baixo nível de escolaridade (ensino fundamental) (57,6\%), cuja renda era proveniente de trabalhos informais (65\%), além de esmolas (12,8\%), com maior tendência ao contexto de rua, sendo que cerca de 40\% não tinham residência fixa (BASTOS; BERTONI, 2013; REIS, 2014).

Dados do Relatório Mundial sobre Drogas descreveram um perfil de usuários de cocaína no contexto mundial constituído principalmente por homens, em uma proporção de 3:1 em relação ao sexo feminino, geralmente adultos (idade $\geq 30$ anos) (UNODC, 2016). O relatório destacou ainda o envelhecimento desses consumidores de droga (UNODC, 2016), sugerindo, possivelmente, uma população de dependentes crônicos de cocaína que vem mantendo uso por vários anos. Por outro lado, estudos demonstraram que o uso crônico de cocaína tem sido associado a: aumento de mortalidade, diminuição da expectativa de vida, maior número de hospitalizações, desemprego, isolamento, estigma social e problemas familiares (LIMA; ROSSINI; REIMÃO, 2008; ALVES; RIBEIRO; CASTRO, 2011).

Em virtude da extensão territorial brasileira, torna-se importante ressaltar que os padrões de consumo de derivados de cocaína, bem como os agravos resultantes, possuem notória variação regional, sendo o consumo nas grandes cidades três vezes maior em relação às demais regiões do país, com destaque a Região Sudeste, onde está concentrada a maior população de usuários de cocaína (independentemente da via), com aproximadamente 1,4 milhão (INPAD, 2013). Entretanto, quanto ao uso de crack, estudo multicêntrico encontrou 
prevalência de consumo de 1,3\% na Região Nordeste, enquanto no Sudeste a taxa foi de 0,6\% (BASTOS; BERTONI, 2013; REIS, 2014).

Esses dados são extremamente preocupantes, considerando a rápida evolução dos índices de uso cocaína e crack nos últimos anos. De acordo com o Relatório Brasil sobre Drogas divulgado em 2009, a prevalência do uso na vida de crack era de apenas 0,7\%, enquanto a de uso de cocaína (independentemente da via) na população geral chegava a 2,1\% (BRASIL, 2009).

Embora não seja possível estimar com exatidão o panorama epidemiológico nacional, a possibilidade de construir um perfil desta população representa um avanço para a organização dos serviços e a produção de conhecimentos. No Brasil, nos últimos anos, observou-se um incremento no aperfeiçoamento metodológico em estudos epidemiológicos a respeito do consumo de drogas, por meio de instrumentos padronizados, com avaliações de diversos grupos da população, além de inquéritos domiciliares mais abrangentes (BASTOS; BERTONI, 2013) e cruzamentos de informações de diferentes instituições, o que possibilita veementes melhores conhecimentos sobre o panorama nacional do uso de drogas (BRASIL, 2009; UNODC, 2015; UNODC, 2016). De acordo com a Junta Internacional de Fiscalização de Entorpecentes (JIFE), vinculada à ONU, o país tem se destacado no cenário mundial em relação à divulgação de resultados sobre o consumo de substâncias psicoativas (UNODC, 2015).

Apesar das importantes contribuições da epidemiologia na explicação dos determinantes sociais e de saúde relacionados ao uso de drogas no país, observa-se um incremento de estudos sobre fatores de risco e de proteção, como também implementação de pesquisas que avaliam as aplicações de intervenções regionais, com populações institucionalizadas, visando aprimorar os programas de prevenção e as tecnologias terapêuticas (MEDINA et al., 2001). Nesse sentido, conduzir estudos em populações assistidas por serviços terapêuticos para o tratamento da dependência de drogas permite explorar os determinantes relacionados à ocorrência de agravos, por meio da análise do contexto de vida e das influências das vulnerabilidades biopsicossociais do indivíduo.

\subsection{Aspectos neuroquímicos da cocaína e vias de uso da substância}

As bases neurobiológicas que caracterizam o processo da dependência de cocaína vêm sendo amplamente estudadas pela comunidade científica nas últimas duas décadas (DOW 
EDWARD; KHANTZIAN, 1985; KORPI et al., 2015; LEWIS, 2015; VOLKOW; KOOB; MCLELLAN, 2016), contudo, ainda permanecem inconclusivas. Nota-se amplo debate sobre as evidências moleculares (VOLKOW; KOOB; MCLELLAN, 2016), psicológicas (KORPI et al., 2015), ambientais e individuais (GALEA; VLAHOV, 2002) que predispõem o sujeito ao uso, além dos fatores comportamentais (VOLKOM; WARENN, 2014; LEWIS, 2015) e biológicos (VOLKOW; KOOB; MCLELLAN, 2016) que agravam ainda mais a dependência e se mantêm ao longo de um continuum de problemas. Entretanto, aquém das discordâncias científicas, o conceito de doença crônica e redicivante do SNC continua sendo a definição mais aceita e baseada em evidências (ABOU-DONIA, 1992; VOLKOW; KOOB; MCLELLAN, 2016).

Na perspectiva nosológica da dependência, o uso continuado de drogas pode induzir diferentes mecanismos modulatórios nos circuitos cerebrais (adaptação, plasticidade, aprendizado e memória) (KORPI et al., 2015), que resultam em um ciclo de consumo, inicialmente de caráter impulsivo (reforço positivo), que se move gradualmente para um comportamento compulsivo (reforço negativo) nas fases posteriores (ABOU-DONIA, 1992; VOLKOW; KOOB; MCLELLAN, 2016).

De acordo com Volkom et al. (2016), o colapso dos períodos de impulsividade e compulsividade produz um ciclo complexo da dependência que compreende três fases: (1) Binge/ Intoxicação; (2) Abstinência/ Sintomas negativos e (3) Preocupação/ Antecipação, que serão explicados a seguir:

\section{Binge / Intoxicação}

O binge, também conhecido como intoxicação, tem por definição um padrão de uso intenso, contínuo e repetitivo dos derivados da cocaína (SEIGEL, 1982). Com base nos pressupostos neuroquímicos, esse comportamento resulta dos reforços positivos ou efeitos prazerosos do uso de cocaína, que ocorrem por meio da excitação dopaminérgica no sistema de recompensa do SNC, via trato Mesolímbico-Mesocortical. Essa estrutura se estende da Área Tegumentar Ventral (ATV) até o córtex pré-frontal. A cocaína atua diretamente inibindo a recaptação de dopamina (DA) liberada pelos neurônios pré-sinápticos no Núcleo Accumbes, ATV e córtex pré-frontal (VOLKOW; KOOB; MCLELLAN, 2016).

O circuito neuronal da DA também sofre a influência de outros neuromoduladores no desempenho dos efeitos agudo da droga. No caso da cocaína, interneurônios GABAérgicos 
fornecem uma via inibitória aferente que modula a libertação de DA (CHASIN; SILVA; CARVALHO, 2008; SULZER, 2011), enquanto os neurônios colinérgicos (nicotínicos), endocanabinoide, etanol, péptidos opioide, serotonina, glutamato, entre outros, proporcionam uma via excitatória para o ATV, favorecendo a libertação de DA (KORPI et al., 2015; VOLKOW; KOOB; MCLELLAN, 2016).

A repetida exposição da droga no sistema de recompensa desencadeia neuroadaptações de aprendizagem e memória (KOURRICH et al 2015), prejudicando a resposta dopaminérgica basal a estímulos naturais de prazeres, iniciando, assim, uma resposta antecipada ao estímulo condicionado pelo uso de cocaína (SULZER, 2011; VOLKOW; KOOB; MCLELLAN, 2016). Nesse tipo de aprendizagem pavloviana, experiências repetidas de recompensa tornam-se associadas com o meio ambiente e o comportamento (KORPI et al., 2015).

O aumento da quantidade de DA liberada no espaço extracelular é modulado pelo tipo de droga, pela quantidade administrada e biodisponibilidade para ocasionar os efeitos psicoativos. Nesse sentido, a via de uso determina o ciclo de consumo, uma vez que, quanto menor o tempo de ação, maior será a quantidade readministrada e, consequentemente, maiores os prejuízos a nível celular (VOLKOW; KOOB; MCLELLAN, 2016). O Quadro 1 apresenta a farmacocinética da cocaína de acordo com as vias de uso.

\begin{tabular}{|c|c|c|c|c|c|}
\hline \multicolumn{2}{|c|}{ Administração } & \multirow{2}{*}{$\begin{array}{l}\text { Início da } \\
\text { ação } \\
\text { (segundos) }\end{array}$} & \multirow{2}{*}{$\begin{array}{l}\text { Duração do } \\
\text { efeito } \\
\text { (Minutos) }\end{array}$} & \multirow{2}{*}{$\begin{array}{c}\text { Pico } \\
\text { plasmático } \\
(\mathrm{ng} / \mathrm{ml})\end{array}$} & \multirow{2}{*}{$\begin{array}{c}\text { Biodisponibilidade } \\
\text { (\% absorvida) }\end{array}$} \\
\hline Via & Apresentação & & & & \\
\hline Oral & $\begin{array}{l}\text { Folhas secas de } \\
\text { coca mascadas }\end{array}$ & $300-600$ & $45-90$ & 150 & 20 \\
\hline Inalada & $\begin{array}{l}\text { Cocaína } \\
\text { refinada }\end{array}$ & $120-180$ & $30-45$ & 150 & $20-30$ \\
\hline Endovenosa & $\begin{array}{l}\text { Cocaína } \\
\text { refinada } \\
\text { diluída em água }\end{array}$ & $30-45$ & $10-20$ & $300-400$ & 100 \\
\hline Fumada & $\begin{array}{c}\text { Pasta de coca } \\
\text { Crack }\end{array}$ & $8-10$ & $5-10$ & $300-800$ & $60-70$ \\
\hline
\end{tabular}

Fonte: CHASIN; SILVA; CARVALHO, 2008

Quadro 1. Farmacocinética da cocaína conforme as vias de uso.

A dose única de uso da cocaína varia de 25 a $50 \mathrm{mg}$ pela via intravenosa, $30 \mathrm{mg}$ e 70 mg pela via intranasal, podendo exceder um grama na sua forma de uso fumada (CHASIN; SILVA; CARVALHO, 2008; SULZER, 2011). A necessidade do uso da próxima dose estará relacionada à duração do efeito estimulante, em geral gradativamente reduzida à medida que aumenta a tolerância. Dessa forma, a fim de manter níveis prazerosos, a droga é utilizada 
repetidamente em um período de tempo relativamente curto, em doses cada vez mais elevadas (ABOU-DONIA, 1992; PALIWALA; HYMANA; SINHA, 2008).

Outro agravante da toxidade do uso da cocaína são os produtos químicos adicionados ao cloridrato de cocaína no processo de produção do crack e suas variações (merla, oxi), com o objetivo de aumentar a produção e obter maior lucro na venda (tráfico), entre os quais se destacam os solventes e ácidos. Outros adulterantes clandestinos incluem os anestésicos, antihistamínicos e vermífugos adicionados à cocaína com o intuito de potencializar os efeitos (CRATOD, 2016).

A presença de metabólitos prejudiciais relacionados à via de uso da cocaína foi observada em estudo laboratorial (GARCI, 2009), de forma que o crack produz uma substância química extremamente tóxica após a sua queima, denominada Metilecgonidina, que potencializa a neurodegeneração, ocasionando danos neurológicos mais severos entre os usuários da via fumada de uso.

Além disso, o consumo simultâneo de cocaína e bebidas alcoólicas resulta na intensificação e duração dos efeitos da droga, devido ao aumento dos níveis plasmáticos de cocaína e norcocaína e indução da síntese do cocaetileno (PAN, HEDAYA, 1999; PENNINGS; LECCESE; WOLFF, 2001). O cocaetileno é o único metabólito ativo da cocaína formado na presença do etanol, que interage no organismo elevando os riscos de sérios problemas cardiovasculares (PENNINGS; LECCESE; WOLFF, 2001), morte súbita (GOSSOP; MANNING; RIDGE, 2006) e toxidade para fígado (GOMES, 2007).

Essa associação é um fenômeno frequentemente observado em usuários de cocaína, o que constitui um desafio para os profissionais de saúde tanto no tratamento da dependência da cocaína como na do álcool, pois, além de ocasionar níveis mais severos para ambas as dependências, prejudica o diagnóstico correto por mascarar diversos sintomas (SCHUCKIT, 2006). Neste caso especificamente, a cocaína pode antagonizar os déficits de comunicação e os prejuízos no desempenho psicomotor (sensação de embriaguez) causados pelo consumo de álcool (PENNINGS; LECCESE; WOLFF, 2001). Por outro lado, o álcool pode modular a excitação dopaminérgica causada pela cocaína, atenuando o comportamento impulsivo de fissura (CHAVES et al., 2011; BRACHE; STOCKWELL; MACDONALD, 2011).

\section{Abstinência e efeitos negativos}


$\mathrm{Na}$ transição entre as fases de abuso e dependência da substância, o comprometimento do sistema dopaminérgico resulta na ativação do sistema de estresse do SNC, responsável pela maioria dos sintomas de abstinência. A síndrome de abstinência da cocaína define-se pela presença de um quadro de desconforto físico e/ou psíquico após a diminuição ou suspensão do consumo da substância (RIBEIRO, LARANJEIRA, 2010). Neste caso, o neurocircuito estressor cerebral ocasiona aumento do hormônio adrenocorticotrófico (ACTH), do corticosterona, da dinorfina e do fator de libertação de corticotrofina (CRF) na amígdala. Esses neurotransmissores são responsáveis pelos reforços negativos durante a fase de abstinência, além de exercerem importante papel na recaída (CHASIN; SILVA; CARVALHO, 2008).

Há evidências ainda de que outros neurotransmissores estão envolvidos na produção dos sinais e sintomas da abstinência da droga, como a norepinefrina, substância $\mathrm{P}$, vasopressina, neuropeptídeo Y (NPY), endocanabinoides e nociceptina (CHASIN; SILVA; CARVALHO, 2008). Os principais efeitos desses componentes estão descritos no Quadro 2.

\begin{tabular}{ll}
\hline \multicolumn{1}{c}{ NEUROTRANSMISSOR } & \multicolumn{1}{c}{ EFEITOS RESULTANTES } \\
\hline$\downarrow$ Dopamina & Disforia \\
$\downarrow$ Serotonina & Disforia \\
$\downarrow$ Ácido y-aminobutírico & Ansiedade/ Ataques de pânico \\
$\downarrow$ Neuropeptídeo Y & Antiestresse \\
$\uparrow$ Dinorfina & Disforia \\
$\uparrow$ Fator de liberação de corticotropina & Estresse \\
$\uparrow$ Norepinefrina & Estresse \\
\hline
\end{tabular}

Fonte: GALANTER; KLEBER; BRADY, 2014.

Quadro 2. Neurotransmissores versus efeitos resultantes da abstinência

A depleção do sistema dopaminérgico é proporcional à intensidade da excitação inicial. Embora o nível de DA tenda a aumentar entre 8-12 horas após término de uso, o nível basal de DA permanece em níveis baixos, justificando o quadro de anedonia dos usuários no período posterior ao uso da droga (VOLKOW; KOOB; MCLELLAN, 2016).

\section{Preocupação e Antecipação}


As alterações ocorridas nos circuitos do sistema de recompensa e emocional no SNC são acompanhadas por alterações na função das regiões corticais pré-frontal, prejudicando seriamente os processos executivos, como a capacidade de autorregulação, tomada de decisão, flexibilidade na seleção e início de ação, atribuição de relevância (a atribuição de valor relativo) (VOLKOW; KOOB; MCLELLAN, 2016).

Esse nível de comprometimento basal dos neurotransmissores, principalmente sistema dopaminérgico e glutamatérgico, ocasiona uma readaptação cerebral do sistema límbico, com consequente neuroplasticidade neuronal devido às novas circunstâncias. Dessa maneira, o comprometimento crônico do córtex pré-frontal prejudica a capacidade do indivíduo de controlar o desejo de consumir a droga (VOLKOW; KOOB; MCLELLAN, 2016), resultando em um quadro de manifestações fisiológicas de antecipação do uso da droga, ou, também, na preocupação antecipada em obter uma nova dose (ABOU-DONIA, 1992; PALIWALA; HYMANA; SINHA, 2008). Marlatt e Gordon (1993) definiram este estado motivacional subjetivo influenciado pelas expectativas do uso da substância como fissura ou craving, na língua inglesa.

A fissura é definida como um desejo intenso de consumir uma substância a fim de repetir a experiência dos seus efeitos prazerosos (WHO, 1992; UNODC, 2016). A fissura surge após o consumo imediato, no período de abstinência e na abstinência prolongada, podendo ser diagnosticada na prática clínica mediante avaliação dos sintomas (Grossi e Oliveira, 2013). O Quadro 3 apresenta as fases de evolução da fissura.

\begin{tabular}{ccc}
\hline & FASES DA EVOLUÇÃO DA FISSURA & \\
FASES & SINTOMAS & DURAÇÃO \\
\hline & $\begin{array}{c}\text { Caracterizado por sintomas } \\
\text { como ansiedade, depressão, } \\
\text { paranoia e intenso desejo de } \\
\text { retomar o uso (craving ou } \\
\text { fissura). }\end{array}$ & $\begin{array}{c}\text { Início: 15" a 30" } \\
\text { Duração: } 8 \text { horas a } 4 \text { dias }\end{array}$ \\
SÍNDROME & $\begin{array}{c}\text { Alteração do padrão do sono, } \\
\text { irritabilidade, anedonia, desejo } \\
\text { pelo consumo, bem como } \\
\text { ideação suicida. }\end{array}$ & $\begin{array}{c}\text { Início: } 12 \text { a } 96 \text { horas } \\
\text { Disfoção: } 2 \text { a } 4 \text { semanas }\end{array}$ \\
FASE DE TARDIA & $\begin{array}{c}\text { Sintomas disfóricos diminuem } \\
\text { ou cessam, e a fissura torna-se } \\
\text { intermitente. }\end{array}$ & Duração de meses \\
\hline
\end{tabular}




\subsection{Síndrome de dependência da cocaína e mensuração da gravidade}

A dependência da cocaína é considerada uma síndrome nosológica moldada por fatores capazes de predispor, potencializar ou bloquear a sua manifestação, sem, no entanto, haver uma causa única ou recorrente (RIBEIRO, LARANJEIRA, 2010). Assim, a gravidade da dependência organiza-se em níveis de intensidade, nos quais os fatores indutores ao uso indevido estão incluídos dentre os critérios diagnósticos e, portanto, retratam a síndrome subjacente e não um diagnóstico absoluto de uso (OMS, 1993; APA, 2014).

Esse conceito de síndrome da dependência considera a complexidade da interação entre um indivíduo e a substância, incluindo elementos ambientais, cognitivos, comportamentais, sociais e fisiológicos que permeiam o contexto situacional desse contato (RIBEIRO, LARANJEIRA, 2016; OMS, 1993; APA, 2014). Considerando que o uso de substâncias psicoativas é multifatorial, a representação esquemática das implicações de fatores psicológicos, biológicos e sociais que influenciam o seu consumo problemático encontra-se na Figura 1.

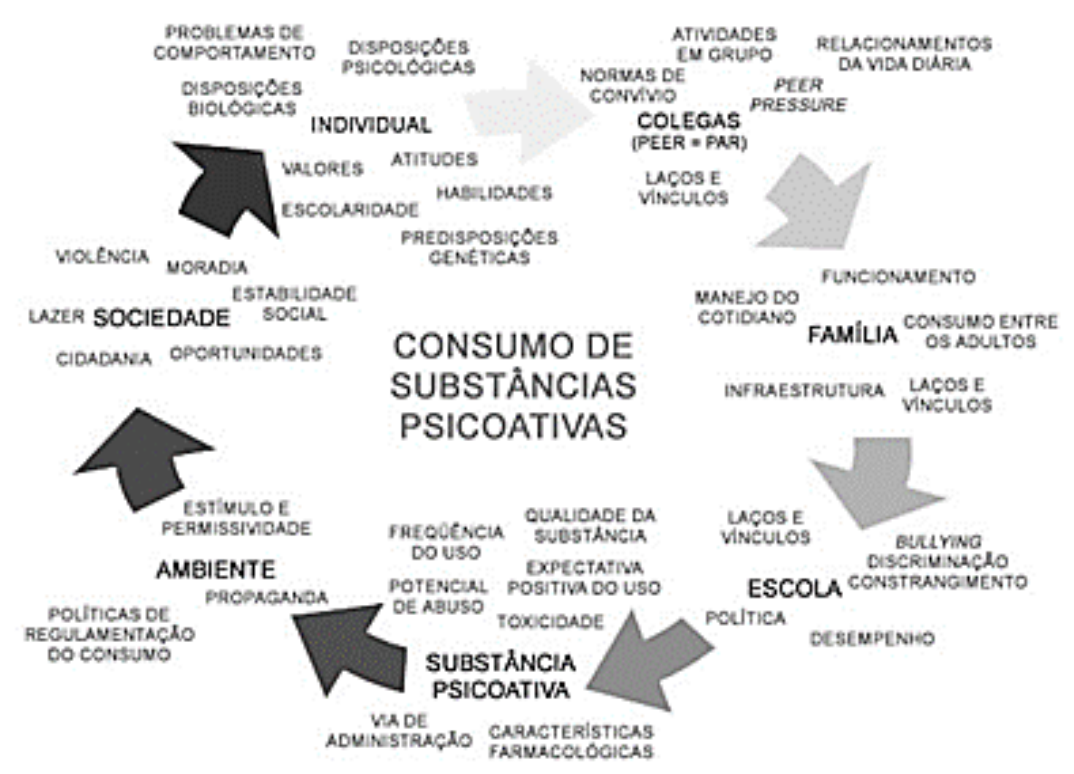

Fonte: RIBEIRO, LARANJEIRA, 2010.

Figura 1. Fatores de risco e de proteção associados ao uso de substâncias psicoativas.

A incorporação dos fatores de risco e proteção na prática clínica é observada na delimitação dos critérios diagnósticos de dependência de substâncias psicoativas (Quadro 3) 
elaborados por Edwards \& Gross (1976). Esses critérios constituíram o alicerce teórico para a elaboração dos dois principais códigos psiquiátricos da atualidade: Classificação Internacional de Doenças (CID) da Organização Mundial de Saúde (OMS), atualmente em sua décima versão, e o Diagnostic and Statistical Manual of Mental Disorders (DSM), criado pela American Psychiatric Association (APA) e recentemente atualizado, tendo sido publicada sua quinta versão (OMS, 1993; APA, 2014).

\begin{tabular}{|c|c|}
\hline CRITÉRIO & DEFINIÇÃO \\
\hline Compulsão para o consumo & $\begin{array}{l}\text { A experiência de um desejo incontrolável de consumir uma substância. O } \\
\text { indivíduo imagina-se incapaz de colocar barreiras a tal desejo e sempre } \\
\text { acaba consumindo. }\end{array}$ \\
\hline Aumento da tolerância & $\begin{array}{l}\text { A necessidade de doses crescentes de uma determinada substância } \\
\text { psicoativa para alcançar efeitos originalmente obtidos com doses mais } \\
\text { baixas. }\end{array}$ \\
\hline Síndrome de abstinência & $\begin{array}{l}\text { O surgimento de sinais e sintomas de intensidade variável quando o } \\
\text { consumo de substância psicoativa cessou ou foi reduzido. }\end{array}$ \\
\hline $\begin{array}{l}\text { Alívio da abstinência pelo } \\
\text { aumento do consumo }\end{array}$ & $\begin{array}{l}\text { O consumo de substâncias psicoativas visando ao alívio dos sintomas de } \\
\text { abstinência. Como o indivíduo aprende a detectar os intervalos que } \\
\text { separam a manifestação de tais sintomas, passa a consumir a substância } \\
\text { preventivamente, a fim de evitá-los. }\end{array}$ \\
\hline Relevância do consumo & $\begin{array}{l}\text { O consumo de uma substância torna-se prioridade, mais importante do } \\
\text { que coisas que outrora eram valorizadas pelo indivíduo. }\end{array}$ \\
\hline $\begin{array}{l}\text { Estreitamento ou } \\
\text { empobrecimento do repertório }\end{array}$ & $\begin{array}{l}\text { A perda das referências internas e externas que norteiam o consumo. À } \\
\text { medida que a dependência avança, as referências voltam-se } \\
\text { exclusivamente para o alívio dos sintomas de abstinência, em detrimento } \\
\text { do consumo ligado a eventos sociais. Além disso, passa a ocorrer em } \\
\text { locais onde sua presença é incompatível, por exemplo, no ambiente de } \\
\text { trabalho. }\end{array}$ \\
\hline $\begin{array}{l}\text { Reinstalação da síndrome de } \\
\text { dependência }\end{array}$ & $\begin{array}{l}\text { O ressurgimento dos comportamentos relacionados ao consumo é dos } \\
\text { sintomas de abstinência após determinado período de abstinência. Uma } \\
\text { síndrome que levou anos para se desenvolver pode se reinstalar em } \\
\text { poucos dias, mesmo o indivíduo tendo atravessado um longo período de } \\
\text { abstinência. }\end{array}$ \\
\hline
\end{tabular}

Fonte: EDWARDS; GROSS, 1976.

Quadro 4. Critérios diagnósticos da dependência de substâncias psicoativas.

No contexto Brasileiro, os Sistemas de Informações em Saúde (SIS) do Sistema Único de Saúde (SUS), de morbidade e mortalidade, incluindo os transtornos relacionados ao uso de substâncias, seguem os critérios diagnósticos da CID-10. Esta, por sua vez, estabelece os critérios definidores da síndrome dependência e do episódio de uso nocivo e estuda a 
possibilidade de incluir, na próxima edição, o "episódio de uso nocivo isolado", para contemplar o padrão de consumo em binge (RIBEIRO; LARANJEIRA, 2012).

De acordo com a CID-10, define-se "síndrome de dependência" como um conjunto de fenômenos comportamentais, cognitivos e fisiológicos ocasionados por consumo repetido de uma substância psicoativa, tipicamente associada ao desejo de usar a droga, à dificuldade de controlar o consumo, à utilização persistente, apesar das suas consequências nefastas, a uma maior prioridade conferida ao uso da droga em detrimento de outras atividades e obrigações, a um aumento da tolerância pela droga e, por vezes, a um estado de abstinência física (OMS, 1993). Assim, o "uso nocivo" foi definido na CID-10 como um padrão de consumo específico, com história natural e critérios diagnósticos próprios, que caracteriza um padrão mal adaptativo de consumo, marcado pela perda do controle do uso e por prejuízos imediatos ou circunscritos ao episódio de consumo (OMS, 1993).

Contudo, torna-se importante salientar que o DSM-5, mais utilizado no cenário internacional, foi atualizado recentemente, vinte anos após sua edição anterior. As principais mudanças foram de natureza conceitual, descrevendo a substituição do binômio "dependência" e "abuso" por "transtornos relacionados a substâncias", com diferentes níveis de gravidade (RIBEIRO; LARANJEIRA, 2012).

De acordo com o DSM-5, define-se transtorno relacionado a substâncias como um padrão problemático de uso (de qualquer substância psicoativa), que leve a comprometimento ou sofrimento clinicamente significativos, manifestados por meio de pelo menos dois critérios (de onze possíveis), durante um período de 12 meses. Quanto à gravidade, a presença de dois ou três critérios caracteriza transtorno por uso de substância "leve"; 4 ou 5, transtorno "moderado"; ao passo que o "grave" possui ao menos 6 sintomas (APA, 2014). 


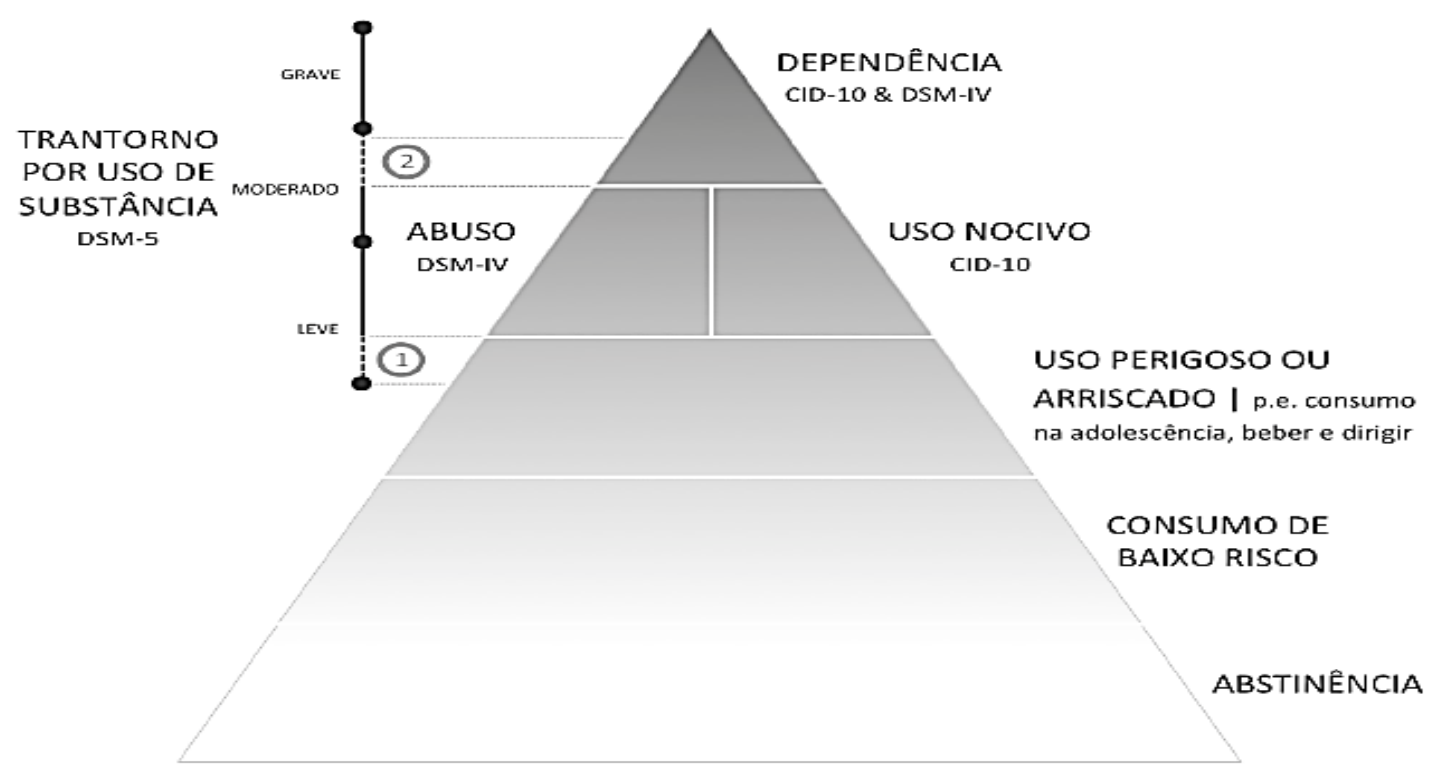

Fonte: RIBEIRO, LARANJEIRA, 2010.

Figura 2. Comparação entre os critérios diagnósticos CID-10 e DSM-5 em relação à mensuração do nível de dependência de substâncias psicoativas.

A dependência causada pelo uso problemático de substâncias psicoativas é considerada uma realidade clínica importante e tem se tornado cada vez mais frequente no panorama epidemiológico atual. Assim, compreender suas implicações faz parte da competência do profissional de saúde para implementar intervenções mais eficientes (EDWARDS; MARSHAL; COOK, 1999). Para o autor, é imperioso o diagnóstico de dependência ou de uso nocivo para a avaliação da gravidade do problema, com a finalidade de individualizar o diagnóstico e obter elementos indispensáveis ao planejamento terapêutico.

O Quadro 4 apresenta a comparação dos critérios diagnósticos do CID-10 e do DSM5. Estudo comparativo entre as duas classificações demonstrou elevado grau de concordância entre "transtorno por uso de substância grave" (DSM-5) e "dependência" (CID-10). Outros autores encontraram apenas baixa sensibilidade do DSM-5 para a detecção de casos de dependência menos severos (HOFFMAN; KOPAK, 2015). Essa fragilidade pode ser considerada um elemento importante em relação ao uso de cocaína, principalmente sob a forma inalada, uma vez que o uso "recreacional" por jovens, na ocasião da iniciação, pode estar invisível à detecção diagnóstica em virtude da baixa gravidade no primeiro contato (BRASIL, 2009; RIBEIRO; LARANJEIRA, 2012; UNODC, 2016). 
CID-10

SÍNDROME DE DEPENDÊNCIA

Diagnóstico definitivo de dependência deve usualmente ser feito somente se três ou mais dos seguintes requisitos tiverem sido experienciados ou exibidos em algum momento do ano anterior:

1. Forte desejo ou senso de compulsão para consumir a substância.

2. Dificuldades em controlar o comportamento de consumir a substância em termos de seu início, término e níveis de consumo.

3. Estado de abstinência fisiológico quando o uso da substância cessou ou foi reduzido, como evidenciado por: síndrome de abstinência para a substância ou uso da mesma (ou de uma intimamente relacionada) com a intenção de aliviar ou evitar sintomas de abstinência.

4. Evidência de tolerância, de tal forma que doses crescentes da substância psicoativa são requeridas para alcançar efeitos originalmente produzidos por doses mais baixas.

5.Abandono progressivo de prazeres e interesses alternativos em favor do uso da substância psicoativa, aumento da quantidade de tempo necessário para se recuperar de seus efeitos.

6. Persistência no uso da substância, a despeito de evidência clara de consequências manifestamente nocivas (são necessários esforços para determinar se o usuário estava realmente consciente da natureza e extensão do dano).
DSM-5

TRANSTORNO POR USO DE SUBSTÂNCIA

Padrão problemático de uso de uma determinada substância, levando a comprometimento ou sofrimento clinicamente significativos, manifestados por pelo menos dois dos seguintes critérios, ocorrendo durante um período de 12 meses:

1. A substância é frequentemente consumida em maiores quantidades ou por períodos mais longos do que os pretendidos.

2. Há um desejo persistente ou esforços malsucedidos no sentido de reduzir ou controlar o uso de álcool.

3. Muito tempo é gasto em atividades necessárias para obtenção da substância, na utilização da substância ou na recuperação dos seus efeitos.

4. Fissura, forte desejo ou necessidade de usar a substância.

5. Uso recorrente da substância, resultando no fracasso de desempenhar papéis importantes no trabalho, na escola ou em casa.

6. Uso continuado da substância, apesar de problemas sociais ou interpessoais persistentes ou recorrentes causados ou exacerbados por seus efeitos.

7. Importantes atividades sociais, profissionais ou recreacionais são abandonadas ou reduzidas em função do uso de substância.

8. Uso recorrente da substância em situação nas quais isso representa perigo à integridade física.

9. O uso de substância é mantido apesar da consciência de ter um problema físico ou psicológico persistente ou recorrente que tende a ser por ela causado ou exacerbado.

10. Tolerância, definida por qualquer um dos seguintes aspectos:

a. Necessidade de quantidades progressivamente maiores de álcool para alcançar intoxicação ou o efeito desejado;

b. Efeito acentuadamente menor com o uso continuado da mesma quantidade de substância.

11. Abstinência, manifestada por qualquer dos seguintes aspectos:

a. Síndrome de abstinência característica da substância.

b. A substância é consumida para aliviar ou evitar os sintomas de abstinência.

Fonte: OMS, 1993; APA, 2014.

Quadro 5. Comparação entre os critérios diagnósticos CID-10 (OMS) e DSM-5 (APA) para classificação do uso problemático de substâncias psicoativas. 


\subsection{Fatores associados à dependência de cocaína}

A dependência de cocaína, embora de origem neurobiológica (VOLKOW; KOOB; MCLELLAN, 2016), não é unicamente um problema mundial de saúde pública pela frequência e intensidade do uso da droga, mas sim pelos danos resultantes de tal consumo (KILUK et al., 2013; NARVAEZ et al., 2015). Partindo desse pressuposto, a magnitude deste tipo de dependência necessita ser nivelada principalmente em relação aos prejuízos ocasionados nos estratos sociais e contextuais que circundam os cenários de vida dos indivíduos (CIBA, 1992; OMS, 1993; APA, 2014).

Desde que Guindalini et al. (2006) identificaram que algumas consequências ampliadas, sobretudo nos aspectos sociais e de saúde, são influenciadas pela forma como a cocaína é consumida, poucos estudos nacionais compararam tais prejuízos em função das diferentes vias de uso. Todavia, ao comparar tais vias, embora a gravidade seja elevada em ambas, os usuários de cocaína (inalada) apresentaram melhores prognósticos no tratamento e menor nível de vulnerabilidade biopsicossocial (KILUK et al., 2013). O mesmo, no entanto, não tem ocorrido em relação aos usuários de crack, uma vez que o consumo da droga ocorre geralmente de forma contínua e prolongada (binge) até o esgotamento físico, psíquico e financeiro dos usuários, situação em que negligenciam, na maioria das vezes, o autocuidado e a assistência básica de saúde (NAPPO et al., 2001).

Há crescente interesse em compreender os diversos fatores potencialmente relacionados ao uso de cocaína entre os usuários em tratamento para dependência química, pois o abuso e a dependência dessa substância (independentemente da forma de uso) não são diagnosticados apenas por meio do uso, ou seja, pelos padrões de consumo, mas são também avaliados por seus efeitos ou consequências nas esferas da saúde, psicológica, social e comportamental, os quais serão descritos a seguir.

Um dos principais prejuízos relacionados ao uso de cocaína envolve a utilização concomitante de outras substâncias psicoativas (lícitas e ilícitas), que, consequentemente, agravam ainda mais a dependência. Os agravos relacionados ao uso simultâneo de múltiplas drogas, descritos em estudos epidemiológicos, têm sido definidos como efeitos clínicos e comportamentais adversos, cumulativos e sinérgicos, via interação entre as substâncias que podem afetar o resultado do tratamento para dependência de cocaína e ainda favorecer a ocorrência de prejuízos nas funções sociais (UNODC, 2016). Geralmente, o usuário de crack 
faz uso associado na mesma ocasião de outras substâncias psicoativas, ou tem antecedente de consumo de outras drogas (BRASIL, 2009; RIBEIRO, LARANJEIRA, 2010; JORA, 2014).

Os danos gerados pelo consumo de múltiplas drogas foram avaliados em usuários sob tratamento (JORA, 2014). Os resultados mostraram níveis mais severos da dependência de álcool nesse grupo (73,3\%), quando comparado aos usuários exclusivos de crack $(42,6 \%)$ e cocaína (22\%). Os usuários de múltiplas drogas também se diferenciaram por apresentarem níveis mais severos de problemas de saúde física e psiquiátricos relacionados ao consumo de drogas, exceto álcool (JORA, 2014).

O tabaco é uma substância muito comum e de alta prevalência entre os usuários de crack. O uso dessa substância tem sido um gatilho disparador do craving entre esses usuários, que, consequentemente, favorece a ocorrência de recaída (ZENI; ARAUJO, 2011). Em usuários de crack internados para tratamento da dependência foi observado que $88 \%$ faziam uso regular de tabaco (FREIRE et al., 2012). Outro estudo comparou o tabagismo entre usuários de crack e identificou que os índices eram maiores nos indivíduos que frequentavam ambiente terapêutico (96\%), quando comparados aos de usuários de crack em situação de rua (92\%) (CRUZ et al., 2014).

Os tranquilizantes, muitas vezes consumidos indiscriminadamente, estão entre as drogas muito utilizadas em usuários de drogas e atuam como antagonistas dos efeitos estimulantes da cocaína (CHAVES et al., 2011). Estudo identificou que o uso associado de tranquilizante dobra as chances da ocorrência de efeitos adversos (exemplo, diminuição do apetite) em dependentes de cocaína (FERRI et al., 2004).

O uso de anfetaminas (metanfetamina fumada) também se destaca entre os usuários de cocaína. Conhecidas como "crack de ricos", ocasionam sinergismo do efeito estimulante do crack, o que resulta em aumento do período de consumo em binge, consequentemente, prolongamento do tempo de exposição a comportamentos de riscos (BRUEHL et al., 2006).

Em relação ao uso de maconha, observa-se um dualismo conceitual acerca da sua associação com a cocaína. De um lado, há um incremento de estudos apontando seus efeitos protetores e de redução de danos, principalmente em relação ao sintoma da fissura em usuários de crack (CHAVES et al., 2011; PEREIRA; WURFEL, 2011; GONCALVEZ; NAPPO, 2015). Por outro, há o seu potencial na predisposição ao uso de outras substâncias, em causar problemas cardíacos (HALL, 2014) e sua capacidade em induzir sintomas psiquiátricos entre usuários de cocaína, principalmente na forma inalada (VALLERSNES et al., 2016). 
Embora a literatura seja substancial sobre o tema, observa-se a necessidade de estudos que explorem como o uso de maconha influencia a dependência de cocaína, as consequências dessa interação e como isso pode ser manejado no tratamento. Estudo explorou os fatores relacionados à mortalidade de pacientes com dependência grave de cocaína, não encontrando relação com o consumo de maconha na ocorrência de óbito (FUSTER et al., 2016). Entretanto, em estudo exploratório com usuários de crack, foram evidenciados resultados insatisfatórios no tratamento ambulatorial desses sujeitos, mostrando associações positivas entre o consumo de maconha e o resultado terapêutico (HSER et al., 2008).

Além do uso associado de outras drogas, há o fenômeno conhecido como "escalada de drogas", ou seja, o início do uso (ou experimentação) de drogas lícitas com transição do consumo para aquelas ilícitas, o que tem sido muito comum entre usuários de cocaína (SELEGHIM; OLIVEIRA, 2013), com importante impacto na gravidade da dependência (KILUK et al., 2013). Estudo avaliou o histórico de pacientes com idade até 30 anos, dependentes de cocaína, e constatou que o início do uso de substâncias psicoativas geralmente se deu com drogas lícitas (tabaco e álcool), em idade precoce e de modo pesado. A maconha tem se destacado por ser a primeira droga ilícita de uso (BRASIL, 2009; RIBEIRO; LARANJEIRA, 2012; SELEGHIM; OLIVEIRA, 2013).

O uso de álcool é frequentemente observado em usuários de cocaína (independentemente da via de administração), por ser a substância mais utilizada por tal grupo (INPAD, 2013; UNODC, 2016). Entretanto, a via de uso da cocaína foi identificada como elemento crucial para a utilização da substância, de modo que os usuários da forma inalada preferem o contexto de grupos para consumo, ou seja, com motivação social, enquanto usuários de crack optam pelo uso mais isolado (MARTINS et al., 2014). Nesse sentido, pressupõe-se que o uso de álcool em grupo de pares, por usuários de cocaína, cesse ao término da reunião social dos indivíduos. No entanto, em usuários de crack, o uso de modo solitário constitui um agravante da dependência, pois pode permanecer por longos períodos na ausência de interferências de fatores externos (RIBEIRO; SANCHEZ; NAPPO, 2010).

Estudo mostrou que usuários de cocaína inalada consomem simultaneamente o álcool como estratégia para controlar a fissura e as emoções, melhorar o desempenho sexual, físico e social, além de minimizar os custos do uso de drogas (BRACHE; STOCKWELL; MACDONALD, 2011).

A combinação do uso de álcool e cocaína também foi apontada como responsável pela menor densidade de mielinização das fibras que compõem a substância branca do SNC (VAN 
SON et al., 2016). A desmielinização neuronal interfere na condução de sinais nos nervos afetados, causando prejuízos na sensação, no movimento e na cognição, ou seja, danifica os processos neurocognitivos (CHEN; ANTHONY, 2004).

A respeito da saúde física, evidências apontam que os desfechos clínicos adversos são três vezes mais frequentes entre usuários de crack quando comparados aos de cocaína inalada. Além disso, tendem a ser mais associados a prejuízos relacionados ao bem-estar emocional, funcionamento social empobrecido e uso de drogas de forma mais grave (CHEN; ANTHONY, 2004; NARVAEZ et al., 2015). Compromete ainda mais essa situação o fato de que a busca por tratamento ocorre apenas em situações agudas, por conseguinte de maior gravidade, na vigência das quais preferem internação e apresentam, posteriormente, baixa adesão ao tratamento ambulatorial (DIAS et al, 2011; PEIXOTO et al, 2010; GALASSI et al., 2016).

Diante de intercorrências clínicas, esses usuários são geralmente encaminhados para unidades hospitalares, tal como observado por Seleghim e Oliveira (2013), que verificaram alta demanda por atendimento de emergência por usuários de crack. Os principais motivos pelos quais esses sujeitos são admitidos nessas unidades são: reações adversas agudas ocasionadas pelo uso da cocaína (FERRI et al, 2004), como traumas físicos por agressão física (VAUGHN et al., 2010), acidentes de trânsito (SCHERER et al., 2016), intercorrências obstétricas (MORANGONI; OLIVEIRA, 2013) e até mesmo complicações do uso, como overdose (RIEZZO et al., 2012; SELEGHIM; OLIVEIRA, 2013).

Com base neste panorama situacional, Silvino et al. (2012) recomendam a implementação de um sistema de notificação sentinela para detecção do agente causal do desfecho clínico e, assim, evitar intervenções restritas ao quadro sintomático observado no momento. Evento sentinela corresponde a eventos que não deveriam ocorrer se os serviços de saúde funcionassem adequadamente (RUTSTEIN, 1976). Assim, danos clínicos, cirurgias não eletivas e doenças secundárias ao uso de drogas representam indicadores de maior gravidade dos casos (SILVINO et al., 2012). Nesse sentido, este sistema de notificação possibilita ampliar as fontes de informações epidemiológicas, uma vez que acessa usuários de cocaína não detectados por serviços ambulatoriais.

Em relação aos danos clínicos relacionados ao uso de cocaína (independentemente da via de uso), as complicações cardiovasculares são responsáveis pela maioria dos casos de overdose (DIAS et al., 2011) e outras complicações, incluindo isquemia e infarto agudo do miocárdio, morte súbita, miocardite, cardiomiopatia, hipertensão, rupturas aórticas e endocardite (MARAJ; FIGUEREDO; MORRIS, 2010). 
A cocaína inalada está mais relacionada com indução de arritmias e dores no peito (MARAJ; FIGUEREDO; MORRIS, 2010), enquanto o crack predispõe os usuários a uma maior incidência de acidentes vasculares cerebrais, tanto isquêmicos quanto hemorrágicos (PETTY et al., 1990). Como a cocaína é um agente simpaticomimético indireto, seu uso aumenta os níveis de dopamina circulante no cérebro, mesmo neurotransmissor também responsável pelo controle do fluxo sanguíneo; dessa forma, o uso de crack, devido às suas características de uso prolongado, leva a uma maior constrição dos vasos e aumento da pressão arterial cerebral (SULZER, 2011).

Complicações renais, principalmente a Insuficiência Renal Aguda (IRA) devido à rabdomiólise, é um desfecho clínico quem vem aumentando significativamente entre dependentes de cocaína. A vasoconstrição severa provoca ruptura de fibras musculares e consequente aumento de células musculares na circulação sanguínea, que causam sobrecarga da filtragem renal (HOSSEINNEZHAD et al., 2011).

Diversas são as complicações respiratórias relacionadas ao uso de cocaína (RIEZZO et al., 2012). Estudo analisou exames de tomografia computadorizada de tórax de usuários de cocaína e identificou, sobretudo, "pulmão de crack", barotrauma, talcose, enfisema bolhoso, pneumonia, infarto pulmonar, embolia séptica e edema pulmonar cardiogênico. (ALMEIDA et al, 2015). O termo "pulmão de crack" refere-se a uma síndrome pulmonar aguda que ocorre após a inalação de cocaína de base livre, havendo associação de febre, hipoxemia, hemoptise, insuficiência respiratória e presença de infiltrados alveolares difusos ricos em eosinófilos (RIEZZO et al., 2012).

Além dos agravos diretos no organismo, o uso de cocaína pode ainda causar implicações clínicas indiretas, por meio de alterações psíquicas - "paranoia" -, ou mesmo pelos prejuízos nos julgamentos das próprias ações, que predispõem os sujeitos a agirem inconsequentemente, sem precauções à saúde física (VOLKOW; KOOB; MCLELLAN, 2016). Os comportamentos sexuais de risco têm sido muito frequentes nesse grupo, principalmente em mulheres que fazem sexo em troca de drogas (CRUZ et al., 2014), aumentando a vulnerabilidade às doenças sexualmente transmissíveis (ex. HIV, hepatite C) (DIEHL et al., 2014). Outro possível desfecho desse comportamento é a gravidez indesejada, sem acompanhamento pré-natal, com elevadas chances de aborto, malformações ou, também, exposição do recém-nascido a síndromes de abstinência neonatal de cocaína, devido à dependência induzida pelo uso ininterrupto da droga durante a gestação (MARANGONI; OLIVEIRA, 2013). 
Acrescentam-se também os prejuízos nos cuidados à saúde, higiene pessoal e permanência em locais insalubres com potencial risco de aquisição de doenças infecciosas quando em situação de rua (CHAVES et al, 2011), complicação de outras doenças crônicas por abandono do tratamento (SANTOS CRUZ et al, 2015), predisposição a situações de risco de vida, incluindo acidentes ou agressões (DIAS et al., 2011; MESQUITA et al, 2011; RIEZZO et al., 2012; PALAMAR; DAVIES; OMPAD, 2015; SCHERER et al, 2016).

A família é outro fator de crucial importância, pois exerce papel fundamental no processo da reabilitação psicossocial do dependente de drogas (BRAUN; DELLAZZANAZANON; HALPERN, 2014), em virtude da sua interação multifacetada nesse contexto. Por um lado, a família pode ser indutora do uso de drogas, por meio de situações de violência intrafamiliar física e psicológica (SELEGHIM et al., 2011). Por outro, pode estar alienada ao tratamento, em decorrência do despreparo, da falta de entendimento e de apoio, de vergonha e preconceito em relação ao uso e à dependência da substância (BRAUN; DELLAZZANAZANON; HALPERN, 2014). Em todos os casos, os familiares sofrem pelas consequências do uso por algum de seus entes, com desestruturação dos papéis dos sujeitos, relações afetivas empobrecidas e isolamentos (SELEGHIM et al., 2011).

Esse pluralismo significativo do convívio entre familiares desafia a prática terapêutica, que é de extrema importância para o processo de reabilitação psicossocial. Estudo internacional com usuários de cocaína em tratamento ambulatorial mostrou que a "Família" foi mencionada por 93,3\% dos entrevistados, como motivação de reversão do quadro problemático e no sentido de contribuir para uma melhor qualidade de vida (MORALESMANRIQUE et al., 2011).

O componente familiar de usuários de crack geralmente tem sido caracterizado por insuficiência de contato parental (SELEGHIM et al., 2011) - o mais prevalecente -, sobretudo ausência paterna no lar (NARVAEZ et al., 2015). Contudo, estudo nacional comparou os danos associados ao aspecto familiar entre usuários de cocaína e crack, não tendo sido observadas diferenças entre os grupos (MOURA et al., 2014). Evidências apontaram que usuários de cocaína inalada obtiveram os melhores resultados na área Família, após início do tratamento (KILUK et al., 2013). Além disso, demostrou-se que a maneira como ocorrem as relações parentais tem sido diferente em cada grupo de usuários, uma vez que, após a mesma intervenção terapêutica, o desfecho foi diferente entre os grupos. Conclui-se, portanto, que a inclusão de familiares no acolhimento e na assistência aos usuários de cocaína contribui para 
mudanças significativas no prognóstico, como apoio mútuo e coesão (BRAUN; DELLAZZANA-ZANON; HALPERN, 2014).

O componente social perpassa todos os demais domínios da vida, uma vez que tem seu papel como agente causador, além de repercutir nas consequências impostas pela dependência de cocaína. Os usuários de drogas, não obstante, apresentam disparidades sociais que afetam negativamente o acesso a serviços de saúde. Fatores sociais e econômicos moldam o comportamento de risco, prejudicando a disponibilidade de recursos, o acesso aos sistemas de previdência social, a marginalização e adesão à medicação (GALEA; VLALOV, 2002).

Quanto aos prejuízos sociais após o uso de drogas, estudo identificou maior fragilidade nas relações sociais, por existir precária e/ou inexistente rede de apoio para a recuperação da origem da família ou de pares de compartilhamento contextual de indivíduos usuários de cocaína (HORTA et al., 2011; BOTTI; MACHADO; TAMEIRÃO, 2014). Há, por exemplo, abandono de práticas rotineiras sociais (OMS, 1993, APA, 2014), afastamento de núcleos sociais, incluindo instituições religiosas e familiar, com receio de estigma (NARVAEZ et al., 2015) e isolamento social (KILUK et al., 2013).

A idade de início e a progressão para uso de outras substâncias psicoativas podem ser avaliados dentre os aspectos relacionados ao componente social, pois, embora seja uma escolha pessoal, é construída em um contexto de convívio compartilhado com pares e, portanto, influenciada por esse meio (GALEA; VLALOV, 2002; BESSA; BOARATI; SCIVOLETTO, 2011). Nesse sentido, os diferentes estágios desse envolvimento com substâncias psicoativas são moldados por um conjunto de fatores de riscos, sou seja, elementos que aumentam a probabilidade de comportamentos com potencial para afetar a saúde em seus componentes biológicos, psicológicos e sociais. Por outro lado, os fatores de proteção seriam aqueles que, ao contrário, diminuiriam tal probabilidade (BESSA; BOARATI; SCIVOLETTO, 2011). De acordo com esse modelo de progressão de consumo, os adolescentes envolvem-se inicialmente com o álcool e/ou tabaco, progridem para a maconha e, posteriormente com drogas mais pesadas, como o crack e a cocaína (DUAILIBI; RIBEIRO; LARANJEIRA, 2008; BRASIL, 2009; SELEGHIM; OLIVEIRA, 2013). Convém salientar, que essa idade de primeiro com crack e/ou cocaína contato tem diminuído nos últimos anos, podendo ocorrer em idades abaixo dos 14 anos de idade, o que aumenta o risco para a dependência (SILVA et al, 2014).

O uso de cocaína inalada se inicia, em média, abaixo dos 18 anos, por influências dos círculos de amizade, relações familiares conflituosas, baixo monitoramento parental, rebeldia e comportamentos antissociais, depressão, uso de drogas pelos pais e ambiente residencial 
urbano (CARROL, 1992; GALEA; VLALOV, 2002; MORALES-MANRIQUE et al., 2011; KPOZEHOUEN et al., 2015). Já o uso crônico é frequente se instala após os 18 anos (BRASIL, 2009, ABDALLA et al., 2014), geralmente progredindo para o uso de crack (DUNN; LARANJEIRA, 1999; KILUK et al., 2013; ABDALLA et al., 2014)

Entre os usuários de crack, observa-se um subgrupo de indivíduos mais velhos (SANTOS CRUZ et al., 2013; HEINZ et al., 2009), que geralmente iniciaram o uso da droga influenciados pelas características dos contextos sociais, como a maior acessibilidade dentro das comunidades desfavorecidas, ou por cônjuges ou parceiros afetivos (RIBEIRO; LARANJEIRA, 2012; SELEGHIM te al., 2011; SELEGHIM; OLIVEIRA, 2013), após consumo prévio de cocaína inalada e outras substâncias lícitas (BRASIL, 2009; SELEGHIM; OLIVEIRA, 2013). De acordo com Roy et al. (2017), os usuários de crack possuem chances aumentadas em engajarem-se em um padrão de consumo em binge (70\%) quando comparados aos usuários de cocaína inalada (9\%), podendo permanecer em média 48 horas em uso ininterrupto da droga, razão pelo qual possuem maior predisposição a situações de moradia de rua.

Dependendo da região do Brasil, a prevalência de usuários de crack, que transitam pelos grandes centros urbanos sem residência fixa, varia de 31\% a 62\% (SANTOS CRUZ et al., 2013). Além, de não receberem atenção qualificada para o tratamento da dependência da droga, esses indivíduos, potencializam a exposição a fatores de risco, uma vez que, convivem em ambientes insalubres, com precárias condições de higiene e segurança. Estudos com usuários de crack em situação de rua elencou exemplos da alta vulnerabilidade presente no cotidiano diário, tais como, situações de agressões físicas, danos clínicos associados ao uso indiscriminado de benzodiazepínicos, prejuízos resultantes do comportamento sexual de risco, ausência de recursos para cuidado pessoal, incluindo alimentação e higiene (RIBEIRO; SANCHEZ; NAPPO, 2010; CRUZ et al., 2014). Outra pesquisa, realizada com usuários de drogas em situação de rua, mostrou que essa população apresenta maior incidência de problemas físicos e mentais, além de alta taxa de mortalidade, que é três vezes maior quando comparada com a daqueles que não usavam drogas e também viviam nas ruas (DRAKE; OSHER; WALLACH, 1991; CRUZ et al., 2014).

A literatura científica evidencia uma ampla diversidade de motivos que levam o indivíduo a buscar ou manter-se em situação de rua (RIBEIRO; LARANJEIRA, 2012; RAUPP; ADORNO, 2011; CHAVES et al., 2011). Além das características ligadas ao próprio uso da droga (RAUPP; ADORNO, 2011; SELEGHIM; OLIVEIRA, 2013; ROY et al., 2017) 
e a agregação aos pares para o ritual do uso de crack (CHAVES et al., 2011; RIBEIRO; SANCHEZ; NAPPO, 2010), observa-se também, a presença de comorbidades psiquiátricas, rompimentos e perdas de vínculos familiares (SELEGHIM et al., 2011, MOURA et al., 2014), desemprego crônico, pobreza extrema e ausência de suporte social (NARVAEZ et al., .2015; DRAKE; OSHER; WALLACH, 1991). Toledo et al. (2017) também acrescentou a escolha pela situação de rua como uma fuga da opressão familiar no espaço de vivencia, que muitas vezes recorre a internação compulsória como alternativa de tratamento do uso problemático de drogas.

O componente social também pode ser protetor, segundo revelou estudo comparativo entre usuários de cocaína em ambiente de tratamento e outros que conviviam na comunidade. A pesquisa identificou níveis mais graves de dependência e menor suporte social entre aqueles que estavam sob vigilância terapêutica (CIBA, 1982). Entretanto, outro estudo identificou que o contato social favoreceu o consumo de outras drogas e maior envolvimento em atos criminais (CARROL, 1992).

Em relação aos elementos de valorização econômica e educação, estudos anteriores documentaram a elevada evasão escolar entre os usuários de cocaína (MARTINS et al., 2014), principalmente de crack (BASTOS; BERTOLONI, 2013). O uso de cocaína (independentemente da via de uso), devido aos fatores neuroquímicos de manutenção compulsiva do uso, prejudica o papel economicamente ativo do sujeito.

A maioria dos estudos realizados com usuários de crack confirmou a pregressa vulnerabilidade sociocontextual que caminha paralelamente ao baixo nível de escolaridade, que consequentemente dificulta a inserção do indivíduo no mercado de trabalho (VAUGHN et al., 2010; BASTOS, BERTOLONI, 2013; MOURA et al., 2014; PALAMAR; DAVIES; OMPAD, 2015). Nesse contexto, os usuários de crack têm sido os mais marginalizados, pois apresentam baixo nível de escolaridade, (GUINDALINI et al., 2006; BASTOS, BERTOLONI, 2014) em relação aos de cocaína inalada (KILUK et al., 2013), e possuem mais chances de depender de programas assistenciais governamentais (PALAMAR; DAVIES; OMPAD, 2015). Estudo nacional identificou que usuários de crack $(85,2 \%)$ possuíam apenas a educação primária e 14,8\% atingiram o ensino secundário. Entretanto, 41,2\% dos não usuários de crack concluíram o nível primário, enquanto 53,6\% finalizaram o secundário (NARVAEZ et al., 2015).

Em relação aos usuários de cocaína inalada, evidências apontaram que esses tendem a permanecer maior período de dias consecutivos em abstinência (KILUK et al., 2013), o que 
permite inferir que sejam capazes de se dedicar mais aos vínculos empregatícios e frequentar a escola. Embora ainda não estejam claras as circunstâncias sociais que moldam o comportamento e influenciam o uso de drogas, é notório que as desvantagens sociais concentram-se entre as minorias que congregam os piores determinantes sociais (GALEA; VLALOV, 2002). Nesse sentido, a menor exposição a situações de vulnerabilidade psicossocial entre usuários de cocaína inalada pode contribuir significativamente para redução de problemas que envolvem escolaridade, emprego e renda (VAUGHN et al., 2010; KILUK et al., 2013).

Entretanto, estudo nacional apontou que a classificação econômica e a escolaridade não interferem na intensidade (quantidade e frequência) do uso de crack (FREIRE et al., 2012). Com base nesse estudo, pressupõe-se que a dependência química ultrapasse a condição financeira obtida por recursos próprios, via terceiros e até mesmo advinda de meios ilegais, pois os usuários sempre encontram formas de adquirir cocaína. Corroborando esta afirmação, estudo multicêntrico realizado com usuários de crack identificou a diversidade de busca de fontes alternativas para obtenção de renda entre dependentes da droga. Na cidade do Rio de Janeiro, por exemplo, verificou-se o envolvimento em prostituição (17\%), atividades criminais $(11 \%)$ e tráfico de drogas $(9 \%)$. O mesmo estudo identificou tais práticas em Salvador, entretanto, com maior prevalência do tráfico de drogas (14\%), seguido por prostituição (8\%) e atividades criminais (6\%) (SANTOS CRUZ et al., 2013).

Quanto ao envolvimento em atividades ilegais por usuários de cocaína (ambas as vias), os resultados de estudos são unânimes no registro de maior prevalência de usuários de crack envolvidos em situações de violência (NUTT et al., 2007; VAUGHN et al., 2010; PALAMAR; DAVIES; OMPAD, 2015;). Por exemplo, estudo realizado na América do Norte mostrou que usar crack aumenta as chances de ser preso, além da forte associação entre múltiplas prisões e o aumento do consumo de droga, incluindo o uso recente (PALAMAR; DAVIES; OMPAD, 2015).

De acordo com resultados de uma escala internacional, que mensurou os potenciais danos relacionados ao uso de diversas drogas, o uso de cocaína foi considerado a segunda maior causa de agravos físicos decorrentes da violência $(2,33 \%)$ e a segunda maior causadora de prejuízos sociais $(2,17 \%)$ (NUTT et al., 2007). As principais atividades ilegais entre os usuários de cocaína descritas na literatura referem-se ao grande número de condenações por atos criminais (PALAMAR; DAVIES; OMPAD, 2015), problemas com a justiça (pensão alimentícia, furtos de propriedade, carros ou pessoa física) (RIBEIRO; SANCHEZ; NAPPO, 
2010; RIBEIRO; LARANJEIRA, 2012), produção e tráfico de drogas (SANTOS CRUZ et al., 2013), homicídios, agressão física e/ou sexual (RIBEIRO; SANCHEZ; NAPPO, 2010; VAUGHN et al., 2010) e direção de veículo sob efeito de droga (SCHERE et al., 2016).

A relação entre crime e comportamento sexual foi avaliada em 587 usuários de drogas em tratamento, a maioria de cocaína (inalada e fumada) (66,4\%). O estudo mostrou que a chance de envolvimento em crimes violentos aumentou em três vezes entre os indivíduos que tiveram relação sexual com algum profissional do sexo (DIEHL et al, 2016). Ainda nessa amostra, o perfil de usuários foi predominantemente do sexo masculino, com baixo nível de escolaridade, católicos e não caucasianos, dos quais 24,4\% possuíam antecedentes de problemas com a justiça, cometeram crimes $(26,8 \%)$, apresentaram comportamentos violentos $(19,3 \%)$ e envolvimento com o tráfico de drogas $(12,2 \%)$.

No que tange ao comportamento violento, especificamente a agressão física, os usuários de crack apresentaram chances dobradas de envolvimento nesse tipo de problema quando comparados aos de cocaína inalada, principalmente a violência doméstica $(34,5 \%)$ (VAUGHN et al., 2010). Observou-se que o risco de comportamentos violentos/homicídio está fortemente associado ao nível de gravidade da dependência (GUINDALINI ET AL., 2006), ao padrão de consumo de cocaína (HSHER, 2008) e ao tempo de consumo da droga (DIEHL et al, 2016). Outra comparação em relação à via de uso da cocaína mostrou que os usuários se diferenciaram entre os índices de crimes contra a pessoa (crack 54,3\% versus cocaína 14,9\%) e contra propriedades (crack 56,5\% versus cocaína 16,2\%) (DIEHL et al, 2016).

Contudo, torna-se importante ressaltar que os usuários de crack têm sido o subgrupo mais vitimado por ações agressivas, conforme constatado nos achados de Ribeiro et al. (2010). A associação entre uso de crack e convívio em ambientes que propiciam brigas e possíveis risco de vida vem sendo documentada na literatura, sobretudo pela prática de delitos no contexto do uso, com destaque para a vitimização (violência sofrida e perpetrada) (TOLEDO; GÓNGORA; BASTOS, 2017), os aspectos psicossociais ligados ao uso de droga (GEBARA et al., 2015) e os déficits cognitivos causados pelo uso pesado da droga que resultam em prejuízos da percepção de perigo (GALEA; VLAHOV, 2002; CHASIN; SILVA; CARVALHO, 2008).

Quanto aos índices de condenações por envolvimentos em atos criminais, usuários de crack apresentaram maior número de prisões prévias em relação aos usuários de cocaína (KILUK, 2013). Segundo estudo brasileiro, os principais motivos das prisões têm sido o 
envolvimento com tráfico e a produção de drogas (17-41\%), seguidos por invasão/furto de propriedade particular (6-25\%) e envolvimento em situações de violências (por exemplo, agressão) (SANTOS CRUZ et al., 2013). Por outro lado, usuários de cocaína inalada, embora também exibam elevadas taxas de condenação, apresentaram menor tempo de encarceramento (cerca de 6 meses) (HSER et al., 2008), possivelmente em virtude da menor gravidade das infrações por eles praticadas.

As taxas de mortalidade são geralmente altas nessa população, cerca de sete vezes maiores em relação à população geral (DIAS et al., 2001; RIBEIRO et al, 2006), o que evidencia a vulnerabilidade e vitimização desse grupo diante das adversidades contextuais e dos riscos do ambiente (GALEA; VLALOV, 2002). Há evidências sugerindo que o ambiente de marginalização social aumenta potencialmente as chances de o indivíduo sofrer agressão, praticada pelos próprios usuários, ou, também, pelo abuso de autoridade de policiais (RIBEIRO; SANCHEZ; NAPPO, 2010).

Quanto aos aspectos psiquiátricos, as alterações do estado psíquico em usuários de cocaína (independente da via de uso) têm sido muito comuns, da mesma forma que são esperados efeitos da euforia (VOLKOW; KOOB; MCLELLAN, 2016). O próprio quadro sintomático do binge de uso da substância provoca uma diversidade de reações psiquiátricas, com início estimulante (agitação psicomotora, anorexia, craving e agressividade), que finaliza com um quadro sindrômico de exaustão (fadiga; sentimentos depressivos, insônia) (GAWIN; KLEBER, 1986). Contudo, os usuários de crack apresentam maior intensidade dos efeitos adversos psíquicos (NARVAEZ et al., 2015) e são mais propensos ao desenvolvimento da tolerância (CHEN; ANTHONY, 2004; NUTT et al, 2007).

Atualmente, em virtude da crescente identificação de transtornos psiquiátricos em usuários com diagnóstico de dependência de cocaína (GAWIN; KLEBER, 1986; FORD et al., 2009), observou-se maior número de estudos explorando essa sobreposição de transtornos, ou seja, a comorbidade ou duplo diagnóstico. De um lado, evidências confirmam a influência do uso de drogas no desenvolvimento de transtornos psiquiátricos (VOLKOW; KOOB; MCLELLAN, 2016), uma vez que indivíduos com dependência grave de cocaína possuem mais chances de apresentar transtorno de personalidade e do humor. Por outro lado, pesquisas também constataram que indivíduos com diagnóstico de hiperatividade apresentam seis vezes mais chances de usar cocaína (EDWARD; KHANTZIAN, 1985).

No contexto do cuidado a usuários de drogas, o mascaramento de sintomas da dependência por comorbidades psiquiátricas (FORD et al., 2009; NARVAEZ et al., 2015) e a 
coexistência de múltiplos diagnósticos de dependência de drogas (BRASIL, 2009) desafiam os profissionais de saúde na implementação de intervenções terapêuticas eficientes, adequadas às reais necessidades do paciente. A complexidade dessa relação pode ser exemplificada no estudo de seguimento, que observou melhoras dos sintomas depressivos em usuários de cocaína com elevados índices de depressão após controle dos sintomas de abstinência (MOURA, 2001). Nesse estudo, convém ressaltar, que a própria abstinência da cocaína ocasiona sintomas depressivos, por meio de déficits de estímulos dopaminérgicos e ativação do sistema de estresse cerebral (VOLKOW; KOOB; MCLELLAN, 2016).

Além disso, a prevalência de transtornos mentais é maior entre os usuários de crack se comparados aos de cocaína inalada, sendo a depressão e a ansiedade as comorbidades psiquiátricas mais recorrentes. Tal achado, porém, parece estar menos relacionado ao modo de consumo (fumado ou inalado), e mais à gravidade da dependência e aos fatores psicossociais combinados. Cabe dizer que a vulnerabilidade para o desenvolvimento da dependência é ainda maior quando os usuários possuem um segundo transtorno mental. O consumo de crack compromete também os diversos campos da vida - trabalho, relacionamentos afetivos, família - e constitui um importante fator de risco para a infecção pelo HIV (FALCK; WANG; CARLSON, 2008).

Os diagnósticos mais prevalentes em usuários de crack foram os relacionados ao uso de álcool, esquizofrenia, transtornos esquizotípicos e delirantes e, por fim, o transtorno do humor (VAUGHN et al., 2010; BOTTI; MACHADO; TAMEIRÃO, 2014). Estudo mostrou que a presença de transtorno de personalidade antissocial entre usuários de cocaína inalada em tratamento também era muito comum (KILUK et al., 2013).

$\mathrm{O}$ aspecto psiquiátrico também pode ser avaliado por meio da busca e do acesso ao tratamento. Em relação à busca, identificou-se, no final da década de 1990, aumento na demanda de usuários de cocaína e crack em serviços de saúde. Nos serviços ambulatoriais, essa população ocupava entre 50 a 80\% das vagas (BASTOS, et. al. 1988, SCHIVOLETO, 1997), no caso das internações, e pacientes internados pelas consequências do uso do crack representavam entre 14 e 22\% das internações (CARLINI, NAPO, GALDUROZ, 1993). Estudo revelou que o grupo de usuários de crack foi o que menos buscou assistência clínica e psiquiátrica (NARVAEZ et al., 2015), incluindo o tratamento para a dependência de drogas (HORTA et al., 2011), mesmo diante de problemas de saúde física e psicológica (SANTOS CRUZ et al., 2013). Contudo, a presença de transtornos psiquiátricos em usuários de cocaína 
inalada foi o principal motivo para a busca por tratamento, e não propriamente pelo uso da droga (ROUNSAVILLE, et. al., 1991). 


\section{JUSTIFICATIVA}

Diversas evidências destacam a diversidade de fatores que permeiam a delimitação do nível da gravidade da dependência do uso de cocaína, entre eles, a influência das vias de uso da droga (fumada ou inalada), além do potencial deletério do uso do crack nas diferentes esferas da vida do sujeito, em virtude dos diferentes padrões de consumo.

No entanto, a proposta terapêutica dispendida na prática assistencial em serviços ambulatoriais para a dependência de cocaína e seus derivados no país nem sempre tem considerado a via de uso da droga na prática clínica. Muitas vezes, as abordagens são mais generalistas, outras pouco satisfazem totalmente as reais demandas do indivíduo, o que contribui para manutenção de barreiras na adesão ao tratamento e baixo impacto no processo da reabilitação psicossocial. Nota-se, portanto, que o sucesso das intervenções terapêuticas que incorporam o componente psicossocial do sujeito carece, primeiramente, de uma compreensão integral dos fatores que circundam a dependência, além de entendimento dos diversos efeitos decorrentes desse uso.

Devido à complexidade dos problemas relacionados ao fenômeno das drogas, as políticas nacionais de saúde direcionadas aos diversos grupos da população devem estar voltadas para a oferta de estratégias diversificadas na implementação de programas preventivos. Devem focar, sobretudo, a promoção de saúde, com vistas a prevenir ou minimizar os fatores de riscos e as possíveis consequências sociais e de saúde.

Acredita-se que, por meio da presente investigação, considerando a complexidade da adesão e manutenção do tratamento dos usuários de drogas, bem como sua relevância no âmbito da promoção da saúde mental, seja possível atender à premente necessidade de conhecer a dimensão e as interfaces peculiares dos agravos relacionados ao uso de cocaína (inalada e fumada) nos aspectos biopsicossociais. Espera-se que os resultados possam auxiliar o processo de sistematização da assistência de enfermagem, de modo a favorecer a reabilitação e o suporte social dessa clientela que utiliza os serviços substitutivos, como o caso do CAPS-ad, além de contribuir para melhorias na qualidade de vida desses indivíduos. 
Objetivos $\mid \mathbf{5 1}$

4 objetívos 


\section{OBJETIVO}

Avaliar os fatores sociais e de saúde associados à gravidade da dependência de cocaína (fumada e inalada) entre usuários em tratamento ambulatorial.

\section{1 Objetivos específicos}

- Identificar as características sociodemográficas de usuários de cocaína (inalada e fumada) em tratamento.

- Avaliar as características de usuários de cocaína (inalada e fumada) em relação a emprego e sustento, uso de álcool e de drogas, situação legal, familiar, social, saúde física e mental.

- Avaliar o padrão de consumo de cocaína (inalada e fumada) e outras drogas em usuários em tratamento.

- Avaliar as possíveis relações entre gravidade da dependência de usuários de cocaína (inalada e fumada) e emprego e sustento, uso de álcool e de drogas, situação legal, familiar, social, saúde física e mental. 
Hi póteses $\mathbf{5 3}$

5 Hipóteses 


\section{HIPÓTESES}

As seguintes hipóteses serão testadas:

\section{Hipótese I}

H0 - Não há diferença dos níveis de gravidade da dependência entre os usuários de crack e os de cocaína.

H1 - Há diferença dos níveis de gravidade da dependência entre os usuários de crack e os de cocaína.

\section{Hipótese II}

H0 - Não há diferenças dos problemas relacionados a emprego e sustento, uso de álcool e de drogas, situação legal, familiar, social, saúde física e mental entre os usuários de cocaína e crack.

H1 - Há diferenças dos problemas relacionados a emprego e sustento, uso de álcool e de drogas, situação legal, familiar, social, saúde física e mental) entre os usuários de cocaína e crack. 


\section{MATERIAL E MÉTODOS}

\subsection{Delineamento metodológico do estudo}

Trata-se de um estudo transversal, de abordagem quantitativa.

\section{2 Local do estudo}

O estudo foi realizado no CAPS-ad II, situado no município de Ribeirão Preto, São Paulo. Esse dispositivo de atenção à saúde integra a Rede de Atenção em Saúde Mental instituída pelo Ministério da saúde, a qual representa um marco político e assistencial da Reforma Política em Saúde Mental no país (BRASIL, 2004).

O CAPS-ad II esta conveniado ao SUS, e integra à rede de serviços em saúde mental ou atenção psicossocial no município, composta pelo Hospital Santa Tereza, Ambulatório Regional de Saúde Mental, Caps-i, Caps-II, CapsIII, UBSs , UBDs, PSFs e UPA. Por dia, o presente serviço atende aproximadamente 50 pacientes e, em média, 40 casos novos por mês (CAPS-AD II, 2017).

O CAPS-ad II funciona diariamente, ofertando uma assistência intensiva até a não intensiva aos usuários com idade acima de 18 anos de ambos os sexos. Entre as modalidades de atendimento, tem se o atendimento individual (medicamentoso, psicoterápico e orientação) e em grupo (acolhimento, oficinas terapêuticas), visitas domiciliares, assistência médica e psiquiátrica, atividades comunitárias enfocando a integração do usuário do serviço na comunidade e sua inserção familiar e social, além de atividades de reinserção social, enfocando passeios, atividades culturais e oficinas de economia solidária (CAPS-AD II, 2017).

Todo o atendimento é realizado por uma equipe profissional multidisciplinar, composta por enfermeiro, psicólogo, terapeuta ocupacional, médico psiquiatra, assistente social, professor de educação física, nutricionista, auxiliares de enfermagem e administrativo, que trabalham de modo integrado e com uma proposta terapêutica em comum (CAPS-AD II, 2017).

O usuário chega ao serviço por demanda espontânea ou por meio de encaminhamento oferecido pela rede de assistência municipal - tanto pela rede de saúde quanto de assistência social e jurídica. Em um primeiro momento, o indivíduo é avaliado por um profissional, que realiza a anamnese com a finalidade de conhecer o tipo de droga, padrão de uso, possíveis sinais de síndrome de abstinência e gravidade da dependência. Esta avaliação é destinada 
àqueles que chegam pela primeira vez ao serviço. Após a avaliação de triagem o sujeito é inserido no serviço em conformidade com as suas demandas e seguindo as propostas de um plano terapêutico previamente discutido com a equipe multiprofissional (CAPS-AD II, 2017)..

O enfermeiro, por sua vez, desempenha diversas atividades na equipe de saúde do CAPS-ad (BRASIL, 2004). Além das práticas comuns da profissão, que se adequaram ao modelo psicossocial, desenvolve atividades administrativas e assistenciais, supervisão da medicação, cuidado com a higiene pessoal, treinamento do pessoal da enfermagem e de outros profissionais e observação dos usuários não inseridos em atividades terapêuticas. Este profissional também verifica ações específicas ao cuidado psicossocial, como atividades de acolhimento, atendimento individualizado, oficinas terapêuticas, grupos terapêuticos, assembleias, reunião de equipe, reuniões de coordenadores dos Serviços de Saúde Mental, visitas domiciliares, acompanhamento em consultas (com abordagens motivacionais, redução de danos e prevenção de recaída), e participa de atividades de lazer/socialização (festas, passeios e jogos) (KANTORSKI et al., 2010).

No Brasil, as diretrizes nacionais e políticas de saúde mental norteiam, desde 2001, a assistência à saúde, mais próxima ao ambiente de convívio, de indivíduos com dependência de substâncias psicoativas, por ser este um passo fundamental para o acesso e acolhimento desses sujeitos e seus familiares nos serviços de saúde, e por considerar que muitos problemas podem ter resolutividade nesse nível de atenção (BRASIL, 2004).

\subsection{Participantes do estudo}

A amostra foi composta por 160 indivíduos em tratamento para dependência de drogas no Centro de Atenção Psicossocial - álcool e drogas (CAPS-ad II).

Constituíram critérios de elegibilidade: ter idade igual ou superior a 18 anos e ser usuário de crack e/ou cocaína.

Foram excluídos indivíduos que apresentaram sintomas de abstinência grave ou efeitos agudos do uso de substância no momento da entrevista, além de sintomas psiquiátricos graves (déficits cognitivos graves, sintomas psicóticos evidentes, alteração do estado de consciência, agitação psicomotora com necessidade de contenção). Para mensuração desses sintomas utilizou-se a Brief Psychiatric Rating Scale - BPRS-A (ANEXO A).

\section{Brief Psychiatric Rating Scale (BPRS-A)}


A versão utilizada no presente estudo foi a BPRS-A com "âncoras" (WOERNER; MANUZZA; KANE, 1988). Esta versão ancorada possui definições operacionais para cada um dos graus de gravidade, diferentemente de sua versão original criada em 1962 por Overall e Gorham, que era muito subjetiva na interpretação dos seus resultados. A BPRS -A foi traduzida para o português por Romano e Elkis (1996).

A BPRS-A é uma escala de avaliação composta de 18 itens que abordam preocupação somática, ansiedade, retraimento emocional, desorganização conceitual, sentimento de culpa, tensão, maneirismos e postura, grandiosidade, humor depressivo, hostilidade, desconfiança, comportamentos alucinatórios, retardo motor, conteúdo de pensamento incomum, afeto embotado, excitação e desorientação (WOERNER; MANUZZA; KANE, 1988; ROMANO; ELKIS, 1996).

Obtém-se a pontuação final pela somatória de cada resposta de acordo com a gravidade dos sintomas observados pelo pesquisador ou relatados pelo entrevistado. Cada item psicopatológico possui cinco níveis de respostas, que variam de 0 (zero), que significa ausência ou não observância de sintomas, a 4 (quatro), que corresponde ao maior nível de gravidade dos sintomas (WOERNER; MANUZZA; KANE, 1988).

Para fins deste estudo, foram considerados isoladamente os escores atribuídos a cada item, de modo que qualquer item com valor igual a 4 (maior gravidade) justificava a exclusão do indivíduo. Em relação aos níveis intermediários, considerou-se o escore total da BPRS-A, tendo sido excluídos os sujeitos com pontuação superior a 16 pontos. Estabeleceu-se essa nota de corte mediante revisão da literatura, embora não haja consenso específico (ELKIS et al., 2000).

\subsubsection{Recrutamento da amostra}

O contato inicial com os potenciais participantes do estudo ocorreu durante as atividades terapêuticas de rotina do serviço, ou mesmo após o atendimento por algum profissional membro da equipe multidisciplinar, seja por meio do atendimento individual (triagem), seja via grupo de acolhimento. A primeira aproximação com cada participante foi mediada por um profissional da equipe. Nessa primeira conversa, os participantes foram apresentados ao pesquisador e, posteriormente, esclarecidos sobre o objetivo e procedimento no estudo. 
Obteve-se a amostra por meio de cálculo amostral, sob erro de 7\%, com nível de significância de $95 \%$. Assim, de um total de 808 indivíduos admitidos no serviço no período da pesquisa, estimou-se entrevistar 158.

Na figura 3 podem ser visualizados os detalhes do processo de recrutamento dos participantes elegíveis para a pesquisa.

PARTICIPANTES (n)

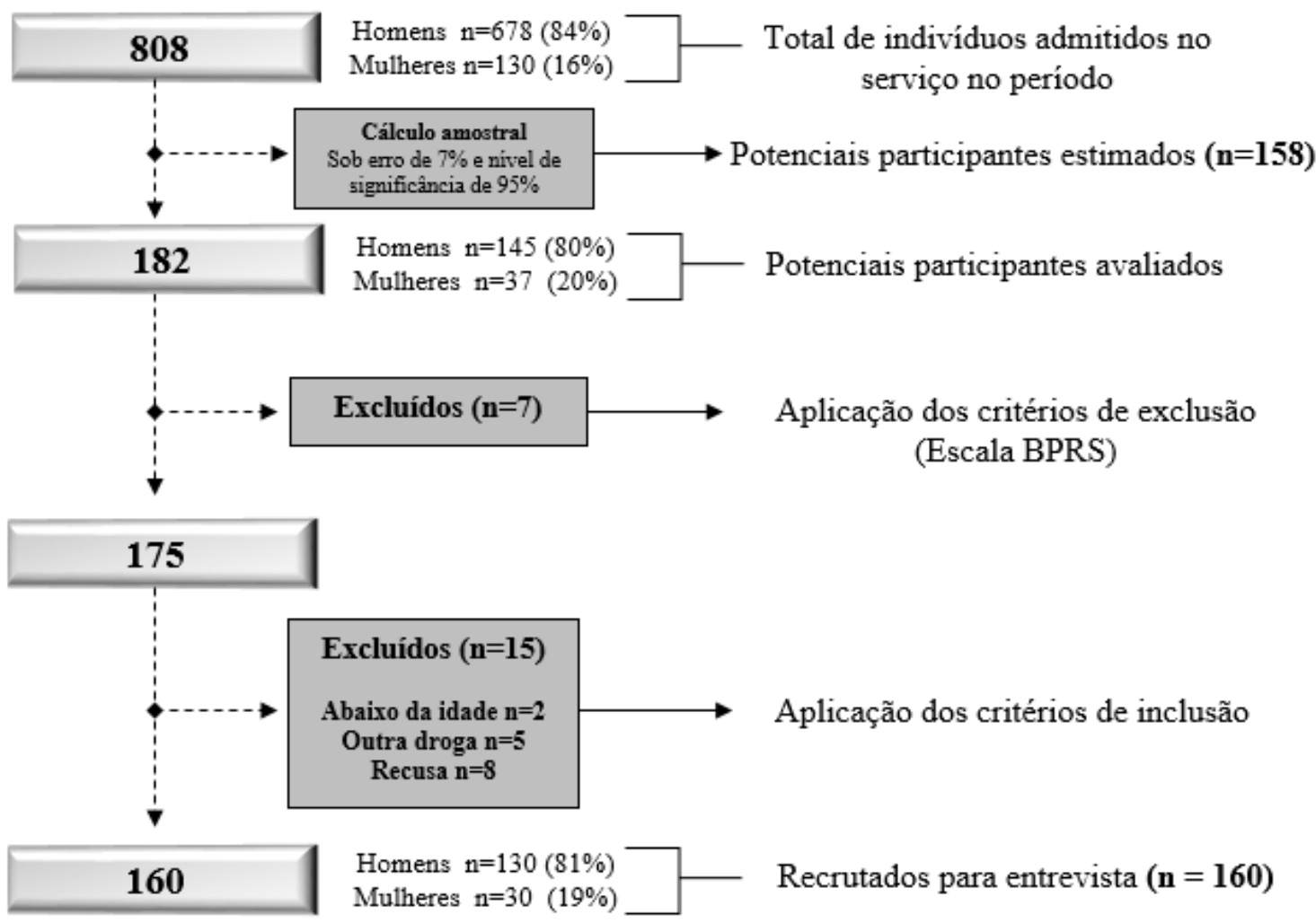

Figura 3. Fluxograma das etapas de recrutamento dos participantes do estudo

\subsection{Procedimentos para a coleta de dados}

\subsubsection{Entrevista}

As entrevistas foram realizadas exclusivamente pela pesquisadora no período de julho de 2013 a julho de 2014 e, tendo em vista a dinâmica do funcionamento do CAPS-ad, não ocorreram imediatamente após a confirmação da elegibilidade, mas conforme a disponibilidade dos indivíduos, procedendo o agendamento, para que não houvesse compatibilidade de 
horários com a programação terapêutica. Para tanto, a pesquisadora permaneceu na unidade em dias pré-agendados com a equipe multiprofissional, em período integral.

Os participantes foram convidados a entrar em uma sala reservada no próprio serviço, para orientações gerais, esclarecimentos sobre os objetivos do estudo e apresentação dos instrumentos de coleta de dados. Nesse momento ocorreu a aplicação da escala BPRS-A, a partir de observação e questionamento sobre os sintomas psiquiátricos. Para tanto, utilizou-se uma linguagem acessível para facilitar o entendimento, resguardando os preceitos éticos dos participantes. Cada entrevista teve duração aproximada de 50 minutos.

Vale ressaltar que poucos casos foram excluídos quando utilizada a BPRS-A ( $n=7)$. Nessas situações, atentou-se para importância de dar um feedback a esses sujeitos, mediante diálogo terapêutico, interrompendo a entrevista e com eles permanecendo até a próxima atividade no serviço.

Em relação aos preceitos ético, humano e moral, a entrevista clínica ocorreu em um contexto de respeito, acolhimento e continência dos aspectos emocionais dos entrevistados. Necessário ressaltar que as demandas psicológicas e os questionamentos que afloraram no decorrer das entrevistas foram manejados pela pesquisadora, conforme preconizam os princípios do Relacionamento - Interpessoal (FUREGATO, 2006), a fim de proporcionar o bem-estar e reduzir possíveis sofrimentos decorrentes do resgate de histórias de vida e contexto do uso de drogas.

\subsection{Instrumentos de coleta de dados}

O instrumento de coleta de dados (ANEXO B) foi composto por cinco questionários e escalas que mensuram a severidade dos efeitos resultantes do consumo de cocaína e outras drogas (Quadro 5).

- Informações sociodemográficas

- Addiction Severity Index (ASI-6)

- Short Alcohol Dependence Data (SADD)

- Severity of Dependence Scale (SDS)

- Cocaine Craving Questionnaire - Brief (CCQ-B) - Versão brasileira

- Alcohol Use Disorders Identification Test - Consumption (AUDIT-C)

- Brief Psychiatric Rating Scale (BPRS-A)

Quadro 6. Composição do instrumento de coleta de dados. 


\subsubsection{Informações sociodemográficas}

As características sociodemográficas foram avaliadas com base nas seguintes informações: idade, sexo, etnia relatada, estado civil, escolaridade, situação ocupacional, religião e renda.

\subsubsection{Addiction Severity Index (ASI)}

O Addiction Severity Index (ASI) é um instrumento de entrevista semiestruturada que avalia amplamente e de forma multidimensional o contexto de vida do indivíduo com problemas relacionados a abuso e/ou dependência de substâncias psicoativas. Devido a essa peculiaridade, o instrumento foi traduzido para diversas línguas e utilizado em várias populações (MCLELLAN et al., 2006).

O instrumento foi criado por Thomas McLellan em 1979, no Center for Studies of Addiction, na Filadélfia, EUA. Desde então, mudanças no perfil das populações e avanços no conhecimento sobre a dependência e seu tratamento evidenciam novos limites que exigem constantes atualizações e adequações (DENIS; CACCIOLA; ALTERMAN, 2013). A versão atual da escala é a de número seis (ASI - 6) (CACCIOLA et al., 2011), a qual foi traduzida e validada para o contexto brasileiro (KESSLER et al., 2007; KESSLER et al., 2012).

Em virtude da reconhecida importância desta escala e da sua aplicabilidade no manejo na terapêutica clínica, a Secretaria Nacional de Políticas sobre Drogas (SENAD) financiou sua validação no Brasil, por meio de convênio entre a comunidade científica, coordenada pelos pesquisadores Felix Kessler e Flavio Pechansky, e o Governo Federal. A orientadora da presente investigação, Profa. Dra. Sandra Cristina Pillon, participou do treinamento para sua validação no país, bem como solicitou, pessoalmente, autorização para sua utilização (DOMINGOS, 2012).

O instrumento compreende informações relacionadas a sete áreas de funcionamento da vida, a saber: (1) médica; (2) emprego; (3) aspectos legais; (4) aspectos familiares; (5) aspectos sociais; (6) psiquiátricos; (7) uso de álcool e outras drogas. Cada área possui questões objetivas que mensuram o número, a extensão e a duração dos sintomas - problemas 
durante toda a vida do indivíduo e, especificamente, nos últimos 30 dias que antecedem a avaliação (MCLELLAN et al., 2006; KESSLER et al., 2007; KESSLER, 2011; CACCIOLA et al., 2011). A compilação das respostas de cada área problemática resulta em um escore final que pode variar entre 0-100 pontos, sendo que escores mais altos indicam maior gravidade do problema. As áreas aspectos familiares e aspectos sociais resultam em três pontuações diferentes: (1) problema familiar e social; (2) apoio familiar e social e (3) problema com crianças (KESSLER et al., 2012).

$\mathrm{Na}$ presente pesquisa, para recodificação e leitura das variáveis, utilizou-se a Syntax (Statistical Program of Social Science (SPSS) versão 19, for Windows e Microsoft Excel), elaborada pela equipe de pesquisadores coordenada pelo Prof. Dr. Pechansky, que resulta nos escores finais da ASI-6. Esse material está disponível na homepage do Observatório Brasileiro de Informações sobre Drogas (OBID), juntamente com o Manual de Aplicação e o Guia de Orientação da escala (DOMINGOS, 2012).

A escala apresenta resultados que evidenciam a sua aplicabilidade, por exemplo, de um estudo multicêntrico realizado em quatro estado brasileiros que comparou a presença de comorbidades psiquiátricas e a gravidade de problemas psicossociais em três grupos de dependentes de drogas (crack, cocaína e outras drogas). Os resultados mostraram que usuários de crack e cocaína têm maior engajamento em eventos violentos e atividades ilegais, além de baixo desempenho de fatores relacionados à qualidade de vida (KESSLER, 2011).

\subsubsection{Short Alcohol Dependence Data (SADD)}

O Short Alcohol Dependence Data é um questionário que mensura o grau de dependência relacionado ao consumo de álcool. Dentre as características que demonstram sua aplicabilidade na prática clínica, estão: (I) fácil utilização em pacientes que procuram ajuda para problemas relacionados ao uso de álcool, (II) mensuração do nível de gravidade da dependência, (III) mostra-se sensível em todas as fases da dependência, (IV) sensível às mudanças ao longo do tempo, (V) e relativamente livre de influência sociocultural (RAISTRICK; DAVIDSON, 1983).

Para sua utilização no contexto brasileiro, o instrumento foi traduzido e validado para o idioma português pelos pesquisadores Jorge e Mansur. A versão utilizada possui 15 itens relacionados ao uso de álcool, com quatro possibilidades de resposta para cada item: (0) Nunca; (1) Poucas vezes; (2) Muitas vezes; (3) Sempre. Obtém-se o resultado final pelo 
somatório dos pontos, que classifica os indivíduos nas seguintes categorias: 1 a 9 pontos = Dependência leve; 10 a 19 pontos = Dependência moderada; 20 a 45 pontos = Dependência grave (JORGE; MANSUR, 1989).

Apesar da versão original do instrumento possuir mais de 20 anos, estudo recente avaliou a consistência interna e dimensionalidade do instrumentou e comprovou que ele mantém as características iniciais. A pesquisa foi realizada com 167 pacientes de um hospital geral, e os resultados finais mostraram elevada consistência interna, sugerindo que as questões convergem para um constructo único (ROSA-OLIVEIRA et al., 2011).

\subsubsection{Severity of Dependence Scale (SDS)}

A Severity of Dependence Scale (SDS) é um instrumento de aplicação rápida e prática, utilizado para rastreamento da gravidade da dependência por usuários de diferentes tipos de drogas, inclusive a cocaína. O conteúdo das questões engloba componentes psicológicos da dependência, tais como prejuízos no controle sobre o consumo da droga e preocupações e ansiedade relacionadas ao uso (GOSSOP et al., 1995).

A versão utilizada na presente pesquisa foi validada no Brasil por Ferri e colaboradores (2000). A SDS é composta por cinco itens que fornecem uma pontuação indicativa no nível de gravidade; cada item é pontuado numa escala de quatro pontos (pontuação de 0 a 3 ). Os quatro primeiros itens da escala possuem as seguintes opções de resposta: (0) nunca ou quase nunca; (1) algumas vezes; (2) sempre; (3) quase sempre. Já o quinto e último item apresentam as seguintes opções: (0) não é difícil; (1) difícil; (2) muito difícil; (3) impossível (FERRI et al., 2000).

A pontuação total é obtida por meio da soma dos cinco itens. Os escores totais da SDS variam de zero a 15 pontos, e quanto maior a pontuação, maior o nível de gravidade da dependência (GOSSOP et al., 1995; FERRI et al., 2000). Evidências mostram que, apesar do instrumento não contemplar integralmente a complexidade dos problemas relacionados ao uso de drogas, seus itens são suficientes para identificar a presença ou ausência de dependência, seguindo os mesmos critérios de classificação do Diagnostic and Statistical Manual of Mental Disorders (DSM) (KAYE, DARKE, 2002; GONZALEZ-SAIZ et al., 2009).

Assim, como não há estudos brasileiros que delimitam um ponto de corte para a SDS, adotou-se a nota de corte utilizada por Ferri e colaboradores (2004) em estudo com 332 usuários de altas doses de cocaína e derivados. A pesquisadora identificou pontuação média na 
SDS de 9,9 pontos. A maioria dos entrevistados era composta de homens (90\%), usuários de cocaína na forma aspirada, fumada (crack) e, em menor quantidade, pela via injetável (20\%), com idade média de 26,5 anos e uso de longo prazo (aproximadamente 7,6 anos).

Assim, no presente estudo, um escore total inferior a oito no somatório dos itens foi classificado como dependência leve, e uma pontuação superior ou igual a nove como dependência grave.

\subsubsection{Cocaine Craving Questionnaire - Brief (CCQ-B)}

Este instrumento é utilizado na prática clínica para mensurar a intensidade do desejo por droga (fissura) que, consequentemente, direciona o indivíduo para um novo uso da substância, ou seja, mensura a intensidade do craving (SILVEIRA et al., 2006). Segundo a Associação Psiquiátrica Americana, o craving é considerado a questão central da dependência, e sua importância foi reconhecida ao ser incluído como item diagnóstico no Diagnostic and Statistical Manual of Mental Disorders - version V (APA, 2014).

A escala original, denominada Cocaine Craving Questionnaire Now (CCQ-Now), foi desenvolvida em 1993, por Tifany e colaborares. O questionário inicial possuía 45 itens que avaliavam o consumo de drogas em cinco domínios: desejo de usar cocaína, antecipação do resultado positivo, alívio dos sintomas de abstinência ou afeto negativo, intenção e planejamento para uso e falta de controle deste uso (TIFFANY et al., 1993). Essa versão foi testada e validada no Brasil em 2006 (SILVEIRA et al., 2006).

A versão utilizada neste estudo consiste de 10 itens da escala original, que permitem uma rápida aplicação com resultados úteis tanto para a clínica como para a pesquisa. Aplicouse essa versão reduzida em uma amostra de 247 usuários de drogas internados, principalmente cocaína, e obteve-se, em sua validação original, alfa de Cronbach $=0.90$, indicando ser um instrumento adequado para avaliar a fissura (craving) (SUSSNER et al., 2006).

Considerando a efetividade da mensuração do craving na avaliação e no tratamento dessa clientela, essa versão reduzida do instrumento passou por uma adaptação transcultural para o português, para melhor se adequar ao contexto de uso no Brasil (ARAUJO; PEDROSO; CASTRO, 2010). Após a validação semântica, o questionário foi avaliado quanto às suas propriedades psicométricas em usuários de crack hospitalizados. Os instrumento se divide em dois fatores: o fator 1 representa o constructo craving, e o fator 2, a falta de controle do uso de cocaína e crack (ARAUJO et al., 2011). O padrão de respostas segue uma 
escala do tipo Likert contendo cinco pontos, que variam de "discordo totalmente" a "concordo totalmente".

A escala pode ser avaliada com base no seu escore total (com os itens 4 e 7 invertidos e somados aos demais). Dos pontos do fator 1 - somam-se todos os itens, exceto 4 e 7 , e, no fator 2 - somam-se os itens 4 e 7 já invertidos (ARAUJO et al., 2011). O escore final do CCQ-Brief é obtido pelo somatório dos pontos de todos os itens, compondo um escore total. Os pontos de corte da escala podem ser observados no quadro 6.

\begin{tabular}{lccc}
\hline CLASSIFICAÇÃO & PONTUAÇÃO & FATOR $\mathbf{~}$ & FATOR 2 \\
\hline Mínimo & 0 a 11 pontos & 0 a 7 pontos & 0 a 2 pontos \\
Leve & 12 a 16 pontos & 8 a 9 pontos & 3 a 4 pontos \\
Moderado & 17 a 22 pontos & 10 a 11 pontos & 5 a 6 pontos \\
Grave & 23 ou mais pontos & 12 ou mais pontos & 7 ou mais pontos \\
\hline
\end{tabular}

Fonte: ARAUJO et al., 2011.

Quadro 7. Classificação e pontuação do CCQ-B - versão brasileira adaptada para o crack.

\subsubsection{Alcohol Use Disorders Identification Test - Consumption (AUDIT-C)}

O AUDIT-C trata-se de uma versão reduzida do AUDIT original (WHO, 2001), composto apenas pelos três primeiros itens. A sua versão original tem sido utilizada como um instrumento de rastreamento em serviços de saúde, desenvolvido pela OMS em 1993. Esse teste permite a detecção precoce de quatro diferentes padrões de consumo de bebidas alcoólicas, além de fornecer subsídios para aplicação da intervenção breve em serviços da atenção primária (WHO, 2001). Embora se trate de um instrumento reduzido, estudo de revisão identificou que a AUDIT-C mantém bons índices de confiabilidade, sensibilidade e especificidade, mesmo em amostras diferentes, algumas vezes superiores aos da escala original (MENESES-GAYA et al., 2009).

Para sua leitura, quanto maior a pontuação no AUDIT-C, maior é a probabilidade de que o consumo esteja afetando a saúde e segurança do sujeito. A pontuação total é mensurada numa escala de 0-12 (pontuação 0 = não consome álcool), a pontuação se diferencia em relação ao gênero, sendo positiva para homens ( $\geq 4$ pontos) e mulheres ( $\geq 3$ pontos). Classifica-se consumo de risco baixo/moderado (pontuação entre 1 e 5 pontos) e risco alto/severo (acima de 6 pontos) (WHO, 2001). 


\subsection{Aspectos Éticos}

O estudo seguiu os preceitos éticos que envolvem pesquisa com seres humanos de acordo com a Resolução 196/96, do Conselho Nacional de Ética em Pesquisa (CONEP).

Para o desenvolvimento do trabalho de campo solicitou-se autorização formal ao coordenador do CAPS-ad de Ribeirão Preto - SP (ANEXO C) e à Comissão de Avaliação de Projetos de Pesquisa da Secretaria Municipal de Saúde do de Ribeirão Preto (ANEXO D). Posteriormente, o projeto de pesquisa foi submetido à apreciação pelo Comitê de Ética e Pesquisa com Seres Humanos da Escola de Enfermagem de Ribeirão Preto - Universidade de São Paulo, recebendo parecer favorável no dia 02.10.2013 (Processo 412/837) (ANEXO E).

Todos os participantes foram esclarecidos quanto aos objetivos da pesquisa, o anonimato dos dados gerados, o direito de encerrarem a participação na pesquisa a qualquer momento, a ausência de riscos físicos, sociais ou psicológicos. Também foi informado o caráter voluntário da participação no estudo, sem a geração de lucros econômicos ou algum tipo de vantagem no seu tratamento no serviço de saúde. Todos os participantes assinaram o Termo de Consentimento Livre e Esclarecido (TCLE) em duas vias, ficando com uma cópia e outra de posse da pesquisadora.

\subsection{Análise estatística}

Um banco de dados foi elaborado no Statistical Program of Social Science (SPSS) versão 19, for Windows. As variáveis categóricas foram extraídas da ASI-6 foram: (1) informações sociodemográficas, (2) educação, emprego e finanças, (3) eventos de violência e envolvimento criminal, (4) vínculo familiar e relacionamentos sociais, (4) condição física e atenção à saúde clínica, (5) sintomas psiquiátricos e atenção saúde mental, (6) uso de drogas na vida, (7) frequência de uso de cocaína, sintomas abstinência, fissura e dinheiro gasto para aquisição da droga, (8) e os escores das escalas SDS, SADD, AUDIT-C, CCQ-B que foram estratificados. A variável independente foi o uso de cocaína (inalada e fumada).

Os resultados foram apresentados por meio por meio de números (n) e porcentagens (\%). Para a análise estatística foi utilizando o teste Chi-quadrado $\left(\chi^{2}\right)$.

$\mathrm{Na}$ análise de regressão logística o uso da cocaína (fumada ou inalada) foi a variável independente, controlada por todas as covariáveis com valores de $\mathrm{p} \leq 0,05$. Assim obteve o Odds ratio (OR) (bruto e ajustado) e respectivos intervalos de $95 \%$ de confiança (IC). 
Os testes de normalidade Kolmogorov Smirnov e Shapiro Wilk foram utilizados para avaliar a simetria das variáveis contínuas, mediante a rejeição da normalidade, aplicou-se o Teste de Mann Whitney $U$ para comparação das médias. As variáveis contínuas foram: situação de moradia nos últimos seis meses (dias); idade de início do uso de cocaína (fumada e inalada) e outras substâncias psicoativas, o período em anos de uso crônico (três ou mais vezes por semana) de álcool e outras substâncias psicoativas, o número de dias de uso de cocaína (fumada e inalada) e outras substâncias psicoativas nos últimos 30 dias e os escores finais das áreas da ASI.

Para análise exploratória das variáveis contínuas resultantes da pontuação final dos instrumentos AUDIT, SADD, SDS e CCQ-B e relação às áreas da ASI (droga; álcool; família; medico; emprego; psiquiátrico; criminal; suporte social e familiar; problema social e familiar), realizou-se a análise de correlação de Spearman, após confirmação da não normalidade na distribuição dos dados, com índice de significância estabelecido em 0,025. O coeficiente de correlação de Spearman avalia a relação entre duas variáveis não paramétricas em uma função monótona (se um número aumenta, o mesmo acontece com o outro, ou viceversa), sem fazer suposições sobre a distribuição de frequências das variáveis (FERGUSON; TAKANE, 1986; PAGANO, GAUVREAU, 2004). 
Resultados | 68

7 Resultados 


\section{RESULTADOS}

\subsection{Características sociodemográficas e uso de cocaína (inalada e fumada)}

A amostra foi composta por 160 usuários de cocaína, sendo $78(48,8 \%)$ de cocaína inalada e $82(51,2 \%)$ de crack. A Tabela 1 apresenta as características sociodemográficas desses usuários, caracterizados predominantemente por serem do sexo masculino 126 (78,8\%), adultos ( $\geq 30$ anos) 94 (58,8\%), não caucasianos 104 (65,0\%), viverem sozinhos 131 (81,9\%), possuírem baixo nível de escolaridade ( $\leq 8$ anos de estudo) 97 (60,6\%), não praticarem religião 110 $(68,8 \%)$, estarem desempregados 64 (40\%), apenas 27 (16,9\%) em situação de moradores de rua e com histórico de algum tratamento anterior $93(58,1 \%)$

As diferenças na amostra envolveram faixa etária ( $\geq 30$ anos) (crack 58,5\% versus cocaína 41,5\%, $\left.\chi^{2}(1)=4,808, p=0,028\right)$, anos de estudo ( $\leq 8$ anos) (crack $57,7 \%$ versus cocaína $\left.42,3 \% \chi^{2}(1)=4,143, p=0,042\right)$, estado ocupacional (desempregados) (crack 62,5\% versus cocaína 37,5\% $\chi^{2}(4)=14,655, p=0,005$ ), situação de morador de rua (crack 81,5\% versus cocaína $\left.18,5 \% \chi^{2}(1)=11,882, p<0,001\right)$ e histórico de tratamentos anteriores (crack 59,1\% versus cocaína 40,9 $\left.\chi^{2}(1)=5,533, p=0,019\right)$ (Tabela 1 ). 
Tabela 1. Características sociodemográficas e uso de cocaína (fumada e inalada) $(\mathrm{N}=160)$. Ribeirão Preto, 2015.

\begin{tabular}{|c|c|c|c|c|c|c|c|}
\hline & \multicolumn{4}{|c|}{ Cocaína } & \multirow{2}{*}{\multicolumn{2}{|c|}{ Total }} & \multirow{3}{*}{ Valor de $p$} \\
\hline & \multicolumn{2}{|c|}{ Fumada } & \multicolumn{2}{|c|}{ Inalada } & & & \\
\hline & $\mathbf{n}$ & $\%$ & $\mathbf{n}$ & $\%$ & $\mathbf{n}$ & $\%$ & \\
\hline \multicolumn{8}{|l|}{ Sexo } \\
\hline Masculino & 64 & 50,8 & 62 & 49,2 & 126 & 100,0 & $\chi^{2}(1)=0,049$ \\
\hline Feminino & 18 & 52,9 & 16 & 47,1 & 34 & 100,0 & $p=0,824$ \\
\hline \multicolumn{8}{|l|}{ Faixa etária } \\
\hline 18-29 anos & 27 & 40,9 & 39 & 59,1 & 66 & 100,0 & $\chi^{2}(1)=4,808$ \\
\hline$\geq 30$ anos & 55 & 58,5 & 39 & 41,5 & 94 & 100,0 & $p=0,028^{*}$ \\
\hline \multicolumn{8}{|l|}{ Etnia } \\
\hline Caucasiano & 29 & 51,8 & 27 & 48,2 & 56 & 100,0 & $\chi^{2}(1)=0,010$ \\
\hline Não caucasiano & 53 & 51,0 & 51 & 49,0 & 104 & 100,0 & $p=0,921$ \\
\hline \multicolumn{8}{|l|}{ Estado civil } \\
\hline Sozinho & 66 & 50,4 & 65 & 49,6 & 131 & 100,0 & $\chi^{2}(1)=0,218$ \\
\hline União & 16 & 55,2 & 13 & 44,8 & 29 & 100,0 & $p=0,640$ \\
\hline \multicolumn{8}{|l|}{ Anos de estudo } \\
\hline$\leq 8$ anos & 56 & 57,7 & 41 & 42,3 & 97 & 100,0 & $\chi^{2}(1)=4,143$ \\
\hline$>8$ anos & 26 & 41,3 & 37 & 58,7 & 63 & 100,0 & $p=0,042^{*}$ \\
\hline \multicolumn{8}{|l|}{ Prática religiosa } \\
\hline Sim & 20 & 40,0 & 30 & 43,6 & 50 & 100,0 & $\chi^{2}(1)=3,684$ \\
\hline Não & 62 & 56,4 & 48 & 60,0 & 110 & 100,0 & $p=0,055$ \\
\hline \multicolumn{8}{|l|}{ Estado ocupacional } \\
\hline Empregado & 13 & 36,1 & 23 & 63,9 & 36 & 100,0 & \multirow{5}{*}{$\begin{array}{c}\chi^{2}(4)=14,655 \\
p=0,005^{*}\end{array}$} \\
\hline Emprego - informal & 1 & 11,1 & 8 & 88,9 & 9 & 100,0 & \\
\hline Bico & 25 & 59,5 & 17 & 40,5 & 42 & 100,0 & \\
\hline Desempregado & 40 & 62,5 & 24 & 37,5 & 64 & 100,0 & \\
\hline Aposentado & 3 & 33,3 & 6 & 66,7 & 9 & 100,0 & \\
\hline \multicolumn{8}{|l|}{ Situação de rua } \\
\hline Sim & 22 & 81,5 & 5 & 18,5 & 27 & 100,0 & $\chi^{2}(1)=11,882$ \\
\hline Não & 60 & 45,1 & 73 & 54,9 & 133 & 100,0 & $p<0.001^{*}$ \\
\hline \multicolumn{8}{|c|}{ Antecedentes de tratamentos } \\
\hline Sim & 55 & 59,1 & 38 & 40,9 & 93 & 100,0 & $\chi^{2}(1)=5,533$ \\
\hline Não & 27 & 40,3 & 40 & 59,7 & 67 & 100,0 & $p=0,019^{*}$ \\
\hline
\end{tabular}

Nota: Teste qui-quadrado $\left(\chi^{2}\right)$. *valor de $p \leq 0.05(\mathrm{~N}=160)$ 


\section{Uso de cocaína: educação, emprego e finanças}

A amostra foi composta por indivíduos com renda mensal inferior a um salário mínimo 120 (75\%), baixa certificação profissional 117 (73,1\%), renda incompatível com as despesas $107(66,8 \%)$ e desprovidos de dependentes financeiros 115 (71,8\%), auxílio financeiro de benefício ou aposentadoria 33 (20,6\%) e auxílio financeiro: dinheiro ilegal 13 $(8,1 \%)$. Os dados estão apresentados na Tabela 2.

Os usuários de crack diferenciaram-se por apresentarem baixa renda mensal $(\leq 1 \mathrm{SM})$ (crack 59,2 \% versus cocaína 40,8\%, $\chi^{2}(1)=12,041 p<0,001$ ) e renda incompatível com as despesas (crack 59,8\% versus cocaína 40,2\%, $\chi^{2}(1)=9,480, p=0,002$ ), auxílio financeiro de familiares ou amigos ( $\operatorname{crack} 66,7 \%$ versus cocaína 33,3\%, $\chi^{2}(1)=3,955, p=0,047$ ), quando comparados aos usuários de cocaína inalada. 
Tabela 2. Informações relacionadas à educação, emprego e finanças, segundo os usuários de cocaína (fumada e inalada) $(\mathrm{N}=160)$. Ribeirão Preto, 2015.

\begin{tabular}{|c|c|c|c|c|c|c|c|}
\hline & \multicolumn{4}{|c|}{ Cocaína } & \multirow{2}{*}{\multicolumn{2}{|c|}{ Total }} & \multirow{3}{*}{ Valor de $p$} \\
\hline & \multicolumn{2}{|c|}{ Fumada } & \multicolumn{2}{|c|}{ Inalada } & & & \\
\hline & $\mathbf{n}$ & $\%$ & $\mathbf{n}$ & $\%$ & $\mathbf{n}$ & $\%$ & \\
\hline \multicolumn{8}{|l|}{ Renda mensal } \\
\hline$\leq 1 \mathrm{SM}^{1}$ & 71 & 59,2 & 49 & 40,8 & 120 & 100 & $\chi^{2}(1)=12,041$ \\
\hline$>1 \mathrm{SM}$ & 11 & 27,5 & 29 & 72,5 & 40 & 100 & $p<0,001^{*}$ \\
\hline \multicolumn{8}{|c|}{ Certificação profissional } \\
\hline Sim & 22 & 51,2 & 21 & 48,7 & 43 & 100 & $\chi^{2}(1)=, 000$ \\
\hline Não & 60 & 51,3 & 57 & 48,8 & 117 & 100 & $p=0,989$ \\
\hline \multicolumn{8}{|c|}{$\begin{array}{l}\text { Renda compatível para as } \\
\text { despesas }\end{array}$} \\
\hline Sim & 18 & 34,0 & 35 & 66,0 & 53 & 100 & $\chi^{2}(1)=9,480$ \\
\hline Não & 64 & 59,8 & 43 & 40,2 & 107 & 100 & $p=0,002 *$ \\
\hline \multicolumn{8}{|c|}{ Dependente financeiro } \\
\hline Sim & 20 & 44,4 & 25 & 55,6 & 45 & 100 & $\chi^{2}(1)=1,161$ \\
\hline Não & 62 & 53,9 & 53 & 46,1 & 115 & 100 & $p=0,281$ \\
\hline \multicolumn{8}{|c|}{$\begin{array}{l}\text { Auxílio financeiro: } \\
\text { familiares ou amigos }\end{array}$} \\
\hline Sim & 22 & 66,7 & 11 & 33,3 & 33 & 100 & $\chi^{2}(1)=3,955$ \\
\hline Não & 60 & 47,2 & 67 & 52,8 & 127 & 100 & $p=0,047^{*}$ \\
\hline \multicolumn{8}{|c|}{$\begin{array}{l}\text { Auxílio financeiro: } \\
\text { benefício ou aposentadoria }\end{array}$} \\
\hline Sim & 19 & 47,5 & 21 & 52,5 & 40 & 100 & $\chi^{2}(1)=0,300$ \\
\hline Não & 63 & 52,5 & 57 & 47,5 & 120 & 100 & $p=0,584$ \\
\hline \multicolumn{8}{|c|}{$\begin{array}{l}\text { Auxílio financeiro: } \\
\text { dinheiro ilegal }\end{array}$} \\
\hline Sim & 9 & 49,7 & 4 & 50,3 & 13 & 100 & $\chi^{2}(1)=1,831$ \\
\hline Não & 73 & 69,2 & 74 & 30,8 & 147 & 100 & $p=0,176$ \\
\hline
\end{tabular}

Nota: Teste qui-quadrado $\left(\chi^{2}\right)$. *valor de $p \leq 0.05(\mathrm{~N}=160)$. SM = Salário Mínimo. 1. Conversão reais (BR) para dólares (EUA): $\mathrm{R} \$ 937,00$ reais ( $\$ 298,00$ dólares).

\section{Uso de cocaína e envolvimento em situações de violência}

Em relação ao envolvimento em situações de violência, da amostra total, uma minoria foi condenada por crimes tanto antes dos 18 anos $13(8,1 \%)$ quanto após esta idade $22(13,7 \%)$, roubos 27 (16,8\%), sofreram agressão por algum conhecido 65 (40,6\%) e por desconhecido 31 $(19,3 \%)$, presenciaram homicídio/agressão 50 (31,2\%) e sofreram abuso sexual $13(8,1 \%)$, dados apresentados na tabela 3.

Os usuários de cocaína fumada diferenciaram-se por envolvimento predominantemente em práticas de roubos (crack 74,1\% versus cocaína $25,9 \%, \chi^{2}(1)=6,773, p=0,009$ ), terem 
sofrido agressões físicas por pessoas conhecidas (crack 64,6\% versus cocaína 35,4\%, $\chi^{2}(1)=$ 7,827, $p=0,005)$ e desconhecidas (crack $71 \%$ versus cocaína $\left.29 \% \chi^{2}(1)=5,983, p=0,014\right)$, além de presenciaram situações de agressão e/ou homicídio (crack 64\% versus cocaína 36\%, $\left.\chi^{2}(1)=4,732, p=0,030\right)$ (Tabela 3).

Tabela 3. Informações sobre envolvimento em situações de violência, segundo os usuários de cocaína (fumada e inalada) $(\mathrm{N}=160)$. Ribeirão Preto, 2015.

\begin{tabular}{|c|c|c|c|c|c|c|c|}
\hline & \multicolumn{4}{|c|}{ Cocaína } & \multirow{2}{*}{\multicolumn{2}{|c|}{ Total }} & \multirow{3}{*}{ Valor de $p$} \\
\hline & \multicolumn{2}{|c|}{ Fumada } & \multicolumn{2}{|c|}{ Inalada } & & & \\
\hline & $\mathbf{n}$ & $\%$ & $\mathbf{n}$ & $\%$ & $\mathbf{n}$ & $\%$ & \\
\hline \multicolumn{8}{|c|}{ Preso antes dos 18 anos } \\
\hline Sim & 10 & 76,9 & 3 & 23,1 & 13 & 100 & $\chi^{2}(1)=3,733$ \\
\hline Não & 72 & 49,0 & 75 & 51,0 & 147 & 100 & $p=0,053$ \\
\hline \multicolumn{8}{|c|}{ Preso após 18 anos } \\
\hline Sim & 15 & 68,2 & 7 & 31,8 & 22 & 100 & $\chi^{2}(1)=2,927$ \\
\hline Não & 67 & 48,6 & 71 & 51,4 & 138 & 100 & $p=0,087$ \\
\hline \multicolumn{8}{|c|}{ Roubou alguém (6 meses) } \\
\hline Sim & 20 & 74,1 & 7 & 25,9 & 27 & 100 & $\chi^{2}(1)=6,773$ \\
\hline Não & 62 & 26,6 & 71 & 53,4 & 133 & 100 & $p=0,009 *$ \\
\hline \multicolumn{8}{|c|}{ Agrediu alguém (6 meses) } \\
\hline Sim & 23 & 62,2 & 14 & 37,8 & 37 & 100 & $\chi^{2}(1)=2,294$ \\
\hline Não & 59 & 48,0 & 64 & 52,0 & 123 & 100 & $p=0,130$ \\
\hline \multicolumn{8}{|c|}{ Sofreu agressão (conhecido) } \\
\hline Sim & 42 & 64,6 & 23 & 35,4 & 65 & 100 & $\chi^{2}(1)=7,827$ \\
\hline Não & 40 & 42,1 & 55 & 57,9 & 95 & 100 & $p=0,005^{*}$ \\
\hline \multicolumn{8}{|c|}{$\begin{array}{l}\text { Sofreu agressão } \\
\text { (desconhecido) }\end{array}$} \\
\hline Sim & 22 & 71,0 & 9 & 29,0 & 31 & 100 & $\chi^{2}(1)=5,983$ \\
\hline Não & 60 & 46,5 & 69 & 53,5 & 129 & 100 & $p=0,014^{*}$ \\
\hline \multicolumn{8}{|c|}{ Presenciou agressão/homicídio } \\
\hline Sim & 32 & 64,0 & 18 & 36,0 & 50 & 100 & $\chi^{2}(1)=4,732$ \\
\hline Não & 50 & 45,5 & 60 & 54,5 & 110 & 100 & $p=0,030^{*}$ \\
\hline \multicolumn{8}{|c|}{ Sofreu abuso sexual } \\
\hline Sim & 8 & 61,5 & 5 & 38,5 & 13 & 100 & $\chi^{2}(1)=0,599$ \\
\hline Não & 74 & 50,3 & 73 & 49,7 & 147 & 100 & $p=0,439$ \\
\hline
\end{tabular}

Nota: Teste qui-quadrado $\left(\chi^{2}\right)$. *valor de $p \leq 0.05(\mathrm{~N}=160)$ 


\section{Uso de cocaína: vínculo familiar e relacionamentos sociais}

Da amostra, poucos participantes mantinham contato pessoal com amigos 42 (26,2\%), mas sustentavam esse contato com familiares 121 (75,6\%). Foram, em maioria, encaminhados para tratamento por algum familiar ou amigo 139 (86,8\%), possuíam filhos 78 (48,7\%) e necessitavam de apoio para manutenção do tratamento 108 (67,5\%), dados disponíveis na tabela 4. Os usuários diferenciaram-se apenas em relação à manutenção de contato pessoal com amigos (crack 33,3\% versus cocaína $66,7 \%, \chi^{2}(1)=7,317, p=0,007$ ).

Tabela 4. Informações sobre vínculo familiar e relacionamentos sociais, segundo os usuários de cocaína (fumada e inalada) $(\mathrm{N}=160)$. Ribeirão Preto, 2015.

\begin{tabular}{|c|c|c|c|c|c|c|c|}
\hline & \multicolumn{4}{|c|}{ Cocaína } & \multirow{2}{*}{\multicolumn{2}{|c|}{ Total }} & \multirow{3}{*}{ Valor de $p$} \\
\hline & \multicolumn{2}{|c|}{ Fumada } & \multicolumn{2}{|c|}{ Inalada } & & & \\
\hline & $\mathbf{n}$ & $\%$ & $\mathbf{n}$ & $\%$ & $\mathbf{n}$ & $\%$ & \\
\hline \multicolumn{8}{|c|}{ Contato amigo (pessoalmente) } \\
\hline Sim & 14 & 33,3 & 28 & 66,7 & 42 & 100 & $\chi^{2}(1)=7,317$ \\
\hline Não & 68 & 57,6 & 50 & 42,4 & 118 & 100 & $p=0,007^{*}$ \\
\hline \multicolumn{8}{|c|}{ Contato familiar (pessoalmente) } \\
\hline Sim & 59 & 48,8 & 62 & 51,2 & 121 & 100 & $\chi^{2}(1)=1,232$ \\
\hline Não & 23 & 59,0 & 16 & 41,0 & 39 & 100 & $p=0,267$ \\
\hline \multicolumn{8}{|c|}{ Possui filhos } \\
\hline Sim & 40 & 51,3 & 38 & 48,7 & 78 & 100 & $\chi^{2}(1)=, 000$ \\
\hline Não & 42 & 51,2 & 40 & 48,8 & 82 & 100 & $p=0,994$ \\
\hline \multicolumn{8}{|c|}{$\begin{array}{l}\text { Encaminhamento tratamento } \\
\text { (familiar ou amigo) }\end{array}$} \\
\hline Sim & 71 & 51,1 & 68 & 48,9 & 139 & 100 & $\chi^{2}(1)=0,012$ \\
\hline Não & 11 & 52,4 & 10 & 47,8 & 21 & 100 & $p=0,911$ \\
\hline \multicolumn{8}{|c|}{ Necessita apoio para tratamento } \\
\hline Sim & 60 & 55,6 & 48 & 44,4 & 108 & 100 & $\chi^{2}(1)=2,466$ \\
\hline Não & 22 & 42,3 & 30 & 57,7 & 52 & 100 & $p=0,116$ \\
\hline
\end{tabular}

Nota: Teste qui-quadrado $\left(\chi^{2}\right)$. ${ }^{\text {valor de } p \leq 0.05(\mathrm{~N}=160)}$ 


\section{Uso de cocaína: situação de moradia nos últimos seis meses}

Quanto à situação de moradia nos últimos seis meses, 5 (3,1\%) moraram em serviços de internação para tratamento da dependência, $5(3,1 \%)$ em hospital geral, 14 (8,7\%) em hospital psiquiátricos, $3(1,8 \%)$ em penitenciárias, $10(6,2 \%)$ em comunidades terapêuticas, $33(20,6 \%)$ em albergues, e uma boa parcela, 65 (40,6\%), em situação de rua.

Os usuários de crack passaram o maior número de dias morando em locais como albergues (crack 40,2 $\pm 48,0$ dias versus cocaína 60,4 $\pm 53,7$ dias, $p=0,010$ ) e em situação de rua

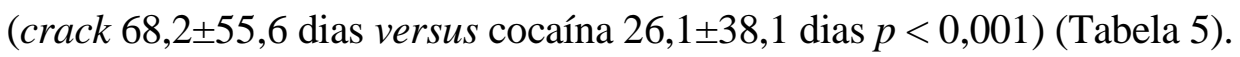

Tabela 5. Informações sobre situação de moradia nos últimos seis meses, segundo os usuários de cocaína (fumada e inalada) $(\mathrm{N}=160)$. Ribeirão Preto, 2015.

\begin{tabular}{|c|c|c|c|c|c|c|}
\hline \multirow[b]{3}{*}{ LOCAIS } & \multicolumn{4}{|c|}{ Cocaína } & \multirow{3}{*}{$\begin{array}{c}\text { Total } \\
\mathbf{N}\end{array}$} & \multirow{3}{*}{$\begin{array}{c}\text { Valor de } \\
p\end{array}$} \\
\hline & \multicolumn{2}{|r|}{ Fumada } & \multicolumn{2}{|r|}{ Inalada } & & \\
\hline & $\mathbf{n}$ & $\begin{array}{l}\text { Média dias } \\
\text { (DP) }\end{array}$ & $\mathbf{n}$ & $\begin{array}{l}\text { Média dias } \\
\text { (DP) }\end{array}$ & & \\
\hline $\begin{array}{l}\text { Internação para } \\
\text { dependência de drogas }\end{array}$ & 4 & $48,7( \pm 33,2)$ & 1 & $10(-)$ & 5 & 0,185 \\
\hline Hospital Geral & 3 & $14,0( \pm 9,6)$ & 1 & $30(-)$ & 4 & 0,347 \\
\hline Hospital Psiquiátrico & 6 & $33,3( \pm 22,5)$ & 8 & $45,8( \pm 26,2)$ & 14 & 0,486 \\
\hline Penitenciária & 2 & $105,0( \pm 63,6)$ & 1 & $90(-)$ & 3 & 0,591 \\
\hline $\begin{array}{l}\text { Comunidade } \\
\text { Terapêutica }\end{array}$ & 8 & $86,2( \pm 63,0)$ & 2 & $40( \pm 28,2)$ & 10 & 0,057 \\
\hline Albergue & 24 & $40,2( \pm 48,0)$ & 9 & $60,4( \pm 53,7)$ & 33 & $0,010 *$ \\
\hline $\begin{array}{l}\text { Situação de rua sob } \\
\text { efeito de cocaína }\end{array}$ & 46 & $68,2( \pm 55,6)$ & 19 & $26,1( \pm 38,1)$ & 65 & $<0,001^{*}$ \\
\hline
\end{tabular}

Nota: Teste Mann Whitney $U$. *valor de $p \leq 0.05(\mathrm{~N}=160)$. 


\section{Uso de cocaína: condição física e atenção à saúde clínica}

Do total da amostra, 30 (18,7\%) (crack 63,3\% versus cocaína 36,7\%) possuíam doenças crônicas não transmissíveis e 11 (6,8\%) (crack 36,4\% versus cocaína 63,6\%) alguma doença crônica transmissível e apenas 88 (55\%) (crack 51,1\% versus cocaína 48,9\%) tinham realizado o teste de HIV. Além disso, 20 (12,5\%) utilizaram serviço de emergência/urgência (crack 65\% versus cocaína 35\%) e $24(15 \%)$ compareceram a consultas ambulatoriais, nos últimos seis meses.

Não foram observadas diferenças estatisticamente significativas em relação à condição física e atenção à saúde clínica entre os usuários de cocaína $(p>0,05)$ (Tabela 6).

Tabela 6. Informações sobre condição física e atenção à saúde clínica, segundo os usuários de cocaína (fumada e inalada) $(\mathrm{N}=160)$. Ribeirão Preto, 2015.

\begin{tabular}{|c|c|c|c|c|c|c|c|}
\hline & \multicolumn{4}{|c|}{ Cocaína } & \multirow{2}{*}{\multicolumn{2}{|c|}{ Total }} & \multirow{3}{*}{ Valor de $p$} \\
\hline & \multicolumn{2}{|c|}{ Fumada } & \multicolumn{2}{|c|}{ Inalada } & & & \\
\hline & $\mathbf{n}$ & $\%$ & $\mathbf{n}$ & $\%$ & $\mathbf{n}$ & $\%$ & \\
\hline \multicolumn{8}{|c|}{ Doença crônica } \\
\hline Sim & 19 & 63,3 & 11 & 36,7 & 30 & 100 & $\chi^{2}(1)=2,158$ \\
\hline Não & 63 & 48,5 & 67 & 51,5 & 130 & 100 & $p=0,142$ \\
\hline \multicolumn{8}{|c|}{ Doença crônica transmissível } \\
\hline Sim & 4 & 36,4 & 7 & 63,6 & 11 & 100 & $\chi^{2}(1)=1,048$ \\
\hline Não & 78 & 52,3 & 71 & 47,7 & 149 & 100 & $p=0,306$ \\
\hline \multicolumn{8}{|c|}{ Teste HIV (na vida) } \\
\hline Sim & 45 & 51,1 & 43 & 48,9 & 88 & 100 & $\chi^{2}(1)=0,001$ \\
\hline Não & 37 & 51,4 & 35 & 48,6 & 72 & 100 & $p=0,975$ \\
\hline \multicolumn{8}{|c|}{$\begin{array}{l}\text { Uso de serviço de emergência } \\
\qquad(6 \text { meses })\end{array}$} \\
\hline Sim & 13 & 65,0 & 7 & 35,0 & 20 & 100 & $\chi^{2}(1)=1,730$ \\
\hline Não & 69 & 49,3 & 71 & 50,7 & 140 & 100 & $p=0,188$ \\
\hline \multicolumn{8}{|c|}{$\begin{array}{l}\text { Consulta ambulatorial } \\
\text { (6 meses })\end{array}$} \\
\hline Sim & 14 & 58,3 & 10 & 41,7 & 24 & 100 & $\chi^{2}(1)=0,567$ \\
\hline Não & 68 & 50,0 & 68 & 50,0 & 136 & 100 & $p=0,451$ \\
\hline
\end{tabular}




\section{Uso de cocaína, sintomas psiquiátricos e atenção à saúde mental}

A presença de sintomas psiquiátricos nos últimos 30 dias, tais como problemas para dormir 118 (73,7\%), humor deprimido 119 (74,3\%), sintomas de ansiedade/nervosismo 110 (68,7\%), alucinações 73 (45,6\%), falta de concentração $110(68,7 \%)$ e dificuldade para controlar temperamento $65(40,6 \%)$ foram predominantes na amostra. Predominaram também sentimentos de ideação suicida $96(60 \%)$ e tentativa de suicídio 15 (9,3\%). Em relação à atenção à saúde mental, 31 (19,3\%) usuários foram internados por problemas psiquiátricos (na vida). Nos últimos seis meses, $123(76,8 \%)$ usaram medicação psicotrópica e 131 (81,3\%) passaram por consulta ambulatorial.

Os usuários de crack, em maioria, apresentaram sintomas psiquiátricos como: dificuldade para dormir (crack 57,6\% versus cocaína 42,4\% $\chi^{2}(1)=7,317, p=0,007$ ), alucinações (crack $72,6 \%$ versus cocaína $27,4 \% \chi^{2}(1)=24,500, p<0,001$ ) e agressividade (crack $61,5 \%$ versus cocaína 38,5\% $\chi^{2}(1)=4,638, p=0,031$ ), diferenciando-se dos usuários de cocaína (Tabela 7). 
Tabela 7. Informações sobre sintomas psiquiátricos e atenção à saúde mental (exceto para problemas relacionados ao uso de substâncias), segundo os usuários de cocaína (fumada e inalada) $(\mathrm{N}=160)$. Ribeirão Preto, 2015.

\begin{tabular}{|c|c|c|c|c|c|c|c|}
\hline & \multicolumn{4}{|c|}{ Cocaína } & \multirow{2}{*}{\multicolumn{2}{|c|}{ Total }} & \multirow{3}{*}{ Valor de $p$} \\
\hline & \multicolumn{2}{|c|}{ Fumada } & \multicolumn{2}{|c|}{ Inalada } & & & \\
\hline & $\mathbf{n}$ & $\%$ & $\mathbf{n}$ & $\%$ & $\mathbf{n}$ & $\%$ & \\
\hline \multicolumn{8}{|c|}{ Problemas para dormir (30 dias) } \\
\hline Sim & 68 & 57,6 & 50 & 42,4 & 118 & 100 & $\chi^{2}(1)=7,317$ \\
\hline Não & 14 & 33,3 & 28 & 66,7 & 42 & 100 & $p=0,007^{*}$ \\
\hline \multicolumn{8}{|c|}{ Humor deprimido (30 dias) } \\
\hline Sim & 65 & 54,6 & 54 & 45,4 & 119 & 100 & $\chi^{2}(1)=2,113$ \\
\hline Não & 17 & 41,5 & 24 & 58,5 & 41 & 100 & $p=0,146$ \\
\hline \multicolumn{8}{|c|}{ Ansioso/Nervosismo (30 dias) } \\
\hline Sim & 60 & 54,5 & 50 & 45,5 & 110 & 100 & $\chi^{2}(1)=1,530$ \\
\hline Não & 22 & 44,0 & 28 & 56,0 & 50 & 100 & $p=0,216$ \\
\hline \multicolumn{8}{|c|}{ Alucinações (30 dias) } \\
\hline $\operatorname{Sim}$ & 53 & 72,6 & 20 & 27,4 & 73 & 100 & $\chi^{2}(1)=24,500$ \\
\hline Não & 29 & 33,3 & 58 & 66,7 & 87 & 100 & $p<0,001^{*}$ \\
\hline \multicolumn{8}{|c|}{ Falta de concentração (30 dias) } \\
\hline Sim & 62 & 56,4 & 48 & 43,6 & 110 & 100 & $\chi^{2}(1)=3,684$ \\
\hline Não & 20 & 40,0 & 30 & 60,0 & 50 & 100 & $p=0,055$ \\
\hline \multicolumn{8}{|c|}{$\begin{array}{l}\text { Dificuldade de controlar } \\
\text { temperamento (dias } 30)\end{array}$} \\
\hline Sim & 40 & 61,5 & 25 & 38,5 & 65 & 100 & $\chi^{2}(1)=4,638$ \\
\hline Não & 42 & 44,2 & 53 & 55,8 & 95 & 100 & $p=0,031^{*}$ \\
\hline \multicolumn{8}{|c|}{ Ideação suicida } \\
\hline Sim & 48 & 50,0 & 48 & 50,0 & 96 & 100 & $\chi^{2}(1)=0,150$ \\
\hline Não & 34 & 53,1 & 30 & 46,9 & 64 & 100 & $p=0,698$ \\
\hline \multicolumn{8}{|c|}{ Tentativa de suicídio } \\
\hline Sim & 10 & 66,7 & 5 & 33,3 & 15 & 100 & $\chi^{2}(1)=1,575$ \\
\hline Não & 72 & 49,7 & 73 & 50,3 & 145 & 100 & $p=0,210$ \\
\hline \multicolumn{8}{|c|}{ Internação psiquiátrica (na vida) } \\
\hline Sim & 16 & 51,6 & 15 & 48,4 & 31 & 100 & $\chi^{2}(1)=0,002$ \\
\hline Não & 66 & 51,2 & 63 & 48,8 & 129 & 100 & $p=0,964$ \\
\hline \multicolumn{8}{|c|}{ Uso de psicotrópico (30 dias) } \\
\hline Sim & 65 & 52,8 & 58 & 47,2 & 123 & 100 & $\chi^{2}(1)=0,542$ \\
\hline Não & 17 & 45,9 & 20 & 54,1 & 37 & 100 & $p=0,462$ \\
\hline \multicolumn{8}{|c|}{ Consulta ambulatorial (30 dias) } \\
\hline Sim & 68 & 51,9 & 63 & 48,1 & 131 & 100 & $\chi^{2}(1)=0,125$ \\
\hline Não & 14 & 48,3 & 15 & 51,7 & 29 & 100 & $p=0,723$ \\
\hline
\end{tabular}

Nota: Teste qui-quadrado $\left(\chi^{2}\right)$. *valor de $p \leq 0.05(\mathrm{~N}=160)$. 


\section{2 Fatores relacionados ao uso de cocaína e outras drogas (ASI)}

\section{Idade do primeiro uso de cocaína, álcool e outras drogas.}

De acordo com o gráfico 1, o envolvimento inicial com substâncias psicoativas ocorreu antes dos 10 anos de idade. Nota-se, como drogas de primeiro uso, maconha $(\mathrm{n}=3)$, álcool $(\mathrm{n}=$ 6), tabaco $(\mathrm{n}=42)$. Na faixa etária de 11 a 15 anos ocorreu o primeiro uso de álcool $(\mathrm{n}=91)$, maconha $(n=90)$, cocaína $(n=57)$ e crack $(n=16)$. Entre os 16 e 20 anos, houve o primeiro consumo de cocaína $(\mathrm{n}=59)$, álcool $(\mathrm{n}=26)$, maconha e crack (ambos $\mathrm{n}=35)$. Na faixa etária de 21 a 25 anos, observa-se o primeiro consumo de tabaco $(\mathrm{n}=17)$, cocaína $(\mathrm{n}=16)$, $\operatorname{crack}(\mathrm{n}=$ 15), maconha $(\mathrm{n}=8)$ e álcool $(\mathrm{n}=5)$. Entre 26 e 30 anos houve o primeiro consumo de crack $(\mathrm{n}$ =21), cocaína $(n=13)$, tabaco $(n=7)$, maconha $(n=4)$ e álcool $(n=3)$. Acima dos 30 anos de idade, observa-se uso inicial de crack $(n=11)$, cocaína e tabaco $(\operatorname{ambos} n=6)$, maconha $(n=2)$ e álcool $(\mathrm{n}=1)$. O uso inicial de inalantes, solventes e alucinógenos ocorreu entre adultos com mais de 30 anos $(n=9)$.

Gráfico 1. Progressão do envolvimento com substâncias psicoativas, segundo usuários de cocaína (independentemente da via de uso) $(\mathrm{N}=160)$. Ribeirão Preto, 2015.

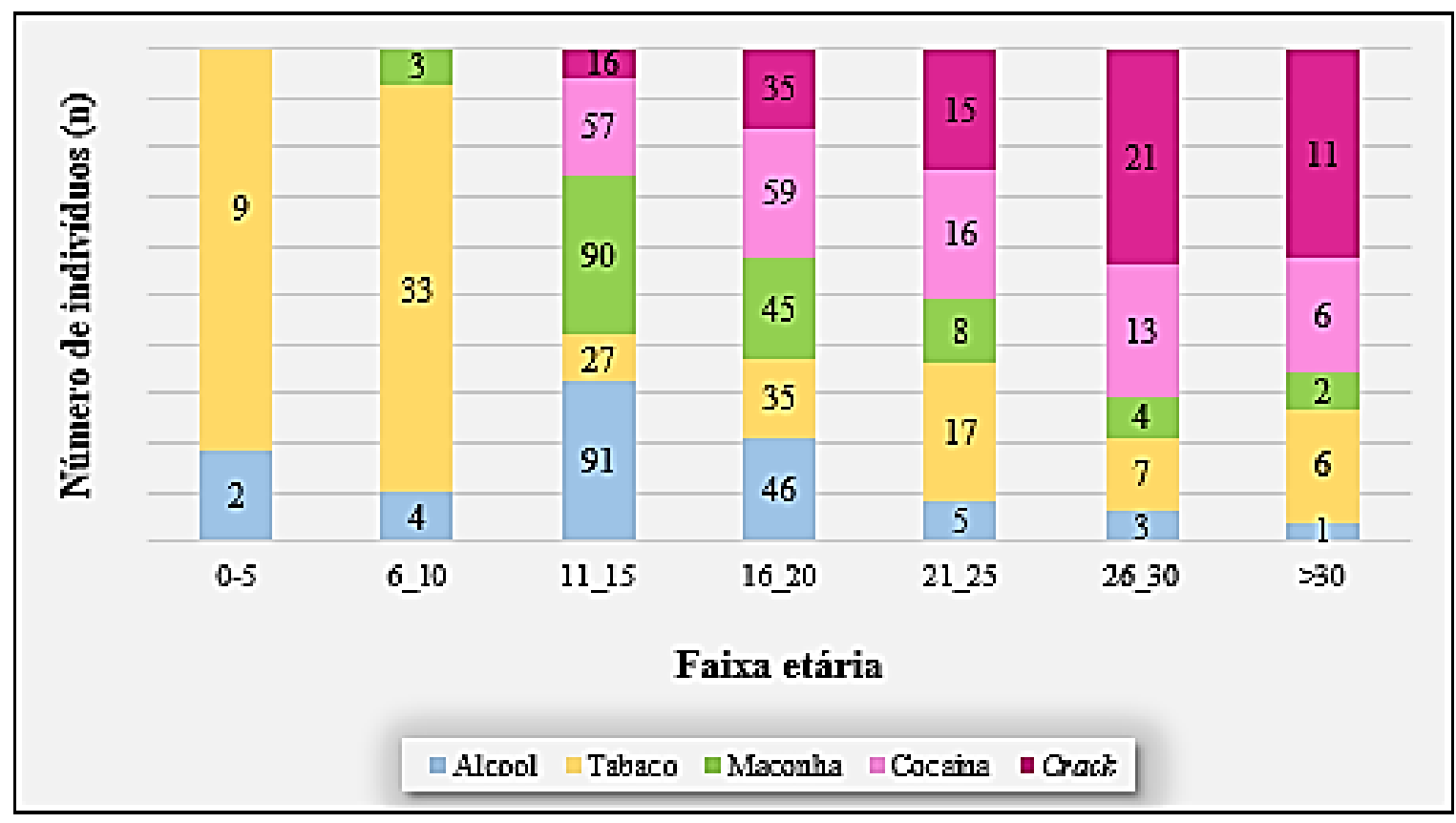


Na tabela 8, nota-se que a idade de início de outras drogas tem variado pouco quando

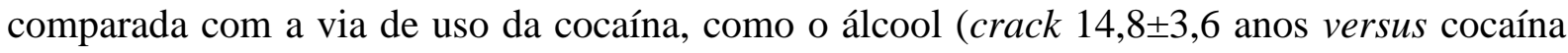
$15,7 \pm 3,5$ anos), maconha (crack 15,7 $\pm 4,5$ anos versus cocaína 15,8 $\pm 3,8$ anos), cocaína (crack

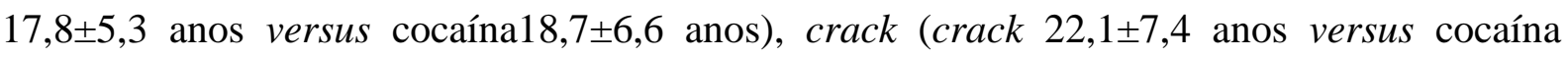
24,1 $\pm 9,1$ anos), tabaco (crack 15,6 $\pm 3,4$ anos versus cocaína 15,6 $\pm 3,0$ anos) e outras drogas (crack 15,5 $\pm 3,1$ anos versus cocaína $16,2 \pm 4,8$ anos). Não houve diferenças em relação à média de idade do primeiro uso de álcool e outras drogas entre os usuários $(p>0,05)$.

Em relação à idade de início do uso da cocaína (fumada e inalada), não foram observadas diferenças entre os grupos $(p>0,05)$. Na tabela 8 , pode-se observar que os usuários de crack iniciaram mais cedo (cocaína aos 17,8 $\pm 5,39$ anos versus crack aos $22,1 \pm 7,42$ anos) quando comparados aos de cocaína inalada (cocaína 18,7 $\pm 6,66$ anos versus crack $24,1 \pm 9,13$ anos).

Tabela 8. Informações sobre a idade de início do uso de álcool e outras drogas, segundo usuários de cocaína (fumada e inalada) (N = 160). Ribeirão Preto, 2015.

\begin{tabular}{|c|c|c|c|c|c|c|c|}
\hline & \multicolumn{6}{|c|}{ Cocaína } & \multirow{3}{*}{$\begin{array}{r}\text { Valor } \\
\text { de } p\end{array}$} \\
\hline & \multicolumn{3}{|c|}{ Fumada } & \multicolumn{3}{|c|}{ Inalada } & \\
\hline & $\begin{array}{c}\text { Variação } \\
\text { (anos) }\end{array}$ & Média & (DP) & $\begin{array}{c}\text { Variação } \\
\text { (anos) }\end{array}$ & Média & (DP) & \\
\hline Álcool & $4-36$ & 14,8 & $( \pm 3,64)$ & $8-27$ & 15,7 & $( \pm 3,51)$ & 0,068 \\
\hline Maconha & $8-40$ & 15,7 & $( \pm 4,52)$ & $9-32$ & 15,8 & $( \pm 3,85)$ & 0,336 \\
\hline Cocaína & $11-47$ & 17,8 & $( \pm 5,39)$ & $11-42$ & 18,7 & $( \pm 6,66)$ & 0,834 \\
\hline Crack & $11-47$ & 22,1 & $( \pm 7,42)$ & $14-45$ & 24,1 & $( \pm 9,13)$ & 0,464 \\
\hline Tabaco & $10-29$ & 15,6 & $( \pm 3,49)$ & $11-26$ & 15,6 & $( \pm 3,08)$ & 0,718 \\
\hline Outras & $11-26$ & 15,5 & $( \pm 3,14)$ & $11-37$ & 16,2 & $( \pm 4,85)$ & 0,511 \\
\hline
\end{tabular}

Nota: Teste Mann Whitney $U p \leq 0.05(\mathrm{~N}=160)$. Outras: Inalantes; Alucinógenos; Estimulantes. 
De acordo com a tabela 9, dos usuários, 135 (84,3\%) fizeram uso de álcool, 133 $(83,1 \%)$ de tabaco, $129(80,6 \%)$ de maconha, da cocaína $142(88,7 \%)$, de crack 87(54,3\%) e de outras substâncias 30 (18,7\%), na vida. Quanto ao uso de drogas, os usuários de crack diferenciaram-se apenas em relação ao uso de tabaco (crack 54,8\% versus cocaína 45,2\% $\chi^{2}$ (1) $=4,173, p=0,041)$, de cocaína (crack 42,7\% versus cocaína 52,8\% $\left.\chi^{2}(1)=8,356, p=0,004\right) \mathrm{e}$ de $\operatorname{crack}\left(\operatorname{crack} 94,3 \%\right.$ versus cocaína 5,7\% $\left.\chi^{2}(1)=141,13, p<0,001\right)$ (Tabela 9).

Tabela 9. Informações sobre o uso de álcool e outras substâncias psicoativas na vida, segundo os usuários de cocaína (fumada e inalada) $(\mathrm{N}=160)$. Ribeirão Preto, 2015.

\begin{tabular}{|c|c|c|c|c|c|c|c|c|}
\hline & & \multicolumn{4}{|c|}{ Cocaína } & \multirow{2}{*}{\multicolumn{2}{|c|}{ Total }} & \multirow{3}{*}{ Valor de $p$} \\
\hline & & \multicolumn{2}{|c|}{ Fumada } & \multicolumn{2}{|c|}{ Inalada } & & & \\
\hline & & $\mathbf{n}$ & $\%$ & $n$ & $\%$ & n & $\%$ & \\
\hline \multicolumn{9}{|l|}{ Álcool } \\
\hline & Sim & 69 & 51,1 & 66 & 48,9 & 135 & 100 & $\chi^{2}(1)=0,007$ \\
\hline & Não & 13 & 52,0 & 12 & 48,0 & 25 & 100 & 0,935 \\
\hline \multicolumn{9}{|l|}{ Tabaco } \\
\hline & Sim & 73 & 54,8 & 60 & 45,2 & 133 & 100 & $\chi^{2}(1)=4,173$ \\
\hline & Não & 9 & 33,3 & 18 & 66,7 & 27 & 100 & $0,041^{*}$ \\
\hline \multicolumn{9}{|c|}{ Maconha } \\
\hline & Sim & 69 & 53,5 & 60 & 46,5 & 129 & 100 & $\chi^{2}(1)=1.335$ \\
\hline & Não & 13 & 41,9 & 18 & 58,1 & 31 & 100 & 0,248 \\
\hline \multicolumn{9}{|l|}{ Cocaína } \\
\hline & Sim & 67 & 47,2 & 75 & 52,8 & 142 & 100 & $\chi^{2}(1)=8,356$ \\
\hline & Não & 15 & 83,3 & 3 & 16,7 & 18 & 100 & 0,004 \\
\hline \multicolumn{9}{|l|}{ Crack } \\
\hline & Sim & 82 & 94,3 & 5 & 5,7 & 87 & 100 & $\chi^{2}(1)=141,13$ \\
\hline & Não & - & - & 73 & 100 & 73 & 100 & $<0,001$ \\
\hline \multicolumn{9}{|l|}{ Outras } \\
\hline & Sim & 20 & 66,6 & 10 & 33,3 & 30 & 100 & $\chi^{2}(1)=3,512$ \\
\hline & Não & 62 & 47,7 & 68 & 52,3 & 130 & 100 & 0,061 \\
\hline
\end{tabular}

Nota: Teste qui-quadrado $\left(\chi^{2}\right)$. *valor de $p \leq 0.05(\mathrm{~N}=160)$. Outras: Inalantes; Alucinógenos; Estimulantes. 
Na tabela 10, observa-se, entre os usuários de crack, que a média de tempo do uso

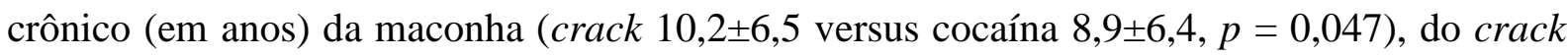

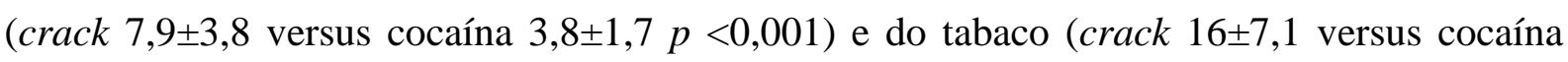
$15 \pm 8,5 p=0,032$ ) foi maior quando comparada à média dos usuários de cocaína inalada. Os usuários de cocaína inalada se destacaram em relação à média de tempo de uso crônico (em anos) da cocaína ( $\operatorname{crack} 7,9 \pm 5,2$ versus cocaína 9,8 $\pm 6,4 p<0,001$ ). Dados disponíveis na Tabela 10.

Tabela 10. Informações sobre anos de uso crônico (3-4 vezes na semana) de álcool e outras drogas, segundo os usuários de cocaína (fumada e inalada) ( $\mathrm{N}=160)$. Ribeirão Preto, 2015.

\begin{tabular}{|c|c|c|c|c|c|c|c|}
\hline & \multicolumn{6}{|c|}{ Cocaína } & \multirow{3}{*}{$\begin{array}{l}\text { Valor } \\
\text { de } p\end{array}$} \\
\hline & \multicolumn{3}{|c|}{ Fumada } & \multicolumn{3}{|c|}{ Inalada } & \\
\hline & $\begin{array}{c}\text { Variação } \\
\text { (anos) }\end{array}$ & Média & (DP) & $\begin{array}{c}\text { Variação } \\
\text { (anos) }\end{array}$ & Média & $\overline{(D P)}$ & \\
\hline Álcool & $1-27$ & 11,0 & $( \pm 6,7)$ & $1-30$ & 11,1 & $( \pm 7,7)$ & 0,796 \\
\hline Maconha & $1-30$ & 10,2 & $( \pm 6,5)$ & $1-40$ & 8,9 & $( \pm 6,4)$ & $0,047 *$ \\
\hline Cocaína & $1-21$ & 7,9 & $( \pm 5,2)$ & $1-30$ & 9,8 & $( \pm 6,4)$ & $<0,001 *$ \\
\hline Crack & $1-21$ & 7,9 & $( \pm 5,6)$ & $3-7$ & 3,8 & $( \pm 1,7)$ & $<0,001 *$ \\
\hline Tabaco & $1-37$ & 16,0 & $( \pm 7,1)$ & $2-36$ & 15,0 & $( \pm 8,5)$ & $0,032^{*}$ \\
\hline Outras & $1-15$ & 6,0 & $( \pm 4,7)$ & $1-6$ & 3,5 & $( \pm 1,8)$ & 0,325 \\
\hline
\end{tabular}


De acordo com a tabela 11, observa-se que, da amostra, $94(58,7 \%)$ consumiram álcool, 79 (49,3\%) fumaram maconha, 61 (38,1\%) crack e 127 (79,3\%) tabaco, nos últimos 30 dias.

Os usuários de cocaína inalada diferenciaram-se em relação aos usuários de crack por

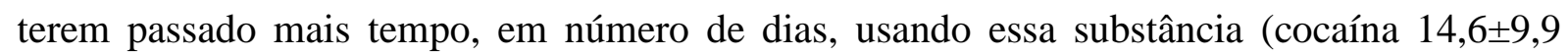

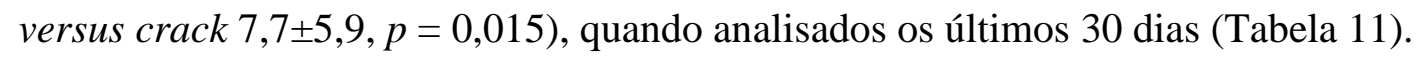

Tabela 11. Informações sobre a média de dias usando álcool e outras substâncias psicoativas nos últimos 30 dias, segundo os usuários de cocaína (fumada e inalada) $(\mathrm{N}=160)$. Ribeirão Preto, 2015.

\begin{tabular}{|c|c|c|c|c|c|c|c|c|}
\hline & \multicolumn{6}{|c|}{ Cocaína } & \multirow{3}{*}{$\begin{array}{c}\text { Total } \\
\mathbf{n}\end{array}$} & \multirow{3}{*}{$\begin{array}{c}\text { Valor de } \\
p\end{array}$} \\
\hline & \multicolumn{3}{|c|}{ Fumada } & \multicolumn{3}{|c|}{ Inalada } & & \\
\hline & $\mathbf{n}$ & Média & (DP) & $\mathbf{n}$ & Média & (DP) & & \\
\hline Álcool & 46 & 14,6 & $(9,1)$ & 48 & 13,5 & $(8,2)$ & 94 & 0,588 \\
\hline Maconha & 43 & 15,6 & $(11,2)$ & 36 & 14,9 & $(12,3)$ & 79 & 0,760 \\
\hline Cocaína & 17 & 7,7 & $(5,9)$ & 61 & 14,6 & $(9,9)$ & 78 & $0,015^{*}$ \\
\hline Crack & 60 & 17,6 & $(9,8)$ & 1 & 17,0 & - & 61 & 0,909 \\
\hline Tabaco & 68 & 29,2 & $(3,4)$ & 59 & 29,6 & $(2,8)$ & 127 & 0,237 \\
\hline
\end{tabular}

Nota: Teste Mann Whitney $U p \leq 0.05(\mathrm{~N}=160)$. 
Pode-se notar na tabela 12 que, da amostra, $142(88,7 \%)$ usaram a droga por período superior a 15 dias/mês (nos últimos seis meses), 109 (68,1\%) apresentaram sintomas de abstinência e 124 (77,5\%) fissura ou desejo de usá-la A maioria dos usuários de cocaína informou ter gasto entre $\mathrm{R} \$ 10,00$ - $\mathrm{R} \$ 250,00$ no último mês para aquisição da droga 63 $(39,3 \%)$.

Os usuários de crack e cocaína diferenciaram-se significativamente pelo uso em frequência superior a 15 dias/mês, nos últimos seis meses (crack 54,9\% versus cocaína $\left.45,1 \%) \chi^{2}(1)=6,840, p=0,009\right)($ Tabela 12).

Tabela 12. Informações sobre frequência de uso, sintomas de abstinência, fissura e dinheiro gasto em droga, segundo os usuários de cocaína (fumada e inalada) $(\mathrm{N}=160)$. Ribeirão Preto, 2015.

\begin{tabular}{|c|c|c|c|c|c|c|c|}
\hline & \multicolumn{4}{|c|}{ Cocaína } & \multirow{2}{*}{\multicolumn{2}{|c|}{ Total }} & \multirow{3}{*}{ Valor de $p$} \\
\hline & \multicolumn{2}{|c|}{ Fumada } & \multicolumn{2}{|c|}{ Inalada } & & & \\
\hline & $\mathbf{n}$ & $\%$ & $\mathbf{n}$ & $\%$ & $\mathbf{n}$ & $\%$ & \\
\hline \multicolumn{8}{|l|}{$\begin{array}{l}\text { Frequência de uso } \\
\text { (últimos } 6 \text { meses) }\end{array}$} \\
\hline Sem uso/raro & 4 & 22,2 & 14 & 77,8 & 18 & 100 & $\chi^{2}(1)=6,840$ \\
\hline > 15 dias/mês & 78 & 54,9 & 64 & 45,1 & 142 & 100 & $p=0,009 *$ \\
\hline \multicolumn{8}{|l|}{$\begin{array}{l}\text { Sintomas de abstinência } \\
\text { (últimos } 30 \text { dias) }\end{array}$} \\
\hline Sim & 56 & 51,4 & 53 & 48,6 & 109 & 100 & $\chi^{2}(1)=0,002$ \\
\hline Não & 26 & 51,0 & 25 & 49,0 & 51 & 100 & $p=0,963$ \\
\hline \multicolumn{8}{|l|}{$\begin{array}{l}\text { Desejo de usar (fissura) } \\
\text { (últimos } 30 \text { dias) }\end{array}$} \\
\hline Sim & 65 & 52,4 & 59 & 47,6 & 124 & 100 & $\chi^{2}(1)=0,302$ \\
\hline Não & 17 & 47,2 & 19 & 52,8 & 36 & 100 & $p=0,583$ \\
\hline \multicolumn{8}{|l|}{$\begin{array}{l}\text { Dinheiro gasto em droga } \\
\text { (últimos } 6 \text { meses) }\end{array}$} \\
\hline Nenhum & 20 & 55,6 & 16 & 44,4 & 36 & 100 & \multirow{3}{*}{$\begin{array}{c}\chi^{2}(1)=0,377 \\
p=0,828\end{array}$} \\
\hline $\mathrm{R} \$ 10,00-\mathrm{R} \$ 250,00^{3}$ & 32 & 50,8 & 31 & 49,2 & 63 & 100 & \\
\hline$>\mathrm{R} \$ 251,00$ & 30 & 49,2 & 31 & 50,8 & 61 & 100 & \\
\hline
\end{tabular}

Nota: Teste qui-quadrado $\left(\chi^{2}\right)$. *valor de $p \leq 0.05$. $(\mathrm{N}=160)$. Conversão reais $(\mathrm{BR})$ para dólares $(\mathrm{EUA})$ : $\mathrm{R} \$ 10,00(\$ 3,18) / \mathrm{R} \$ 250,00(\$ 79,59)$ 


\subsection{Modelo final regressão logística}

A partir da análise multivariada demostrada na Tabela 13, observa-se que os indivíduos adultos ( $\geq 30$ anos) (OR 3,18 95\% CI 1,50;6,7) e em situação de rua (OR 4,51 95\% CI 1,49;13,61) mantiveram chances aumentadas de utilizar crack.

Tabela 13. Tabela de frequências, Odds Ratio Bruto e Ajustado para a variável de desfecho uso de crack segundo algumas variáveis explicativas $(\mathrm{N}=160)$. Ribeirão Preto, 2015.

\begin{tabular}{|c|c|c|c|c|c|c|}
\hline \multirow{2}{*}{ Variáveis } & \multicolumn{2}{|c|}{ Cocaína [n (\%)] } & \multirow{2}{*}{$\begin{array}{c}\text { OR } \\
\text { Bruto }\end{array}$} & \multirow{2}{*}{$\begin{array}{c}\text { Valor } \\
\mathbf{p}\end{array}$} & \multirow{2}{*}{$\begin{array}{c}\text { OR } \\
\text { Ajustado* }\end{array}$} & \multirow{2}{*}{$\begin{array}{c}\text { Valor } \\
\mathbf{p} \\
\end{array}$} \\
\hline & Inalada & Fumada & & & & \\
\hline \multicolumn{7}{|l|}{ Faixa Etária } \\
\hline $18-29$ & $39(59,1)$ & $27(40,9)$ & Ref. & & Ref. & \\
\hline$>=30$ & $39(41,5)$ & $55(58,5)$ & $2,04(1,08 ; 3,86)$ & 0,03 & $3,18(1,50 ; 6,75)$ & $<0,01$ \\
\hline \multicolumn{7}{|l|}{ Anos de Estudo } \\
\hline$<=8$ & $43(42,6)$ & $58(57,4)$ & $1,97(1,02 ; 3,78)$ & 0,04 & $1,25(0,59 ; 2,64)$ & 0,57 \\
\hline$>8$ & $35(59,3)$ & $24(40,7)$ & Ref. & & Ref. & \\
\hline \multicolumn{7}{|l|}{ Ocupação } \\
\hline Desempregado & $24(38,1)$ & $39(61,9)$ & $2,04(1,07 ; 3,9)$ & 0,03 & $1,71(0,79 ; 3,70)$ & 0,17 \\
\hline Empregado & $54(55,7)$ & $43(44,3)$ & Ref. & & Ref. & \\
\hline \multicolumn{7}{|l|}{ Situação de Rua } \\
\hline Não & $73(54,9)$ & $60(45,1)$ & Ref. & & Ref. & \\
\hline Sim & $5(18,5)$ & $22(81,5)$ & $5,35(1,91 ; 14,98)$ & $<0,01$ & $4,51(1,49 ; 13,61)$ & $<0,01$ \\
\hline \multicolumn{7}{|l|}{ Trat. Anterior } \\
\hline Nunca & $40(59,7)$ & $27(40,3)$ & Ref. & & Ref. & \\
\hline Sim & $38(40,9)$ & $55(59,1)$ & $2,14(1,13 ; 4,06)$ & 0,02 & $1,47(0,713,04)$ & 0,30 \\
\hline \multicolumn{7}{|l|}{ Renda Mensal } \\
\hline$>1 \mathrm{SM}$ & $29(72,5)$ & $11(27,5)$ & Ref. & & Ref. & \\
\hline$<1 \mathrm{SM}$ & $49(40,8)$ & $71(59,2)$ & $3,82(1,74 ; 8,36)$ & $<0,01$ & $2,09(0,80 ; 5 ; 51)$ & 0,13 \\
\hline \multicolumn{7}{|l|}{$\begin{array}{l}\text { Renda Compatível } \\
\text { Com despesas }\end{array}$} \\
\hline Não & $43(40,2)$ & $64(59,8)$ & $2,89(1,45 ; 5,75)$ & $<0,01$ & $1,62(0,67 ; 3,92)$ & 0,28 \\
\hline Sim & $35(66,0)$ & $18(34,0)$ & Ref. & & Ref. & \\
\hline
\end{tabular}




\subsection{Aspectos relacionados à gravidade da dependência da cocaína}

Ao comparar os níveis de gravidade do consumo, dependência e fissura (AUDIT, SADD, SDS e CCQ) entre os usuários de cocaína (fumada ou inalada) ( $p>0,05)$, não foram observadas diferenças estatisticamente significativas entre essas variáveis. Da amostra total, nota-se que os usuários foram classificados como: 108 (67,5\%) consumo de álcool em nível de alto risco (AUDIT), porém $77(48,1 \%)$ com nível baixo da dependência do álcool (SADD) e nível grave da dependência de drogas (SDS) 90 (56,2\%) e nível severo de fissura (CCQ-B) $71(44,3 \%)$ (Tabela 14).

Tabela 14. Classificação dos níveis de gravidade do uso e dependência de álcool (AUDIT, SADD), drogas (SDS) e fissura (CCQ-B), segundo os usuários de cocaína (fumada e inalada) (N = 160). Ribeirão Preto, 2015.

\begin{tabular}{|c|c|c|c|c|c|c|c|c|}
\hline & & \multicolumn{4}{|c|}{ Cocaína } & \multirow{2}{*}{\multicolumn{2}{|c|}{ Total }} & \multirow{3}{*}{ Valor de $p$} \\
\hline & & \multicolumn{2}{|c|}{ Fumada } & \multicolumn{2}{|c|}{ Inalada } & & & \\
\hline & & $\mathbf{n}$ & $\%$ & $\mathbf{n}$ & $\%$ & n & $\%$ & \\
\hline \multirow{2}{*}{ AUDIT-C } & Baixo risco & 28 & 53,8 & 24 & 46,2 & 52 & 100 & \multirow{2}{*}{$\begin{array}{c}\chi^{2}(1)=.0208 \\
p=0,648\end{array}$} \\
\hline & Alto risco & 54 & 50,0 & 54 & 50,0 & 108 & 100 & \\
\hline \multirow{3}{*}{ SADD } & Baixo & 37 & 48,1 & 40 & 51,9 & 77 & 100 & \multirow{3}{*}{$\begin{array}{c}\chi^{2}(1)=0,780 \\
p=0,677\end{array}$} \\
\hline & Moderado & 24 & 52,2 & 22 & 47,8 & 46 & 100 & \\
\hline & Severo & 21 & 56,8 & 16 & 43,2 & 37 & 100 & \\
\hline \multirow{2}{*}{ SDS } & Leve & 31 & 44,3 & 39 & 55,7 & 70 & 100 & \multirow{2}{*}{$\begin{array}{c}\chi^{2}(1)=2,416 \\
p=0,120\end{array}$} \\
\hline & Grave & 51 & 56,7 & 39 & 43,3 & 90 & 100 & \\
\hline \multirow{4}{*}{ CCQ-B } & $\begin{array}{l}\text { Mínimo/ } \\
\text { Ausente }\end{array}$ & 10 & 37,0 & 17 & 63,0 & 27 & 100 & \multirow{4}{*}{$\begin{array}{c}\chi^{2}(1)=2,416 \\
p=0,263\end{array}$} \\
\hline & Baixo & 6 & 40,0 & 9 & 60,0 & 15 & 100 & \\
\hline & Moderado & 26 & 55,3 & 21 & 44,7 & 47 & 100 & \\
\hline & Severo & 40 & 56,3 & 31 & 43,7 & 71 & 100 & \\
\hline
\end{tabular}

Nota: Teste qui-quadrado $\left(\chi^{2}\right)$. *valor de $p \leq 0.05(\mathrm{~N}=160)$ 
Em relação aos escores finais das áreas da escala ASI, a tabela 15 mostra que os usuários diferenciaram-se apenas em relação a problemas com emprego (crack 47,3 $\pm 6,9$

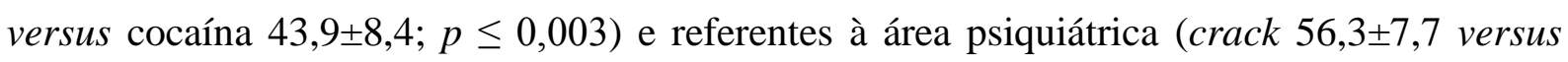
cocaína 51,5 $\pm 9,6 ; p \leq 0,001$ ), quando comparados aos de cocaína (inalada).

Não foram observadas diferenças estatisticamente significativas quando comparadas as médias dos escores das áreas drogas, família, álcool, médica, aspectos legais e suporte/problema sociofamiliar $(p<0,05)$.

Tabela 15. Comparação das médias dos escores finais das áreas da ASI, segundo os usuários de cocaína (fumada e inalada) $(\mathrm{N}=160)$. Ribeirão Preto, 2015.

\begin{tabular}{cccccc}
\hline & \multicolumn{4}{c}{ Cocaína } & \multirow{2}{*}{ Valor de $\boldsymbol{p}$} \\
\cline { 2 - 4 } & \multicolumn{2}{c}{ Fumada } & \multicolumn{2}{c}{ Inalada } & \\
\cline { 2 - 4 } & Média & (DP) & Média & (DP) & \\
\hline Drogas & 52,9 & 6,4 & 52,69 & 7,3 & 0,835 \\
Família & 48,0 & 9,3 & 47,4 & 9,9 & 0,920 \\
Álcool & 49,0 & 9,6 & 49,4 & 9,8 & 0,813 \\
Psiquiátrica & 56,3 & 7,7 & 51,5 & 9,6 & $0,003^{*}$ \\
Médica & 37,5 & 13,2 & 39,4 & 14,4 & 0,395 \\
Aspectos Legais & 50,4 & 9,5 & 49,8 & 8,6 & 0,413 \\
Emprego & 47,6 & 6,9 & 43,9 & 8,4 & $0,005^{*}$ \\
Suporte Familiar e & 50,3 & 8,3 & 50,1 & 10,1 & 0,919 \\
Social & & & & & \\
Problemas Familiar e & 48,5 & 9,4 & 48,8 & 8,6 & 0,766 \\
social & & & & & \\
\hline
\end{tabular}

Nota: Teste Mann Whitney $U .{ }^{*}$ valor de $p \leq 0.05(\mathrm{~N}=160)$ 
$\mathrm{Na}$ tabela 16, podem ser observadas correlações positivas entre o AUDIT e as áreas Álcool $(r=, 83 p<0,001)$ e Drogas $(\mathrm{r}=, 18 p=0,022)$ da ASI. A gravidade da dependência de álcool (SADD) foi fortemente correlacionada com a área Álcool $(r=, 80 p<0,001)$.

A gravidade da dependência de drogas (SDS) também foi correlacionada às áreas Drogas $(r=, 54 p<0,001)$, Álcool $(r=, 22 p=0,004)$, Problema Familiar e Social $(\mathrm{r}=, 18 \mathrm{p}=$ $0,021)$ e Psiquiátrica $(r=, 48 p<0,001)$, mas negativamente com a área Médica $(r=-, 15 p=$ 0,045) da ASI. Além disso, a CCQ-B correlacionou-se com as áreas Drogas $(r=, 53 p$ $<0,001)$, Família $(r=, 21 p=, 006)$; Álcool $(r=, 20 p=0,008)$, Psiquiátrica $(r=, 41 p<0,001)$ e Problema Familiar e Social $(r=, 16 p=0,040)$.

Tabela 16 - Coeficiente de correlação entre as escalas (AUDIT, SADD, SDS, CCQ-B) e as áreas da ASI ( $\mathrm{N}=160)$. Ribeirão Preto, 2015.

\begin{tabular}{lcccccccccccc}
\hline Escalas & Média & Max & \multicolumn{10}{c}{ Domínios da ASI } \\
\cline { 6 - 13 } & $(\mathbf{D P})$ & - -Min & DR & FA & AL & PSI & ME & LE & EM & SS & PS \\
& & & $(\boldsymbol{r})$ & $(\boldsymbol{r})$ & $(\boldsymbol{r})$ & $(\boldsymbol{r})$ & $(\mathbf{r})$ & $(\boldsymbol{r})$ & $(\boldsymbol{r})$ & $(\boldsymbol{r})$ & $(\boldsymbol{r})$ \\
\hline AUDIT & $6,3 \pm 4,5$ & $0-12$ &, $18^{*}$ &, 05 &, $83^{* *}$ &, 14 &,- 02 &, 04 &,- 14 &,- 00 &, 13 \\
SADD & $11,7 \pm 11,5$ & $0-45$ &, 15 &, 11 &, $80^{* *}$ &, 19 &, 01 &, 05 &,- 11 &, 10 &, 09 \\
SDS & $9,0 \pm 3,3$ & $0-15$ &, $54^{* *}$ &, 07 &, $22^{* *}$ &, $48^{* *}$ &,$- 15^{*}$ &, 12 &,- 00 &, 12 &, $18^{*}$ \\
CCQB & $22,0 \pm 8,2$ & $0-50$ &, $53^{* *}$ &, $21^{* *}$ &, $20^{* *}$ &, $41^{* *}$ &,- 00 &, 13 &,- 01 &, 11 &, $16^{*}$
\end{tabular}

Nota: Correlação de Spearman *p < 0,05; ** p < 0,001. Áreas da ASI: DR - Droga; FA - Família; AL -Álcool; PSI - Psiquiátrica; ME - Área Médica; LE -Legal; EM - Emprego; SS - Suporte Familiar e Social; PS Problema Familiar e Social. 


\section{DISCUSSÃO}

O presente estudo analisou peculiaridades de usuários de cocaína (inalada e fumada) em tratamento quanto a prejuízos nas distintas esferas da vida, e consequentemente, nos níveis de gravidade da dependência da droga. Integram as principais características dos usuários de crack: inexistência de níveis seguros de consumo, a presença de prejuízos associados (FERRI et al., 2004; CHEN; ANTHONY, 2004; REBOUSSIN; ANTHONY, 2006), atribuídos ao padrão de consumo, bem como uso associado de outras drogas (HATSUKAMI; FISCHMAN, 1996; DUNN; LARANJEIRA, 1999; DUAILIBI et al., 2008; KILUK et al., 2013) e implicações biopsicossociais (DEGENHARDT et al, 2008; BORDERS et al., 2009). Essas características constituem alguns dos tributos multifatoriais que determinam os níveis de gravidade da dependência.

\subsection{Fatores associados com a dependência de cocaína (fumada e inalada)}

No que se refere às características sociodemográficas, os usuários de crack destacaramse por serem adultos ( $\geq 30$ anos), com baixo nível de escolaridade, desempregados, maior predisposição à situação de moradia de rua, além de apresentarem histórico de tratamento anterior para a dependência (Tabela 1). Embora seja notório que as condições socioeconômicas e de saúde mostram-se precárias entre usuários de drogas de um modo geral (UNODC, 2016), percebe-se que o uso de crack agrava ainda mais a vulnerabilidade dessa clientela. Esse subgrupo possui maior número de riscos à saúde e de comportamentos disfuncionais, sobretudo pela condição de pobreza e exposição à criminalização no contexto de origem (CIBA, 1992; SANTOS CRUZ et al., 2013; FISCHER et al., 2015; PALAMAR; DAVIES; OMPAD, 2015; TOLEDO; GÓNGORA; BASTOS, 2017).

As precárias condições de vida, bem como as elevadas desigualdades sociais, exercem efeito direto e indireto sobre o bem-estar de usuários de crack. A esse respeito, a literatura é ampla em retratar um perfil de indivíduos com uso problemático de crack repleto de fragilidades sociais e de saúde (HORTA et al., 2011; SANTOS CRUZ et al., 2013; SELEGHIM; OLIVEIRA, 2013; BOTTI; MACHADO; TAMEIRÃO, 2014; CRUZ et al, 2014; GALASSI et al., 2016). Convém destacar também que os sujeitos que acessam serviços de saúde para tratamento dessa dependência (HORTA et al., 2011; BOTTI; MACHADO; 
TAMEIRÃO, 2014; CRUZ et al., 2014) convivem em ambientes de exclusão social e, portanto, o uso da droga emerge como um agravante no contexto de marginalização preexistente (HORTA et al., 2011, FREIRE et al., 2012; SANTOS CRUZ et al., 2013; SELEGHIM; OLIVEIRA 2013; BOTTI; MACHADO; TAMEIRÃO, 2014; NARVAEZ et al., 2015; GALASSI et al., 2016; TOLEDO; GÓNGORA; BASTOS, 2017).

Já os usuários de cocaína apresentaram melhores indicadores sociodemográficos quando comparados aos de crack (Tabela 1), mas, ainda assim, compõem um subgrupo de considerável risco. Entretanto, por apresentarem circunstâncias sociais e de sustento um pouco melhores, tendem a desfrutar de melhores condições de saúde (RIEZZO et al., 2012; NARVAEZ et al., 2015) e, consequentemente, apresentam diferentes taxas de mortalidade e morbidade associadas às doenças (RIEZZO et al., 2012), incluindo os transtornos psiquiátricos relacionados ao uso de drogas (FORD et al., 2009; GALEA; VLAHOV, 2002).

Pôde-se observar homogeneidade na amostra quanto a sexo, etnia, estado civil e prática religiosa, sendo, portanto, representativa do grupo geral de usuários de cocaína (independentemente da via) (Tabela 1). Esses resultados corroboram estudos que avaliaram usuários de cocaína e encontraram um perfil majoritário de indivíduos do sexo masculino, solteiros, não caucasianos e sem envolvimento religioso (SANTOS CRUZ et al., 2013; REIS, 2014; NARVAEZ et al., 2015; GALASSI et al., 2016; DIEHL et al., 2016)

No que diz respeito à faixa etária, os usuários de crack compuseram uma população de indivíduos mais adultos, com idade igual ou acima dos 30 anos (Tabela 1), assim como na análise multivariada, a qual evidenciou as chances aumentas de usar crack nessa faixa etária (Tabela 13).

A variação na idade e a escolha pela via de uso da cocaína podem ser explicadas por duas hipóteses: o uso de crack pode estar ocorrendo em função do estágio da progressão do envolvimento com droga em busca de efeitos mais potentes, o que reforça a premissa de que nem sempre o crack é a primeira droga utilizada por usuários mais adultos (RIBEIRO, LARANJEIRA, 2012); e em virtude das situações de vulnerabilidades psicossociais que permeiam o fácil acesso, a alta disponibilidade e os preços acessíveis que contribuem para que o indivíduo use o crack em idade mais tardia. Esse contexto revela ainda a interseção entre os fatores neurobiológicos e sociocontextuais na delimitação da gravidade do uso do crack, que, apesar do seu elevado potencial de dependência, tem sido agravado principalmente pelo contexto social, aspecto amplamente documentado na literatura (SANTOS CRUZ et al., 2013; BOTTI; MACHADO; TAMEIRÃO, 2014; GALASSI et al., 2016; BASTOS; BERTONI 
2013; ABDALLA et al., 2014). O Relatório Mundial sobre Drogas (UNODC, 2016) descreve os potenciais impactos do uso de cocaína (ambas as vias) na saúde e no bem-estar dos usuários e pessoas no seu entorno, como a família e a comunidade.

Dados da Pesquisa Brasileira de Álcool e Drogas mostram que o uso de cocaína inalada, na comparação com o crack, tem sido muito comum entre os jovens (20-29 anos), por ser esta a via preferencial nos estágios iniciais e de maior acessibilidade nos locais de convívio dos jovens, como festas, ambientes universitários e escolares (NOTO; NAPPO; GALDURÓZ, 1998; DUNN; LARANJEIRA et al., 1999; ABDALLA et al., 2014). Uma das maiores preocupações em relação à idade é que quanto mais precoce e pesado for o uso de uma droga, maiores são as chances de progressão para o consumo de outras substâncias e desenvolvimento da dependência ao longo da vida. Por outro lado, há evidências de que o aumento da idade é um forte preditor de melhoras com diminuição ou cessação do uso da droga (RIBEIRO LARANJEIRA 2012).

Na população jovem ainda são grandes os desafios para detecção do uso precoce de cocaína (ABDALLA et al., 2014; REIS, 2014), em decorrência do pouco reconhecimento da gravidade do uso recreativo da substância inalada, por exemplo entre jovens universitários (BRASIL, 2009; RIBEIRO; SANCHEZ; NAPPO, 2010; UNODC, 2016). Esse fator pode estar relacionado ao baixo nível de gravidade da síndrome da dependência e de outros problemas que raramente impulsionam os usuários a buscar tratamento, o que contribui para subestimação de casos precoces nos relatórios epidemiológicos. Por fim, trata-se de um subgrupo de sujeitos que não apresenta as mesmas fragilidades dos usuários de crack. Tais dados corroboram os apresentados por Falck et al. (2008), em estudo longitudinal com amostra de 172 usuários de crack, no qual observaram que 62,8\% deles tiveram diagnóstico de dependência de cocaína em algum momento durante o período de uso da droga.

Quanto ao uso de crack, a progressão em pessoas com idade mais avançada pode evidenciar um grupo que não acessa os serviços de saúde (SPRICIGO et al., 2004) e, portanto, mantém o uso prolongando da droga, o que contribui para exposições a riscos (BOTTI; MACHADO; TAMEIRÃO, 2014; NARVAEZ et al., 2015). Observam-se, entre os diversos riscos decorrentes do uso da droga, elevados índices de complicações clínicas (RIEZZO et al., 2012), de aquisição e transmissão sexual do HIV e hepatites, overdose, com possível desfecho fatal (MESQUITA et al., 2001; DIAS et al., 2011), além de agravamento dos sintomas psiquiátricos preexistentes (SCHUCKIT, 2006; FORD et al., 2009). 
Como destacado, esses usuários adultos podem representar um subgrupo de início tardio da droga que, por serem marginalizados (FISHER et al., 2015) e disporem de precárias oportunidades na vida, buscam refúgio e alívio no uso do crack. Trata-se da busca de “paraísos artificiais", citada por Aldous Huxley (1954) em sua obra “As Portas da Percepção”. Nesse contexto, reitera-se a complexidade do entorno do uso da droga, de modo que se torna imperativo valorizar, nas propostas assistenciais, as demais áreas de funcionamento da vida do sujeito, uma vez que o sucesso do tratamento da dependência de cocaína depende, além de outros fatores, da reabilitação psicossocial, ou seja, a reinserção social, tal como preconizado pela Política do Ministério da Saúde para a atenção integral a usuários de álcool e outras drogas (BRASIL, 2004; SANTOS; OLIVEIRA, 2013)

Quanto à escolaridade, na presente amostra, metade dos usuários de crack possuía baixo nível de escolaridade (Tabela 1), resultado também observado em estudos com usuários de drogas, sobretudo de cocaína e crack (HORTA et al., 2011, FREIRE et al., 2012; SANTOS CRUZ et al., 2013; SELEGHIM; OLIVEIRA 2013; BOTTI; MACHADO; TAMEIRÃO, 2014; PALAMAR; DAVIES; OMPAD, 2015; NARVAEZ et al., 2015; GALASSI et al., 2016). O uso crônico dessa substância ocasiona perdas cognitivas importantes (SHORTER; DOMINGO; KOSTEN, 2015), as quais contribuem significativamente para o abandono de diversas atividades sociais, por exemplo os estudos. Vaughn et al. (2010) descreveram que os usuários de crack possuem duas vezes mais chances de não concluir o ensino médio quando comparados a usuários de cocaína inalada. Eles também apresentam baixos níveis de escolaridade - ensino fundamental $(76,2 \%)$ - em relação aos usuários de cocaína inalada $(83,3 \%)$, embora com pouca diferença (KILUK et al., 2013).

No entanto, o nível educacional deve ser analisado com cautela, por ter importante implicação em diversas esferas da vida dessas pessoas. Da mesma forma, fatores contextuais e psicossociais têm participação determinante nos padrões de consumo, de modo que podem ocasionar perdas em distintas facetas, em específico na educacional. Embora o uso de cocaína (fumada ou inalada) favoreça o emergir de diversos fatores que resultam em desligamento escolar (DEGENHARDT et al., 2008; BORDERS et al., 2009; CHAVES et al., 2011), convém salientar que o convívio em contextos de baixo poder aquisitivo (FISHER et al., 2015), a necessidade de trabalhar em prol da própria sustentabilidade ou de familiares e a independência financeira também podem contribuir significativamente para o abandono escolar. Nota-se que as exigências impostas pelo próprio contexto social podem causar o descompromisso com a educação, por meio do uso da substância ou pela inserção precoce no 
mercado de trabalho. Nesse sentido, empregos informais nos grandes centros urbanos expõem os jovens ao uso experimental de drogas, por exemplo quando estão na condição de vendedores ambulantes (NOTO et al., 2004) e malabares de rua (CIRINO; ALBERTO, 2009).

A garantia de sucesso no âmbito educacional depende, sobretudo, de ações pontuais direcionadas a adolescentes, por meio de estratégias preventivas e educativas em saúde e promoção de saúde (RODRIGUES et al., 2013). Deve-se investir no incremento de parcerias intersetoriais que conciliem a inserção no mercado de trabalho com as práticas educativas, a fim de inibir o consumo precoce de diversas substâncias (SILVA et al., 2014; TOLEDO; GÓNGORA; BASTOS, 2017) e o envolvimento com o tráfico de drogas como meio de obtenção de renda (UNODC, 2016).

No que se refere à situação ocupacional, os usuários de crack representaram, neste estudo, a maioria dos desempregados e, quando exerciam atividades laborais, realizavam "bicos", trabalhando em atividades informais e temporárias (Tabela 1). Além disso, literatura destaca que essa característica pode ser um elemento negativo que influencia diretamente as questões laborais, pois quanto menor for à formação ou qualificação profissional, menor será as chances de inserção no mercado de trabalho e somado a frustração causada pela incapacidade de encontrar emprego, favorece assim o consumo de drogas, gerando assim um círculo vicioso (FREIRE et al., 2012; DIEHL et al., 2014). Esses resultados corroboram os observados por Galassi et al. (2016) que avaliaram 143 usuários de crack e outras drogas em tratamento ambulatorial no Distrito Federal, tendo encontrado 57\% deles desempregados e apenas 36\% com o ensino médio concluído (GALASSI et al., 2016).

Além disso, há de ressaltar que o uso de crack no padrão binge (CHAVES et al., 2011) interfere na vida produtiva do indivíduo, pois favorece o absenteísmo e presenteísmo com atividades laborais disfuncionais, o que, consequentemente, causa diminuição da produtividade e aumento do risco de acidentes no trabalho, podendo comprometer tanto o próprio trabalhador como a equipe de trabalho (OMS, 2011), bem como levar à perda do emprego. Tais motivos podem explicar os elevados índices de usuários de crack e ou outras drogas que exercem trabalhos informais ou "bicos" (SANTOS CRUZ et al., 2013; CRUZ et al., 2014; GALASSI et al., 2016).

Os usuários de cocaína inalada representaram um grupo mais ativo economicamente, com vínculo de emprego formal ou informal, incluindo "bicos" (Tabela 1). Como descrito anteriormente, o tipo, a quantidade e a frequência de uso, somados ao estilo de vida, interferem nas atividades de funcionalidade ocupacional desses usuários. Esses resultados 
corroboram estudo que identificou, no período de um mês, maior número de dias de trabalho remunerado entre os usuários de cocaína $(13,1 \pm 10,1$ dias) quando comparados aos de crack (9,6 $\pm 9,8$ dias) (KILUK et al., 2013).

O Relatório Brasil sobre drogas também pontuou o uso de cocaína como a segunda maior causa de afastamento/aposentadoria, perdendo posição apenas para o álcool e tabaco (BRASIL, 2009), fato que justifica o crescimento de 254\%, entre os anos de 2006 e 2013, do número de pedidos de auxílio-doença a dependentes de cocaína e seus derivados (merla, crack) (URIBE, 2014). Esses dados expressam a amplitude dos danos decorrentes do uso de cocaína na sociedade, os quais impactam na redução do papel economicamente ativo do sujeito, causam prejuízos físicos e psicológicos incapacitantes e geram gastos aos cofres públicos.

Evidencia-se, portanto, a necessidade de investimentos em intervenções com abordagens para além dos limites de atuação da saúde, estendendo-os a outros setores da sociedade, como educação e assistência social (BRASIL, 2004; SANTOS; OLIVEIRA, 2013). São também necessárias intervenções terapêuticas que considerem as diferenças do perfil ocupacional entre os usuários de cocaína e crack, como observado na área Emprego (ASI) (Tabela 15), pois esta contribui para melhores resultados no tratamento. Sabe-se que a satisfação com a situação ocupacional tem sido associada positivamente com qualidade de vida e reinserção social dos usuários de cocaína (MORALES-MANRIQUE et al., 2011; NIMTZ et al., 2016).

Em geral, os usuários de cocaína que possuem vínculos empregatícios formais podem ser beneficiados pela oferta de tratamento nos serviços com horários flexíveis, o que possibilita conciliarem o emprego com as atividades terapêuticas. Já os usuários de crack que respondem positivamente às intervenções psicossociais que preconizam o empoderamento pessoal e valorizam suas habilidades, como forma de instrumentalizar o indivíduo a buscar sua própria autonomia e reinserção social por meio do trabalho, apresentam maior compromisso com o tratamento (NIMTZ, et al., 2016; SINGULANE; SILVA; SARTES, 2016).

Pertinente discutir também neste estudo a denominada situação de rua. Os usuários de crack diferenciaram-se significativamente por esta situação (Tabela 1) e moradia em albergues públicos (Tabela 5). Tais características, comumente identificadas nessa população, como descrito em estudos sobre o perfil desses usuários (RAUPP; ADORNO, 2011; RIBEIRO; SANCHEZ; NAPPO, 2010; SANTOS CRUZ et al., 2013), foram observadas na 
análise multivariada, a qual evidenciou que estar em situação de rua aumenta potencialmente as chances de uso de $\operatorname{crack}$ (Tabela 13).

Dos usuários de crack, 26,8\% referiram permanência estável em situação de rua (Tabela 1), proporção superior à observada em estudo com usuários de crack em tratamento ambulatorial no Rio de Janeiro (10\%) (CRUZ et al., 2014). Esse subgrupo representa uma clientela de maior risco, pois, além dos altos níveis de mortalidade, transtornos mentais e prevalência de doenças infecciosas (DRAKE; OSHER; WALLACH, 1991; RIBEIRO; SANCHEZ; NAPPO, 2010; CRUZ et al., 2014), necessitam de assistência de saúde para problemas físicos e psíquicos ocasionados pelo uso da droga.

Estudo internacional assinalou a moradia como um ponto de apoio e reforço de segurança, por ser um local mais seguro, onde os indivíduos podem consumir o crack com pessoas nas quais confiam e os apoiam em termos de segurança (BUNGAY et al, 2010). No âmbito nacional, o manejo da exposição a riscos nos ambientes de uso ocorre por meio da segregação dos usuários em espaços urbanos denominados "cracolândias" (RAUPP; ADORNO, 2011), como forma de proteção e ajuda mútua durante o ritual de uso da droga (CHAVES et al., 2011; RIBEIRO; SANCHEZ; NAPPO, 2010). Embora essas áreas urbanas colaborem para a prática de atos ilícitos e aumentem a sensação de insegurança da vizinhança (TOLEDO; GÓNGORA; BASTOS, 2017), permitem visualizar a precária situação do uso do crack e, principalmente, localizar os indivíduos, antes ocultos do olhar da sociedade, em condição de vulnerabilidade que necessitam de assistência.

No presente estudo, observou-se também que os usuários de crack eram os que frequentavam albergues por mais tempo (dias) (Tabela 5). Albergues ou abrigos para indivíduos em situação de rua são locais que oferecem assistência emergencial de sobrevivência, mas que não possuem responsabilização e compromisso terapêutico com a dependência da droga, Nesse sentido, tem sido muito comum que usuários de crack, pelas dificuldades de sustentabilidade, acessem esses serviços de apoio social entre os ciclos de uso em binge da droga, apenas como forma de obtenção de vestuários, alimentação ou algum atendimento profissional de assistência social (CRUZ et al., 2014).

$\mathrm{Na}$ amostra, 29,2\% dos usuários de crack viviam em albergues, dados semelhantes aos observados entre usuários de crack em tratamento ambulatorial no Rio de Janeiro (27\%) (CRUZ et al., 2014). Trata-se de um resultado esperado, uma vez que na presente amostra há considerável parcela de usuários em situação de moradia de rua, além de elevados índices de 
marginalização socioeconômica e carência de serviços de suporte social para sobrevivência (DRAKE; OSHER; WALLACH, 1991; CRUZ et al., 2014).

No presente estudo, vale destacar que os usuários de cocaína inalada em situação de moradia de rua eram minoria $(6,4 \%)$ (Tabela 1$)$. No entanto, na avaliação dos últimos seis meses, esse número foi bem superior $(24,3 \%)$ e o mais preocupante refere-se ao uso da droga no padrão binge (Tabela 5). A situação de rua vem sendo identificada como um fator social relacionado a diferentes condições de saúde entre usuários de drogas (GALEA; VLAHOV, 2002). Em usuários de cocaína inalada, o uso intenso foi associado a estar em condições de moradia instável e a um estilo de vida precário entre indivíduos em tratamento ambulatorial (Morales-Manrique et al., 2011).

No âmbito do tratamento, esses sujeitos representam um grupo prioritário para a assistência à saúde, de modo que necessitam, veementemente, serem acolhidos pelos profissionais dos diversos serviços de saúde, inclusive Unidades Básicas de Saúde (UBS) (SANTOS; OLIVEIRA, 2013) e serviços especializados para tratamento da dependência, como os CAPS-ad e os Consultórios de Rua (BRASIL, 2014). Já os profissionais de saúde precisam direcionar suas intervenções terapêuticas às especificidades desses sujeitos em situação de rua, as quais incluem, entre outros aspectos, ausência de documentação pessoal, condição que com frequência prejudica a inserção em atendimentos nos serviços de assistência social e de saúde (TOLEDO; GÓNGORA; BASTOS, 2017).

Outro dado a ser pontuado diz respeito a tratamentos prévios, cuja maior frequência ocorreu entre os usuários de crack (Tabela 1). Trata-se de um dado até certo ponto esperado e bastante descrito na literatura, entre usuários de drogas, principalmente pela cronicidade do problema (DENNIS et al., 2005; RIBEIRO, LARANJEIRA, 2012). Observa-se, ao longo do tempo e com base nos primeiros estudos que avaliaram os usuários de crack em tratamento, que esse grupo foi o que menos buscou ajuda, postergando o máximo a busca por tratamentos e restringindo-a a situações agudas, na vigência das quais preferem abordagens em ambientes de internação, com baixa adesão ambulatorial posterior (RIBEIRO, LARANJEIRA, 2012). Este aspecto foi descrito em estudo longitudinal que evidenciou maior busca por tratamento em serviços de saúde (internação ou ambulatórios) por parte de usuários de crack se comparados aos de cocaína. Entretanto, esses usuários permanecem no serviço por menor período de tempo (média 21,6 dias) na comparação com usuários de cocaína inalada (em média 27,4 dias) (KILUK, et al, 2013). 
Nesse sentido, a presença de tratamento anterior, a severidade da dependência, incluindo os recorrentes períodos de abstinência e recaída, além dos fatores motivacionais, predispõem a busca para o tratamento (RIBEIRO, LARANJEIRA 2012; MILLER; ROLLNICK, 2001). A motivação é um dos elementos mais importantes para o sucesso da terapêutica, e a literatura mostra que os usuários de crack possuem dificuldades de se manter sob tratamento (SOUZA et al., 2013).

Estudo mostrou que o tempo decorrido entre o uso da cocaína e a abstinência total tem sido muito longo e variado, incluindo os períodos sem uso da droga (DENNIS et al., 2005), o que contribui para frequentes passagens em serviços de saúde (MARLATT, DONAVAN, 2009). Essa característica também foi observada em um dos maiores estudos de seguimento realizados no Brasil com usuários de crack, cujos resultados revelaram, após cinco anos de tratamento, que apenas uma pequena parcela dos usuários estava em abstinência (39,7\%); outros 22,3\% tinham sido readmitidos novamente no serviço para desintoxicação e 47,5\% procuraram outros locais para tratamento da dependência (RIBEIRO et al., 2007).

Há de se destacar que, no presente estudo, uma grande parte dos usuários de crack apresentava envolvimento em atividades criminais, residia em moradia instável, relatou prejuízos nas relações pessoais, problemas financeiros, baixo funcionamento social (emprego e nível educacional) e comprometimentos na área psiquiátrica. Tais fatores podem não só resultar em situações de alto risco e sofrimento psíquico, como também contribuem tanto para o processo da recaída e manutenção do uso da droga quanto para baixas motivações para o tratamento, aspectos que favorecem a ocorrência de diversas passagens por serviços de saúde (RIBEIRO et al., 2007; STOTTS et al., 2007; MARLATT; DONAVAN, 2009; PEDROSO et al., 2013).

Além disso, outros fatores relacionados ao padrão de consumo, como maior intensidade dos efeitos e aumento da duração do tempo de uso de crack (ROSA, 2015; ROY et al., 2017), uso associado de outras substâncias psicoativas (DUNN; LARANJEIRA, 1999; JORA, 2014), principalmente o álcool (PENNINGS; LECCESE; WOLFF, 2001), predispõem o usuário a recaídas e contribuem para a baixa adesão ao tratamento e subsequentes retornos aos serviços terapêuticos.

Diante do exposto, o principal foco na prática assistencial deve ser o manejo de fatores de risco para a recaída, com busca de estratégias que favoreçam a adesão terapêutica com base no conhecimento das peculiaridades dos usuários e de suas vulnerabilidades. De acordo com Mckay et al. (2004) e Ribeiro et al. (2007), usuários de crack que receberam tratamento 
contínuo reduziram o consumo da droga nos meses subsequentes e apresentaram melhores prognósticos em relação à gravidade da síndrome de dependência.

Neste estudo, os usuários de crack, em maior frequência, passaram por serviços de saúde para tratamento da dependência, em ambulatório e internação (Tabela 7 e Tabela 5), com uso crônico de drogas (Tabela 10). O maior número de passagens por serviço de tratamento pode estar associado a diversos problemas físicos, mentais, sociais e, ainda, ao próprio uso crônico da droga com importantes prejuízos sociais e contextuais que comprometem o acompanhamento e desfecho no tratamento (MCKAY et al., 2004; RIBEIRO et al., 2007; STOTTS et al., 2007; RIBEIRO; LARANJEIRA, 2012; RODRIGUES et al., 2013).

Por outro lado, convém ressaltar que o tratamento para a dependência de crack permanece um desafio entre os profissionais de saúde, em virtude da singularidade dos fatores causais (BORDERS et al., 2009; RIBEIRO; LARANJEIRA, 2012). Estudo de revisão sistemática da literatura sobre os tratamentos psicossociais oferecidos a usuários de crack verificou ausência de consenso acerca das intervenções mais eficazes no desfecho do tratamento; contudo, bons prognósticos são otimizados por intervenções individualizadas, com manejo dos elementos facilitadores ou determinantes de recaídas, como os problemas ocupacionais e financeiros, ou mesmo as complexidades referentes ao ambiente de tratamento (MCKAY et al., 2004; RODRIGUES et al., 2015). Nesse sentido, um olhar direcionado às reais necessidades dos usuários de crack ou de cocaína potencializa as possibilidades de sucesso do tratamento. A abordagem completa da dependência inicia-se logo na triagem realizada pelos profissionais de saúde, por meio do fortalecimento de vínculos, cuidado personalizado e identificação das metas desejáveis no tratamento, como estratégia de melhorar a adesão terapêutica (RANGÉ, 2001; KANTORSKI et al, 2010, ALVES; RIBEIRO; CASTRO, 2011).

Em relação a emprego e finanças (Tabela 2), os usuários de crack destacaram-se como um subgrupo detentor de precárias condições financeiras, tanto por baixa renda mensal $(\leq \mathrm{um}$ salário mínimo) quanto por renda incompatível com as despesas. Considera-se o aspecto socioeconômico um indicador social diretamente relacionado à vulnerabilidade desse grupo (GALEA; VLAHOV, 2002) e documentado na literatura (HORTA et al., 2011, FREIRE et al., 2012; SANTOS CRUZ et al., 2013; SELEGHIM; OLIVEIRA 2013; BOTTI; MACHADO; TAMEIRÃO, 2014; PALAMAR; DAVIES; OMPAD, 2015; GALASSI et al., 2016). Estudos mostram que quase a metade $(40 \%$ a $45 \%)$ dos usuários de crack em tratamento (internação e 
ambulatorial) ganha salários muito baixos (um salário mínimo) (ZENI; ARAÚJO, 2011, DIEHL et al., 2014).

Destaca-se que o baixo poder aquisitivo dos usuários de crack da presente amostra pode estar sendo influenciado diretamente pela baixa escolaridade e ausência de vínculos empregatícios, como já mencionado (Tabela 1). A carência de recursos financeiros, além de prejudicar o compromisso com as despesas do próprio indivíduo, foi identificada por Narvaez et al. (2015) como elemento capaz de potencializar os prejuízos individuais e comprometer os diversos aspectos que envolvem saúde física, suporte social e familiar, com interferências na qualidade de vida.

Por fim, vale destacar que os usuários de crack, embora desempregados e com baixa renda mensal, usaram algum tipo de droga pelo menos 15 dias no último mês (Tabela 10) e reportaram valores gastos com a compra entre $\mathrm{R} \$ 10,00$ e $\mathrm{R} \$ 250,00$ nos últimos seis meses (Tabela 12). Todavia, nota-se que receberam auxílio financeiro de familiares e/ou amigos, uma vez que o contato com essas pessoas tem sido preservado nesse grupo (Tabela 2). Os usuários de crack, pela sua precária condição socioeconômica, geralmente dependem financeiramente de familiares e de auxílios governamentais para pagamento de suas despesas, incluindo o dinheiro para aquisição droga (PALAMAR; DAVIES; OMPAD, 2015). Cruz et al. (2014) descreveram também ser muito comum que esses indivíduos busquem fontes alternativas de renda, como esmolas, roubo ou prostituição (troca de sexo por dinheiro ou drogas). Por outro lado, é mais provável que os usuários de cocaína adquiram a droga com dinheiro proveniente do emprego, uma vez que estão em situações mais estáveis e apresentam melhores funcionamentos sociais (KILUK et al., 2013).

No que concerne aos aspectos legais (ASI) (Tabela 15), não houve diferenças entre a amostra; no entanto, os usuários de crack apresentaram maior envolvimento em situações de violência (sofrer agressão, roubos e presenciar homicídio) nos últimos seis meses (Tabela 3). Apesar das peculiaridades entre os grupos, evidências apontam que o envolvimento em situações de violência que resultam em agressões físicas tem sido comum nessa população, em virtude do próprio comportamento de uso do crack (violência psicofarmacológica) (GOLDSTEIN, 1985; PENNINGS; LECCESE; WOLFF, 2001) estar intimamente relacionado à exposição em contextos ambientais, sociais, situacionais e culturais com potencial para ocorrência de episódios de violência, e de serem locais onde há uso e tráfico de drogas (violência sistêmica) (GOLDSTEIN, 1985; RAUPP; ADORNO, 2011; BOLES; MIOTTO, 2013; ZHAO et al, 2015; PAIM KESSLER et al., 2012). Esse dado foi revelado 
em estudos que observaram associações entre as situações de vulnerabilidade psicossocial em grupos de usuários com baixo perfil socioeconômico e o tráfico de drogas (CARVALHO; SIEBEL 2009; BEATO FILHO et al., 2001).

Percebe-se que, além da intrínseca influência da violência psicofarmacológica ocasionada pelo uso do crack, o uso concomitante de álcool ou outras substâncias pode contribuir para potencializar as situações de agressão (GOLDSTEIN, 1985; PENNINGS; LECCESE; WOLFF, 2001). De acordo com Zhao et al. (2015), os efeitos da intoxicação aguda do uso simultâneo do álcool e da cocaína aumentam significativamente o risco de sofrer lesão após agressão e de vivenciar mais situações de violência. Outros fatores que possivelmente explicam os quadros de envolvimento em situações que resultam em agressão física sofrida são os conflitos vivenciados com a polícia e os traficantes (RIBEIRO; SANCHEZ; NAPPO, 2010).

A intensidade dos efeitos do uso do crack (HATSUKAM; FISCHMAN, 1996), a capacidade dessa substância desencadear sintomas psiquiátricos agudos e os prejuízos na capacidade de julgamento das próprias ações (SCHUCKIT, 2006; FORD et al, 2009), incluindo a paranoia, contribuem para o engajamento em agressões nas quais o sujeito pode ser perpetrante ou vítima da ação (GOLDSTEIN, 1985; VAUGHN et al., 2010).

Os resultados identificados neste estudo corroboram achados da literatura, por apontarem um grupo de indivíduos em precárias situações de vulnerabilidades psicossociais e financeiras, com padrão peculiarmente intenso de uso da droga que compromete aspectos relacionados a emprego e sustentabilidade e favorece maior envolvimento em situações de risco para obtenção da droga e manutenção do uso (VAUGHN et al., 2010; SANTOS CRUZ et al., 2013; PALAMAR; DAVIES; OMPAD, 2015). Essa sobreposição de problemas conduz à necessidade de novamente adquirir a droga, definida por Goldstein (1985) como "violência de compulsividade econômica", intensamente induzida pelos sintomas de abstinência, com presença de fissura. Nesse sentido, a urgência pelo consumo do crack e a falta de dinheiro para suprir sua demanda colocam o usuário em situação de vulnerabilidade, fazendo com que se submeta a estratégias e situações de risco (tráfico de drogas, sexo sem proteção, dentre outros comportamentos de risco) e violência para obtê-lo (assaltos, brigas, homicídios) (OLIVEIRA; NAPPO, 2008; OLIVEIRA; NAPPO, 2008; SANTOS CRUZ et al., 2013; PALAMAR; DAVIES; OMPAD, 2015; DIEHL et al., 2016). 
Em relação aos problemas legais, no estudo de Carvalho e Siebel (2009), 97\% da amostra se envolveram apenas com violência, $84 \%$ uso de drogas e situações de violência, e o uso de crack foi associado a ameaças de morte (OR = 2,0 IC 1,6-5,3).

Pode-se afirmar ainda que os usuários de crack apresentaram maior exposição a ambientes de risco, como os de tráfico, em virtude da maior frequência de uso da droga (Tabela 12). A esse respeito, a literatura mostra que o uso dessa droga está, muitas vezes, interligado à forte repressão do tráfico que, somada ao estigma e preconceito, estabelece um contexto propício ao envolvimento em ambientes altamente vulneráveis a situações de violências e práticas ilegais (HATSUKAMI; FISCHMAN, 1996; TOLEDO; GÓNGORA; BASTOS, 2017).

Os dados aqui apresentados reiteram a necessidade de rompimento com a visão simplista de que todo usuário apresenta comportamentos agressivos, uma vez que há predisposição de se tornar vítima nesse contexto do uso de drogas em função da própria ilegalidade do tráfico de drogas, de modo que a violência é frequentemente empregada como regra social (FAGAN 1993).

Além das explicações sobre os tipos de violências descritos por Goldstein (1985) e Fagan (1993), há de se reconhecer o papel das questões socioculturais que contribuem para a violência perpetrada em função da estigmatização do contexto em que vivem ou mesmo de aspectos pertinentes à individualidade do sujeito, como as comorbidades psiquiátricas (ALVEZ; RIBEIRO; CASTRO, 2011).

Outro resultando importante refere-se às condenações criminais presentes na amostra, com encarceramentos antes e depois dos 18 anos, além de prática de agressão física (Tabela 3). Estudo nacional mostrou envolvimento em atividades violentas ou ilegais entre usuários de crack e cocaína, sendo que os primeiros apresentaram maiores danos associados às diversas áreas de funcionamento da vida (ASI) (PAIM, KESSLER et al., 2012). Considerando que o uso de crack tem sido um preditor para diversos comportamentos violentos (HATSUKAMI; FISCHMAN, 1996; KILUK et al, 2013; PALAMAR; DAVIES; OMPAD, 2015; DIEHL et al., 2016) e para envolvimento criminal, evidencia-se um incremento do número de usuários nesta situação (KILUK et al., 2013; KESSLER et al., 2012).

No que concerne aos aspectos familiares, os usuários não se diferenciaram em relação à presença de problemas familiares (ASI) (Tabela 15), porém a fissura (CCQ-B) foi correlacionada com a área Família (ASI) (Tabela 16), dado que reforça o comprometimento das relações familiares pelo consumo de crack (SELEGHIM; OLIVEIRA, 2013; NARVAEZ 
et al., 2015). Estudo avaliou tais problemas entre usuários de crack e cocaína e identificou elevados índices de prejuízos no contexto familiar quando comparados aos de álcool e outras drogas (MOURA et al., 2014).

Os achados corroboram os resultados de um estudo que evidenciou problemas familiares semelhantes entre usuários de crack e de cocaína, por exemplo, discussão com alguém da família (crack 66,5\% versus cocaína inalada 63,3\%) ou com parceiros (crack 61,5\% versus cocaína inalada 64,6\%) (MOURA et al., 2014).

A presença de fissura e outros sintomas de abstinência do crack ou cocaína pode ser um dos fatores responsáveis pelos conflitos familiares quando se compara o uso de outras substâncias psicoativas. Os prejuízos que influenciam as relações interpessoais (familiares e membros da comunidade local) são muitas vezes resultantes da alteração comportamental de natureza psíquica, a paranoia induzida pela cocaína (MORALES-MANRIQUE et al., 2011). Nesse aspecto, os usuários de crack estão mais vulneráveis, visto que vivenciam efeitos agudos mais intensos quando comparados aos de cocaína (ROY et al., 2017).

Outros estudos identificaram possíveis associações com maiores problemas nesses grupos por ausência da figura paternal (NARVAEZ et al., 2015), deficiência no apoio dos pais para tratamento, cultura familiar de uso de álcool e outras drogas, além de desinformação e falta de conhecimento na família sobre o uso de crack e outras drogas (OLIVEIRA; SELEGHIM, 2013).

Apesar da presença de problemas no âmbito familiar, os usuários de cocaína inalada e de crack mantinham contato próximo (pessoalmente) com algum familiar (Tabela 4). Esses resultados corroboram os do estudo de Moura et al. (2014), em que se verificou que a maioria dos usuários de crack/cocaína em tratamento ambulatorial ou internação passou algum tempo com parentes no último mês. A presença de suporte familiar é especialmente comum entre usuários em tratamento ambulatorial (PEIXOTO et al., 2008), em virtude da importante influência da rede de suporte social ou familiar na monitorização da saúde e no encaminhamento para tratamento (Tabela 4).

De maneira geral, a família desempenha papel fundamental no adoecimento psíquico relacionado ao uso problemático de drogas. Nesse sentido, como preconizado pelas diretrizes assistenciais (BRASIL, 2004), ela deve ser inserida no processo de tratamento e instrumentalizada para acompanhar o projeto terapêutico no âmbito domiciliar (KANTORSKI et al., 2012). 
Assim, cabe aos profissionais que atuam em serviços de saúde para a dependência de drogas avaliar e manejar de modo realístico os possíveis conflitos familiares que possam emergir no cotidiano dos usuários de cocaína (fumada e inalada), e propor uma assistência individualizada, capaz de direcionar intervenções específicas (ALVAREZ et al., 2012). Para tanto, torna-se imperativo desenvolver intervenções que contemplem as especificidades de cada unidade familiar e a sua influência no desenvolvimento da dependência (SELEGHIM et al., 2011; MORALES-MANRIQUE et al., 2011; KILUK et al., 2013).

Em relação aos relacionamentos sociais, os usuários de cocaína inalada, em maioria, mantiveram contatos com amigos (Tabela 4). Já os usuários de cocaína e/ou crack apresentam maiores prejuízos no funcionamento social, quando comparados com a população em geral (NARVAEZ et al., 2015; RIBEIRO et al., 2016). No entanto, os usuários de crack destacamse pela presença de severos prejuízos no funcionamento adaptativo em função da dependência, principalmente no que diz respeito aos vínculos de amizade (88\%) (SAYAGO et al., 2014). Outro fator que prejudica a manutenção de vínculos sociais é o próprio consumo da droga, geralmente no padrão binge com busca compulsiva pela droga, que leva a rompimentos nas relações sociais (RIBEIRO et al., 2016). Segundo Morales-Manrique et al. (2011), os usuários crônicos de crack que apresentam padrão de uso pesado também relatam prejuízos nos relacionamentos com pessoas na rua, na vizinhança, família e entre amigos.

Por outro lado, os usuários de cocaína (inalada) apresentaram características peculiares e mais preservadas, como melhor nível educacional, ocupação profissional e menor número de problemas psiquiátricos, o que favorece a ocorrência de interações sociais, por terem comportamentos menos desajustados nos aspectos sociais (KILUK et al., 2013; NARVAEZ et al., 2015; RIBEIRO; SANCHEZ; NAPPO, 2010; RAUPP; ADORNO, 2011; BORDERS et al., 2009). A maior funcionalidade social dos usuários da cocaína inalada também tem sido avaliada no ritual de uso da droga, uma vez que optam pelo consumo, inclusive em associação com álcool, em grupos de amigos, enquanto os usuários de crack possuem menos motivações para tanto, preferindo o uso mais isolado da droga (MARTINS et al., 2014).

As relações sociais precárias entre os usuários de crack (Tabela 4) representam ainda um potencial fator de risco à saúde. De acordo com Marinho et al. (2011), esses usuários, ao reduzirem os contatos pessoais e afetivos, diminuem o apoio recebido por parte da rede de relacionamentos e, consequentemente, restringem o monitoramento da saúde exercido por tal rede de convívio. 
Nesse sentido, a terapia de rede social emerge como uma intervenção promotora de saúde com resultados mais promissores na reinserção social (MARINHO; SILVA; FERREIRA, 2011), além de ser uma importante ferramenta de apoio na execução do plano terapêutico das equipes multidisciplinares dos CAPS-ad (PILLON; JORA; MANOEL, 2011). Tais achados corroboram os apresentados por Heinz et al., (2009), os quais avaliaram que a disponibilidade de apoio do parceiro ou a manutenção de estreitos vínculos de amizades foram associadas a melhores resultados do tratamento entre usuários de cocaína inalada.

No presente estudo, observou-se correlação positiva entre síndrome de dependência (SDS), fissura (CCQ-B) e a área Problema Familiar e Social (ASI) (Tabela 16). Esse resultado sinaliza que o entrosamento social pode ser alterado à medida que aumentam os níveis de gravidade da dependência da cocaína inalada. Indivíduos usuários crônicos de cocaína inalada também são susceptíveis ao desenvolvimento de problemas no componente social à medida que elevam o consumo da droga, pois isso resulta em uma maior propensão à moradia em comunidades com maior risco para a violência, pouca utilização de recursos comunitários, isolamento social, além de problemas de relacionamentos com amigos e parceiros (MORALES-MANRIQUE et al., 2011).

Observaram-se, na amostra, baixos índices de problemas relacionados a condições físicas, testagens de HIV e pouca utilização de serviços de saúde nos últimos seis meses (Tabela 6). Entretanto, esses resultados chamam a atenção porque, em geral, tais usuários apresentam diversas complicações físicas (cardiovasculares, hepáticas, neurológicas) decorrentes do uso, dos efeitos da própria droga e ainda da ação de outras substâncias (adulteradas) sobre o organismo, as quais, somadas ao estilo de vida, os expõem às mais diversas situações de risco (DST) que agravam expressivamente o estado clínico e mental (DUAILIBI; RIBEIRO; LARANJEIRA, 2008). Nesse sentido, a literatura descreve que diante de complicações agudas relacionadas ao uso da droga ou de agravos clínicos por causas externas, essas pessoas muito frequentemente buscam por serviços de urgência/emergência (SELEGHIM et al., 2011; SILVINO et al., 2012). Deve-se considerar ainda que o uso de droga é um dos principais responsáveis pela disseminação do vírus do HIV (UNAIDS, 2006).

Segundo dados do Relatório mundial sobre o panorama de infecção pelo vírus HIV, cerca de $27 \%$ dos usuários de crack brasileiros apresentam sorologia positiva para HIV/AIDS, sendo a prevalência e a incidência da doença maiores entre as mulheres (UNAIDS, 2006). Outro estudo no município de Campinas (São Paulo) verificou que o uso de crack e a prática de sexo sem proteção estão associados à infecção por HIV de usuários de crack (11\%) em 
tratamento para a dependência da droga, sendo predominante no sexo masculino (AZEVEDO; BOTEGA; GUIMARÃES, 2007).

Estudo com usuários de crack realizado nas cidades de Salvador e do Rio de Janeiro mostrou que, embora metade da amostra reportasse problemas de saúde física ou psicológica, a maioria não recebeu tratamento para tais agravos (SANTOS CRUZ et al., 2013). Outros estudos sugerem que o próprio sistema de saúde tende a excluir esses usuários dos serviços, pela oferta apenas das tradicionais modalidades de assistência, pouco apropriadas para acolher as peculiaridades desse grupo de indivíduos (CAMPBELL et al. 1998; SANTOS; OLIVEIRA 2013).

O acesso a serviços clínicos fornece um indicador indireto da gravidade da dependência de cocaína (fumada ou inalada) e, sob tal perspectiva, estudo com amostra similar observou associações positivas entre ocorrência de reações adversas agudas do uso da droga em usuários que nunca passaram por serviços de saúde (FERRI et al., 2004).

Outro elemento importante a ser considerado são as barreiras e os desafios enfrentados pelos profissionais na assistência a esses usuários, tais como preconceito, exclusão, além de baixa qualificação e despreparo técnico dos membros das equipes de saúde para trabalhar com essa população em evidente crescimento, de modo a contemplar as diversas necessidades biopsicossociais dessa clientela (DUNN; LARANJEIRA; 1999; SANTOS; OLIVEIRA; 2013; UNODC, 2016; DIEHL et al., 2014).

Também se observou, independentemente da via de uso da cocaína, que à medida que diminuem os problemas relacionados à síndrome de dependência da droga (SDS), aumentam significativamente os problemas de saúde mensurados na área Médica (ASI) (Tabela 16). Esses resultados sugerem que o uso crônico da cocaína ou de outras drogas pode estar mascarando os sintomas físicos, os quais muitas vezes passam despercebidos pelos usuários (VOLKOW; KOOB; MCLELLAN, 2016). Assim, no momento da remissão dos sintomas eminentemente psíquicos associados à dependência da droga é possível que os sintomas clínicos possam sobrepujar o antigo quadro sindrômico relacionado ao uso problemático de drogas, assim evidenciando graves implicações na saúde física até então mascaradas pelo uso. Segundo Falck et al. (2000), a percepção do estado de saúde apresenta associação negativa com o nível de dependência do crack, ou seja, quando maior a dependência, menor o cuidado com a saúde física. Contudo, após a diminuição do consumo de droga, há pequenas melhorias na percepção do estado de saúde físico entre os usuários durante os primeiros dois anos de 
tratamento, o que pode contribuir para o aumento de diagnósticos clínicos (BORDERS et al., 2009).

Sobre os dados relativos à área Psiquiátrica, a presença de problemas nessa esfera (ASI) (Tabela 15), como dificuldades para dormir, controlar o temperamento e alucinações (Tabela 7) foi a mais evidente entre os usuários de crack. Trata-se de um resultado esperado, pois transtornos psiquiátricos como ansiedade e depressão e outras comorbidades são muito frequentes entre usuários de drogas (SCHUCKIT et al., 2006; PAIM KESSLER, et al., 2012; JORA, 2014), além da maior intensidade das alterações comportamentais resultantes dos prejuízos neurobiológicos dessa via de uso (GOLDSTEIN, 1985; HATSUKAMI; FISCHMAN, 1996; VOLKOW; KOOB; MCLELLAN, 2016). Dessa forma, tais sujeitos apresentam maiores prejuízos psicopatológicos tanto pelo uso pesado e crônico da droga quanto pelo rápido desenvolvimento da dependência (REBOUSIN; ANTHONY, 2006; CHAVES et al., 2011) (SCHUCKIT et al., 2006).

Estudo brasileiro relatou alta prevalência de sintomas psiquiátricos entre usuários de cocaína, com variações entre 27,4 e 53,4\% (KESSLER et al., 2008). Aqueles em uso preferencial da via fumada apresentavam maior prevalência de transtorno depressivo maior $(47,8 \%)$, ideação suicida $(47,4 \%)$ e transtorno de déficit de atenção e hiperatividade $(36,8 \%)$, enquanto os usuários de cocaína inalada apresentaram mais ideação suicida (66,7\%), dependência de álcool (58,3\%), transtorno de déficit de atenção e hiperatividade $(47,2 \%)$ (PAIM KESSLER, et al., 2012). Convém ressaltar que o diagnóstico de transtorno depressivo maior, embora não relacionado à gravidade da dependência, é um dos principais danos associados à busca de tratamento (FORD et al., 2010).

Outro estudo internacional avaliou usuários de cocaína (ambas as vias) em tratamento e identificou presença de transtornos relacionados ao uso de álcool (crack $74.6 \%$ versus cocaína $79.7 \%$ ), transtorno depressivo maior (crack $18.6 \%$ versus cocaína $20.7 \%$ ), transtorno de ansiedade (crack $11.8 \%$ versus cocaína $2.4 \%$ ) e transtorno de personalidade antissocial (crack $24.2 \%$ versus cocaína 35.2\%) (KILUK et al., 2013). Kiluk et al. (2013) destacaram que os usuários de cocaína inalada alcançaram, após um ano de tratamento, os melhores resultados em relação aos problemas psiquiátricos.

A área Psiquiátrica (ASI) correlacionou-se positivamente com a síndrome de dependência de cocaína (SDS) e níveis de fissura (CCQ-B) (Tabela 16). Entre usuários de cocaína, tanto no uso crônicos quanto naqueles que utilizam a droga por poucos dias, em forma de uso compulsivo ou binge, esses resultados são esperados tendo em vista os 
entrelaces entre síndrome da dependência da droga (SDS), períodos de abstinência (fissura) e complicações psiquiátricas ou comorbidades que são muito frequentes nessa população, além de tudo favorecem as chances para busca de tratamentos. De acordo com um estudo de revisão de literatura sobre o abuso e dependência de crack (MARQUES, RIBEIRO, LARANJEIRA, ANDRADA, 2012), os autores destacaram que os sintomas de abstinência da cocaína são eminentemente psíquicos, sendo os depressivos e ansiosos os mais comumente encontrados.

Nesse sentido, a literatura evidencia que a dependência, o uso da cocaína gera uma série de efeitos físicos e psíquicos desagradáveis nos usuários, como prejuízos neurológicos e complicações psiquiátrica, podendo ter sintomas depressivos durante a abstinência da droga ou psicóticos (RIBEIRO; NAPPO; SANCHEZ, 2012).

Nesse sentido, a presença de sintomas psiquiátricos de insônia, episódios de alucinação e dificuldade para controlar o temperamento e a agressividade, comuns durante os episódios de intoxicação aguda (HASIN; SILVA; CARVALHO, 2008), podem ajudar a compreender a associação observada entre o grave consumo de crack e a presença de comorbidades psiquiátricas. Segundo Roy et al., (2017), analisar as alterações de humor induzidas pela droga em conjunto com as adversidades sociais do indivíduo permite identificar uma série de mecanismos, envolvendo fatores cognitivos e psicológicos, que contribuem para o início dos episódios de uso em binge ou a instalação de um quadro de psicopatológico. Importante assinalar que a alteração do padrão do sono constitui um sinal de alerta de estresse cerebral, comumente relacionado a alguma comorbidade psiquiátrica (SCHUCKIT et al., 2006).

\subsection{Fatores associados ao uso de cocaína (fumada e inalada) e outras drogas}

Quanto ao uso de cocaína e crack, os usuários diferenciaram-se nos seguintes aspectos: frequência de uso nos últimos seis meses, uso recente (últimos 30 dias) e uso associado de álcool e/ou de outras drogas (na vida), com predomínio entre os usuários de crack (Tabela 8-12), exceto em relação ao tempo, em anos, de uso crônico (3-4 vezes na semana), que foi maior apenas entre os usuários de cocaína inalada (Tabela 10).

A síndrome de dependência da cocaína (SDS) e fissura (CCQ-B) foram correlacionadas com a área Droga (ASI). Além disso, merece destaque a área Álcool (ASI), correlacionada aos níveis de gravidade da dependência do álcool (SADD e AUDIT) da droga 
(SDS) e fissura (CCQB) (Tabela 16). Percebe-se que a dependência da cocaína (SDS) interfere na maioria das áreas avaliadas pela ASI.

De acordo com resultados obtidos por Domingo (2012) em estudo comparativo com usuários de cocaína e crack de um CAPS-ad, há similar correlação entre as áreas Droga (ASI), Dependência da cocaína (SDS) e Fissura (CCQ-B). Outro estudo que utilizou a ASI para avaliar a gravidade da dependência de cocaína de acordo com as vias de uso da droga em relação a outras substâncias psicoativas verificou que os usuários de crack apresentavam problemas mais graves nas áreas Psiquiátrica, Problema Familiar e Social, Aspectos Legais e Drogas quando comparados aos outros dois grupos (PAIM KESSLER et al., 2012).

As variações do padrão de consumo segundo a via de uso da cocaína vêm sendo descritas na literatura como resultantes da velocidade com que se instala o consumo compulsivo, o qual culmina em um quadro grave de dependência, incluindo tolerância e sintomas de abstinência (HATSUKAMI; FISCHMAN, 1996; VOLKOW; KOOB; MCLELLAN, 2016). Dessa forma, estudos comparativos com amostras similares convergem para a maior gravidade do uso em usuários de crack (DUNN; LARANJEIRA, 1999; GUINDALINI et al., 2006; KILUK et al., 2013; JORA, 2014; ROY et al., 2017).

Como exposto previamente, a maior biodisponibilidade da forma fumada da cocaína (CHASIN; SILVA; CARVALHO, 2008) resulta em um padrão de consumo intenso (DUNN; LARANJEIRA, 1999; GUINDALINI et al., 2006; ROY et al., 2017) e maior gravidade da dependência (DUNN; LARANJEIRA, 1999; GUINDALINI et al., 2006; BORDERS et al., 2009; MORALES-MANRIQUE et al., 2011). Na presente amostra, os usuários de crack, como esperado, apresentaram um padrão de consumo mais pesado da droga, com aumento concomitante e progressivo da gravidade dos riscos associados (Tabela 12).

Mais da metade dos usuários de crack $(54,9 \%)$ usou a droga por mais de 90 dias nos últimos seis meses (Tabela12), o que revela que apresentam maior intensidade de uso compulsivo e são mais vulneráveis à progressão do uso problemático e a problemas associados (HATSUKAMI; FISCHMAN, 1996; CHASIN; SILVA; CARVALHO, 2008; ROY et al. 2017).

Esses resultados concordam com os achados de Roy et al. (2017), que identificaram maior prevalência de episódios de consumo no padrão binge em usuários de crack quando comparados aos de cocaína, com média de consumo intenso de três vezes ao mês. Esses autores destacaram a complexidade dos fatores relacionados à dependência do crack ao avaliarem que, além do alto potencial de dependência, outros aspectos podem determinar a 
ocorrência do consumo pesado, tal como idade mais avançada, estar em situação de rua, apresentar psicopatologias, engajamento em atividade criminais e níveis graves de dependência (ROY et al., 2017). Esses fatores corroboram o perfil dos usuários de crack identificados no presente estudo e, mais uma vez, evidenciam a maior gravidade e amplitude de agravos resultantes dessa via de consumo quando comparada à droga inalada.

Apesar da frequência de uso do crack ter sido mensurada nos últimos 30 dias (Tabela 12), a literatura relata que usuários com níveis graves de dependência e padrão de consumo intenso apresentam consumo quase diário (média = 5,2 g) da droga (FERRI et al., 2004). Por outro lado, os usuários de cocaína inalada usaram a droga com menor frequência, geralmente três a quatro vezes por semana (HATSUKAMI; FISCHMAN, 1996; KILUK et al., 2013). Entretanto, esta variação na frequência de uso não significa diminuição da sua gravidade (independentemente da via de uso), uma vez que cada nível de consumo possui distintos graus de prejuízos associados (MORALES-MANRIQUE et al., 2011), tal como observado entre os usuários de cocaína inalada no presente estudo, os quais apresentaram problemas nas diversas áreas de funcionamento da vida (ASI) (Tabela 15).

Em relação aos usuários de cocaína inalada, aproximadamente 17\% deles relataram situação de rua devido ao uso compulsivo da cocaína (binge), excluindo-se os usuários dessa via em situação de rua antes mesmo do início de uso $(\mathrm{n}=5)$ (Tabela 5). Embora de natureza esporádica e com percentual pouco expressivo quando comparado aos usuários de crack, essas características foram descritas como potenciais de risco para a ocorrência de alguns comportamentos, como o engajamento em atividades criminais (CHAVES et al., 2011; ROY et al., 2017) e relacionamento sexual de risco (DIEHL et al, 2016).

Os usuários de cocaína inalada apresentaram maior tempo de consumo crônico dessa droga $(9,8 \pm 6,4$ anos), aproximadamente três anos a mais que os de crack (Tabela 10). Evidências apontam que usuários de cocaína tendem a usar a droga por longos períodos até procurarem tratamento, o que ocorre geralmente após o décimo ano de uso (DENNIS et al., 2005). A via inalada, por ter uma duração de efeito maior e consequente menor intensidade do padrão de consumo permite o uso prolongado da droga e possivelmente retardamento dos riscos associados (HATSUKAMI; FISCHMAN, 1996; VAUGHN et al., 2010).

Outro elemento que pode favorecer a percepção de riscos associados ao uso da droga ou até mesmo episódios de uso esporádicos de forma menos prejudicial é o monitoramento sistemático das redes de suporte social e familiar (MARINHO; SILVA; FERREIRA, 2011). Conforme evidenciado no presente estudo, os usuários de cocaína inalada apresentaram maior 
entrosamento social, expresso por vínculo empregatício, suporte de amigos e constante contato familiar (Tabela 1, Tabela 4).

Acrescenta-se que o uso inalado de cocaína é geralmente a forma inicial de experimentação dessa droga, o que dificulta identificar a progressão do uso recreacional para o uso nocivo e/ou instalação da dependência pelos usuários e, portanto, pode favorecer o uso prolongado da droga e a busca por serviços de saúde somente quando os danos estão agravados, ou seja, já afetam outras áreas de funcionamento da vida (BRASIL, 2009; RIBEIRO; LARANJEIRA, 2012; KPOZEHOUEN et al., 2015; UNODC, 2016).

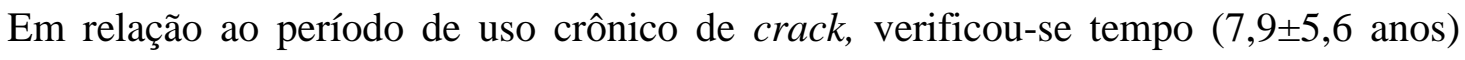
superior ao esperado na comparação com os resultados de usuários de crack de municípios brasileiros ( \pm 5 anos). As estimativas do último levantamento epidemiológico nacional alertam para a estreita relação entre o padrão de consumo e as singularidades de cada contexto regional (BORDERS et al., 2009), em virtude de possíveis influências nas variações da composição química da droga em distintos locais (ANDRADE, 2005).

A argumentação desses achados deve ser realizada com base na análise da progressão do envolvimento com a cocaína e diversidade de fatores que influenciam cada estágio desse processo (BESSA; BOARATI; SCIVOLETTO, 2011). Nesse sentido, pressupõe-se que o período de uso crônico de crack represente uma dependência cumulativa (DENNIS et al., 2005), que progrediu em virtude da tolerância adquirida pelo uso intenso da cocaína inalada. Embora a literatura assinale casos com início por essa via (GUINDALINI et al., 2006), a transição de via é mais esperada (DUNN; LARANJEIRA, 1999).

No presente estudo, observou-se também que $81,7 \%$ dos usuários de crack utilizaram na vida a cocaína inalada (Tabela 9) e 20,7\% fizeram uso recente da droga (Tabela 11), o que permite inferir que o uso crônico de crack, por si só, seja um indicativo de severidade do consumo da droga (cocaína) e de grave dependência devido à tolerância prévia da via inalada. Estudo longitudinal que examinou a experiência de uso de crack de 131 indivíduos identificou que quase todos consumiram outras substâncias previamente (99,2\%), sendo as mais comuns cocaína inalada (83,2\%) e maconha $(68,1 \%)$ (RIBEIRO et al., 2006).

Em relação à idade de início de uso da cocaína (fumada ou inalada), embora não existam diferenças entre os grupos, trata-se de um dado que chama a atenção, pois ocorre durante a adolescência (Tabela 8). Isso mostra a precocidade da exposição dos adolescentes ao uso de cocaína e crack e, portanto, às vulnerabilidades intrínsecas a este uso da droga que, como identificado por outros autores, é de fundamental importância na determinação do perfil 
na progressão do consumo (DENNIS et al., 2005; DUNN; LARANJEIRA, 1999; ROSA, 2015; ROY et al., 2017)

No Brasil, geralmente o uso inicial de cocaína ocorre pela via inalada, posteriormente ao consumo de álcool, tabaco e maconha, presente entre 12 e 24 anos (BASTO; BERTONI 2013, ADBALLA et al., 2014; REIS, 2014). Já o início do uso do crack e as mudanças na via de uso ocorrem em média 24 meses após o uso inicial pela via inalada (DUNN; LARANJEIRA, 1999), por volta dos 22 anos de idade (GUINDALINI et al., 2006; RIBEIRO et al., 2006). Os fatores que contribuem para essa transição têm sido relacionados a uma maior duração do tempo de consumo de cocaína inalada, à idade precoce de início do uso de cocaína (por via inalada) e a contato prévio com outras drogas (DUNN; LARANJEIRA, 1999), aliados a um perfil de marginalização econômica e social (GUINDALINI et al., 2006; KESSLER et al., 2012; ROY et al., 2017).

O tempo de uso crônico da cocaína é longo, pode ultrapassar 20 anos até a estabilização da abstinência (DENNIS et al., 2005), o que confere aos profissionais de saúde tempo hábil para intervir na redução de danos junto a esses usuários, cujo uso da droga é prolongado. Segundo Dennis et al. (2005), aqueles que iniciam muito cedo o uso da droga passam mais de 10 anos sem procurar tratamento, submetem-se a mais de três tratamentos prévios para a dependência, vivenciam uso problemático de álcool e sintomas psicopatológicos e apresentam riscos de manutenção do uso crônico da cocaína (inalada ou fumada) por mais anos.

Portanto, a compreensão dos aspectos associados ao padrão de consumo constitui uma fonte de informação importante para subsidiar a prática assistencial. Estudo sobre a trajetória de usuários de cocaína identificou que mesmo aqueles que iniciaram o consumo precocemente e com um nível de consumo mais grave conseguiram cessar o uso ou reduzir os níveis em um período de 10 anos após tratamento (HSER et al., 2008).

Na presente amostra, merece ser destacado o uso concomitante de cocaína e crack por usuários de crack (Tabela 11). Estudo com usuários de cocaína constatou que o uso inalado e fumado da droga eleva a gravidade da dependência e potencializa os riscos ao uso de outras substâncias psicoativas e envolvimento em atividades criminais (GUINDALINI et al., 2006). Não há consenso na literatura acerca dos motivos que direcionam os usuários de crack ao uso concomitante da via inalada e fumada (HATSUKAMI; FISCHMAN, 1996; DUNN; LARANJEIRA, 1999; GUINDALINI et al., 2006; KILUK et al., 2013; UNODC, 2016; ROY et al., 2017). Pode-se atribuir este comportamento a mais uma tentativa de minimizar os danos 
entre os usuários de crack no sentido de manejar com os efeitos do craving (RIBEIRO; SANCHEZ; NAPPO,2010; CHAVES et al.,2011), em virtude da menor agressividade do consumo em binge da via inalada (ROY et al., 2017).

Outra explicação plausível seria a busca pelos efeitos prolongados proporcionados pela via inalada diante do baixo poder aquisitivo para manutenção do binge do crack, que, embora de menor custo que a cocaína em pó, torna-se mais oneroso em virtude da necessidade de repetidas doses (RIBEIRO; LARANJEIRA, 2012). Segundo Horta et al. (2011), a maioria dos usuários de crack $(69,5 \%)$ atendidos em CAPS-ad na Região Sul do país relatou consumir mais de 10 pedras da droga em um episódio de uso típico. Porém, essa hipótese deve ser observada com cautela, uma vez que outro estudo desenvolvido nessa mesma região não verificou diferença entre a quantidade de pedras consumidas e o poder aquisitivo (FREIRE et al., 2012).

Os usuários de crack e de cocaína usaram outras substâncias psicoativas (álcool, maconha e tabaco) nos últimos 30 dias (Tabela 11). O uso de outras substâncias ou mesmo de múltiplas drogas é um fenômeno muito comum entre usuários de cocaína (inalada e fumada). De acordo com estudo conduzido por Jora (2014) com usuários de cocaína (fumada ou inalada) em tratamento ambulatorial em um CAPS ad, 32,1\% da amostra usavam múltiplas drogas, sendo o álcool e a maconha as principais.

Da mesma forma, as drogas mais utilizadas no último mês pelos usuários de cocaína (independentemente da via) analisados no presente estudo foram o tabaco (79,3\%), o álcool $(58,7 \%)$ e a maconha $(49,3 \%)$ (Tabela 11$)$. Esses resultados vão ao encontro do esperado para o cenário brasileiro e corroboram dados de um levantamento epidemiológico que observou forte superposição do uso de cocaína e similares com o de outras drogas, sobretudo álcool $(77,0 \%)$, tabaco $(85,0 \%)$ e maconha $(67,3 \%)$, como verificado no presente estudo (BASTOS; BERTONI, 2014).

Outro importante achado extraído da investigação sobre o uso recente de outras substâncias psicoativas (álcool, maconha e tabaco), incluindo a cocaína (Tabela 11), diz respeito à dificuldade de manutenção do tratamento devido ao potencial indutor de recaídas do uso de outras drogas. Segundo Zeni e Araújo (2011), o gatilho desencadeador do craving pelo uso da droga pode ser o consumo de tabaco (100\%), de álcool $(81,3 \%)$ ou simplesmente a mera observação de alguém usando $\operatorname{crack}(78,1 \%)$.

Conforme descrito por Borders et al. (2009), grande parte dos usuários de cocaína em tratamento ambulatorial (59\%) tende a manter o consumo de alguma substância. Essa 
evidência corrobora os resultados de estudos conduzidos em ambientes ambulatoriais, que descrevem um perfil de dependentes de cocaína com transitórias e frágeis motivações para o tratamento, bem como susceptibilidade a episódios de recaída (BORDERS et al., 2009; MILLER; ROLLNICK, 2001; KILUK et al., 2013; CRUZ et al., 2014). Dessa forma, reafirmam-se a importância do acolhimento assistencial e a fundamental incumbência da equipe multiprofissional em programar intervenções adequadas às demandas desses sujeitos, de forma a fortalecer a motivação para o tratamento (MILLER; ROLLNICK, 2001; KANTORSKI et al., 2010; PILLON; JORA; MANOEL, 2011).

Em relação ao uso associado de outras drogas, a maioria dos usuários de crack e cocaína investigados neste estudo iniciou a trajetória de consumo de drogas por meio de substâncias lícitas e seguiu, posteriormente, com drogas ilícitas em idade bastante jovem (GRÁFICO 1). Esses resultados sugerem que o consumo precoce de álcool, tabaco ou outras substâncias exerce importante influência sobre os futuros comportamentos de risco para a saúde desses usuários, além de ser fator de risco para a progressão do envolvimento com o uso problemático da cocaína (inalada e fumada). (SANTOS CRUZ et al., 2013; BOTTI; MACHADO; TAMEIRÃO, 2014; GALASSI et al., 2016; BASTOS; BERTONI 2014; UNODC, 2016, ROY et al., 2017).

Estudo realizado no interior da Bahia analisou o perfil de 475 jovens atendidos em um CAPS-ad e verificou que aqueles que iniciaram o consumo de drogas até os 14 anos de idade apresentaram maiores riscos para o uso frequente de álcool, maconha e cocaína (SILVA et al., 2014).

A progressão para o uso de outras drogas (álcool, maconha, tabaco, estimulantes, inalantes e solventes) entre os usuários de cocaína (fumada ou inalada) não foi diferente nos grupos (Tabela 8). Apesar das evidências de que usuários de crack possuem mais experiência de uso de outras drogas em relação aos de cocaína inalada (DENNIS et al., 2005), os resultados encontrados na presente pesquisa mostram que ambos os grupos apresentaram perfil similar de uso.

Essas características do perfil de consumo de cocaína e de outras substâncias psicoativas no decorrer dos anos reforçam a asserção da dinamicidade do uso da cocaína, principalmente da forma fumada que, embora tenha sido apenas recentemente introduzida no contexto nacional, apresentou uma rápida evolução problemática (RODRIGUES et al., 2015). $\mathrm{Na}$ comparação com estudos realizados décadas atrás, observa-se também alteração do seu padrão de consumo (HATSUKAMI; FISCHMAN, 1996; DUNN; LARANJEIRA, 1999). 
Esses dados caracterizam o perfil etário dos sujeitos em maior vulnerabilidade para a experimentação e progressão do consumo de substancias psicoativas. Embora exista um grande esforço político e assistencial para o tratamento de usuários com alguma dependência química, o subgrupo de sujeitos expostos (LENAD, 2012; BRASIL, 2009, REIS, 2014; BASTOS; BERTOLONI, 2014, ABDALLA et al., 2014), ao desenvolvimento da dependência e majoritariamente maior, e passiveis de intervenções preventivas. A partir da delimitação das características desses jovens em maior risco é possível direcionar ações de intervenções breves, educação preventiva e fortalecimento de habilidades sociais que impeçam que se instale um uso problemático de álcool ou drogas (BESSA; BOARATI; SCIVOLETTO, 2011; VASTER; PILLON, 2011; NIEL; DA SILVEIRA, 2008; SILVA et al., 2014; FISCHER et al., 2015; BARRY et al., 2016).

Em relação aos jovens já em uso problemático de substâncias, Vaster e Pillon (2011), destacam que o vínculo e o acolhimento dos adolescentes e suas famílias aos serviços de saúde, uma equipe multiprofissional adequada para o atendimento aos adolescentes, intervenções terapêuticas mais motivadoras e interessantes para os adolescentes, agrupamento dos jovens segundo a mesma faixa etária para tratamento, facilidade de acesso do serviço especializado e horários flexíveis foram designados como facilitadores para maior aderência ao tratamento.

Os usuários de crack destacaram-se em relação à duração do consumo crônico de tabaco e maconha (Tabela 10). O uso dessas substâncias nos estágios iniciais de consumo é muito frequente, assim como sua manutenção no decorrer da progressão. (BASTOS; BERTONI 2014; UNODC, 2016). Em concordância com os resultados do Relatório Mundial sobre Drogas (2016), o uso inicial da droga e a continuação no decorrer da vida envolvem uma escolha pessoal, moldada, sobretudo, por fatores individuais, biológicos, culturais, sociais e ambientais. Dessa maneira, o perfil de consumo dos usuários de crack analisados possivelmente reflita, em parte, a baixa escolaridade, marginalização socioeconômica e vulnerabilidade sociais no entorno de suas vidas.

Outro aspecto investigado foi o consumo de tabaco. Nesse sentido, houve predomínio de uso desta substância na vida (Tabela 9) e maior número de anos de uso crônico (Tabela 10) entre os usuários de crack. Esse resultado já era esperado, uma vez que diversos estudos similares, assim como o Relatório Mundial sobre Drogas (2016), já haviam identificado elevados índices de consumo de tabaco neste subgrupo (DUNN; LARANJERA, 1999; FERRI et al., 2004; GUINDALINI et al., 2006; BORDERS et al., 2009; ZENI; ARAUJO, 2011; 
SELEGHIM; OLIVEIRA, 2013; CRUZ et al., 2014). Estudo de Guindalini et al. (2006) também identificou, em uma população de usuários de crack, $74 \%$ de fumantes.

Com base na análise dos potenciais para ocorrência de danos de ambas as drogas, Nutt et al. (2007) verificaram que, embora o tabaco apresente menores danos sociais e físicos quando comparado à cocaína, possui potencial de dependência similar, que induz ao uso crônico e prolongado, com aumento importante dos danos associados quando ambas as substâncias são utilizadas conjuntamente (STORY; BOTHAMLEY; HAYWARD, 2008; GIGLIOTTI et al., 2010; RIEZZO et al., 2012). Assim, é comum que indivíduos com intenso padrão de consumo e níveis elevados de dependência de cocaína também apresentem consumo de tabaco (GIGLIOTTI et al., 2010).

A associação entre tabaco e cocaína possui importantes implicações no desenvolvimento de doenças pulmonares crônicas, que podem contribuir para o aumento dos índices de morbidade entre os usuários (STORY; BOTHAMLEY; HAYWARD, 2008; RIEZZO et al., 2012), além de ser um preditor de piora no desfecho do tratamento, pois pode prejudicar as tentativas de abstinência (ZENI; ARAUJO, 2011).

O uso concomitante de tabaco e crack decorre de diversos fatores, entre eles: estimulação da via dopaminérgica que causa reforço positivo para ocorrência simultânea de ambas as dependências (ZENI; ARAUJO, 2011; VOLKOW; KOOB; MCLELLAN, 2016), maior acessibilidade por se tratar de uma droga lícita (UNODC, 2016), início precoce de uso (SILVA et al., 2014) e manutenção do uso em grupos de baixo status social e menor educação em saúde, que desconhecem seus efeitos prejudiciais (BORDERS et al., 2009). Outra recente hipótese envolve a dependência comportamental e a repetição de movimentos estereotipados mediante revezamento do uso de substâncias que compartilham a mesma via de uso (inalada) (KORPI et al., 2015; LEWIS, 2015).

Sobre o uso de maconha, verificou-se progressão após consumo inicial (Gráfico 1), resultando em um maior tempo de uso crônico (anos) (média 10,2 \pm 6,5 anos) entre os usuários de crack (Tabela 10). Apesar do uso desta substância estar relacionado aos seus efeitos recreacionais nos estágios iniciais da progressão de consumo de drogas (BESSA; BOARATI; SCIVOLETTO, 2011; SILVA et al., 2014), usá-la concomitantemente ao crack vem sendo descrito como uma estratégia de enfrentamento dos efeitos indesejáveis do crack, principalmente fissura e sintomas psicóticos (CHAVES et al., 2011; GONCALVES; NAPPO, 2015). 
Oliveira e Nappo (2008) em um estudo sobre a caracterização de usuários de crack na cidade de São Paulo, encontraram uma combinação frequente entre crack, álcool, maconha e cocaína. A maconha também foi usada como mediador dos efeitos negativos do crack. $\mathrm{O}$ álcool foi relatado como um modulador aos efeitos do crack, sendo interposto com o uso para manutenção do consumo por maior tempo.

Na prática clínica, Pereira e Wurfel (2011) descreveram o potencial da maconha como um redutor de danos em usuários de crack atendidos em um CAPS-ad, por meio da redução da síndrome de abstinência, em especial a fissura. No entanto, os autores alertam para a possibilidade de efeitos opostos, tendo em vista que a maconha atua como um disparador no processo de recaída para o uso de crack (PEREIRA; WURFEL, 2011), ou exacerbação de sintomas psiquiátricos (VALLERSNES et al., 2016). Dessa forma, recomendam uma avaliação individualizada, capaz de identificar outros fatores biopsicossociais do sujeito, e não somente a mera substituição do crack pela maconha (PEREIRA; WURFEL, 2011).

A esse respeito, convém pontuar que os usuários de crack analisados, embora em uso crônico de maconha, apresentaram mais problemas relacionados com a área Psiquiátrica (ASI) (Tabela 15), uso mais frequente da droga (Tabela 12), recaídas descritas pelo uso recente da droga (Tabela 10) e maior número de históricos de tratamento (Tabela 1). Esses resultados ressaltam a incipiente experiência sobre essa propriedade redutora de danos da maconha, pois, segundo Silveira (2005), as pesquisas atuais que mensuraram esse efeito protetor ainda carecem de resultados mais abrangentes e generalizáveis. Nesse sentido, o uso associado dessas substâncias não exclui o inegável potencial de risco intrínseco ao consumo de qualquer substância psicoativa, segundo o qual é possível atribuir ao consumo de maconha quadros temporários de natureza ansiosa, tais como reações de pânico, ou sintomas de natureza psicótica, redução do funcionamento cognitivo devido ao uso crônico, agravamentos de quadros de esquizofrenia preexistentes, além de constituir um importante fator desencadeador da doença em indivíduos predispostos (RIBEIRO et al., 2005).

Os resultados identificados no subgrupo dos usuários de crack do presente estudo convergem para uma associação negativa do uso concomitante dessas duas substâncias. Como verificado, a experimentação precoce (Gráfico 1) e a manutenção do uso crônico da maconha (Tabela 11) foram características comuns entre tais usuários. Estudos com amostras similares identificaram que a maioria dos usuários de crack (93,9-96,3\%) também apresentou dependência de maconha (ZENI; ARAUJO 2011; LEWGOY et al., 2014), e que quanto mais cedo iniciam o uso de maconha, mais precoce é o consumo de crack (LEWGOY et al., 2014). 
Outra característica dos efeitos negativos dessa associação foi o maior número de tratamentos entre os usuários de crack (Tabela 1). Nesse sentido, estudo verificou que o consumo precoce e crônico da maconha associa-se a uma pior resposta ao tratamento de desintoxicação entre dependentes de cocaína (VIOLA et al., 2014).

Preconiza-se, portanto, que o manejo adequado nestas situações seja balizado por resultados de uma avaliação individualizada de cada caso pelos profissionais de saúde, seguida da adoção da intervenção mais adequada (CAMPBELL; GABRIELLI; LASTER, 1998; LEWGOY et al., 2014), com especial atenção à presença de comorbidades psiquiátricas subjacentes e/ou momentaneamente ocultadas pelos efeitos do uso da droga (SCHUCKIT, 2006).

Em relação ao uso do álcool, não foram observadas diferenças no padrão de consumo de bebidas alcoólicas comparando-se as vias de consumo da cocaína, se avaliados o uso na vida, uso crônico e uso recente. Entretanto, na classificação do AUDIT, os usuários de cocaína e de crack apresentaram, de modo geral, consumo de bebidas alcoólicas em nível elevado de risco (Tabela 14), aspecto amplamente documentado em estudos com amostras clínicas e nos levantamentos epidemiológicos nacionais e internacionais (SANTOS CRUZ et al., 2013; BOTTI; MACHADO; TAMEIRÃO, 2014; GALASSI et al., 2016; BASTOS; BERTONI 2014; ROY et al., 2017). Segundo o Relatório Mundial sobre Drogas (2016), o consumo associado de álcool e cocaína (independentemente da via) aumenta as chances de comportamentos violentos, danos clínicos aos usuários, além de agravar a dependência de cocaína. Já o Relatório Brasil sobre Drogas (2009) destaca o álcool como a principal droga de uso concomitante entre os usuários de crack no país.

A área Álcool (ASI) foi correlacionada positivamente com todas as demais escalas (AUDIT, SADD, SDS e CCQ-B), o que reforça possíveis associações de problemas relacionados ao uso de álcool, à síndrome da dependência da droga e do álcool, ao uso de risco e à fissura pelo uso de cocaína (fumada ou inalada) (Tabela 6). Esses dados expõem o potencial deletério do uso dessas substâncias na progressão da dependência de cocaína, que, além de representar um possível desencadeador do envolvimento com substâncias psicoativas nos estágios iniciais de experimentação (Gráfico 1), contribui para o aumento do consumo problemático da droga (Tabela 11) e agravamento dos danos associados à dependência da cocaína.

Estudo realizado com uma amostra clínica de usuários em processo de desintoxicação mostrou que em $80 \%$ das situações o álcool foi o principal desencadeador do craving para uso 
de cocaína fumada (ZENI; ARAUJO, 2011). Essa associação foi considerada responsável por danos na esfera financeira, no trabalho, na situação de moradia, nas relações familiares e na saúde física e mental (BRACHE; STOCKWELL; MACDONALD, 2012), além de aumentar o envolvimento em comportamentos violentos (PENNINGS; LECCESE; WOLFF, 2001). O uso do álcool também foi descrito em outros estudos como fator de risco para a ocorrência do consumo em binge (ROY et al., 2017), para a não adesão ao tratamento (PEIXOTO et al., 2008) e indutor do uso crônico da droga por vários anos (DENNIS et al., 2005).

Segundo Nutt et al. (2207), o uso problemático do álcool é evidenciado principalmente pelos danos sociais resultantes, os quais, conforme descrito pela literatura, são intensificados pelo uso associado de cocaína (PENNINGS; LECCESE; WOLFF, 2011). Nesse sentido, os enfermeiros e os demais profissionais que atuam em serviços ambulatoriais de atenção à saúde precisam explorar a possível coexistência desse duplo diagnóstico de dependência química, muitas vezes com sintomas mascarados pelo uso paralelo (BRACHE; STOCKWELL; MACDONALD, 2012). Assim, a atenção terapêutica se faz por meio de estratégias criativas que se adequem às especificidades do indivíduo (FISCHER et al., 2015) e, principalmente, de ações voltadas à prevenção de recaída $(\mathrm{PR})$, que instrumentalizem o indivíduo a manejar as situações de risco de recaída causadas pelo uso de álcool (MARLATT; DONAVAN, 2009). 
Limites e Recomendações $\mid \mathbf{1 2 0}$

9. Limites e Recomendações 


\section{LIMITES E RECOMENDAÇÕES}

\section{Limitações do estudo}

O estudo possui limitações em relação à seleção amostral, por investigar um subgrupo de usuários de drogas que acessaram o serviço de saúde e que, apesar dos importantes danos associados ao uso da droga e padrão de consumo, constituem um clientela já acolhida pela rede assistencial em saúde mental e, portanto, com incipiente motivação para o tratamento. Acredita-se que exista uma grande parcela populacional de dependentes de cocaína e/ou crack que nunca buscou tratamento para a dependência, por não perceber o uso problemático da droga, ou também por falta de conhecimento sobre a existência de serviços especializados para o tratamento da dependência química, assim constituindo um grupo com maior gravidade, visto que são indivíduos totalmente desassistidos sob o ponto de vista da saúde.

Em relação a essa população oculta, diversos estudos realizados com amostras acessadas em serviços de tratamentos expõem indiretamente essa baixa utilização dos serviços terapêuticos ao classificarem o atual tratamento como primeira busca por assistência especializada. Essa afirmação pode ser observada no estudo de Cruz et al. (2014), que identificou uma amostra de usuários crônicos de crack em situação de rua, a qual, apesar de diversos anos de uso crônico da droga e importantes problemas associados a esse uso, nunca havia passado por serviços de tratamento.

Ressalta-se que os resultados encontrados devem ser explorados com cautela, pois embora tenham sido investigados por meio de um inquérito retrospectivo do histórico de vida dos últimos seis meses e também dos últimos 30 dias, não fornecem evidências teóricas suficientes para comprovar as relações causais dos elementos avaliados. Acrescenta-se também que, apesar da aplicação de uma escala de avaliação cognitiva e psicológica dos sujeitos, a obtenção de informações por meio de autorrelatos impossibilitou a descrição fidedigna de informações importantes, como presença de diagnóstico de transtornos psiquiátricos, uso de medicamentos, descrição do perfil clínico e psiquiátrico e trajetória terapêutica anterior ao serviço atual. 


\section{Implicações futuras}

Os resultados do presente trazem importantes implicações para a prática terapêutica, principalmente em relação aos efeitos das diferentes vias de uso da cocaína sobre o organismo e seus problemas físicos, mentais e sociais e as implicações nas diversas áreas da vida que devem ser trabalhadas por meio de estratégias psicossociais e de redução de danos, tendo em vista a minimização do uso e suas consequências.

Compreender as peculiaridades das diferentes apresentações de consumo da cocaína, bem como a gravidade da dependência relacionada e os fatores associados (necessidades psicossociais e de vulnerabilidade social) pode contribuir de modo efetivo para melhoria da oferta de cuidados e suporte para essa clientela, assim como para a capacitação dos profissionais na linha de frente do cuidado assistencial.

Enfermeiros e outros profissionais de saúde têm a responsabilidade que prover uma assistência integral às diversas necessidades biopsicossociais de usuários de cocaína que se apresentam nos serviços, por meio de intervenções individualizadas que correspondam as reais demandas apresentadas. Nesse sentido, valorizar a influência dos aspectos neurobiológicos da cocaína e suas diferentes alterações do comportamento humano proporciona uma análise mais fidedigna dos diversos fatores relacionados a dependência, bem como a mensuração dos seus níveis de gravidade.

No plano de promoção e prevenção de saúde, esses dados pontuam as variações do perfil sociodemograficos e socioeconômicos desses usuários, e delimitam elementos de vulnerabilidade dessa clientela, contribuindo para o estabelecimento de subgrupos de prioritários e com elevado riscos de progressão do uso problemático da droga, que necessitam de maior atenção dos serviços de saúde e dos dispositivos governamentais. 


\section{CONCLUSÕES}

Os resultados obtidos no presente estudo permitem rejeitar todas as hipóteses testadas e revelam diferenças entre os usuários de cocaína e crack, o que permite afirmar que o uso de cocaína apresenta variações em relação aos níveis de gravidade da dependência da droga e dos problemas relacionados às áreas emprego e sustento, uso de álcool e de drogas, situação legal social e saúde mental. Assim, conclui-se que:

- Os usuários de cocaína e crack apresentaram, de modo geral, níveis severos de gravidade da síndrome de dependência da droga e acentuados sintomas de fissura, mas diferenciaram-se em relação ao uso problemático da droga. Isso evidencia uma clientela com distintas reações comportamentais e biológicas e, consequentemente, demandas assistenciais específicas, as quais devem ser consideradas no planejamento do projeto terapêutico.

- Em relação às características sociodemográficas, os usuários de crack são indivíduos mais adultos ( $\geq 30$ anos), com baixo nível de escolaridade e desemprego, maior predisposição à situação de moradia de rua e histórico de tratamentos para a dependência da droga. Observou-se também que estar em situação de moradia de rua e ser adulto ( $\geq 30$ anos) aumenta potencialmente as chances de consumir a droga entre os usuários de crack. Esse perfil converge para a totalidade dos estudos realizados com amostras similares e expõe a visível cronificação social dessa dependência que, apesar da irrefutável origem neurobiológica, é significativamente agravada por fatores individuais e influenciada pelo entorno contextual.

- Em relação ao perfil socioeconômico, os usuários de crack e cocaína diferenciaram-se na área Emprego (ASI), sendo que os primeiros se destacaram pelo status ocupacional de desempregados e/ou com empregos temporários (bicos), renda mensal menor ou igual a um salário mínimo e renda insuficiente para arcar com suas despesas quando comparados aos usuários de cocaína. Essas características reiteram a precária condição econômica desses sujeitos e os diversos prejuízos sociais resultantes do uso de cocaína, os quais, além de prejudicarem a própria sobrevivência e de seus 
dependentes, afetam indiretamente todas as demais áreas de funcionamento de suas vidas.

- Em relação ao envolvimento em situações de violência, os usuários de crack se destacaram por terem praticado roubos nos últimos seis meses, sofrido agressão física por alguém (conhecido ou desconhecido) e presenciado situações de riscos, como agressões ou homicídios.

- Quanto ao vínculo familiar, os usuários de crack e cocaína não apresentaram diferenciações em relação aos problemas familiares (ASI).

- No que se refere ao relacionamento interpessoal, os usuários de cocaína possuíam maior contato pessoal com amigos.

- Estar em situação de moradia de rua (nos últimos seis meses) foi uma característica marcante entre os usuários de crack, uma vez que permanecem nesta situação durante dias ou optam por procurar abrigo em albergues.

- Não foram observadas diferenças em relação às condições de saúde física e utilização de serviços de saúde pelos usuários. Contudo, os problemas observados na área Médica (ASI) foram correlacionados negativamente com a síndrome de dependência de cocaína (SDS), o que sugere que podem, de fato, estar ausentes ou mascarados pelo uso crônico ou pela dependência da cocaína.

- Quanto à área Psiquiátrica (ASI), os usuários de crack se destacaram pela presença de maior número de problemas relacionados, inclusive sintomas psiquiátricos, como alucinação, dificuldade para dormir e controlar o temperamento. Notou-se também que a área Psiquiátrica (ASI) foi correlacionada com a síndrome de dependência da cocaína (SDS) e fissura (CCQ-B), aspecto que sinaliza para possível coexistência desses problemas.

- Em relação ao uso de outras drogas (álcool, maconha, tabaco, estimulantes, inalantes e solventes), os usuários de crack apresentaram tempo mais longo de uso crônico da maconha e do tabaco, que progrediu da adolescência até a vida adulta. Observou-se também que os problemas referentes à área Droga (ASI) se correlacionaram com a 
gravidade da dependência da droga (SDS), com o consumo de risco de álcool (AUDIT) e com a fissura (CCQ-B)

- Quanto ao uso de álcool, não foram observadas variações entre os grupos analisados (ASI), contudo identificou-se consumo de risco na amostra geral. Houve correlação positiva de problemas relacionados ao uso de álcool (ASI) e ao consumo de risco de bebidas alcoólicas (AUDIT) com a gravidade da síndrome de dependência da cocaína (SDS) e os sintomas da fissura (CCQ-B).

- No que diz respeito à frequência do uso de cocaína (fumada e inalada), os usuários de crack se diferenciaram pelo consumo da droga com maior frequência nos últimos seis meses.

- Em relação ao tempo de uso crônico da droga, os usuários de cocaína inalada utilizaram-na por maior número de anos se comparados aos de crack. Convém também destacar que a maioria dos usuários de crack utilizou cocaína inalada na vida e, em alguns casos, também no mês que antecedeu a entrevista, diferentemente dos usuários da via inalada, que são mais exclusivos.

Por fim, os achados indicam que a gravidade da dependência entre os usuários de cocaína (fumada e inalada) tem sido codeterminada pelo contexto da vulnerabilidade individual dos sujeitos, considerando-se a diferenciação significativa do perfil sociodemográfico e de uso da substância. Os dependentes de crack integram um subgrupo de maior vulnerabilidade entre os excluídos já dependentes, com baixa escolaridade, desempregados, mais velhos, histórico de tratamentos para dependência, predisposição à situação de rua, maior gravidade da dependência de cocaína e potenciais associações com problemas psiquiátricos, emprego e com a justiça/Legal. Esses dados confirmam a necessidade de integrar cuidados de saúde e sociais nos serviços especializados no tratamento da dependência de drogas, de modo a melhorar o cuidado e o suporte, com vistas à qualidade de vida dessa população. 


\section{REFERÊNCIAS BIBLIOGRÁFICAS}

ABDALLA, R. R. et al. Prevalence of cocaine use in Brazil: data from the II Brazilian National Alcohol and drugs survey (BNADS). Addict behavior, v. 39, n. 1, p. 297- 301, 2014.

ABOU-DONIA, M. Neutotoxicology. Drugs of Abuse. Flórida: Teolford, 1992.

ALVAREZ, S, Q. et al. Grupo de apoio/ suporte como estratégia de cuidado: importância para familiares de usuários de drogas. Rev Gaúcha Enferm, v. 33, n. 2, p. 102-108, 2012.

ALVES, H. N. P.; RIBEIRO, M.; CASTRO, D. S. Cocaína e Crack. In: DIEHL, A.; CORDEIRO, D. C.; LARANJEIRA, R. (org). Dependência Química: Prevenção, Tratamento e Políticas Públicas. Porto Alegre: Artmed, 2011.

AMERICAN PSYCHIATRIC ASSOCIATION. Manual diagnóstico e estatístico de transtornos mentais. Porto Alegre: Artmed; 2014.

ANDRADE M. V. O. Oxi ou pasta base? [Oxi or pasta base?] [in Portuguese]. Perícia Federal 2005; 6: 11-13.

ARAUJO, R.B. et al. Validação Psicométrica do Cocaine Craving Questionaire - brief versão brasileira adaptada para o crack para dependentes hospitalizados. Jornal Brasileiro de Psiquiatria, v. 60, n. 4, p. 233-239, 2011.

ARAUJO, R.B.; PEDROSO, R.S.; CASTRO, M.G.T. Adaptação transcultural para o idioma português do Cocaine Craving Questionnaire - Brief. Rev. psiquiatr. Clín, vol.37, n.5, 2010.

AZEVEDO, R.C.S.; BOTEGA, N.J.; GUIMARÃES, L.A.M. Crack users, sexual behavior and risk of HIV infection. Revista Brasileira de Psiquiatria, São Paulo, v.29, n.1, p.26-30, 2006.

BARRY, A. E. et al. Prioritizing Alcohol Prevention: Establishing Alcohol as the Gateway Drug and Linking Age of First Drink With Illicit Drug Use. Journal of School Health, v. 86, n. $1,2015$.

BASTOS, F. I. et al. Smoked crack cocaine in contemporary Brazil: the emergence and spread of "oxi”. Addiction, v.106, p. 1190-1193, 2011.

BASTOS, F.I.; BERTONI, N. Pesquisa Nacional sobre o uso de crack: quem são os usuários de crack e/ ou similares do Brasil? Quantos são nas capitais brasileiras? Rio de Janeiro, ICICT/FIOCRUZ, 228 p, 2014.

BELL, M.; MILSTEIN, R.; BEAM-GOULET, J. et al: The Positive and Negative Syndrome Scale and the Brief Psychiatric Rating Scale: reliability, comparability, and predictive validity. J Nerv Ment Dis, v. 180, p. 723-728, 1992.

BESSA, M.A.; BOARATI, M.A.; SCIVOLETTO, S. Crianças e Adolescentes. In: DIEHL, A.; CORDEIRO, D. C.; LARANJEIRA, R. Dependência química: prevenção, tratamento e políticas públicas. Porto Alegre: Artmed, 2011. 
BOLES, S. M.; MIOTTO, K. Substance abuse and violence A review of the literature. Aggression and Violent Behavior, v. 8, p. 155 - 174, 2003.

BORDERS, T. F.; BOOTH, B. M.; FALCK. R.S. et al. Longitudinal changes in drug use severity and physical health-related quality of life among untreated stimulant users. Addictive Behaviors, v. 34, p. 959-964, 2009.

BOTTI, N. C. L.; MACHADO, J. S. A.; TAMEIRÃO, F. V. Perfil sociodemográfico e padrão do uso de crack entre usuários em tratamento no Centro de Atenção Psicossocial. Estud Pesqui Psicol, v.14, n. 1, p. 290-303, 2014.

BRACHE, K.; STOCKWELL, T.; MACDONALD, S. Functions and harms associated with simultaneous polysubstance use involving alcohol and cocaine. Journal of Substance Use, v. 17, n. 5-6, p. 399-416, 2012.

BRASIL. Ministério da Saúde. A política do Ministério da Saúde para atenção integral a usuários de álcool e outras drogas. Brasília: CN-DST/AIDS, 2004.

BRASIL. Ministério da Saúde. Atenção psicossocial a crianças e adolescentes no SUS: tecendo redes para garantir direitos. Brasília : Ministério da Saúde, 2014.

BRASIL. Ministério da Saúde. Sistema único de saúde. Conselho nacional de saúde. Comissão Organizadora da III CNSM. Relatório Final da III Conferência Nacional de Saúde Mental. Brasília, 11 a 15 de dezembro de 2001. Brasília: Conselho Nacional de Saúde/Ministério da Saúde, 2002, 213 p.

BRASIL. Secretaria Nacional de Políticas sobre Droga. Primeira Pesquisa Nacional sobre o uso de álcool, tabaco e outras drogas entre estudantes universitários nas 27 capitais brasileiras (Brasília, 2010).

BRASIL. SENAD: Secretaria Nacional de Políticas sobre Drogas. Relatório Brasil sobre Drogas, 2009.

BRAUN, L. M.; DELLAZZANA-ZANON, L. L.; HALPERN, S. C. A família do usuário de drogas no CAPS: um relato de experiência. Rev. SPAGESP, v.15, n.2, p. 122-144, 2014.

BROWN, E. J.; HILL, M. A.; GIROUX, S. A. "A 28-day program ain't helping the crack smoker"--perceptions of effective drug abuse prevention interventions by north central Florida African Americans who use cocaine. J Rural Health, v. 20, n. 3, p. 286-95, 2004.

BRUEHL, M. A. et al. Craving and control: methamphetamine users' narratives. J Psychoactive Drugs, suppl 3, p. 385-92, 2006.

BUCHER, R. Drogas e drogadição no Brasil. Porto Alegre: Artes Médicas; 1992. p. 323.

CACCIOLA, J. S et al. Recent status scores for version 6 of the Addiction Severity Index (ASI-6). Addiction, v. 106, p. 1588-1602, 2011.

CAMPBELL, J.; GABRIELLI, W.; LASTER, L. J. et al. Eficácia do tratamento intensivo em ambulatório do abuso de substâncias. J Addictiv Dis, v. 2, n.2, p.43-54, 1998.

CAPS-AD II (Centro de Atenção Psicossocial álcool e drogas II). Plano de Ação. Ribeirão Preto/SP, 2017.48p. 
CARLINI, E. A; GALDURÓZ, J. C.; SILVA, A. A. B. et al.. II Levantamento domiciliar sobre o uso de drogas psicotrópicas no Brasil: estudo envolvendo as 108 maiores cidades do país: 2005. São Paulo: Cebrid - Unifesp, 2006.

CHASIN, A.A.M.; SILVA, E. S.; CARVALHO, V. M. Estimulante do Sistema Nervoso Central. In: S. OGA; CAMARGO, M. M. A.; BATISTUZZO, J. A. O. (ed) Fundamentos de Toxicologia, 3ed, Atheneu (SP), p. 353-374, 2008.

CHAVES T. V et al. Fissura por crack: comportamentos e estratégias de controle de usuários e ex usuários. Rev Saúde Pública, v. 45, n. 6, p.1168-75, 2011

CHEN, C. Y.; ANTHONY, J. C. Epidemiological estimates of risk in the process of becoming dependent upon cocaine: cocaine hydrochloride powder versus crack cocaine. Psychopharmacology, v.172, n. 1, p. 78-86, 2004.

CIBA Foundation, editor. Cocaine: scientific and social dimensions. Chichester: John Wiley and Sons; 1992. p. 125-42.

CICAD. Inter-American Drug Abuse Control Commission. Report on drug use in the Americas, 2015. clinical syndrome. BMJ 1976; 1: 1068-71.

CIRINO, D.P.S; ALBERTO, M.F.P. Uso de drogas entre trabalhadores precoces na Atividade de malabares. Psicologia em Estudo, v. 14, n. 3, p. 547-555, 2009.

CRUZ, M. et al. Comparing key characteristics of young adult crack users in and out-oftreatment in Rio de Janeiro, Brazil. Substance Abuse Treatment, Prevention, and Policy, v. 10, n. 9, 2014.

DEGENHARDT, L.; CHIU, W. T.; SAMPSON, N. Et al. Toward a global view of alcohol, tobacco, cannabis, and cocaine use: Findings from the WHO World Mental Health Surveys. PloS Med, v.5, n. 7, p. 141. 2008.

DENIS, M. C.; CACCIOLA, J. S.; ALTERMAN, A. I. Addiction Severity Index (ASI) sumary scores : compararison of the Recent Status Score of the ASI-6 and the Composite Scores of the ASI-5. J. Subst. Abuse Treat, n. 45, v. 5, p. 444-450, 2013.

DENIS et al., 2005. The duration and correlates of addiction and treatment carrear. J. Subst. abuse, 28 Suppl 1:S51-62, 2005.

DIAS, A. C. et al. Mortality rate among crack/cocaine-dependent patients: A 12-year prospective cohort study conducted in Brazil. Journal Substance Abuse Treatment, Lebanon, v. 41, no. 3, p. 273-278, 2011.

DIEHL, A. et al. Sexual risk behaviors in non-injecting substance-dependent Brazilian patients. Adicciones, v. 26, n. 3, p. 208-220, 2014.

DIEHL, A.; PILlON, S. C. ; SANTOS, M. A. ; RASSOOL, G. H. ; LARANJEIRA, R. . Criminality and Sexual Behaviours in Substance Dependents Seeking Treatment. Journal of Psychoactive Drugs, v. 48, p. 124-134, 2016 
DILLEHAY, T. D. et al. Early Holocene coca chewing in northern Peru. Antiquity. V.84, n. 326, p. 939-953. 2010.

DOMINGOS, J. B. C. Fatores associados ao uso de cocaína e/ou crack em clientes de um CAPSad. 167 f. Tese (Doutorado). Escola de enfermagem de Ribeirão Preto, Universidade de São Paulo, São Paulo, 2012.

DOW-EDWARDS, D. Sex differences in the effects of cocaine abuse across the life span. Physiology \& Behavior, v. 100, p. 208-215, 2010.

DRAKE, R.E.; OSHER, F.C.; WALLACH, M.A. Homelessness and dual diagnosis. Am. Psychol, v. 46, p. 1149-1158, 1991.

DUAILIBI, L. B.; RIBEIRO, M.; LARANJEIRA R. Profile of cocaine and crack users in Brazil. Cadernos de Saúde Pública (ENSP. Impresso), v. 24, p. 545-557, 2008.

DUNN, J. et al. Crack cocaine: an increase in use among patients attending clinics in São Paulo: 1990-1993. Subst Use Misuse, v.31, n. 4, p.519-27. 1996.

DUNN, J.; FERRI, C. P.; LARANJEIRA, R. Does multisite sampling improve patient heterogeneity in drug misuse research? Drug Alcohol Depend. v. 63, n. 1, p.79-85. 2001.

DUNN, J.; LARANJEIRA, R. Transitions in the route of cocaine administration-characteristics, direction and associated variables. Addiction, v. 94, n. 6, p. 813-24, 1999.

EDWARD, J.; KHANTZIAN, M. D. The Self-Medication Hypothesis of Addictive Disorders: Focus on Heroin and Cocaine dependence. Am J Psychiatry, v. 142, n. 11, 1985.

ELKIS, et al. et al. BPRS Ancorada (BPRS-A): diretrizes de uso, estrutura fatorial e confiabilidade da versao em portugues. In: Escalas de avaliação clínica em psiquiatria e psicofarmacologia [S.l: s.n.], 2000.

FALCK, R. S.; WANG, J.; CARLSON, R. G. Among long-term crack smokers, who avoids and who succumbs to cocaine addiction? Drug and Alcohol Dependence, v. 98, n. 1/2, p. 2429, 2008.

FALCK, R. S.; WANG, J.; CARLSON, R. G; SIEGAL, H. A. Crack-cocaine use and health status as defined by the SF-36. Addictive Behaviors,, v. 25, n. 4, p: 579-584, 2000.

FERGUSON, G. A.; TAKANE, Y. Statistical analysis in psychology and education. 6th Edition. New York: McGrawHill, 1986.

FERRI, C. P. et al. Factors associated with adverse reactions to cocaine among a sample of long-term, high-dose users in São Paulo, Brazil. Addict Behav, v. 29, p. 365-74, 2004.

FERRI, C. P. et al. Validity and reliability of the Severity of Dependence Scale (SDS) in a Brazilian sample of drug users. Drug and Alcohol Review, v. 19, p. 451-55, 2000.

FISCHER, B. et al. Effectiveness of secondary prevention and treatment interventions for crack-cocaine abuse: a comprehensive narrative overview of English-language studies. Int J Drug Policy, v. 26, n. 4, p. 352-63, 2015. 
FISCHER, B. et al. Effectiveness of secondary prevention and treatment interventions for crack-cocaine abuse: A comprehensive narrative overview of English-language studies. Int J Drug Policy, v. 26, n. 4, p. 352-63, 2015

FORD, J. D. et al. Association of psychiatric and substance use disorder comorbidity with cocaine dependence severity and treatment utilization in cocaine-dependent individuals. Drug and Alcohol Dependence, v. 99, p.193-203. 2009.

FREIRE, S. D. et al. Intensity of crack consumption according the economic level of the admitted users in the city of Porto Alegre/Brazil. Jornal Brasileiro de Psiquiatria, v. 61, n. 4, p. 221-226, 2012.

FUREGATO, A. R. F. Núcleo de Estudos e Pesquisa das Relações Interpessoais em Enfermagem - NUPRI. In: Agnaldo Garcia (org.). Relacionamento interpessoal - estudos brasileiros. Vitória: UFES, 2006. 136 p.

FUSTER, D. et al. Cannabis as Secondary Drug Is Not Associated With a Greater Risk of Death in Patients With Opiate, Cocaine, or Alcohol Dependence. J Addict Med. 2016 [Epub ahead of print]

GAlanter, M.; KLEBER, H. D.; BRADY, K. The American Psychiatric Publishing Textbook of Substance Abuse Treatment, Fifth Edition. Edited by. American Psychiatric Publishing: Washington, DC, 2014.

GALEA, S.; VLAHOV, D. Social determinants and the health of drug users: socioeconomic status, homelessness, and incarceration. Public Health Rep, v. 117, suppl 1, p. 135-45, 2002.

GALLASSI, A. D. et al. Characteristics of clients using a community-based drug treatment service ('CAPS-AD') in Brazil: An exploratory study. International Journal of Drug Policy, v.31, p. 99-10, 2016.

GARCIA, R. C. T. Efeitos neurodegenerativos da metilecgonidina e da cocaína em cultura celular primária de hipocampo. Dissertação de Mestrado. São Paulo, 2009 Faculdade de Ciências FarmacêuticasÁrea do Conhecimento Toxicologia e Análises Toxicológicas 140p.

GAWIN, F. H.; KLEBER, H. D. Abstinence symptomatology and psychiatric diagnosis in cocaine abusers. Arch Gen Psychiatry, v. 43, p.107-13, 1986.

GEBARA, C. F. P. et al. Patterns of domestic violence and alcohol consumption among women and the effectiveness of a brief intervention in a household setting: a protocol study. BMC Womens Health, v. 15, n. 1, p. 78, 2015.

GONÇALVES, J.R.; NAPPO, S. A. Email. Factors that lead to the use of crack cocaine in combination with marijuana in Brazil: a qualitative study. BMC Public Health, v. 15, 2015.

GONZÁLEZ-SAIZ, F. el al. Severity of Dependence Scale as a Diagnostic Tool for Heroin and Cocaine Dependence. European Addiction Reserach, v. 15, p. 87-93, 2009.

GOOTENBERG, Paul. Cocaine: global histories. Routledge: Oxton, 1999. p.12. 
GOSSOP, M. et al. The Severity of Dependence Scale (SDS): psychometric properties of the SDS in English and Australian samples of heroin, cocaine and amphetamine users. Addiction, v. 90, n. 5, p. 607-14. 1995.

GOSSOP, M.; MANNING, V.; RIDGE, G. Concurrent use of alcohol and cocaine: differences in patterns of use and problems among users of crack cocaine and cocaine powder. Alcohol Alcohol, v. 41, n. 2, p. 121-125, 2006.

GROSSI, F. T.; OLIVEIRA, R. M. Diretrizes Clínicas Protocolos Clínicos. Manejo Clínico do Usuário de Crack. Disponível em www.fhemig.mg.gov.br. Acesso em: 23/01/2017.

GUINDALINI, C.; VALLADA, H.; BREEN, G.; LARANJEIRA, R. Concurrent crack and powder cocaine users from Sao Paulo: Do they represent a different group? BMC Public Health, v. 6, 10, 2006.

HALL, W.; DEGENHARD, L. High potency cannabis: A risk factor for dependence, poor psychosocial outcomes, and psychosis. BMJ, v. 350, 2015.

HATSUKAMI, D. K.; FISCHMAN, M. W. Crack cocaine and cocaine hydrochloride: Are the differences myth or reality. JAMA, v. 276, n. 19, p. 1580-1588, 1996

HEINZ. A. J. et al. Marriage and relationship closeness as predictors of cocaine and heroin use. Addictive Behaviors, v. 34, n. 3, p. 258 - 262, 2009.

HOFFMANN NG, KOPAK AM. How well do the DSM-5 alcohol use disorder designations map to the ICD-10 disorders? Alcohol Clin Experiment, v. 39, n. 4, p. 697-701, 2015.

HORTA, R. L. et al. Perfil dos usuários de crack que buscam atendimento em Centros de Atenção Psicossocial. Cad. Saúde Pública, v. 27, n. 11, 2011.

HSER, Y. et al. Integrated.Contrasting Trajectories of Heroin, Cocaine, and Methamphetamine Use J Addict Dis, v. 27, n.3, p. 13, 2008.

HSER, Y. I. et al. A 12-year follow-up of a treated cocaine-dependent sample. J. Subst. Abuse Treat, v. 30, p. 219-226, 2006.

HUXLEY, A. As portas da percepção e Céu e inferno. São Paulo: Biblioteca Azul, 2015, 160 $\mathrm{p}$

INSTITUTO NACIONAL DE CIÊNCIA E TECNOLOGIA PARA POLÍTICAS PÚBLICAS DO ÁlCOOL E OUTRAS DROGAS. Unidade de Pesquisa em Álcool e Drogas - UNIAD. II Levantamento Nacional do uso de Álcool e Drogas LENAD, 2012.

JORA, N. P. Consumo de cocaína, crack e múltiplas drogas: interfaces com a qualidade de vida de usuários. 2014. Tese (Doutorado em Enfermagem Psiquiátrica) - Escola de Enfermagem de Ribeirão Preto, Universidade de São Paulo, Ribeirão Preto, 2014.

JORGE, M. R.; MANSUR, J. Questionário padronizado para avaliação do grau de severidade da Síndrome de Dependência do Álcool. Jornal Brasileiro de Psiquiatria, v. 35, n. 5, p. 287 $292,1986$. 
KANTORSKI, L. P. et al. A atuação do enfermeiro nos centros de atenção psicossocial à luz do modo psicossocial. REME rev. min. enferm, v. 14, n. 3, p. 399-407, 2010.

KARCH, S. B. Cocaine: history, use, abuse. J R Soc Med, v. 92, n. 8, p.393-7.1999.

KAYE, S.; DARKE, S. Determining a diagnostic cut-off on the Severity of Dependence Scale (SDS) for cocaine dependence. Addiction, v. 97, n. 6, 2002.

KESSLER, F. et al. Adaptação transcultural multicêntrica da sexta versão da Escala de Gravidade de Dependência (ASI6) para o Brasil. Revista de Psiquiatria do Rio Grande do Sul, v. 29, p. 335-6, 2007.

KESSLER, F. et al. Psychometric properties of the sixth version of the Addiction Severity Index (ASI-6) in Brazil. Rev. Bras. Psiquiatr,, v. 34, n. 1, p. 24-33, 2012.

KESSLER, F. H. P. Desenvolvimento e validação da sexta versão do Addiction Severity Index (ASI - 6) para o Brasil e outras análises em uma amostra multicêntrica de usuários de drogas que buscam tratamento no país. 2011 [tese de doutorado]. Universidade Federal do Rio Grande do Sul. Faculdade de Medicina (UFRGS). Centro de Pesquisa em Álcool Drogas.

KESSLER, F.; PECHANSKY, F. Uma visão psiquiátrica sobre o fenômeno do crack na atualidade. Rev Psiquiatr Rio Gd Sul, v. 30, n. 2, p. 96-98. 2008

KILUK, B. D.; BABUSCIO T. A.; NICH C.; CARROLL, K. M. Smokers versus snorters: Do treatment outcomes differ according to route of cocaine administration? Exp Clin Psychopharmacol, v. 21, n. 6, p. 490-498, 2013.

KORPI, E. R. et al. Mechanisms of Action and Persistent Neuroplasticity by Drugs of Abuse. Pharmacol Rev, v. 67, p. 4, p. 872-1004, 2015.

KOURRICH, S. et al. Intrinsic plasticity: an emerging player in addiction. Nature Reviews Neuroscience, v. 16, p. 173-184, 2015.

KPOZEHOUEN, A. et al. Factors associated with psychoactive substance use among Beninese adolescents. Sante Publique, v. 27, n. 6, p. 871-80, 2015.

LARANJEIRA R. et al. (Coord.). Usuários de substâncias psicoativas: abordagem, diagnóstico e tratamento. 2. 134d. São Paulo: Conselho Regional de Medicina do Estado de São Paulo; Associação Médica Brasileira. 2003.

LEWGOY, L. B. et al. Padrão de uso de cannabis em dependentes de crack cocaína internados para desintoxicação. Clin Biomed Res, v. 34, n. 3, p. 274-280, 2014.

LEWIS, M. The Biology of Desire: Why Addiction Is Not a Disease, 2015.

LOWENSTEIN, D. H. et al. Acute neurologic and psychiatric complications associated with cocaine abuse. Am J Med, p. 841-6, 1987.

MACRAE, E. Redução de danos para o uso da cannabis. In: Silveira DX, Moreira FG. Panorama atual de drogas e dependências. São Paulo: Editora Atheneu. p. 361-370, 2006 
MARAJ, S.; FIGUEREDO, V. M.; MORRIS, D. L. Cocaine and the heart. Clin Cardiol, v. 33, n. 5, p. 264-9, 2010.

MARANGONI, S. R.; OLIVEIRA, M.L.F. Fatores Desencadeantes do Uso de Drogas de Abuso em Mulheres. Texto Contexto Enferm, v. 22, n. 3, p. 662-70, 2013.

MARIANI, J. J.; KHANTZIAN E. J.; LEVIN, F. R .The Self- Medication Hypothesis and Psychostimulant Treatment of Cocaine Dependence: An Update. The American Journal on Addictions, XX: 1-5, 2013

MARLATT A, GORDON J. Prevenção de recaída - estratégias de manutenção no tratamento de comportamentos adictivos. Porto Alegre: Artes Médicas; 1993.

MARLATT, G. A.; DONAVAN, D. M. Prevenção de recaída: estratégias de manutenção no tratamento de comportamentos adictivos. Porto Alegre (RS): Artmed; 2009.

MARTIN, G. et al. A comparison of motivations for use among users of crack cocaine and cocaine powder in a sample of simultaneous cocaine and alcohol users. Addictive Behaviors, v. 39, p. 699-702, 2014.

MCKAY, J. R. et al. Step down continuing care in the treatment of substance abuse: correlates of participation and outcome effects. Eval Program Plann, v. 27, n. 3, p.321-31, 2004.

MCLELLAN, A. T. et al. The Addiction Severity. Index at 25: origins, contributions and transitions. American Journal of Addiction, v. 15, n. 2, p. 113-24. 2006.

MEDINA, M. G. et al. Epidemiologia do consumo de substâncias psicoativas. In: Seibel, S. D.; Toscano Jr; A. (Orgs.). Dependência de drogas. (pp. 161-179). São Paulo: Editora Atheneu. 2001.

MENESES-GAYA, C. et al. Alcohol Use Disorders Identification Test (AUDIT): An updated systematic review of psychometric properties. Psychology \& Neuroscience, v. 2, n. 1, p. $83-$ 97, 2009.

MESQUITA, F. et al. Overdoses among cocaine users in Brazil. Addiction, v. 96, n.12, p.1809-13. 2001.

MORALES-MANRIQUE, C. C. et al. Quality of Life, Needs, and Interest Among Cocaine Users: Differences by Cocaine Use Intensity and Lifetime Severity of Addiction to Cocaine. Substance Use \& Misuse, v. 46, p. 390-397, 2011.

MOURA, H. F. et al. Crack/cocaine users show more family problems than other substance users. Clinics, v. 69, n. 7, p. 497-499, 2014.

NAPPO, S. A. et al. Changes in cocaine use as viewed by key informants: a qualitative study carried out in 1994 and 1999 in Sao Paulo, Brazil. J Psychoactive Drugs, v.33, n. 3, p. 24153, 2001.

NARVAEZ, J.C.M. et al. Quality of life, social functioning, family structure, and treatment history associated with crack cocaine use in youth from the general population. Rev. Bras. Psiquiatr, v. 37, n. 3, p. 211-218, 2015. 
NATIONAL INSTITUTE ON DRUG ABUSE (NIDA). Principles of Drug Addiction Treatment: A Research-Based Guide (Second Edition). NIH Publication; 2009.

NEGRETE, J. C. Cocaine problems in the coca-growing countries of South America. In: BOCK, G. R.; WHELAN, J. (editors). Cocaine: scientific and social dimensions. Chichester: John Wiley \& Sons, p. 40-56. 1992

NIEL, M.; DA SILVEIRA, D. X. Drogas e Redução de Danos: uma cartilha para profissionais de saúde, São Paulo, 2008. xi, 149f

NOTO, A. R. et al. Levantamento nacional sobre uso de drogas entre crianças e adolescentes em situação de rua nas 27 capitais brasileiras - 2003. São Paulo: Universidade Federal de Sao Paulo (CEBRID / SENAD); 2004

NOTO, A. R.; NAPPO, S. A.; GALDURÓZ, J. C. F. et al. IV levantamento sobre uso de drogas entre crianças e adolescentes em situação de rua de seis capitais brasileiras: 1997. São Paulo: CEBRID/UNIFESP; 1998.

NUTT, D. J. et al. Development of a rational scale to assess the harm of drugs of potential misuse. Lancet, v. 369, p. 1047-53, 2007.

NUTT, D. J. et al. Mechanisms of Action and Persistent Neuroplasticity by Drugs of Abuse. Pharmacol Rev 67:872-1004, 2015

OLIVEIRA, L. G.; NAPPO, S. A. Caracterização da cultura de crack na cidade de São Paulo: padrão de uso controlado. Rev Saúde Pública, v.42, n.4, p.664-71, 2008.

ORGANIZAÇÃO MUNDIAL DA SAÚDE (OMS). Classificação dos transtornos mentais e de comportamento da CID-10. Porto Alegre: Artmed; 1993

ORGANIZACIÓN PANAMERICANA DE LA SALUD (OPA). Epidemiología del uso de drogas en América Latina y el Caribe: un enfoque de salud pública. Washington, D. C.: OPA, 2009.

OVERALL, J. E.; GORHAM, D. R. The brief psychiatric rating scale. Psychol. Rep. 10:799812, 1962.

PAIM KESSLER, F. H. et al. Crack users show high rates of antisocial personality disorder, engagement in illegal activities and other psychosocial problems. Am J Addict, v. 21, n. 4, p.:370-80, 2012.

PALAMAR, J. J.; DAVIES, S.; OMPAD, D. C. Powder cocaine and crack use in the United States: An examination of risk for arrest and socioeconomic disparities in use. Drug and Alcohol Dependence, v. 149, p. 108-116, 2015.

PALIWALA, P.; HYMANA, S. M.; SINHA, R. Craving predicts time to cocaine relapse: Further validation of the Now and Brief versions of the cocaine craving questionnaire. Drug and Alcohol Dependence. v. 93, n. 3. P. 252-259. 2008.

PAN, W. J.; HEDAYA, M.A. Cocaine and alcohol interactions in the rat: contribution of cocaine metabolites to the pharmacological effects. J Pharm Sci 88: 468-76, 1999. 
PEIXOTO, C. et al. Impacto do perfil clínico e sociodemográfico na adesão ao tratamento de pacientes de um Centro de Atenção Psicossocial a Usuários de Álcool e Drogas (CAPSad). J Bras Psiquiatr, v. 59, n. 4, p. 317-321, 2010.

PENNINGS, E. J. M.; LECCESE, A. P.; WOLFF, F. A. Effects of concurrent use of alcohol and cocaine. Addiction, v. 97, p. 773-783, 2001

PEREIRA, A. S.; WURFEL, R. F. O uso de maconha como estratégia de redução de danos em dependentes de crack. Aletheia, n. 34, p. 163-174, 2011.

PETTY, G. W. L. et al. Embolic stroke after smoking "crack" cocaine. Stroke, v. 21, n. 11, p. 1632-5, 1990.

RAISTRICK, D.; DAVIDSON, D. G. Development of a questionnaire to measure alcohol dependence. Brit. J. Addict, v. 78, p. 89-95, 1983.

RANGÉ, B. Psicoterapias cognitivo-comportamentais - um diálogo com a psiquiatria. Porto Alegre: Artes Médicas; 2001.

RAUPP, L.; ADORNO, R. C. F. Circuitos de uso de crack na região central da cidade de São Paulo (SP, Brasil). Ciência \& Saúde Coletiva, v. 16, n. 5, p. 2613-2622, 2011.

REBOUSSIN, B.A.; ANTHONY, J.C. Is there Epidemiological Evidence to Support the Idea that a Cocaine Dependence Syndrome Emerges Soon after Onset of Cocaine Use? Neuropsychopharmacology, v. 31, n. 9, p. 2055-2064, 2006.

RIBEIRO M, LARANJEIRA R. O tratamento do usuário de crack. $2^{\mathrm{a}}$ Ed. Porto Alegre: Artmed; 2012.

RIBEIRO, F.A. et al. Antisocial behavior in crack-cocaine users. Contextos Clínicos, v. 9, n. 2, p. 216-224, 2016.

RIBEIRO, J. LP. Avaliação das intenções comportamentais relacionadas com a promoção e proteção da saúde e com a prevenção das doenças. Análise Psicológica, v. 2, n.22, p. 387397, 2004.

RIBEIRO, L.A.; SANCHEZ, Z.M.; NAPPO, S.A. Surviving crack: a qualitative study of the strategies and tactics developed by Brazilian users to deal with the risks associated with the drug. BMC Public Health, v. 10, p. 671, 2010.

RIBEIRO, M. et al. Crack cocaine: a five-year follow-up study of treated patients. Eur Addict Res, v. 13, n. 1, p. 11-9, 2007.

RIBEIRO, M.; LARANJEIRA, R. Estimativa do número de usuários de crack e /ou similares nas capitais do pais. Ministério da Saúde. FIOCRUZ, 2013.

RIBEIRO, Marcelo et al . Abuso e dependência da maconha. Rev. Assoc. Med. Bras., São Paulo, v. 51, n. 5, p. 247-249, Oct. 2005.

RIEZZO, I. et al. Side effects of cocaine abuse: multiorgan toxicity and pathological consequences. Curr Med Chem, v. 19, n. 33, p. 5624-46, 2012. 
RODRIGUES, D. R. S. R.; CONCEICAO, M. I. G.; IUNES, A. L. S. Representações Sociais do Crack na Mídia. Psic.: Teor. e Pesq, v. 31, n. 1, p. 115-123, 2015

RODRIGUES, V. et al. Revisão sistemática sobre tratamentos psicológicos para problemas relacionados ao crack. Jornal Brasileiro de Psiquiatria, v.62, n. 3, p. 208-216. 2013.

ROMANO, F.; ELKIS, H. Tradução e adaptação de um instrumento de avaliação psicopatológica das psicoses: a escala breve de avaliação psiquiátrica - versão ancorada

ROSA-OLIVEIRA, L. Q. et al. Reability and dimensionality of the Short Alcohol Dependence Data (SADD) questionaires in a clinical sample of hospitalized patient: using the SADD in a general setting. Revista Brasileira de Psiquiatria, v. 33, n. 1, 2011.

ROSENBERG, K. P.; FEDER, L. C. Behavioral Addictions. Criteria, Evidence, and Treatment. 381 p. San Diego, California: Elsevier, 2014.

ROY, E. et al. Examining the link between cocaine binging and individual, social and behavioral factors among street-based cocaine users. Addictive Behaviors, v. 68, p. 66-72, 2017.

RUTSTEIN DD. Measuring the quality of medical care: a clinical method. New England Journal Med. 1976; 294: 582- 588.

SANTOS CRUZ M. et al. Key drug use, health and socio-economic characteristics of young crack users in two Brazilian cities. Int J Drug Policy, v. 24, n. 5, p. 432-8, 2013.

SANTOS, J. A. T.; OLIVEIRA, M. L. F. Implantação De Ações Para Enfrentamento Do Consumo De Drogas Na Atenção Primaria A Saúde Cogitare Enferm, v. 18, n. 1, p. 21-8, 2013a.

SANTOS, J. A. T.; OLIVEIRA, M. L. F. Políticas públicas sobre álcool e outras drogas: breve resgate histórico. Saúde \& Transformação Social, v. 4, n. 1, p. 82-89, 2013 b.

SAYAGO, C. B. W. et al . Perfil clínico e cognitivo de usuários de crack internados. Psicol. Reflex. Crit., v. 27, n. 1, p. 21-28, 2014.

SCHERER, J.N. et al. Prevalence of driving under the influence of psychoactive substances and road traffic crashes among Brazilian crack-using drivers. Drug Alcohol Depend, v. 1, n. 168, p. 255-262, 2016.

SCHUCKIT, M. A. Comorbidity between substance use disorders and psychiatric conditions. Addiction, n. 101, supl. 1, p. 76-88, 2006.

SEIBEL, S. Equilíbrio Precário no Uso das Pedras. Scientific American International, n. 38, p. 22-31, 2010.

SELEGHIM, M. R. et al. Vínculo familiar de usuários de crack atendidos em uma unidade de emergência psiquiátrica. Revista Latino-americana de Enfermagem, v. 19, n. 5, 2011. 
SELEGHIM, M. R.; OLIVEIRA, M. L. F. Padrão do Uso de Drogas de Abuso em Usuários de Crack em Tratamento em Uma Comunidade Terapêutica. Revista Neurocienc., v. 21, n. 3, p. 339-348, 2013.

SHORTER, D.; DOMINGO, C. B.; KOSTEN, T. R. Emerging drugs for the treatment of cocaine use disorder: a review of neurobiological targets and pharmacotherapy. Expert Opin Emerg Drugs, v. 20, n. 1, p. 15-29, 2015.

SHORTER, D.; KOSTEN, T. R. Novel pharmacotherapeutic treatments for cocaine addiction - BMC Medicine, v. 9, p. 119-125. 2011

SIEGEL, R. K. Changing patterns of cocaine use: longitudinal observations, consequences, and treatment. NIDA Res Monogr, v. 50, n. 92, p. 110, 1984.

SIEGEL, R. K. Cocaine smoking. J Psychoactive Drugs, v. 14, n. 4, p. 271-359, 1982.

SILVA, C. C. et al. Iniciação e consumo de substâncias psicoativas entre adolescentes e adultos jovens de Centro de Atenção Psicossocial Antidrogas/CAPS-AD. Ciência \& Saúde Coletiva, 19(3):737-745, 2014

SILVEIRA, D. X Cannabis realmente pode causar esquizofrenia? (2005). Disponível em: http://www.proad.unifesp.br/pdf/cannabis_pode_realmente_causar_esquizofrenia.pdf Acesso em 21 fevereiro de 2017

SILVEIRA, D. X. et al. Cocaine craving questionnaire: assessing craving among cocaine users in Brazil. Psychiatric Res, n. 142, p. 257-259, 2006.

SILVERMAN, K.; DeFULIO, A.; SIGURDSSON, S. O. Maintenance of reinforcement to address the chronic nature of drug addiction. Preventive Medicine, v. 55, suplemento 1, p. 46-53. 2012.

SILVINO, M. C. S. et al. Operacionalização De Evento Sentinela Para Vigilância Do Uso De Drogas De Abuso. Sau. \&Transf. Soc, v.3, n.2, p.59-66, 2012

SPRICIGO, J. S. et al. Atenção ao usuário de drogas - um espaço para o enfermeiro. Rev Texto e Contexto Enfermagem, v. 13, p. 296-302. 2004.

STORY, A.; BOTHAMLEY, G.; HAYWARD, A. Crack cocaine and infectious tuberculosis. Emerging Infectious Diseases Journal, Atlanta, v. 14, no. 9, p. 1466-1469, 2008.

STOTTS, M. E. et al. Illusory predictors: Generalizability of findings in cocaine treatment retention research. Addictive Behaviors, v. 32, p. 2819-2836. 2007.

SULZER D. How addictive drugs disrupt presynaptic dopamine neurotransmission. Neuron, v. 69, p. 628-649, 2011.

SUSSNER, B. et al. The validity and reability of a brief measure of cocaine craving. Drug Alcohol Dependence, v. 83, n. 3, p. 233-287, 2006.

TIFFANY, S.T. et al. The development of a cocaine-craving questionnaire. Drug Alcohol Depend, v. 34, p. 19-28, 1993. 
TOLEDO, L; GÓNGORA, A.; BASTOS, F.I.P.M. À margem: uso de crack, desvio, criminalização e exclusão social - uma revisão narrativa. Ciência \& Saúde Coletiva, v. 22, n. 1, p. 31-42, 2017.

UCHÔA, M. A. Crack: o caminho das pedras. 2. 140d. São Paulo: Ática; 1996.

UNAIDS. Report on the global HIV/AIDS epidemic. Geneva: 2006.

UNITED NATIONS OFFICE ON DRUGS AND CRIME (UNODC). International Narcotics control board: world drug report, 2014. Vienna: United Nations Publication, 2015.

UNITED NATIONS OFFICE ON DRUGS AND Crime (UNODC). World drug report 2016, n. E.16.XI.7. Vienna: United Nations Publication.

URIBE, G. No INSS, pedidos de auxílio-doença para usuários de drogas triplicam em oito anos. O Globo, 10 fev. 2014. Disponível em: <http://oglobo.globo.com/brasil/no-insspedidos-de-auxilio-doenca-para-usuarios-de-drogas-triplicam-em-oito-anos-11555129>.

Acesso em: 14 nov. 2014.

VALLERSNES, O. M. et al. Psychosis associated with acute recreational drug toxicity: a European case series. BMC Psychiatry, v. 16, p. 293, 2016.

VAN SON, W. R.;CATENA, PEREZ-GARCIA, VERDEJO-GARCÍA. White matter disruptions in male cocaine polysubstance users: Associations with severity of drug use and duration of abstinence. Drug Alcohol Depend, v. 168, p. 247-254, 2016.

VASTERS, G. P.; PILLON, S. C. Drugs use by adolescents and their perceptions about specialized treatment adherence and dropout. Rev. Latino-Am. Enfermagem, v. 19, n. 2, p. 317-324, 2011.

VAUGHN, M. G. et al. Is Crack Cocaine Use Associated with Greater Violence than Powdered Cocaine Use? Results from a National Sample. The American Journal of Drug and Alcohol Abuse, v. 36, p. 181-186, 2010.

VOLKOW, N. D.; KOOB, G. F.; MCLELLAN, T. Neurobiologic Advances from the Brain Disease Model of Addiction. The New England Journal of Medicine, v. 374, p. 363-71, 2016.

VOLKOW, N. D.; WARREN, K. R. Drug addiction: the neurobiology of behavior gone awry. In: RIES, R. et al. (org.) ASAM The Principles of Addiction Medicine, 5ed. 2014.

WASHTON, A. M. Cocaine Addiction: treatment, recovery and relapse prevention. New York: W. W. Norton \& Company Ltd, 1989.

WOERNER M.; MANUZZA S.; KANE J. Anchoring the BPRS-A: an Aid to Improve Reliability. Psychopharmachology Bulletin, v. 24, p.112-117.1988.

World Health Organization (WHO). Informal Expert Committe on Drug-Craving Mechanism (v. 92-54439 T). Vienna, Report, 1992 
ZARKIN, G. A. et al. The effect of treatment completion and length of stay on employment and crime in outpatient drug-free treatment. Journal of Substance Abuse Treatment, v. 23, n. 4, p. 261-271. 2002.

ZENI, T. C.; ARAUJO, R. B. Relação entre o craving por tabaco e o craving por crack em pacientes internados para desintoxicação. J Bras Psiquiatr, v. 60, n. 1, p. 28-33, 2011.

ZHAO, J. et al. The rate ratio of injury and aggressive incident for alcohol alone, cocaine alone and simultaneous use before the event: A case-crossover study . Accident Analysis and Prevention, v. 75, p. 137-143, 2015.

ZUARDE, A. W. et al. Estudo da estrutura fatorial, fidedignidade e validade da tradução e adaptação para o português da escala de avaliação psiquiátrica breve modificada. Rev ABPAPAL, v. 16, p. 63-68 
A pêndice $\mid \mathbf{1 4 2}$

Apêndice 


\section{APÊNDICE A}

\section{TERMO DE CONSENTIMENTO LIVRE E ESCLARECIDO}

Gostaríamos de convidá-lo para participar da pesquisa que tem como título: "Evolução do Tratamento de Usuários de Cocaína e/ou Crack: um estudo de seguimento". O objetivo deste estudo, é identificar as características de usuários de cocaína e/ou crack que procuraram tratamento em um serviço especializado e explorar os fatores que podem estar associados a sua evolução no tratamento. Acreditamos que conhecendo melhor esses aspectos, poderemos auxiliar no desenvolvimento de melhores estratégias de tratamento. Para isso a sua participação é muito importante, e se dará, caso aceite por meio de três entrevistas individuais, sem a necessidade de sua identificação pessoal. Essas entrevistas ocorreram num período de seis meses, com intervalos de três meses entre cada uma. As entrevistas acontecerão em sala reservada dentro do CAPSad -II, de modo a assegurar sua integral privacidade. Inicialmente o entrevistador aplicará uma escala para avaliar se você está em condições psíquicas para participar da entrevista, caso contrário, será suspensa a entrevista e prestada assistência pela equipe de saúde do serviço, se necessário. A ocorrência de situações de desconforto ou riscos eventuais, também cancelará a realização da entrevista com prestação de devida assistência. $\mathrm{O}$ entrevistador lhe fará perguntas referentes a um conjunto de quatro questionários, contendo opções de resposta já definida, onde ele apenas assinalará sua resposta. A duração de cada entrevista é de aproximadamente 60 minutos. A pesquisa garante-lhe que: todas as suas dúvidas em relação ao estudo serão respondidas; você poderá desistir de participar a qualquer momento sem qualquer tipo de prejuízo pessoal ou no atendimento no serviço, não terá despesas para participar do estudo, o conteúdo da entrevista poderá ser usado para fins científicos, porém seu nome nunca será revelado; as informações que você julgar serem secretas serão mantidas em segredo; você poderá ter acesso a esta pesquisa quando finalizada.

Assim, pedimos para que assine este termo de consentimento em duas vias, também assinadas por nós, sendo que uma das duas vias, ficará com você para contato quando necessário.

$\mathrm{Eu}$, aceito participar da pesquisa sobre "Evolução do Tratamento de Usuários de Cocaína e/ou Crack: um estudo de seguimento", após ter sido informado sobre os aspectos éticos a que serei submetido, e que terei como benefício o acolhimento proporcionado pela pesquisadora em entrevista clínica. Sei que minha participação é voluntária, sem ganhos financeiros, e que posso deixar de participar da pesquisa a qualquer momento.

Ribeirão Preto, de de 20

Assinatura do participante:

Profa. Dra. Sandra Cristina Pillon

Orientadora do Projeto de Pesquisa

Escola de Enfermagem de Ribeirão Preto

Av. Bandeirantes, 3900, CEP: 14040-902,

Telefone: (16) 3602-0531

\author{
Jéssica Adrielle Teixeira Santos \\ Doutoranda do Programa de Enfermagem \\ Psiquiátrica da EERP/USP. \\ E-mail: jessicadrielle@yahoo.com.br \\ Telefone: (16) 8185-1936
}

\section{Centro de Atenção Psicossocial para Usuários de Álcool e outras Drogas II. \\ R: Pará,1310 - Ipiranga, Ribeirão Preto - SP. CEP: 14060440 Fone: (16) 361533}

Comitê de Ética em Pesquisa da Escola de Enfermagem de Ribeirão Preto - USP

Av. Bandeirantes, 3900 - Monte Alegre, Ribeirão Preto -SP. CEP: 14040

-902. Fone: (16) 3602.3386. E-mail cep@eerp.usp.br. Horário de atendimento: 08:00 às 17:00 de segunda a sexta -feira. 
Anexos|144

Anexos 


\section{ANEXO A}

\section{Escala Breve de Avaliação Psiquiátrica - BPRS-A}

BP 1- PREOCUPAÇÕES SOMÁTICAS. Este item compreende a hipocondria. Os graus 1 e 2 da escala referem-se à hipocondria não delirante e os graus 3 e 4 , a hipocondria delirante.

( ) 0 - Atenção normal com a saúde física.

( ) 1 - Grau mínimo ou duvidoso de preocupação excessiva com a saúde física.

( ) 2 - O paciente expressa ideias de ter uma doença orgânica (por ex. câncer ou doença cardíaca), mas sem interpretações delirantes.

( ) 3 - As queixas são bizarras (por ex. estar apodrecendo por dentro), mas pode-se conseguir que o paciente, por breves períodos, admita que esse não é o seu caso.

( ) 4 - Está convencido, por ex., de que seus órgãos estão podres ou desaparecendo, ou de que vermes estão devorando seu cérebro. Nem por breves períodos se pode fazê-lo admitir que esse não é o seu caso.

BP 2- ANSIEDADE PSÍQUICA. (Nos últimos 3 dias). Este item compreende tensão (central), irritabilidade, preocupação, insegurança, medo e apreensão, que se aproximam ao pavor subjugante. Frequentemente pode ser difícil distinguir entre a vivencia da ansiedade do paciente (os fenômenos de ansiedade "psíquica" ou "central") e as manifestações fisiológicas de ansiedade (periférica) que podem ser observadas, como tremor das mãos e sudorese. Muito importante, nesse item, é o relato do paciente de preocupação, insegurança, vivencias de pavor, ou seja, de ansiedade psíquica "central".

( ) 0 - O paciente não se encontra nem mais nem menos inseguro ou irritável do que o habitual.

( ) 1 - É duvidoso se o paciente está mais inseguro ou irritável do que o habitual.

( ) 2 - A paciente expressa mais claramente estar em um estado de ansiedade, apreensão e irritabilidade, que pode achar difícil de controlar. Isso ocorre sem influir no dia-a-dia do paciente, porque a preocupação ainda diz respeito a questões pouco importantes.

( ) 3- A ansiedade ou insegurança é, às vezes, mais difícil de controlar porque a preocupação diz respeito a perdas ou danos importantes, que podem ocorrer no futuro. Por exemplo, a ansiedade pode ser vivenciada como pânico, ou seja, como pavor subjugante. Ocasionalmente essa ansiedade já interferiu no dia-a-dia do paciente.

( ) 4 - A sensação de pavor está tão frequentemente presente que interfere acentuadamente no dia-a-dia do paciente.

BP 3- RETRAIMENTO EMOCIONAL: Este item compreende a vivencia introspectiva de contato emocional com o paciente durante a entrevista. Ele se contrapõe ao item 16 (afeto embotado ou inapropriado), que compreende o grau emocional com outras pessoas, avaliado, retrospectivamente durante os três dias precedentes.

( ) 0 - Contato emocional normal.

( ) 1 - Alguma (ou duvidosa) distância emocional.

( ) 2 - Reações emocionais reduzidas, como, por exemplo, contato visual duvidoso.

( ) 3 - Reações emocionais mais limitadas, como, por ex, contato visual ocasionalmente inadequado.

( ) 4 - Quando o contato emocional está fortemente reduzido ou quase ausente, como por exemplo, quando evita contato visual.

BP 4- DESORGANIZAÇÃo CONCEITUAL (incoerência) Este item compreende os distúrbios do processo de pensamento (forma), desde certa imprecisão na expressão verbal até produções verbais completamente desorganizadas.

( ) 0 - Ausência de desorganização conceitual.

( ) 1 - O pensamento é caracterizado por uma certa imprecisão, mas a fala não é gramaticalmente inusual.

( ) 2 - Distúrbio moderado do pensamento. As palavras podem estar ligadas por meio de uma forma gramaticalmente inusual e particular e a informação parece "vazia".

( ) 3 - Acentuada desorganização conceitual. Ocasionalmente, torna-se difícil entender o paciente, podendo surgir neologismos ou bloqueio.

( ) 4 - Desorganização conceitual extremamente grave. Apenas fragmentos da fala são compreensíveis.

BP 5- AUTODEPRECIAÇÃO E SENTIMENTOS DE CULPA. Este item compreende a diminuição da auto-estima, com sentimentos de culpa.

( ) 0 - Ausência de auto-depreciação e sentimento de culpa.

( ) 1 - É duvidoso se sentimentos de culpa estão presentes, pois o paciente está apenas preocupado com o fato de que ele, durante a doença atual, seja um peso para a família ou os colegas, devido a sua reduzida capacidade de trabalho.

( ) 2 - Autodepreciação ou sentimentos de culpa estão mais claramente presentes, pois o paciente está preocupado com incidentes do passado, anteriores ao episódio atual. Por exemplo, o paciente acusa-se de pequenas omissões ou falhas, de não ter cumprido com seu dever ou de haver prejudicado outras pessoas.

( ) 3 - O paciente experimenta sentimentos de culpa mais graves. Ele pode afirmar que sente que seu sofrimento atual é algum tipo de punição. Assinale três, desde que o paciente possa perceber intelectualmente que sua opinião é infundada.

( ) 4 - Os sentimentos de culpa são firmemente mantidos e resistem a qualquer argumentação, de modo que se convertam em idéias paranóides.

BP 6- ANSIEDADE SOMÁTICA (durante a entrevista) Este item compreende os concomitantes fisiológicos da ansiedade que se manifestam durante a entrevista. Todos os estados subjetivos de ansiedade devem ser assinalados no item 2, e não aqui.

( ) 0 - Quando o paciente não está nem mais nem menos propenso que o habitual a experimentar concomitantes somáticos de estados de ansiedade.

( ) 1 - Quando o paciente ocasionalmente apresenta leves manifestações, como sintomas abdominais, sudorese ou tremores. Entretanto, a descrição desses sintomas é vaga e questionável.

( ) 2 - Quando paciente ocasionalmente apresenta sintomas abdominais, sudorese, tremores, etc. Os sinais e sintomas são claramente descritos, porém não são acentuados nem incapacitantes.

( ) 3 - Os concomitantes emocionais dos estados subjetivos de ansiedade são acentuados e, às vezes, muito preocupantes. 
( ) 4 - Os concomitantes fisiológicos dos estados sujeitos de ansiedade são numerosos, persistentes e frequentemente incapacitantes.

BP 7-DISTÚRBIOS MOTORES ESPECÍFICOS Este item compreende os graus variáveis de comportamento motor bizarro, que vai desde certa excentricidade na postura até a agitação catatônica severa.

( ) 0 - Ausente/

( ) 1 - Leve ou de presença duvidosa durante a entrevista.

( ) 2 - Moderada. Presente durante a maior parte da entrevista.

( ) 3 - Severa. Anormalidades motoras contínuas, podem ser interrompidas.

( ) 4 - Extremamente severa. Anormalidades motoras persistentes e incontroláveis. Entrevista difícil.

BP 8- AUTO-ESTIMA EXAGERADA Este item compreende graus variáveis de exagero da auto-estima, variando desde uma acentuada autoconfiança ou presunção, até os delírios de grandeza grotescos.

( ) 0 - Auto-estima normal.

( ) 1 - Auto-estima aumentada levemente ou de maneira duvidosa, como por ex.: ocasionalmente superestima suas próprias capacidades habituais./

( ) 2 - Auto-estima moderadamente aumentada. Por exemplo, superestima mais constantemente suas próprias capacidades habituais ou insinua possuir capacidades incomuns.

( ) 3 - Idéias acentuadamente irreais, como por ex., de que tem habilidades, poderes ou conhecimentos (científicos, religiosos, etc) extraordinários, mas pode, por breves períodos ser corrigido.

( ) 4 - Idéias de grandeza que não podem ser corrigidas.

BP 9- HUMOR DEPRIMIDO Este item compreende tanto a comunicação verbal como a não verbal de tristeza, depressão, desanimo, desamparo, desesperança.

( ) 0 - Humor neutro/

( ) 1 - O paciente indica vagamente que está mais desanimado e deprimido que o habitual.

( ) 2 - Quando o paciente está mais claramente preocupado com vivências desagradáveis, embora ainda não esteja se sentindo desamparado ou desesperançado.

( ) 3 - O paciente exibe sinais não verbais claros de depressão e/ou, as vezes, sente-se dominado pelo desamparo ou desesperança.

( ) 4 - As observações do paciente sobre desânimo e desamparo, ou as suas manifestações não verbais dominam a entrevista, não sendo possível afastá-lo dessa temática.

BP 10-HOSTILIDADE Este item compreende o relato verbal do paciente de sentimentos ou ações hostis em relação a outras pessoas fora da entrevista. Trata-se de um julgamento retrospectivo dos três dias precedentes. Diferenciar do item 14 (falta de cooperação), que corresponde ao contato formal durante a entrevista.

( ) 0 - Ausência de sinais de impaciência, irritabilidade ou hostilidade.

( ) 1 - Esteve um pouco impaciente ou irritável, mas o controle foi mantido.

( ) 2 - Esteve moderadamente impaciente ou irritável, mas tolerou as provocações.

( ) 3 - Esteve verbalmente hostil, faz ameaças e quase chegou a ser fisicamente destrutivo, mas ainda pôde ser acalmado.

( ) 4 - Extremante hostil, com violência física manifesta. Fisicamente destrutivo

BP 11. DESCONFIANÇA Este item compreende a desconfiança, a suspeita ou as interpretações distorcidas, variando desde uma acentuada falta de confiança nos outros até os delírios de perseguição floridos.

( ) 0 - Ausente.

( ) 1 - Vagas idéias de referência. Tende a suspeitar que as outras pessoas estão falando ou rindo de si. Sente que "alguma coisa está ocorrendo". Responde ao reasseguramento; portanto, fica duvidoso se existem idéias de referência ou delírios.

( ) 2 - Idéias de referência com delírios vagos, não sistematizados, de perseguição. "Alguém pode ter más intenções". Isso é insinuado pela televisão ou pelos jornais. Ainda se trata de uma vivência do tipo "como se".

( ) 3 - Delírios com alguma sistematização. reasseguramento difícil.

( ) 4 - Delírios paranóides sistematizados, floridos, de perseguição. Correção impossível

BP 12-ALUCINAÇÕES Este item compreende as percepções sensoriais sem os estímulos externos correspondentes. As vivencias alucinatórias devem ter ocorrido nos últimos três dias e, com exceção das alucinações hipinagógicas, não devem ter ocorrido durante os estados de turvação da consciência (delirium).

( ) 0 - Ausente.

( ) 1 - Em grau leve ou de presença duvidosa. Vivências alucinatórias hipinagógicas ou vivências alucinatórias elementares isoladas (ouvir sons, ver luzes).

( ) 2 - Alucinações ocasionais, mas plenamente desenvolvidas (ouvir vozes, ver formas), que não afetam o comportamento.

( ) 3 - Alucinações ocasionais que influenciam o comportamento.

( ) 4 - Mais ou menos constantemente absorto(concentrado) em vivências alucinatórias.

BP 13-RETRAIMENTO PSICOMOTOR Este item compreende a redução do nível de atividade psicomotora, que inclui a velocidade de associações e a capacidade para verbalizar os pensamentos. Os sintomas do retardo motor dizem respeito à postura, aos gestos e à expressão facial.

( ) 0 - Atividade verbal normal, atividade motora normal, com expressão facial adequada.

( ) 1 - Velocidade de conversação duvidosa ou levemente reduzida e expressão facial duvidosa ou levemente diminuída.

( ) 2 - Velocidade de conversação claramente reduzida, com pausas; gestos reduzidos e movimentação lenta.

( ) 3 - A entrevista é claramente prolongada devido às longas latências e respostas curtas; todos os movimentos estão muito lentos.

( ) 4 - A entrevista não pode ser completada; o retardo se aproxima de (e inclui) estupor (paralisia). 
BP 14-FALTA DE COOPERAÇÃO Este item compreende a atitude e as respostas do paciente ao entrevistador e a situação da entrevista. Difere do item 10 (hostilidade) porque este compreende a falta de cooperação com outras pessoas durantes os três dias precedentes à entrevista.

( ) 0 - Atitude cooperativa natural.

( ) 1 - Excessivamente formal e reservado na situação da entrevista. Responde um pouco resumidamente.

( ) 2 - Resistência moderada. Responde evasivamente ou opõe-se a determinadas perguntas. Atitude acentuadamente hostil para com o entrevistador. ( ) 3 - Resistência pronunciada. Responde inapropriadamente ou recusa-se a responder. Atitude abertamente hostil. Entrevista completa não é possível.

( ) 4 - Entrevista impossível. O paciente recusa-se a permanecer na situação de entrevista.

BP 15-CONTEÚDO DO PENSAMENTO INCOMUM (conteúdo) Este item diz respeito ao conteúdo da verbalização do paciente e não da organização da linguagem, que é assinalada no item quatro. $\mathrm{O}$ item refere-se às qualidades incomuns até os vários os vários níveis de idéias delirantes. Observe que os delírios de grandeza são assinalados no item 8 (auto-estima exagerada), que os "delírios de culpa" são assinalados no item 5 e que os delírios de perseguição são assinalados no item 11 (desconfiança). Os delírios que apresentam interesse especial aqui são os delírios de controle, influência ou despersonalização, ciúme mórbido, delírios sexuais, delírios religiosos ou expansivos. Assinale apenas o grau de raridade do conteúdo expresso no pensamento, a importância que apresenta para o paciente ou a influência que exerce sobre o seu comportamento.

\section{( ) 0 - Ausente.}

( ) 1 - Grau leve ou presença duvidosa (por ex. idéias supervalorizadas).

( ) 2 - Grau moderado (por ex. idéias com alguma qualidade delirante, mas ainda se constituindo em uma vivencia do tipo "como se").

( ) 3 - Os delírios delimitam a maior parte do conteúdo do pensamento e ocasionalmente influenciam o comportamento.

( ) 4 - Delírios subjugantes(dominantes) delimitam o conteúdo do pensamento e comportamento.

BP 16- AFETO EMBOTADO OU INAPROPRIADO Este item compreende a diminuição da capacidade ou da motivação para sentir ou expressar as emoções normais, como tristeza, alegria, raiva. As emoções, manifestadas verbalmente e não verbalmente, são perceptivelmente inapropriadas à situação ou ao conteúdo do pensamento. Esse item compreende, assim, o retraimento emocional relativo às outras pessoas, durante os últimos três dias precedentes. Discriminar do item 3(retraimento emocional), que diz respeito a vivencia introspectiva do contato emocional durante a entrevista.

( ) 0 - Reações e envolvimento apropriados.

( ) 1 - reações emocionais escassas ou questionavelmente inapropriadas. Por ex., menos desejo ou capacidade de estar em companhia de pessoas que conhece há mais ou menos tempo.

( ) 2 - Afeto perceptivelmente embotado. Não apresenta necessidade ou capacidade de estabelecer contato mais íntimo com pessoas não pertencentes ao seu círculo familiar (companheiros de trabalho, outros pacientes, equipe terapêutica).

( ) 3 - Emocionalmente indiferente e apático, mesmo em relação aos amigos íntimos e a família.

( ) 4 - Emocionalmente ausente, ou então os afetos manifestados são grosseiramente inapropriados, sem qualquer motivação para o contato humano.

BP 17- AGITAÇÃO PSICOMOTORA Este item compreende o aumento no nível da atividade psicomotora.

( ) 0 - Atividade motora normal. Expressão facial adequada e atividade verbal normal.

( ) 1 - Atividade motora duvidosa ou levemente aumentada; por ex, expressão facial vívida ou certa loquacidade (falador).

( ) 2 - Atividade motora moderadamente aumentada; por ex., gestos vívidos, grande loquacidade ou fala em vos alta e rapidamente.

( ) 3 - Atividade motora claramente excessiva, movimentando-se durante a maior parte do tempo. Levanta-se uma ou várias vezes durante a entrevista. Fuga de idéias. Dificuldade para compreendê-lo.

( ) 4 - Constante e incansavelmente ativo. Fala desintegrada. Comunicação significativa impossível.

BP 18- DESORIENTAÇÃO E CONFUSÃO Este item compreende os graus de turvação da consciência, com redução ou perda de orientação no tempo e/ou quanto a dados pessoais.

( ) 0 - O paciente está completamente orientado no tempo, no espaço e quanto aos dados pessoais.

( ) 1 - O paciente ocasionalmente tem algumas dificuldades, mas pode corrigir espontaneamente sua afirmação sobre a orientação no tempo, e/ou no espaço, e/ou quanto aos dados pessoais.

( ) 2 - O paciente apresenta falhas que não são corrigidas espontaneamente. Por ex., não sabe o dia da semana ou do mês, embora saiba o mês e o ano corretamente, e/ou tem dificuldades espaciais, embora esteja orientado na enfermaria (ou em sua casa), e/ou tem dificuldades para recordar nomes, embora saiba seu próprio nome.

( ) 3 - O paciente está acentuadamente desorientado. Por exemplo, não sabe o mês e o ano corretamente, embora ainda se localiza quanto a períodos significativos do ano (carnaval, festas juninas, natal), e/ou tem dificuldades para localizar o banheiro ou a sua cama sem auxílio, e/ou lembra seu próprio nome apenas por meio de alguma ajuda.

( ) 4 - Está completamente desorientado no tempo e/ou no espaço, e/ou quanto aos dados pessoais. 


\section{ANEXO B}

\section{DADOS SÓCIODEMOGRÁFICO}

1. Nome:

2. Idade: 3. Data de nascimento: 4. Gênero: 4.1 feminino $4.2 \square$ masculino

5. Estado Civil:

$5.1 \square$ Solteiro (a)

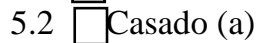

5.3 Divorciado (a)

$5.4 \square$ Separado (a)

5. $5 \square$ União consensual

$5.6 \square$ Viúvo (a)
7. Etnia relatada:

7.1 $\square$ Caucasiano/branco

$7.2 \square$ Pardo

$7.3 \square$ Negro

$7.4 \square$ Oriental

\section{Religião/credo:}

$8.1 \square$ Católico

8.2 $\square$ Evangélico

6. Escolaridade

$6.2 \square 1^{\circ}$ grau

$6.3 \square 2^{\circ}$ grau

$6.4 \square$ Superior

$6.5 \square$ Outro. Especificar:
8.3 Espírita

8.4 Afro-brasileiros (umbanda, candomblé)

9. Praticante: $9.1 \square \operatorname{sim} \quad 9.2 \square$ não 11. Vínculo Formal: $11.1 \square \operatorname{sim} 11.2 \square$ não

10. Ocupação atual:

12. Naturalidade: 13. Residência atual (município):

14. Mora sozinho: $14.1 \quad \square \mathrm{m} \quad 14.2 \square$ ão (se não, preencher quadro 15)

15. Composição familiar (somente pessoas que moram no mesmo domicilio)

\begin{tabular}{|c|c|c|c|c|c|c|c|}
\hline & $\begin{array}{l}\text { Parentesco } \\
\text { [a] }\end{array}$ & Idade [b] & Escolaridade [c] & Ocupação [d] & $\begin{array}{l}\text { Contribui para as } \\
\text { despesas [e] }\end{array}$ & Uso de drogas [f] & $\begin{array}{l}\text { Uso de drogas. Se } \\
\text { sim, quais?[g] }\end{array}$ \\
\hline 15.1 & & & & & ( ) sim ( )não & ( ) $\operatorname{sim}$ ( )não & \\
\hline 15.2 & & & & & ( ) $\operatorname{sim}$ ( )não & ( ) $\operatorname{sim}$ ( )não & \\
\hline 15.3 & & & & & ( ) $\operatorname{sim}$ ( )não & ( ) $\operatorname{sim}$ ( )não & \\
\hline 15.4 & & & & & ( ) $\operatorname{sim}($ ( )não & ( ) sim ( )não & \\
\hline 15.5 & & & & & ( ) $\operatorname{sim}($ ( )não & ( ) $\operatorname{sim}($ ( )não & \\
\hline 15.6 & & & & & ( ) $\operatorname{sim}($ ( )não & ( ) $\operatorname{sim}$ ( )não & \\
\hline 15.7 & & & & & ( ) $\operatorname{sim}($ ) $)$ ão & ( ) $\operatorname{sim}($ ( )não & \\
\hline
\end{tabular}

\section{DADOS SÓCIOECONÔMICO}

16. Critério de Classificação Econômica Brasil por Sistema de Pontos

\begin{tabular}{|c|c|c|c|c|c|c|c|}
\hline \multirow{2}{*}{ Itens } & \multicolumn{5}{|c|}{ Quantidade } & \multirow{2}{*}{\multicolumn{2}{|c|}{ Grau de Instrução do chefe de família }} \\
\hline & $\mathbf{0}$ & 1 & 2 & 3 & 4 out & & \\
\hline Televisão em cores & 0 & 1 & 2 & 3 & 4 & & \\
\hline Rádio & 0 & 1 & 2 & 3 & 4 & Analfabeto/ Fundamental 1 Incompleto & 0 \\
\hline Banheiro & 0 & 4 & 5 & 6 & 7 & Fundamental 1 Completo / Fundamental 2 Incompleto & 1 \\
\hline Automóvel & 0 & 4 & 7 & 9 & 9 & Fundamental 2 Completo/ Médio Incompleto & 2 \\
\hline Empregada mensalista & 0 & 3 & 4 & 4 & 4 & Médio Completo/ Superior Incompleto & 4 \\
\hline Maquina de lavar & 0 & 2 & 2 & 2 & 2 & Superior Completo & 8 \\
\hline Vídeo cassete ou DVD & 0 & 2 & 2 & 2 & 2 & & \\
\hline Geladeira & 0 & 4 & 4 & 4 & 4 & & \\
\hline $\begin{array}{l}\text { Freezer (aparelho independente ou parte } \\
\text { da geladeira duplex) }\end{array}$ & 0 & 2 & 2 & 2 & 2 & $\sum$ dos pontos & \\
\hline
\end{tabular}

Fonte: ABEP - Associação Brasileira de Empresas de Pesquisa

Renda Familiar do entrevistado

\begin{tabular}{|l|c|c|c|}
\hline & Classes & Renda média bruta familiar nomes e R\$ \\
\hline 16.1 & A & 9.263 & \\
\hline 16.2 & B1 & 5.241 & \\
\hline 16.3 & B2 & 2.654 & \\
\hline 16.4 & C1 & 1.685 & \\
\hline 16.5 & C2 & 1.147 & \\
\hline 16.6 & DE & 776 & \\
\hline
\end{tabular}

\begin{tabular}{|l|c|}
\hline Classe & Pontos \\
\hline A1 & $42-46$ \\
\hline A2 & $35-41$ \\
\hline B1 & $29-34$ \\
\hline B2 & $23-28$ \\
\hline C1 & $18-22$ \\
\hline C2 & $14-17$ \\
\hline D & $8-13$ \\
\hline E & $0-7$ \\
\hline
\end{tabular}




\section{Escala de Gravidade de Dependência}

The Addiction Severity Index (ASI)

Versão 6

\section{Observação:}

Este instrumento encontra-se em fase de validação para a cultura brasileira. Seus direitos autorais pertencem à Universidade da Pensilvânia, e suas informações não podem ser divulgadas ou distribuídas sem o prévio consentimento dos autores. O Centro de Pesquisa em Álcool e Drogas da Universidade Federal do Rio Grande do Sul (UFRGS) é o responsável pela utilização desta versão em português, que ainda se encontra em fase de testes. Quaisquer informações sobre o instrumento no Brasil podem ser obtidas pelos seguintes contatos:

Dr. Felix Kessler: kessler.ez@terra.com.br

Dr. Flavio Pechansky: fpechans@uol.com.br

Resumo dos Escores de Gravidade do ASI

\begin{tabular}{|l|l|l|l|l|}
\hline Sub-escalas & $\begin{array}{c}\text { Ques- } \\
\text { tão }\end{array}$ & $\begin{array}{c}\text { Grau de } \\
\text { Preocupação }\end{array}$ & $\begin{array}{c}\text { Ques- } \\
\text { tão }\end{array}$ & $\begin{array}{c}\text { Necessidade de } \\
\text { Tratamento }\end{array}$ \\
\hline Médica & M23 & $0-1-2-3-4$ & M24 & $0-1-2-3-4$ \\
\hline Emprego/S. & ---- & ---------------- & E23 & $0-1-2-3-4$ \\
\hline Álcool & D22 & $0-1-2-3-4$ & D23 & $0-1-2-3-4$ \\
\hline Drogas & D47 & $0-1-2-3-4$ & D48 & $0-1-2-3-4$ \\
\hline Legal & L25 & $0-1-2-3-4$ & ---- & ----------------- \\
\hline Lazer & F22 & $0-1-2-3-4$ & ---- & ---------------- \\
\hline Família/Soc. & F14 & $0-1-2-3-4$ & F15 & $0-1-2-3-4$ \\
\hline Trauma & F38 & $0-1-2-3-4$ & F39 & $0-1-2-3-4$ \\
\hline Filhos & F48 & $0-1-2-3-4$ & F49 & $0-1-2-3-4$ \\
\hline Psiquiátrica & P20 & $0-1-2-3-4$ & P21 & $0-1-2-3-4$ \\
\hline
\end{tabular}

Códigos para aplicação do instrumento:

$X$ - não sabe ou não entendeu a questão

$\mathrm{N}$ - não se aplica

$Q$ - não quis responder

B - o entrevistador deixou em branco incorretamente 
Informacões Gerais - Esta é uma entrevista padronizada que pergunta sobre várias áreas da sua vida - saúde, emprego, uso de álcool e drogas, etc. Algumas questões referem-se aos últimos 30 dias ou aos últimos seis meses, enquanto outras são sobre a sua vida inteira. Toda informação que você fornecer é confidencial (explique) e será utilizada para (explique). Por favor, responda às questões com a sua melhor estimativa. Se houver perguntas que você não entender ou preferir não responder, por favor, me informe. A entrevista terá uma duração de aproximadamente uma hora. Você tem alguma pergunta antes de nós começarmos? Primeiro começaremos com algumas informações gerais.

Nome do Paciente:

G6. Os dados da entrevista serão referentes ao período:

1 - Anterior à data da própria entrevista:

2 - Anterior à data de admissão:

3 - Anterior à outra data:
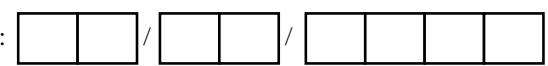

G8. Gênero (1 - Masculino, 2 - Feminino):

G10. Qual raça / cor você se considera? [Marque todas q. se aplicam]

$\begin{array}{ll}\text {-1. Negra/Preta } & \text { 5. Indígena } \\ \text { _. Branca } & \text { 6. Outros } \\ \text { 3. Amarela/Oriental } & \text { 7. Não respondeu }\end{array}$

4. Parda/Mestiça

G11. Está em internação (1), ambulatório (2), outro local (3)?

G12. Qual o seu estado conjugal?
1 - casado
2 - vivendo como casado
4 - Divorciado
3 - viúvo
5 - Separado $\quad 6 \rightarrow \mathrm{G} 14$
6 - Nunca casou

G14. Como você foi encaminhado para o tratamento?
- i.e. encaminhado para este programa específico de tratamento
1 - Por si próprio, cônjuge, familiar ou por amigo
2 - Instituição ou pessoa ligada a tratamento de álcool e drogas
3 - Instituição de saúde ou profissional de saúde
4 - Escola/Faculdade
5 - Trabalho ou programa de assistência ao emprego
6 - Serviço Comunitário (programa desemprego, abrigo, igreja, etc.)
7 - Sistema penal ou pelo juiz

\section{$\begin{array}{llllllllllll}\mathbf{J} & \mathbf{F} & \mathbf{M} & \mathbf{A} & \mathbf{M} & \mathbf{J} & \mathbf{J} & \mathbf{A} & \mathbf{S} & \mathbf{O} & \mathbf{N} & \mathbf{D}\end{array}$}

Moradia - As questões seguintes perguntam se você morou em algum tipo de local restrito ou supervisionado durante os últimos 6 meses desde e os últimos 30 dias desde

[NOTA: 6 meses $=180$ dias, informe ao entrevistado se necessário] H1. Nos últimos 6 meses, aproximadamente quantas noites você ficou em um hospital, unidade de internação psiquiátrica ou de tratamento para álcool e/ou drogas (internação), prisão ou delegacia, pensão protegida ou albergue para paciente psiquiátrico, ou comunidade terapêutica?

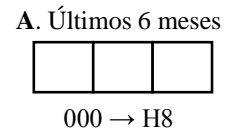

Dessas noites, quantas foram em:
H2. Unidade de internação para tratamento de álcool ou drogas?

H3. Hospital geral?

H4. Hospital psiquiátrico?

H5. Delegacia ou prisão?

H6. Pensão protegida, comunidade terapêutica ou albergue (p/ pac. psiq.)?
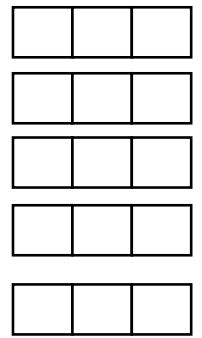

H7. Outro tipo de situação de moradia restrita ou supervisionada? Que tipo de lugar?

H8. Quantas noites você passou em um abrigo para moradores de rua?
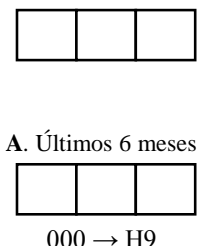

H9. Quantas noites você passou na rua, ou em lugares como prédios abandonados, carros, parques ou praças, porque você não tinha outro lugar para ficar?

A. Últimos 6 meses

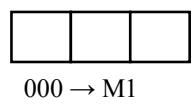

Médico - As questões a seguir são sobre sua saúde física.

M1. Que tipo de convênio/seguro de saúde você tem?

[Marque todas que se aplicam]

1. Nenhum (SUS)

2. Seguro privado, plano de saúde privado ex. Unimed, IPE, Golden Cross, Bradesco Saúde

3. Convênio público

4. Convênio militar

5. Outros (especifique:

6. Não respondeu

[NOTA: Se homem, Pule a M2.]

M2. Você está grávida neste momento?

1 - Sim, 0 - Não 2 - Não tem certeza

Alguma vez algum médico ou um profissinal de saúde lhe disse que você tinha alguma das seguintes doenças?

1 - Sim, 0 - Não

M3. Pressão Alta

M4. Diabetes

M5. Doença Cardíaca..

M6. Derrame / Isquemia (Acidente Vascular Cerebral)......

M7. Epilepsia ou convulsões

M8. Câncer ...

M9. HIV/AIDS

M10. Tuberculose

M11. Hepatite

M12. Cirrose ou outra doença crônica do fígado

M13. Doença renal crônica

M14. Problema respiratório crônico ex. asma, enfisema, DPOC, bronquite 
M15. Outro problema ou doença crônica ex. artrite, dor lombar crônica, prob. digestivos, hipotireoidismo, - se "Sim" especifique:

M16. Qualquer incapacidade física que seriamente prejudica sua visão, audição ou movimentos? - se "Sim," especifique:

[NOTA: Se M3 - M16 forem todas 0 - Não, Pule a M17.]

M17. Você já recebeu prescrição de medicação para qualquer uma dessas condições? 0 - Não

1 - Sim, e ainda estou tomando todos os remédios como prescrito.

2 - Sim, e deveria estar tomando, mas não estou (ou toma apenas alguns).

3 - Sim, mas me disseram (médico) que a medicação não era mais necessária.

M18. Você já solicitou ou recebeu qualquer tipo de pensão para doença física ou incapacidade? 1 -Sim, 0 - Não - exclua incapacidade psiquiátrica

M19. Nos últimos 30 dias, você diria que sua saúde física esteve?
0 - Excelente
3 - Razoável
1 - Muito Boa
4-Ruim
2 - Boa

\section{(M20 - M23) Nos últimos 30 dias:}

[NOTA: NÃO inclua problemas que são totalmente causados por estar sob efeito, intoxicado ou em abstinência de álcool ou drogas. Também não inclua transtornos psiquiátricos.]

M20. Quantos dias você teve sintomas ou problemas físicos ou clínicos?

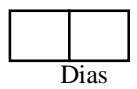

ex. doença, lesão, dor, desconforto, incapacidade

- incluir problemas dentários

M21. Quantos dias você esteve incapacitado para exercer atividades normais por causa de sintomas ou problemas clínicos/físicos?

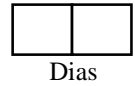

[NOTA: Apresente a Escala de Avaliação do Entrevistado]

M22. Quanto desconforto ou dor física você experimentou?
0 - Nada
3 - Consideravelmente
1 - Levemente
4 - Extremamente
2 - Moderadamente

M23. Quão preocupado ou incomodado você tem estado com sua saúde física ou qualquer problema clínico?
0 - Nada
3 - Consideravelmente
1 - Levemente
4 - Extremamente

2 - Moderadamente

M24. Neste momento, quão importante é para você o tratamento (atual ou adicional) para qualquer problema clínico ou físico?
0 - Nada
3 - Consideravelmente
1 - Levemente
4 - Extremamente
2 - Moderadamente

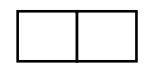

M25. Quantas vezes na sua vida você já esteve hospitalizado (ao menos uma noite) por problemas físicos ou clínicos?
- não inclua hospitalizações para tratamento de álcool/

drogas ou psiquiátrico, ou partos não complicados.

A. Últimos 6 meses $\quad$ B. 30 Dias

M26. Quantos dias você utilizou serviços de emergência para tratar algum problema clínico?
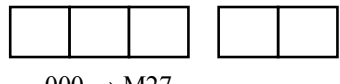

$000 \rightarrow \mathrm{M} 27$

M27. Quantos dias você tomou medicações prescritas para uma doença física? - não inclua remédios para problemas com álcool/drogas/psiquiátricos.

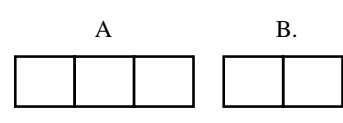

$000 \rightarrow \mathrm{M} 28$

M28. Quantos dias você fez visitas ambulatoriais ou de consultório com um médico ou profissional de saúde? ex. exame físico de qualquer natureza ou outro monitoramento/cuidado para algum problema médico ou doença. - não inclua tratamento para álcool/ drogas ou psíquico.

Emprego/Sustento - As questões seguintes são sobre a sua educação, emprego e finanças.

E1. Qual é o grau máximo de estudo que

você completou?
1 - Ensino Fundamental
4 - Bacharelado
2 - Ensino Médio
5 - Mestrado ou mais
3 - Ensino Superior (Faculdade)
6-Nenhum

E2. Você tem algum outro diploma, licença ou certificado de algum treinamento formal?

1 - Sim, 0 - Não

E3. Qual é a última série ou ano que você completou?

01 = Não alfabetizado

$02=1^{\underline{a}}$ à $4^{\underline{a}}$ série

$16=3^{\circ} \mathrm{e} / \mathrm{ou} 4^{\circ}$ ano de faculdade

$12=5^{a}$ à $8^{\underline{a}}$ série

$17=5^{\circ}$ e $/$ ou $6^{\circ}$ ano de faculdade

$13=1^{\circ}$ e $/$ ou $2^{\circ}$ ano do E.M.

$18=1^{\circ}$ ao $2^{\circ}$ ano de pós-g. (mestrado)

14 = 3o ano Ensino Médio

$19=$ Doutorado completo ou não

$15=1^{\circ}$ e/ou $2^{\circ}$ ano de faculdade

20 = Pós-doutorado completo ou não

E4. Você prestou serviço militar?

1 - Sim, 0 - Não

E5. Você participa atualmente de treinamento técnico ou programa educacional?

0 - Não, 1 - Meio-Turno, 2 - Turno Integral

E6. Você tem carteira de motorista válida?

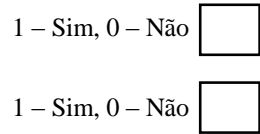

E7. Você usa ou tem um carro ou moto?$$
1-5
$$

E8. Neste momento, é difícil ir ao trabalho/escola, ou procurar trabalho por causa de meio de transporte?

[NOTA: Codifique E9. Pergunte apenas se incapaz de codificar baseado na informação prévia]

E9. Você lê/escreve (português) suficientemente bem para preencher uma ficha de emprego? 
E10. Qualé a stra prineipal sittação de emprego attual? Marque una]

_1. Turno Integral (TI) $(35+\mathrm{h} /$ trabalho $), \rightarrow$ E12

2. Meio Turno ( $<35 \mathrm{~h} /$ trabalho $), \rightarrow \mathrm{E} 12$

3. Desempregado e ativamente procurando por trabalho "dispensa temporária", $\rightarrow \mathrm{E} 14$

4. Fora do mercado de trabalho

- não trabalha e não procura ativamente por trabalho

5. Bicos (trabalho irregular e sem horário fixo)

E14. Quanto tempo durou seu trabalho de turno integral mais longo? - com um empregador ou como autônomo

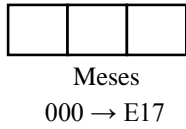

E17. Nos últimos 6 meses (desde ) , quantas semanas você teve um trabalho pago? - inclua licenças, férias,

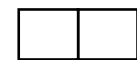

Semanas, $\operatorname{Max}=26$ dias como autônomo, trabalho informal e bicos.

$00 \rightarrow$ E22

E18. Nos últimos 6 meses, quanto dinheiro você ganhou (renda bruta)? - incluir bicos

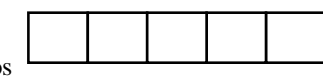

\section{(E19 - E22) Nos últimos 30 dias:}

E19. Quantos dias remunerados você trabalhou? - inclua licenças, férias, dias como autônomo, trabalho informal e bicos.

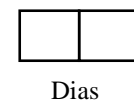

$00 \rightarrow$ E22

E20. Quanto dinheiro você ganhou (renda bruta)? - incluir bicos

$\mathrm{R} \$$

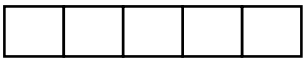

E22. Você procurou algum emprego? ex. mandou um currículo, preencheu uma ficha de emprego, falou com um possível empregador

$1-\operatorname{Sim}, 0-$ Não

As próximas perguntas (E25 - E36) são sobre as suas fontes de suporte financeiro e renda.

Nos últimos 30 dias, quanto dinheiro você recebeu de:
E25. pensão, seguro social, seguro

$\mathrm{R} \$$

$\mathrm{R} \$$

E26. assistência pública? ex. bolsa família / bolsa escola / moradia / roupas

E26b.... últimos 6 meses?

$\mathrm{R} \$$

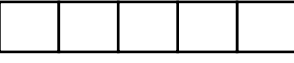

S

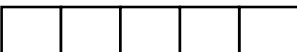

$\mathrm{R} \$$

$\mathrm{R} \$$

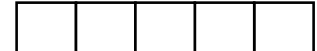

E27. outra assistência? ex. vale-refeição ou vale-transporte

E27b.... últimos 6 meses?

E28. sustento ou pensão alimentícia para crianças? do pai da criança ou ex-cônjuge.

$\mathrm{E} 28 \mathrm{~b} . .$. últimos 6 meses?

$\mathrm{R} \$$

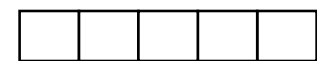

$\mathrm{R} \$$

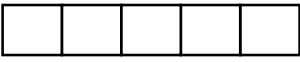

$\mathrm{R} \$$

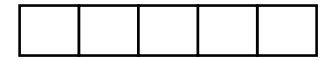

E29. atividades ilegais? ex. tráfico de drogas, prostituição, jogo ilegal, venda de objetos ilegais E29b.... últimos 6 meses?
$\mathrm{R} \$$

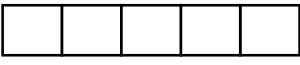

$\mathrm{R} \$$ desemprego? ex. previdência social ou INSS

E25b....últimos 6 meses?

\section{E29c.bicos?}

E29d.... últimos 6 meses?

$\mathrm{R} \$$

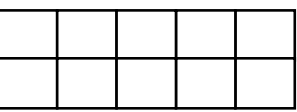

E30. alguma outra fonte?

ex. pediu emprestado/recebeu dinheiro

$\mathrm{R} \$$

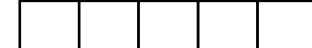

da família ou renda inesperada

(herança, impostos, loteria, etc.)

E30b.... últimos 6 meses?
E31. Quais são suas fontes atuais de sustento finan moradia, comida e outras despesas de vida?

[Marque todas que se aplicam]

1. Emprego

2. Aposentadoria

- ex. pensão, seguro social (INSS)

3. Invalidez / Incapacidade

- ex. pensão, seguro social (INSS), indenização

4. Seguro desemprego

5. Assistência pública ou governamental - ex. previdência social, vale-refeição, moradia subsidiada

_6. Sustento ou pensão alimentícia para criança

7. Família, amigos ou sócios

8. Dinheiro ilegal

9. Institucionalizado ou vivendo em supervisão - ex: Hospital, pensão protegida, albergue ou pensão

10. Outras, ex. economias, etc Especifique:

11. Bicos

12. Nenhuma

E32. Você alguma vez declarou falência?

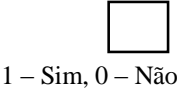

E33. Você já deixou de pagar um empréstimo para o governo ou instituição privada?

ex. crédito educativo, casa, empréstimos bancários.

E34. Você está mais do que um mês atrasado nos seus pagamentos para alguma coisa? ex: habitação, serviços, cartões de crédito, pensão de filhos, outros empréstimos/débitos (contas médicas, custos legais, empréstimos pessoais)

E35. Quantas pessoas (não inclua você mesmo) atualmente dependem de você para o sustento financeiro regular?

ex. para moradia, comida, sustento de filho, mesada, etc. inclua pessoas que o sujeito sustente, bem como aquelas que ele/ela é obrigado a sustentar

E36. Você tem renda suficiente para pagar necessidades como moradia, comida e roupas para você mesmo e seus dependentes?
1 - Sim, 0 - Não 
Drogas / Álcool-As questões a seguir são sobre o seu uso de álcool e drogas, e sobre qualquer tratamento para abuso de substâncias que você tenha recebido.

\section{Histórico de Tratamentos}

D1. Quantas vezes diferentes você já foi tratado para seu uso de álcool ou drogas? - inclua avaliações para tratamento mesmo que não tenham se transformado em tratamento. Não incluir AA / NA.

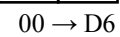

D2. Quantos desses tratamentos foram apenas para desintoxicação?

- desintoxicação não seguida por tratamento adicional.

\section{Quantos dias você:}

D4. Participou de programa ambulatorial ou de consulta médica

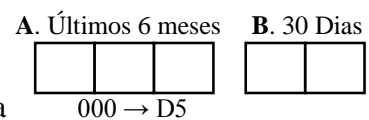
para tratamento de problemas relacionados a álcool ou drogas)?

D5. Tomou medicação prescrita para tratar seu uso de álcool ou drogas?
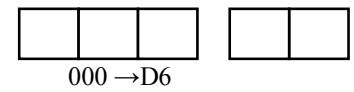
ex. dissulfiram, naltrexone (Revia), acamprosato (Campral), medicamento para desintoxicação, diazepam, metadona, etc. - exclua medicações para dependência de nicotina.

D6. Participou de reuniões de auto-ajuda (ex.: AA, NA)?

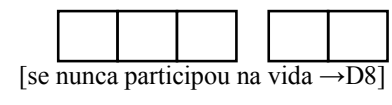

D7. Qual o período de tempo contínuo mais longo que você participou de reuniões de auto-ajuda, pelo menos 2 dias/semana?
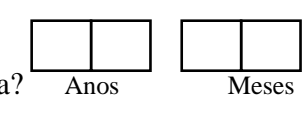

\section{$\underline{\text { Uso de Álcool }}$}

D8. Quantos anos na sua vida você bebeu álcool regularmente, $3 \mathrm{ou}+$ dias/semana?

- exclua períodos sem álcool

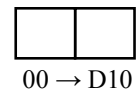

D9. Quantos anos na sua vida você bebeu pelo menos (5-homem, 4-mulher) drinques ${ }^{1}$ por dia regularmente, 3 ou + dias por semana?

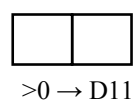

D10. Você bebeu pelo menos ( 5 - homem, 4 - mulher) drinques por dia em 50 dias ou mais em sua vida? 1 - Sim, 0 - Não

D11. Que idade você tinha quando bebeu e sentiu pela primeira vez os efeitos do álcool?

[se nunca, codifique NN]

D12. Nos últimos 6 meses, durante o mês em que você estava bebendo mais, com que frequiência você bebia?

$\begin{array}{ll}0-\text { Sem uso }(\rightarrow \text { D20) } & 3-3-6 \text { vezes por semana } \\ 1-1-3 \text { vezes por mês } & 4-\text { Diariamente }\end{array}$

$2-1-2$ vezes por semana
D13. Nos últimos 30 dias, quantos dias você bebeu qualquer tipo de bebida alcoólica?

D15. Nos últimos 30 dias, quantos dias você bebeu pelo menos ( 5 p/homens, 4 p/mulheres) drinques em um dia?

D16. Nos últimos 30 dias, quanto dinheiro você gastou em álcool para você?

$\mathrm{R} \$$

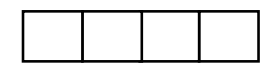

Um drinque: considere aproximadamente 1 dose de destilado, 1 cálice de vinho ou uma lata de cerveja.

\section{Nos últimos 30 dias:}

$\underline{\text { Sintomas do Álcool }}$

D17. Você teve qualquer sintoma de abstinência logo após ter diminuido ou parado de beber?

D18. Você teve alguma dificuldade em controlar, diminuir ou parar de beber ou passou grande parte do dia bebendo?

D19. Por causa do seu beber, você teve algum problema médico ou psicológico;

ou

teve problemas no emprego (escola) ou em casa, teve discussões; ou

teve problema com a lei?

D20. Você foi incomodado por fissuras ou desejos intensos de beber?

$1-\operatorname{Sim}, 0-$ Não

D21. Quantos dias você teve essas ou qualquer outra dificuldade devido ao uso de álcool?

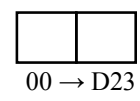

D22. Nos últimos 30 dias, quão preocupado ou incomodado você tem estado com esses problemas com álcool?
0 - Nada
3 - Consideravelmente
1 - Levemente
4 - Extremamente
2 - Moderadamente

D23. Neste momento, quão importante é para você o tratamento (atual ou adicional) para o seu uso de álcool?
0 - Nada
3 - Consideravelmente
1 - Levemente
4 - Extremamente
2 - Moderadamente

D24. Quão importante é para você alcançar/manter abstinência total do álcool (i.e., não beber nada)?
- Nada
3 - Consideravelmente
1 - Levemente
4 - Extremamente

2 - Moderadamente 
Tabela de Uso de Drogas - Substâncias Individuais

NOTA: Entregue ao entrevistado a Lista de Drogas e diga: Eu vou perguntar sobre cada grupo de drogas listado. Nós já falamos sobre o álcool. Vamos começar com a maconha:

Pré-A. Você já experimentou ou usou (mesmo se foi somente uma vez ou prescrita)?
A. Que idade você tinha quando experimentou pela primeira vez ?
B. Por quantos anos de sua vida você usou 3 ou mais dias por semana? - Exclua períodos sem a droga
C. Você já usou em 50 ou mais dias na sua vida?
D. Nos últimos 30 dias, quantos dias você usou
E. Nos últimos 30 dias, você usou
([0] - somente como prescrito, ou [1] - ilegalmente ou mais do que foi prescrito)?

NOTA: Se o entrevistado relata:

1. Nunca ter experimentado uma droga específica (ex. D25-A), codifique "N" e passe para a próxima substância (D26-A).

2. Ter usado 3 ou mais dias por semana por um ano ou mais (ex. D25-B), pule o item seguinte (D25-C), e continue.

3. Nenhum uso nos últimos 30 dias (ex. D25-D =00), passe para a próxima substância (D26-A).

\begin{tabular}{|c|c|c|c|c|}
\hline & $\begin{array}{l}\text { A. Idade de } 1^{\circ} \text { uso? } \\
{[\mathbf{N} \rightarrow \text { próxima } \mathbf{A}]}\end{array}$ & $\begin{array}{l}\text { B. Anos de uso regular } \\
\text { (Na vida)? } \\
{[>\mathbf{0 0} \rightarrow \mathbf{D}]}\end{array}$ & $\begin{array}{c}\text { C. Usou } 50 \text { ou }+ \text { dias ( } \mathrm{Na} \\
\text { vida)? } \\
{[\mathbf{1}-\text { Sim, } \mathbf{0}-\mathbf{N a ̃ o}]}\end{array}$ & $\begin{array}{c}\text { D. Uso nos Últimos } 30 \\
\quad \text { dias? } \\
{[\mathbf{0 0} \rightarrow \text { próxima A] }}\end{array}$ \\
\hline D25. Maconha & & & & \\
\hline D26. Sedativos & & & & \\
\hline D27. Cocaína & & & & \\
\hline D27.7c Crack & & & & \\
\hline D28. Estimula & & & & \\
\hline D29. Alucinóg & & & & \\
\hline D30. Heroína & & & & \\
\hline D31. Metadon & & & & \\
\hline D32. Outros O & & & & \\
\hline D33. Inalantes & & & & \\
\hline
\end{tabular}


Uso de Substâncias - Categorias Problema

$$
\begin{aligned}
& 01 \text { - Álcool } \\
& 02 \text { - Maconha } \\
& 03 \text { - Sedativos } \\
& 04 \text { - Cocaína } \\
& 05 \text { - Estimulantes } \\
& 06 \text { - Alucinógenos }
\end{aligned}
$$

\author{
07 - Heroína \\ 08 - Metadona \\ 09 - Outros Opióides \\ 10 - Inalantes

\begin{tabular}{|c|c|c|c|c|c|}
\hline $\begin{array}{l}\text { Problema Primário } \\
\text { D34. Qual das substâncias listadas }(01-12) \\
\text { está causando a você mais dificuldade } \\
\text { e pode tê-lo levado a buscar tratamento? } \\
\text { Indique a substância específica } \\
\text { dentro das categorias codificadas: }\end{array}$ & $\begin{array}{l}\text { A. Categoria } \\
\begin{array}{|l|l|} & \\
12 \rightarrow \text { D37 }\end{array}\end{array}$ & \multicolumn{2}{|c|}{$\underset{\text { [marque todas que se aplicam] }}{\text { B. Na vida }}$} & $\begin{array}{l}\text { C. } \text { Últin } \\
\text { [marque toda } \\
\text {-1. Ingerida } \\
\text {-2. Inalada } \\
\text {-3. Fumada }\end{array}$ & $\begin{array}{l}\frac{30 \text { Dias }}{\text { ue se aplicam }} \\
\text { 4. Injetada } \\
\text {-5. Outra } \\
\text {-6. Sem uso }\end{array}$ \\
\hline $\begin{array}{l}\text { Problema Secundário } \\
\text { D35. Qual das substâncias listadas (01-12) } \\
\text { está causando a } 2^{\text {a }} \text { maior dificuldade } \\
\text { e pode tê-lo levado a buscar tratamento? } \\
\text { Indique a substância específica } \\
\text { dentro das categorias codificadas: }\end{array}$ & A. Categoria & \multicolumn{2}{|c|}{$\begin{array}{l}\text { B. } \text { Na vida } \\
\text { [marque todas que se aplicam] }\end{array}$} & \multicolumn{2}{|c|}{ 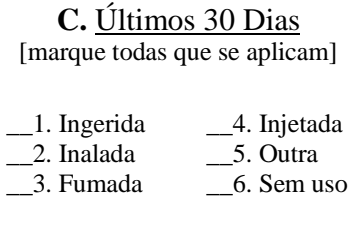 } \\
\hline $\begin{array}{l}\text { Problema Terciário } \\
\text { D36. Qual das substâncias listadas }(01-12) \\
\text { está causando a 3a maior dificuldade } \\
\text { e pode tê-lo levado a buscar tratamento? } \\
\text { Indique a substância específica } \\
\text { dentro das categorias codificadas: }\end{array}$ & $\begin{array}{l}\text { A. Categoria } \\
\begin{array}{|l|l|} & \\
12 \rightarrow \mathrm{D} 37\end{array}\end{array}$ & \multicolumn{2}{|c|}{ 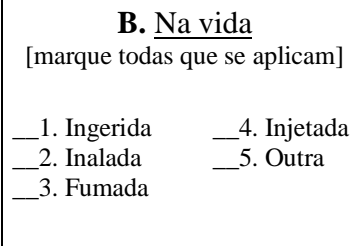 } & \multicolumn{2}{|c|}{ 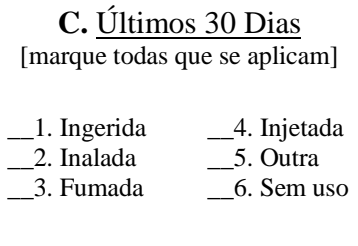 } \\
\hline
\end{tabular} \\ 11 - Outras Substâncias (inclui nicotina) \\ 12 - Nenhuma \\ 13- Crack
}

Rota(s) de Administração

De que forma você já usou 


\section{$\underline{\text { Uso de Drogas - Geral (exceto álcool e tabaco) }}$}

D37. Quantos anos na sua vida você usou qualquer tipo de droga ilegal ou de rua, ou abusou de qualquer medicação prescrita por pelo menos 3 ou mais dias por semana?

- se nunca usou drogas ou medicação $\rightarrow$ D54

D38. Nos últimos 6 meses, durante o mês em que você estava usando mais drogas ilegais ou de rua (e/ou abusando de medicação prescrita), qual a freqüência de uso de quaisquer drogas?
$0-$ Sem uso $(\rightarrow$ D45)
$3-3-6$ vezes por semana
$1-1-3$ vezes por mês
4 - Diariamente
$2-1-2$ vezes por semana

D39. Nos últimos 30 dias, em quantos dias você usou qualquer tipo de droga ou abusou de medicações prescritas?

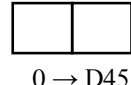

D41. Nos últimos 30 dias, quanto dinheiro você gastou em drogas? $\mathrm{R} \$$ - exclua dinheiro para medicações que são parte do tratamento para drogas (e.x. metadona, medicações para desintoxicação, etc.)

$\underline{\text { Sintomas de Drogas (exceto álcool e tabaco) }}$

\section{Nos últimos 30 dias:}

D42. Você teve algum sintoma de abstinência logo após diminuir ou parar qualquer droga?

D43. Você teve algum problema em controlar, diminuir ou parar com as drogas, ou gastou muito do seu dia usando, sob efeito, recuperando-se, ou apenas tentando obter drogas?

D44. Por causa do seu uso de drogas - você teve algum problema médico ou psicológico; ou teve problemas no trabalho (escola) ou em casa, entrou em discussões; ou teve problemas com a lei?

D45. Você tem sido incomodado por fissuras ou desejos de usar?

D46. Quantos dias você teve essas ou qualquer outra dificuldade devido ao uso de drogas?

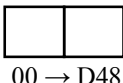

D47. Nos últimos 30 dias, quão preocupado ou incomodado você tem estado com esses problemas com drogas?
0 - Nada
3 - Consideravelmente
1 - Levemente
4 - Extremamente
2 - Moderadamente

D48. Neste momento, quão importante é para você o tratamento (atual ou adicional) para o seu uso de drogas?
0 - Nada
3 - Consideravelmente
1 - Levemente
4 - Extremamente

D49. Quão importante é para você alcançar/manter a abstinência total das drogas (isto é, não usar nenhuma droga)?
0 - Nada
1 - Levemente
3 - Consideravelmente
2 - Moderadamente
4 - Extremamente

D50. Desde que você começou a usar, você já esteve completamete abstinente (limpo) das drogas e do álcool por pelo menos 1 ano?

- exclua medicações prescritas e apropriadamente) tomadas (ex. metadona, medicações psiquiátricas

\section{Riscos para a Saúde}

[NOTA: Caso ainda não se saiba, pergunte a D52. Caso contrário, preencha de acordo com as informações prévias]

D52. Alguma vez você se injetou drogas? [Injetou = IV (intravenosa) e não-IV]

D53. Quando foi a última vez que você compartilhou seringas ou equipamento de injeção?

- se nunca, codifique $\mathrm{N}$ e $\mathrm{N}$

- se no último mês, codifique 0000

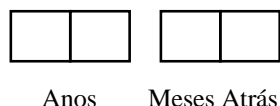

D54. Nos últimos 6 meses, com quantas pessoas diferentes você fez sexo oral, anal ou vaginal?

D55. Quando foi a última vez que você fez teste para HIV/AIDS?

- se nunca, codifique $\mathrm{N}$ e $\mathrm{N}$

- se no último mês, codifique 0000

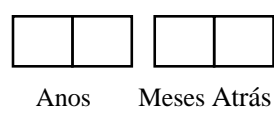

\section{Tabaco - Cigarros, etc}

D56. Que idade você tinha quando fumou o primeiro cigarro ou usou tabaco de outra forma?

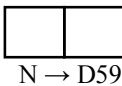

ex. mascou tabaco, charutos, cachimbo

- se nunca experimentou, codifique $\mathrm{N}$

D57. Quantos anos na sua vida você fumou cigarros (ou usou tabaco de outra forma) diariamente?

D58. Nos últimos 30 dias, quantos dias você fumou cigarros (ou usou tabaco de outra forma)?

\section{$\underline{\text { Jogo }}$}

D59. Na sua vida, você alguma vez teve dificuldade financeira por causa de jogo?

D60. Nos últimos 30 dias, quantos dias você participou de qualquer forma de jogo, como bingo, loteria, corrida de cavalo, jogo do bicho, rinha de galo, cassinos, ou jogo ilegal de qualquer natureza?

Legal-As próximas questões são a respeito de seu envolvimento a Justiça Criminal e/ou atividades ilegais. 
L1. Na sua vida inteira, você já esteve em uma prisão ou detido em delegacia, mesmo que por poucas horas?

L2. Na sua vida inteira, você já foi preso?

$$
1-\operatorname{Sim}, 0-\text { Não }
$$
$\mathrm{Se} \mathrm{L} 1$ e L2 $=0 \rightarrow \mathrm{L} 18$

L4. Antes dos 18 anos, você já foi preso por? [Marque todas que se aplicam]

1. Crimes violentos ou crimes contra pessoas ex. roubo, agressão, estupro

2. Ato ilícito ligado a drogas ex. porte, tráfico, manufatura de drogas

3. Crimes visando lucro ou contra a propriedade

ex. roubo de carro ou em loja, arrombamento, vandalismo, incêndio

4. Infrações praticadas somente por jovens

ex. fugir de casa, violação do toque de recolher, vadiagem

5. Outras infrações (Especifique: )

L5. Quantas vezes você foi condenado por um ato infracional antes dos 18 anos?

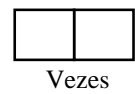

L6. Antes dos 18 anos, qual o tempo total que você passou trancado em centros de detenção ou instituições para menores infratores (FASE/FEBEM/DEGASE)?

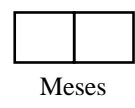

\section{(L7 - L14) Desde os 18 anos:}

Pré-A. Você já foi preso ou detido por

[NOTA: Se Não, codifique 00 para A. e passe para o próximo item]

A. Quantas vezes no total?

B. Quantas vezes nos últimos 6 meses?

L7. Porte de drogas?

- ou equipamentos de droga (parafernália)

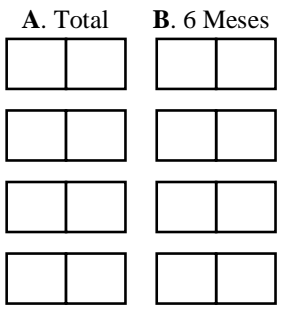

L8. Venda ou produção de drogas?

- vender inclui traficar/ distribuir

L9. Roubo?

- roubo à força, ou sob ameaça de força

L10. Outros crimes visando lucro?

- fraude venda de objetos roubados, vandalismo, incêndio - em loja

L11. Crime violento?... - violência doméstica, estupro, assassinato.

L12. Armas, prostituição ou jogo? ... - inclua cafetinagem, dinheiro por sexo, pornografia

L13. Dirigir alcoolizado?. - ou sob efeito de drogas

L14. Alguma outra infração criminal?............. - violação da condicional, conduta desordeira, - invasão, violação de ordem restritiva, negligência ou deserção, etc.

L16. Quantas vezes você foi condenado por um crime cometido após os 18 anos de idade?
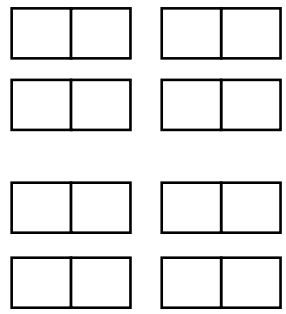

17. Desde os 18 anos, quanto foi o tempo total que você passou na cadeia ou prisão? Anos
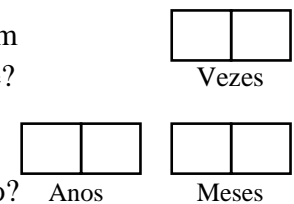

L18. A sua admissão para o tratamento foi ordenada pela justiça? ex. um juiz a requisitou

Você está atualmente envolvido com a justiça criminal de alguma das seguintes formas?

1 - Sim, 0 - Não

L19. Investigado em inquérito policial

L20. Suspensão condicional do processo.

L21. Aguardando julgamento ou sentença

L22. Sursis ou em Liberdade condicional

L23. Participando de um programa de justiça terapêutica

L24. Outros

ex. procurado pela justiça, mandado de prisão, prisão domiciliar,

supervisão pré-julgamento, está cumprindo pena

L25. Quão graves você considera seus problemas atuais com a justiça criminal?
0 - Nada
3 - Consideravelmente
1 - Levemente
4 - Extremamente
2 - Moderadamente

\section{(L26 - L30) Nos últimos 6 meses:}

Pré-A. Você ?

[NOTA: Se Não, codifique 000 para A. e passe para o próximo item]

A. número de dias, últimos 6 meses

B. número de dias, últimos 30 dias

L26. Vendeu ou fabricou drogas?

- traficou ou distribuiu para fazer dinheiro,

por sexo ou lucro de qualquer outra maneira

L27. Roubou alguém?

L28. Furtou, roubou, arrombou, fraudou, falsificou prescrições ou cheques, destruiu propriedade ou incendiou algo?

L28c. Roubou em loja

L28d.Praticou arrombamento

L28e. Roubou veículo a motor

L28f. Falsificou.

L28g. Fraudou

L28h.Cometeu vandalismo

L28i. Provocou incêndio (premeditado)...

L28j. Roubou / danificou propriedade . A. Últimos 6 Meses B. 30 Dias
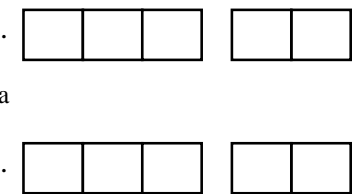

L29. Ameaçou ou agrediu alguém?

- com ou sem uma arma;

- inclua violência doméstica, estupro e assassinato

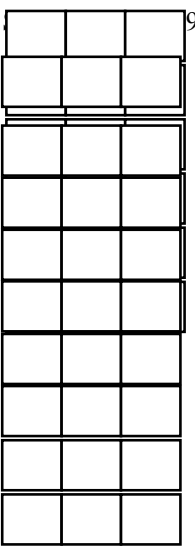

- exclua roubo

L29c. Ameaçou sem agressão física

L29d.Agrediu fisicamente com uma arma .

L29e. Agrediu fisicamente sem uma arma .

L29f. Agrediu sexualmente 
L29g. Assassinou alguém.

L29h. OUTRO.

L30. Fez qualquer outra coisa ilegal?A. Últimos 6 Meses B. 30 Dias - portou arma sem licença, envolveu-se com prostituição,

cafetinagem ou jogo ilegal, etc. [exclua uso de droga pessoal ou posse, dirigir sob influência de álcool]

L30c. Carregar uma arma sem licença ...

L30d.Prostituição / cafetinagem

L30e. Jogo ilegal .

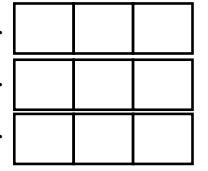

L31. No total, nos últimos 30 dias, quantos dias você fez qualquer uma das atividades/coisas acima?

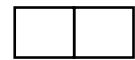

L32. Quantos dias, no total, você dirigiu sob efeito de drogas ou álcool?

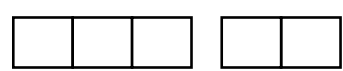

Família/Social - As questões seguintes são sobre sua família e relacionamentos sociais.

F1. Você teve um relacionamento amoroso ou sexual com um(a) parceiro(a) durante o último mês? 1-Sim, 0 - Não [NOTA: Se não, pule a coluna A (F3A-F9A).]

F2. Quantos amigos íntimos/verdadeiros ${ }^{2}$ você tem? - exclua parceiros sexuais/cônjuge, e quaisquer outros familiares adultos. [NOTA: Se 00, pule a coluna C (F3C-F9C).]

NOTA: Para F3 - F9:

A. Refere-se a esposa/marido ou parceiro

B. Refere-se a quaisquer outros membros adultos da família ou parentes. ex. pais, avós, irmãos, filhos crescidos, tios/tias, primos

C. Refere-se a qualquer amigo íntimo/verdadeiro

Nos últimos 30 dias, você:

$$
\text { (1 - Sim, } 0 \text { - Não) }
$$

A. Parceiro(s) B.Parentes C.Amigos Adultos Íntimos

F3. passou tempo (pessoalmente) com (seu A/quaisquer B,C):

F4. teve qualquer contato, como, cartas, telefonemas ou e-mail (outro) com: . - se F3+F4 = 0, Pule para F9

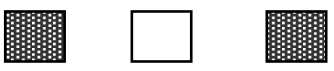

F9. Se você precisa de ajuda, você pode contar com:
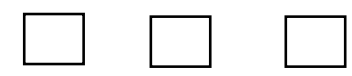

F10. Você atualmente tem alguma ordem judicial de afastamento contra alguém?

2 Amigo íntimo / verdadeiro: considere alguém com quem você convive com uma certa freqüência e pode contar, sem conotação sexual.
F11. Nos últimos 30 dias, alguma situação com seu parceiro, parentes adultos ou amigos íntimos resultou em empurrar/bater ou atirar coisas?

F12. Além do seu parceiro, outros parentes adultos e amigos íntimos, existe alguém com quem você possa contar caso você realmente precise de ajuda? 1 - Sim, 0 - Não ex. padre/pastor, médico, padrinho de AA, conselheiro, advogado, etc.

F13. No geral, nos últimos 30 dias, quão satisfeito você tem estado com os seus relacionamentos com adultos? ex. número de relacionamentos, quantidade de contato, qualidade da comunicação, se dá bem, ajudam-se mutuamente, etc. 0 - Nada 3-Consideravelmente 1 - Levemente $\quad 4$ - Extremamente

2 - Moderadamente

F14. Nos últimos 30 dias, quão preocupado ou incomodado você tem estado com quaisquer problemas com os seus relacionamentos com adultos?
0 - Nada
3 - Consideravelmente
1 - Levemente
4 - Extremamente

2 - Moderadamente

F15. Neste momento, quão importante é para você receber um auxílio, aconselhamento ou tratamento (atual ou adicional) para seus problemas de relacionamento com adultos?
0 - Nada
3 - Consideravelmente
1 - Levemente
4 - Extremamente
2 - Moderadamente

F16. Você acha difícil falar sobre os seus sentimentos ou problemas mesmo com pessoas íntimas (inclui parentes)?

F17. Você sente-se nervoso ou desconfortável quando está com outras pessoas?

F18. É importante para você ter relacionamento próximo/íntimo com pessoas?

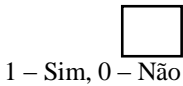

\section{Nos últimos 30 dias (F19-F22):}

F19. você foi à missa/serviços ou atividades religiosas organizados pela sua igreja/congregação?

- exclua reuniões de auto-ajuda ou AA

F20. você fez algum trabalho voluntário?

$1-\operatorname{Sim}, 0-$ Não

F21. você freqüentemente sentiu-se chateado ou com dificuldade para aproveitar o seu tempo livre?

1 - Sim, 0 - Não

As questões seguintes são sobre qualquer abuso ou trauma que você possa ter sofrido ao longo da sua vida.

F23. Você já foi fisicamente agredido/abusado por alguém que você conhecia?

- exclua abuso sexual, pois este será codificado em F26

$1-$ Sim, 0 - Não $0 \rightarrow \mathrm{F} 26$

F26. Alguma vez você já foi agredido/abusado sexualmente por alguém?

$0 \rightarrow \mathrm{F} 29$

F29. Você alguma vez foi vítima de um crime violento como ser espancado ou agredido? 
- exclua familiares, amigos e pessoas conhecidas

- exclua abuso como descrito em F26 e experiência de guerra

F32. Você já esteve em alguma outra situação

de risco de vida?

ex. desastre, acidente grave/incêndio, guerra

- exclua abuso, crimes violentos como descritos acima

F35. Você já esteve em uma situação onde você viu alguém sendo morto, espancado/agredido ou muito ferido? - exclua desastres/acidentes graves ou incêndio e guerra como descrito acima em F32

[NOTA: Se não há história de abuso ou trauma (i.e., F23, F26, F29, F32, e F35. São todos 0 - Não), pule para F40.]

F38. Nos últimos 30 dias, quão preocupado ou incomodado você tem estado com sentimentos, pensamentos ou outras reações relacionadas a esses eventos? - inclua pesadelos/sonhos, lembranças (flashbacks), etc.
0 - Nada
3 - Consideravelmente
1 - Levemente
4 - Extremamente
2 - Moderadamente

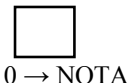

F39. Neste momento, quão importante é para você receber auxílio, aconselhamento ou tratamento (atual ou adicional) para quaisquer sentimentos, pensamentos ou outras reações relacionadas a esses eventos?
0 - Nada
3 - Consideravelmente
1 - Levemente
4 - Extremamente
2 - Moderadamente

As questões seguintes são sobre seus filhos ou qualquer outra criança vivendo com você.

F40. Quantos filhos biológicos e/ou adotivos você tem?

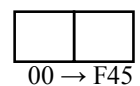

F42. Existe algum processo de guarda aberto pela mãe/pai ou qualquer outro parente?

1 - Sim, 0 - Não

F43. Quantos dos seus filhos estão atualmente afastados da família por decisão judicial? - inclua também aqueles cuidados por parentes via decisão judicial

F44. Nos últimos 30 dias, quantos filhos (menores de 18 anos) moraram com você pelo menos por algum tempo?

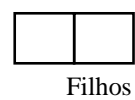

F45. Nos últimos 30 dias, alguma outra criança (enteado/neto/sobrinho(a), etc.), menor de 18 anos morou com você por pelo menos algum tempo? - codifique crianças que passam a noite regularmente ou que tenham ficado na sua casa por longo período de tempo

[NOTA: Se F44 e F45 são 0, i.e. sem crianças

nos últimos 30 dias, pule para F51]

F46. Quantas das crianças (que moraram com você) têm problema(s) grave(s) de saúde, de comportamento ou de aprendizado que requerem cuidado profissional, tratamento ou atendimento especializado?

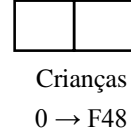

F47. Neste momento, quão necessários são serviços adicionais para tratar esses problemas?
0 - Nada
3 - Consideravelmente
1 - Levemente
4 - Extremamente
2 - Moderadamente

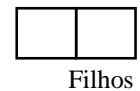

F48. Nos últimos 30 dias, você teve problemas para conviver bem com essas crianças $(<18)$ que moraram com você por pelo menos algum tempo?
0 - Nada
3 - Consideravelmente
1 - Levemente
4 - Extremamente
2 - Moderadamente

F49. Neste momento, quão importante é para você o aconselhamento (ex. aulas para pais) para ajudar a conviver melhor com essas crianças $(<18)$ que moraram com você?

- aconselhamento atual ou adicional
0 - Nada
3 - Consideravelmente
1 - Levemente
4- Extremamente

2 - Moderadamente

F50. Neste momento, você precisa de mais auxílio para cuidar das crianças a fim de participar do tratamento para drogas, trabalhar/estudar ou procurar trabalho? 1 - Sim, 0 - Não

F51. Você já foi investigado ou esteve sob supervisão do Conselho Tutelar ou outro programa de proteção a crianças?

[NOTA: se 0 ou nunca teve filhos passe para seção psiquiátrica]

F52. Alguma vez um filho seu já foi retirado de casa pelo Conselho Tutelar ou outro programa?

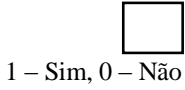

F53. Alguma vez seu poder de pai/mãe (pátrio poder)

foi suspenso?

- teve seus direitos de ser pai/mãe (poder familiar) ou a guarda dos seus filhos retirados pela justiça

F54. Atualmente você está respondendo a processo de guarda, ou sendo investigado / supervisionado pelo Conselho Tutelar ou outro programa de proteção a crianças?

1 - Sim, 0 - Não

Psiquiátrico - As questões seguintes são sobre qualquer tratamento ou avaliação que você tenha recebido para problemas psicológicos ou psiquiátricos.

P1. Na sua vida, quantas vezes você foi internado por problemas psicológicos / psiquiátricos?

ex. em hospital ou clínica (exclua int. por álcool/drogas)

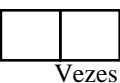

P2. Na sua vida, você já recebeu prescrição de medicações para tratar problemas psicológicos / psiquiátricos?

$$
0 \rightarrow \mathrm{P} 4
$$

P3. Quantos dias você tomou medicações para tratar problemas psicológicos / psiquiátricos?

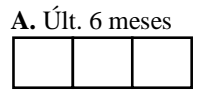

B. 30 Dias

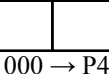

P4. Na sua vida, quantas consultas ambulatoriais você teve para problemas psicológicos / psiquiátricos? - inclua avaliações individuais em consultório médico (pessoalmente) mesmo que não seguidas de tratamento. - também inclua atendimento primário/família para problemas psiquiátricos e monitorização de medicações para problemas psiquiátricos
0 - Nenhuma
$3-26-50$ sessões
$1-1-5$ sessões
4 - mais de 50 sessões

$2-6-25$ sessões

P5. Quantas consultas ambulatoriais ou em consultório você teve?
A. Últ. 6 meses

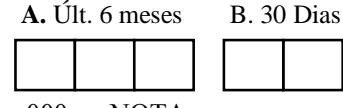

$000 \rightarrow$ NOTA 
[NOTA: Se P1, P2, P4 são todas 0-Não, i.e. sem história de tratamento psiquiátrico, pule para $\mathrm{P} 7]$

P7. Você atualmente recebe pensão (ou benefício) para incapacidade/invalidez psicológica?

1 - Sim, 0 - Não

As seguintes questões são sobre como você pode ter se sentido ou agido. Algumas questões são sobre como você já se sentiu ou se comportou em qualquer período da sua vida e outras são sobre os últimos 30 dias.

Código $\quad$ 0 - Não

para A/B: $\quad 1-$ Sim $\quad 2-$ Sim, mas somente sob efeito de droga ou em abstinência.

[NOTA: Se o entrevistado concorda com um sintoma, i.e., "Sim" pergunte: "Isso foi APENAS sob efeito de droga ou em abstinência?" e codifique 1 ou 2 como apropriado.]

(P8 - P17): A. Na sua vida

B. Durante qualquer um dos últimos 30 dias

Você (já):

B. 30 Dias

P8. Teve dificuldades para dormir, manter o sono*, ou acordar muito cedo?

* dormir por toda a noite

P9. Sentiu-se deprimido ou para baixo a maior parte do dia (quase todos os dias por pelo menos 2 semanas seguidas)?

- nos últimos 30 dias, codifique quaisquer dias $\quad 0 \rightarrow \mathrm{P} 10$

\section{Você (já):}

A. B

Na vida 30 Dia

P10. Sentiu-se ansioso, nervoso ou preocupado a maior parte do dia (quase todos os dias por pelo menos 2 semanas seguidas)? - para os últimos 30 dias, codifique quaisquer dias $0 \rightarrow \mathrm{P} 11$

P11. Teve alucinações?

- viu ou ouviu coisas que outras pessoas não viram ou ouviram

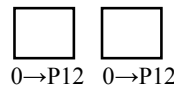

P12. Teve dificuldade para pensar/ concentrar-se, compreender ou lembrar, ao ponto disso lhe causar $\quad 0 \rightarrow \mathrm{P} 13 \quad 0 \rightarrow \mathrm{P} 13$ problemas?

P13. (Desde os 18 anos) Teve dificuldade para controlar seu temperamento, ou seus impulsos de bater ou ferir alguém?

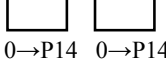

P14. (Desde os 18 anos) Empurrou, bateu, atirou coisas ou usou armas contra alguém?

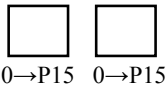

P15. Teve pensamentos sérios sobre suicídio (ou sobre se matar)?

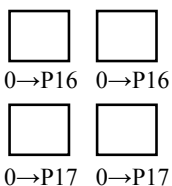

P16. Tentou o suicídio (se matar)?

P17. Passou por outro problema psicológico ou psiquiátrico não mencionado ainda? ex. transtorno alimentar, mania, etc.

Especifique:

[NOTA: Se todas P9 - P17 são 0 - Não, i.e. sem sintomas ou problemas psiquiátricos nos últimos 30 dias, pule para P21]

(P18 - P20) Nos últimos 30 dias:

- exclua P8 (problemas com o sono) para P18 - P21

P18. Quantos dias você teve esses problemas psicológicos ou psiquiátricos?

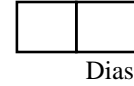

P19. Quantos dias você esteve incapaz de exercer as suas atividades normais por causa dos problemas psicológicos ou sintomas psiquiátricos?

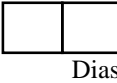

P20. Quão preocupado ou incomodado você tem estado com esses problemas psicológicos ou psiquiátricos?
0 - Nada
3 - Consideravelmente
1 - Levemente
4 - Extremamente

2 - Moderadamente

P21. Neste momento, quão importante é para você o tratamento (atual ou adicional) para problemas psicológicos / psiquiátricos?
0 - Nada
3 - Consideravelmente
1 - Levemente
4 - Extremamente
2 - Moderadamente

G15. Hora de Término:

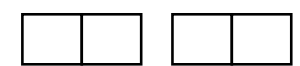




\section{Avaliação do grau de dependência do álcool - Short Alcohol Dependence Data (SADD)}

\section{Instruções:}

1. As seguintes perguntas dizem respeito a uma série de fatores relacionados com o consumo de bebidas alcoólicas. Por favor, leia cuidadosamente cada pergunta.

2. Responda as questões tendo em vista a época em que você estava bebendo.

3. Responda cada pergunta assinalando a resposta que lhe pareça mais apropriada.

\begin{tabular}{|c|c|c|c|c|}
\hline & Nunca & $\begin{array}{c}\text { Poucas } \\
\text { vezes }\end{array}$ & $\begin{array}{c}\text { Muitas } \\
\text { vezes }\end{array}$ & Sempre \\
\hline \multicolumn{5}{|l|}{ 1. Você acha difícil tirar o pensamento de beber da cabeça? } \\
\hline \multicolumn{5}{|l|}{ 2. Acontece de você deixar de comer por causa de bebida? } \\
\hline \multicolumn{5}{|l|}{ 3. Você planeja seu dia em função da bebida? } \\
\hline \multicolumn{5}{|l|}{$\begin{array}{l}\text { 4. Você bebe em qualquer horário (manhã, tarde e/ou } \\
\text { noite)? }\end{array}$} \\
\hline \multicolumn{5}{|l|}{$\begin{array}{l}\text { 5. Na falta de sua bebida preferida você toma qualquer } \\
\text { outra? }\end{array}$} \\
\hline \multicolumn{5}{|l|}{$\begin{array}{l}\text { 6. Acontece de você beber sem levar em conta os } \\
\text { compromissos que tenha depois? }\end{array}$} \\
\hline \multicolumn{5}{|l|}{$\begin{array}{l}\text { 7. Você acha que o quanto você bebe chega a lhe } \\
\text { prejudicar? }\end{array}$} \\
\hline \multicolumn{5}{|l|}{$\begin{array}{l}\text { 8. No momento em que você começa a beber, é difícil } \\
\text { parar? }\end{array}$} \\
\hline \multicolumn{5}{|l|}{ 9. Você tenta se controlar (tenta deixar de beber)? } \\
\hline \multicolumn{5}{|l|}{$\begin{array}{l}\text { 10. Na manhã seguinte a uma noite em que tenha bebido } \\
\text { muito, você precisa beber para se sentir melhor? }\end{array}$} \\
\hline \multicolumn{5}{|l|}{\begin{tabular}{|l|}
11. Você acorda com tremores nas mãos na manhã seguinte \\
a uma noite em que tenha bebido muito?
\end{tabular}} \\
\hline \multicolumn{5}{|l|}{$\begin{array}{l}\text { 12. Depois de ter bebido muito, você levanta com náuseas } \\
\text { ou vômitos? }\end{array}$} \\
\hline \multicolumn{5}{|l|}{$\begin{array}{l}\text { 13. Na manhã seguinte a uma noite em que tenha bebido } \\
\text { muito, você levanta não querendo ver ninguém na sua } \\
\text { frente? }\end{array}$} \\
\hline \multicolumn{5}{|l|}{$\begin{array}{l}\text { 14. Depois de ter bebido muito, você vê coisas que mais } \\
\text { tarde percebe que era imaginação sua? }\end{array}$} \\
\hline $\begin{array}{l}\text { 15. Você se esquece do que aconteceu enquanto esteve } \\
\text { bebendo? }\end{array}$ & & & & \\
\hline
\end{tabular}

*1 a 9 pontos = Dependência leve; 10 a 19 pontos = Dependência moderada; e 20 a 45 pontos $=$ Dependência grave . 


\section{Severity of Dependence Scale - (SDS)}

\begin{tabular}{|l|l|l|l|l|}
\hline $\begin{array}{l}\text { 1 Você acha que o uso de (crack/cocaína) } \\
\text { está fora de controle }\end{array}$ & ( ) 0 - nunca & ( ) 1 - algumas vezes & $\begin{array}{l}\text { ( ) } 2 \text { - quase } \\
\text { sempre }\end{array}$ & ( ) 3 - sempre \\
\hline $\begin{array}{l}\text { 2 Se faltar } \text { crack/cocaína, isso lhe deixa } \\
\text { ansioso ou preocupado? }\end{array}$ & ( ) 0 - nunca & ( ) 1 - algumas vezes & $\begin{array}{l}\text { ( ) } 2 \text { - quase } \\
\text { sempre }\end{array}$ & ( ) 3- sempre \\
\hline $\begin{array}{l}\text { 3 Você se preocupa com o uso de } \\
\text { crack/cocaína? }\end{array}$ & ( ) 0 - nunca & ( ) 1 - algumas vezes & $\begin{array}{l}\text { ( ) } 2 \text { - quase } \\
\text { sempre }\end{array}$ & ( ) 3 - - suncempre \\
\hline $\begin{array}{l}\text { 4 Você gostaria de parar de usar } \\
\text { crack/cocaína? }\end{array}$ & ( ) 1 - algumas vezes & $\begin{array}{l}\text { ( ) } 2 \text { - quase } \\
\text { sempre }\end{array}$ & ( ) 3 - sempre \\
\hline $\begin{array}{l}5 \text { Quanto difícil você acha para parar ou ficar } \\
\text { sem usar (crack/cocaína)? }\end{array}$ & ( ) 0 - não é difícil & ( ) 1 - difícil & ( ) 2 - muito difícil & ( ) 3 - impossível \\
\hline
\end{tabular}

\section{AUDIT - The Alcohol Use Disorder Identification Test}

1. Com que frequência consome bebidas que contêm álcool? [Escreva o número que melhor corresponde à sua situação.]
( ) $0=$ nunca
( ) $1=$ uma vez por mês ou menos
( ) $2=$ duas a quatro vezes por mês
( ) $3=$ duas a três vezes por semanas
( ) 4 = quatro ou mais vezes por semana

2. Quando bebe, quantas bebidas contendo álcool consome num dia normal?

( ) $0=$ uma ou duas

( ) $1=$ três ou quatro

( ) $2=$ cinco ou seis

( ) $3=$ de sete a nove

( ) $4=$ dez ou mais

3. Com que frequência consome seis bebidas ou mais numa única ocasião?
( ) $0=$ nunca
( ) $1=$ menos de um vez por mês
( ) $2=$ pelo menos uma vez por mês
( ) 3 = pelo menos uma vez por semana
( ) 4 = diariamente ou quase diariamente 


\section{Questionário sobre Cocaína - (CCQ-B) - Versão Brasileira}

\begin{tabular}{|l|c|c|c|c|c|}
\hline & $\begin{array}{c}\text { Concordo } \\
\text { muito }\end{array}$ & Concordo & Indiferente & $\begin{array}{c}\text { Discordo } \\
\text { Discordo } \\
\text { Muito }\end{array}$ & 5 \\
\hline $\begin{array}{l}\text { 1. Eu desejo tanto usar cocaína que } \\
\text { quase posso sentir seu gosto. }\end{array}$ & 1 & 2 & 3 & 4 & 5 \\
\hline $\begin{array}{l}\text { 2. Eu tenho um desejo muito forte por } \\
\text { cocaína. }\end{array}$ & 1 & 2 & 3 & 4 & 5 \\
\hline 3. Vou usar cocaína assim que puder. & 1 & 2 & 3 & 4 & 5 \\
\hline $\begin{array}{l}\text { 4. Acho que poderia resistir a usar } \\
\text { cocaína neste momento. }\end{array}$ & 1 & 2 & 3 & 4 & 5 \\
\hline 5. Eu estou com fissura por cocaína. & 1 & 2 & 3 & 4 & 5 \\
\hline $\begin{array}{l}\text { 6. Tudo que queria fazer agora era usar } \\
\text { cocaína. }\end{array}$ & 1 & 2 & 3 & 4 & 5 \\
\hline $\begin{array}{l}\text { 7. Não sinto nenhum desejo por cocaína } \\
\text { neste momento. }\end{array}$ & 1 & 2 & 3 & 4 & 5 \\
\hline $\begin{array}{l}\text { 8. Usar cocaína agora faria as coisas } \\
\text { parecerem perfeitas. }\end{array}$ & 1 & 2 & 3 & 4 & 5 \\
\hline $\begin{array}{l}\text { 9. Eu vou usar cocaína assim que tiver a } \\
\text { chance. }\end{array}$ & 1 & 2 & 3 & 3 & 4 \\
\hline $\begin{array}{l}\text { 10. Nada seria melhor do que usar } \\
\text { cocaína agora. }\end{array}$ & 1 & 2 & 5 & 5 \\
\hline
\end{tabular}


ANEXO C

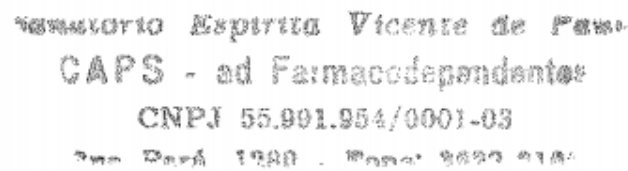

$\mathrm{A} / \mathrm{C}$ :

Escola de Enfermagem de Ribeirão Preto -.. Universidade de São Paulo.

A Coordenação do Centro de Atenção Psicossocial - Alcool e Drogas II autoriza para os devidos fins a permanência da aluna da aluna lessica Adrielle Teixeira Santos orientanda da Proft. Dr". Sandra Cristina Pillon da. EERP/USP na unidade para a realização da pesquisa de doutorado intutulada "Evolução do Tratamento de Usuá éos de Cocaina e/on Crack: um estudo de seguimento". Sem mais para o momento, colocamo nos a disposição para maiores esclarecimentos.

Atenciosamente.

Ribeiräo Preto, 06 de Novembro de 2012

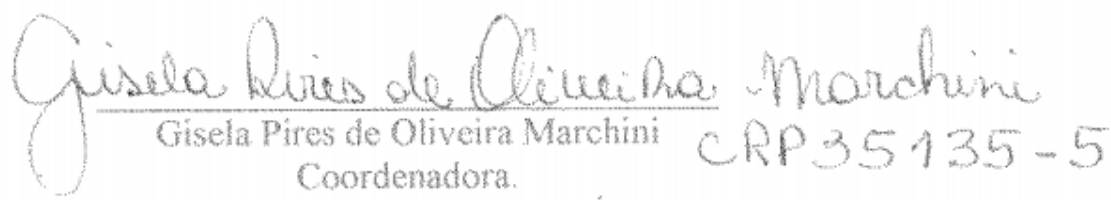

Centro de Atenção Psicossocial para Usuários de Álcool e outras Drogas II.

R: Para, 1310-Ipiranga, Ribeirão Preto - SP. CEP: 14060440

Fone: (16) 361533 


\section{ANEXO D}

\section{Prefeitura Municipal de Ribeirão Preto}

Estado de São Paulo - Secretaria Municipal da Saúde

Of. $n^{2} 1151 / 13$

CAAP-fcp

Ribeirão Preto, 21 de março de 2013.

Prezado Orientador,

Prof ${ }^{\mathrm{a}}$. Dr ${ }^{\text {* }}$. Sandra Cristina Pillon

Prezada pesquisadora

Jessica Adrielle Teixeira Santos

A Diretora do Departamento de Atenção à Saúde das Pessoas - llka Barbosa Pegoraro, e o

Coordenador do Programa de Saúde Mental - Alexandre Firmo de Souza Cruz; manifestaram a concordância para a coleta de dados do projeto de pesquisa "EVOLUÇĀO DO TRATAMENTO DE USUÁRIOS DE COCAINA E/OU CRACK: UM ESTUDO DE SEGUIMENTO", nas dependências desta Secretaria da Saúde. Conforme despachos no Processo Administrativo 0220130028076.

Como o seu campo de pesquisa se trata de Unidade de Saúde - CAPS - AD, ressaltamos que vossa senhoria se apresente à coordenação destas com antecedência para agendamento da pesquisa, tendo em vista as rotinas destes estabelecimentos de saúde.

Informo que a pesquisa somente poderá iniciar quando obtiver a aprovação do Comitê de Ética em Pesquisa da instituição proponente e a concordância da SMS-RP como instituição coparticipante.

Cordiaimente,

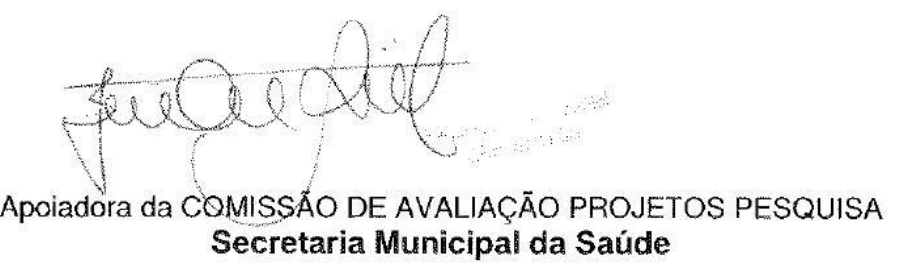

Secretaria Municipal da Saúde

Rua Prudente de Moraes, 457 - Centro - Ribeirão Preto/SP

Fones: 3977.9305 / Fax: 3941.4934/e-mail: gabinete@saude.pmrp.com.br 


\section{ANEXO E}

\section{ESCOLA DE ENFERMAGEM DE $Q$ Ploboforma RIBEIRÃO PRETO - USP \\ erasi}

\section{PARECER CONSUBSTANCIADO DO CEP}

\section{DADOS DO PROJETO DE PESQUISA}

TItulo da Pesqulsa: Evoluçăo do tratamento de usuarios de cocaina eiou crack: um estudo de segulmento

Pesqulsador: Jessica Adriele Telxelra Santos

Área Tematica:

Versato: 4

CAAE: 15304513.3 .0000 .5393

Institulçăo Proponente:Escola de Enfermagem de Fuberäo Preto - USP

Patrocinador Principal: Financlamento Proprio

\section{DADOS DO PARECER}

Número do Parecer: 412.837

Data da Relatorla: $02 / 10 / 2013$

Apresentaçao do Projeto:

Trata-se de anallse de pendenclas que foram socilltadas providenclas no Parecer Consubstanclado $n^{2} 402.628$.

Objettvo da Pesquisa:

Nalo se aplica.

Avallaça dos Riscos $\theta$ Beneficlos:

Fol solicitada alteraçăo no TCLE com a substitulç5̆o do texto "terel como beneficlo possivels mudanças e melhorlas no meu tratamento" pelo texto apresentado na Plataforma Brasll em que ressaita o beneficlo de participar de uma entrevista em que o entrevistador podera conversar com 0 entrevistado sobre suas dinculdades pessoals. A alteraçăo fol providenclada.

Comentarios $\theta$ Consideraçoes sobre a Pesqulsa:

Năo se aplica.

Consideraç0es sobre 08 Termos de apresentaça obrigatorla:

Foram anexados acs demals documentos apresentados anteriomente: oflcio de encaminhamento ao CEP (com correçbes); TCLE III (com as alteraçbes sollcitadas); Projeto do pesquisador com a sollctaçâo de alteraçato no cronograma; Cronograma; Projeto PB. 


\section{ESCOLA DE ENFERMAGEM DE C Ploboforma
RIBEIRÃO PRETO - USP}

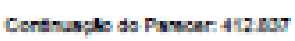

Recomendaçoes:

Nada consta.

Conclusoes ou Pendenclas $\theta$ Llata de Inadequaçere:

Foram providencladas as correçbes sollcitadas no Parecer 402.268, a saber. 1) fol inserido o Projeto do Pesquisador com a alteraçăo no Cronograma; 2) fol inserido o TCLE com a correçăo referente ao texto sobre benefliclos.

situaça do Parecer:

Aprovado

Necesalta Apreclaça da CONEP:

Năo

Consideraç0es Finals a criterio do CEP:

Parecer apreciado "ad referendum".

RIBEIRAO PRETO, $Q 2$ de Qutubro de 2013

Assinador por.

Claudla Benedita dos Santos

(Coordenador) 